\title{
ANÁLISE TEÓRICA E EXPERIMENTAL DO COMPORTAMENTO DA ADERÊNCIA ENTRE O CONCRETO E BARRAS DE FIBRA DE VIDRO IMPREGNADA POR POLÍMERO
}

\author{
lara Andrade Couto
}

\author{
Dissertação apresentada à \\ Escola de Engenharia de São \\ Carlos da Universidade de \\ São Paulo, como parte dos \\ requisitos para a obtenção do \\ Título de Mestre em \\ Engenharia de Estruturas.
}

Orientador: José Samuel Giongo

São Carlos 

Dedico este trabalho aos meus pais Lauro e Rosana e ao Osmar 



\section{AGRADECIMENTOS}

Aos meus pais Lauro e Rosana, pelo amor dedicação, paciência, dando sempre apoio e compreensão, para me transformar no que sou. Aos meus irmãos Tiago, Filipe e José pelo amor e companheirismo em todos os momentos.

Ao Osmar, pelo amor, paciência, dedicação, incentivo e apoio, mesmo estando longe.

Ao Professor José Samuel Giongo, pela excelente orientação, apoio, incentivo e, principalmente, pela amizade e compreensão.

Ao Fernando, que teve grande participação nesta pesquisa, com muitas conversas, ensinamentos, incentivo, e principalmente pela amizade.

Aos professores do Departamento de Engenharia Civil da Universidade Federal de Viçosa, em especial ao prof. Dario, pelo apoio e incentivo, contribuindo de maneira fundamental para meu crescimento pessoal e profissional.

Aos meus avós maternos, José e Ana Rosa e paternos, Lauro (in memorian) e Zélia, pela paciência, apoio e principalmente pelo carinho que sempre tiveram por $\operatorname{mim}$.

À Gisely, pela grande amizade, mesmo longe sempre me apoiando. Sem me esquecer da sua enorme contribuição nesta pesquisa.

A todas as amizades conquistadas nesta etapa: Fernanda, Mariana, Danusa, Dênis, Marlos, Saulo, Gustavo, Filipe, Luiz, André, Ronaldo, Eduardo, Aquino, Rodrigo,... e muitos outros amigos e amigas, pelos momentos de alegria e apoio que, direta ou indiretamente, contribuíram para este trabalho.

À Gláucia, pela amizade, carinho e compreensão, com seu jeito ímpar sempre nos divertiu.

À Karenina e Lívia, grandes amigas, com quem tive a oportunidade de conviver bem perto (pena que por pouco tempo), pelo carinho, compreensão, pela força que sempre me deram e pelos grandes momentos.

À Vanessa, Cristiane e Adriana, que me acolheram no inicio desta etapa em São Carlos, pela amizade e pela enorme força. 
Aos funcionários do Departamento e do Laboratório de Engenharia de Estruturas da EESC/USP Nadir, pela atenção e eficiência nos serviços prestados.

Ao CNPq, pelo auxílio financeiro.

À Holcim e à Camargo Corrêa pela doação do cimento de da sílica.

À Hughes Brothers e a Owen's Corning pela doação e importação das barras não-metálicas. 


\section{SUMÁRIO}

RESUMO . $\mathbf{v}$

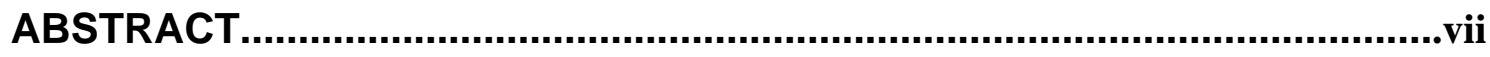

1. INTRODUÇÃO …................................................................................1

1.1. Considerações iniciais............................................................................ 1

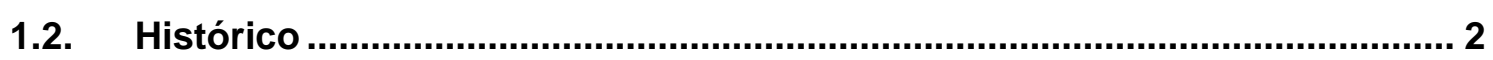

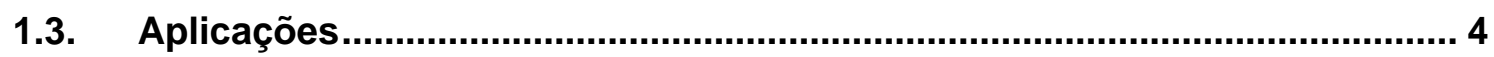

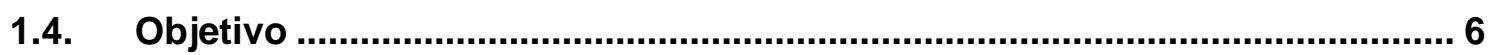

1.5. Justificativa .................................................................................................... 7

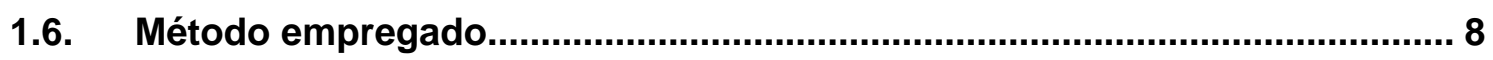

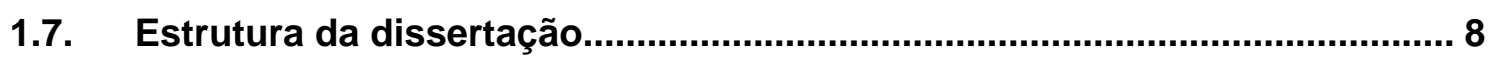

2. BARRAS DE FIBRA DE VIDRO IMPREGNADA POR POLÍMERO (GFRP). ........................................................................................... 11

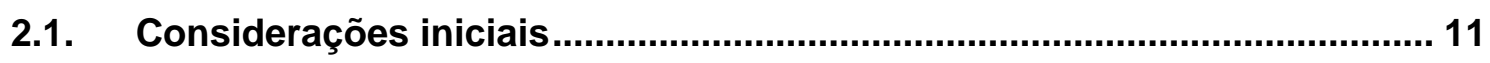

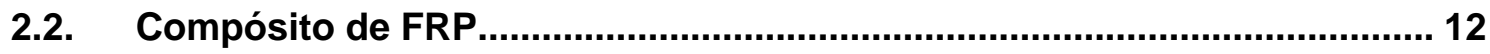

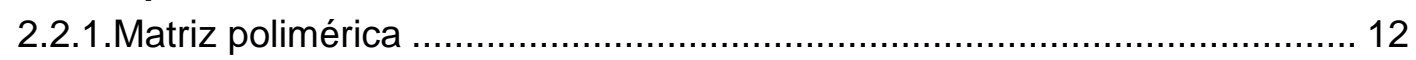

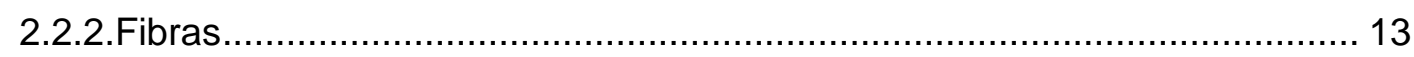

2.3. Processo de fabricação das barras de FRP ............................................. 14

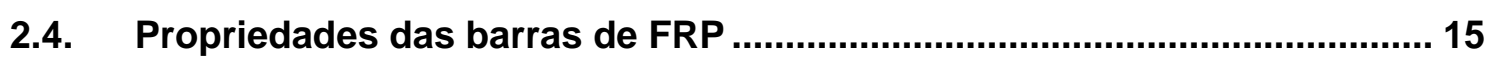

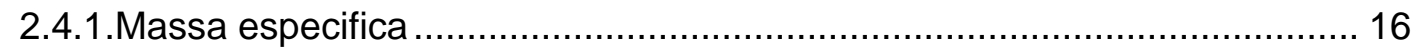

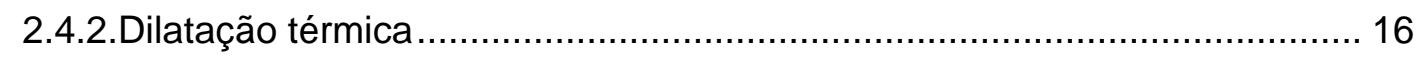

2.4.3. Resistência à tração (longitudinal) .................................................. 17

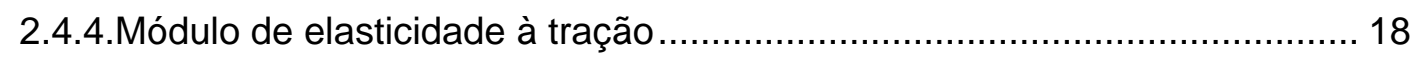

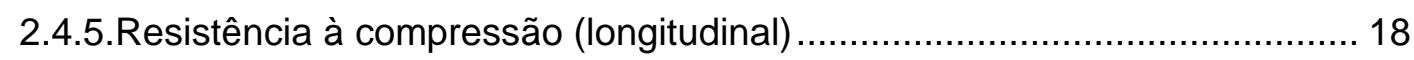

2.4.6. Módulo de elasticidade à compressão ................................................. 18

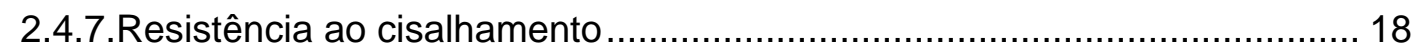

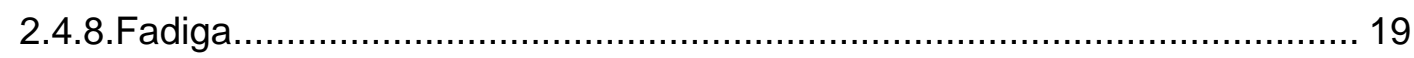

2.5. Fatores que afetam as propriedades mecânicas das barras de FRP...... 19

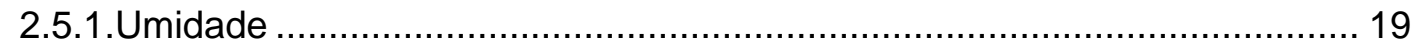

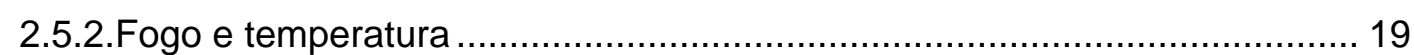

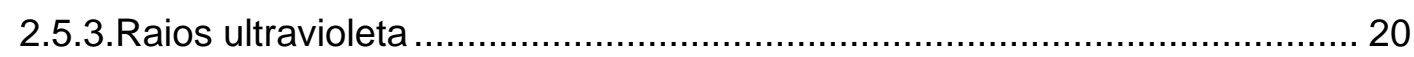




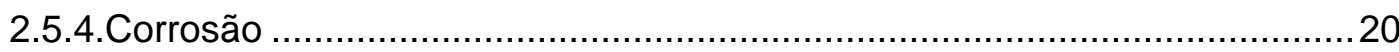

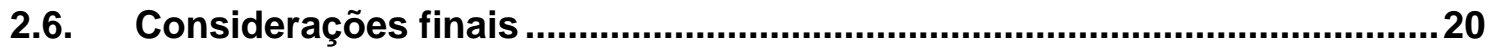

3. ADERÊNCIA ENTRE O CONCRETO E A ARMADURA ........................21

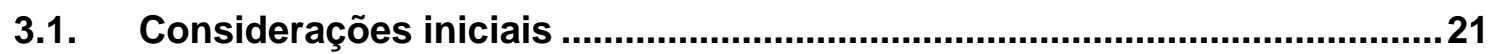

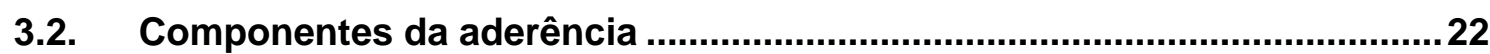

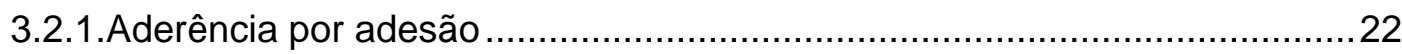

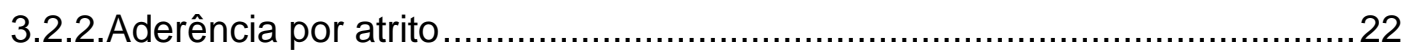

3.2.3.Aderência mecânica..................................................................... 23

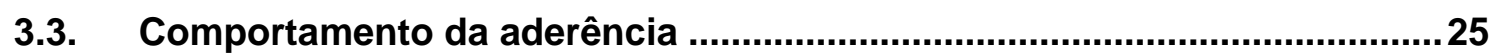

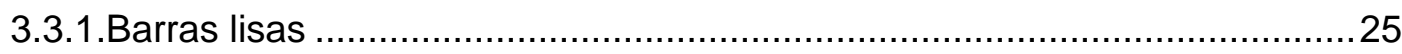

3.3.2.Barras com superfície deformada ou tratada........................................... 25

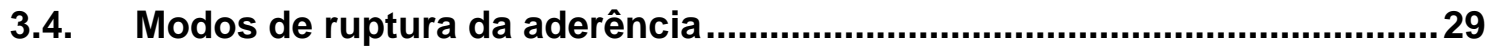

3.5. Fatores que influenciam o comportamento da aderência............................31

3.5.1.Forma da seção transversal da barra ...................................................... 32

3.5.2. Conformações superficiais das barras........................................................ 32

3.5.3.Pequeno módulo de elasticidade na direção longitudinal ........................... 33

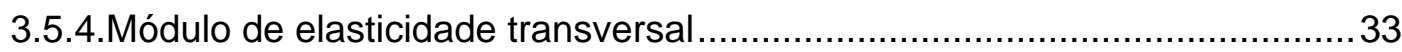

3.5.5.Efeito do coeficiente de Poisson ........................................................... 33

3.5.6. Posição das barras na seção transversal do elemento de concreto.............. 34

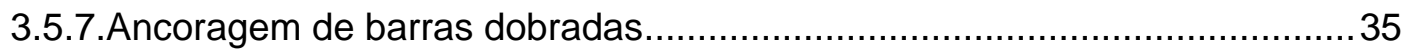

3.5.8. Cobrimento do concreto e distância entre barras paralelas........................ 35

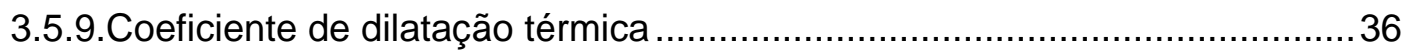

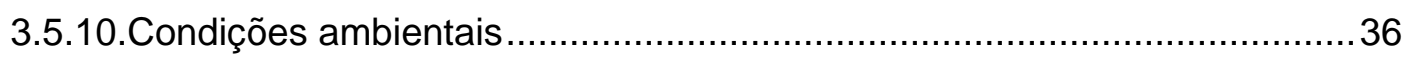

3.5.11. Diâmetro da barra ............................................................................ 36

3.5.12. Resistência à compressão do concreto ................................................... 37

3.5.13.Armadura transversal................................................................. 38

3.5.14.Comprimento das fissuras e retração ….............................................. 38

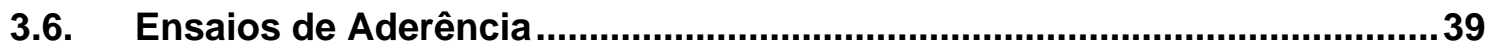

3.6.1.Ensaio de Arrancamento (Pull-out test) ................................................ 39

3.6.1.1.Ensaio de arrancamento RILEM-FIP-CEB (1973) ..............................4 41

3.6.1.2.Ensaio de arrancamento ASTM C-234 (1991) .................................4. 42

3.6.1.3.Ensaio de arrancamento segundo RHEM ....................................... 44

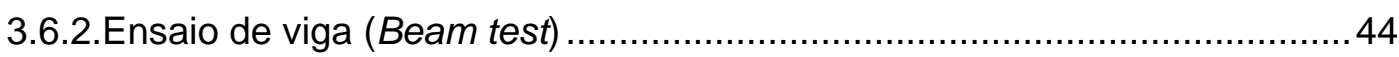

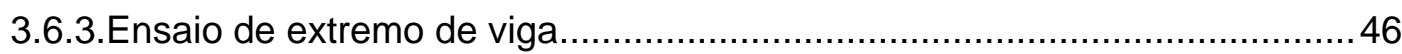

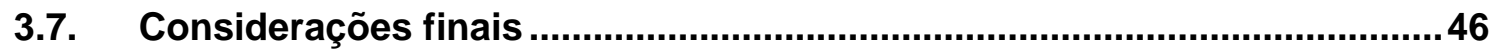

4. INVESTIGAÇÃO EXPERIMENTAL DA ADERÊNCIA ............................49

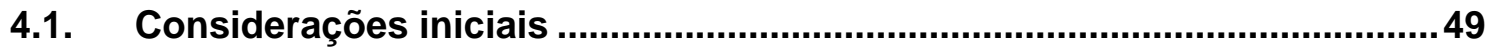

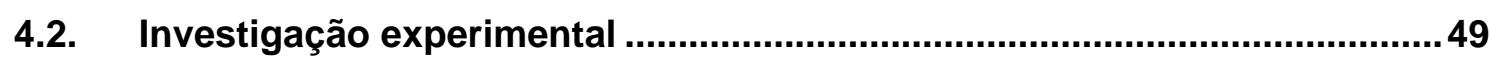

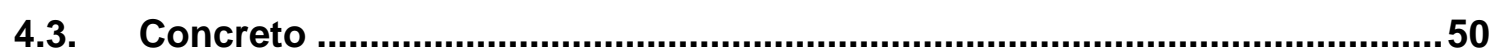

4.3.1.Caracterização dos materiais constituintes do concreto ............................ 50

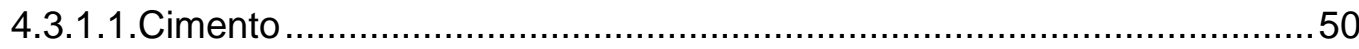




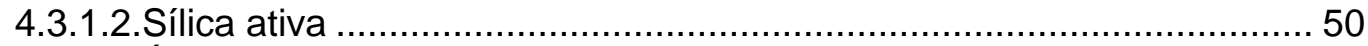

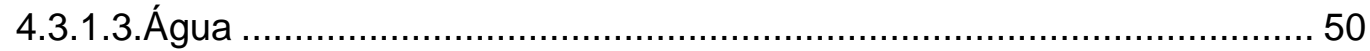

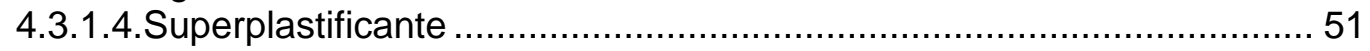

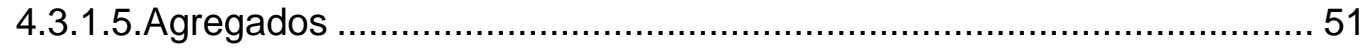

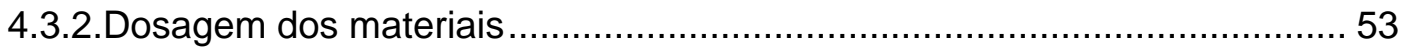

4.3.3.Execução da mistura .......................................................................... 53

4.3.4.Ensaios de caracterização do concreto..................................................... 53

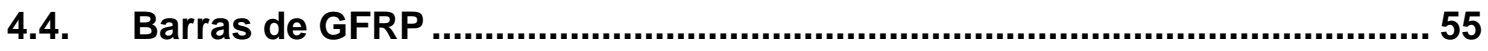

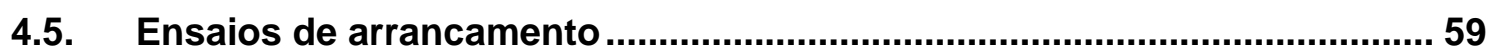

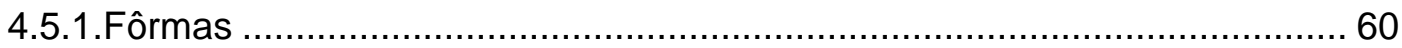

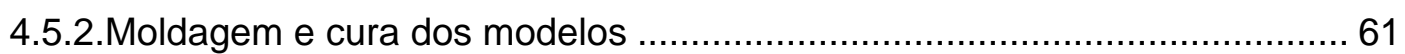

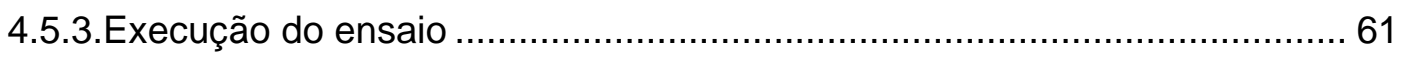

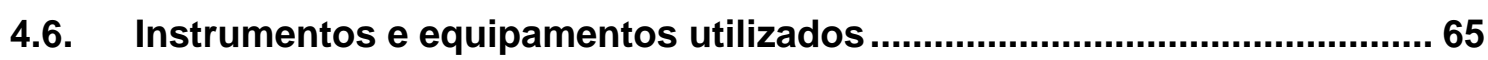

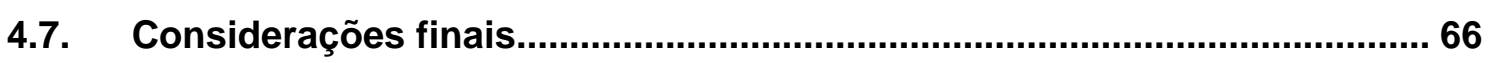

5. SIMULAÇÃO NUMÉRICA DA ADERÊNCIA ........................................69

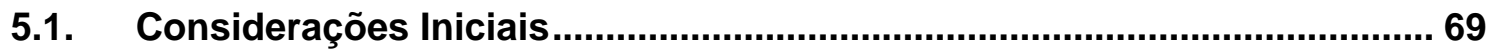

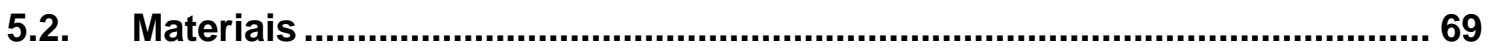

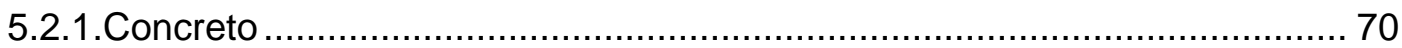

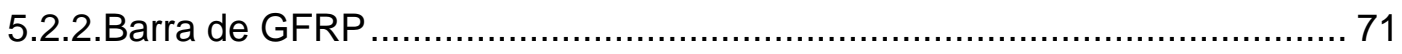

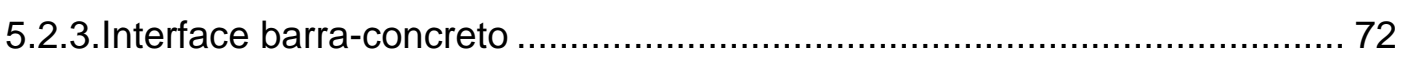

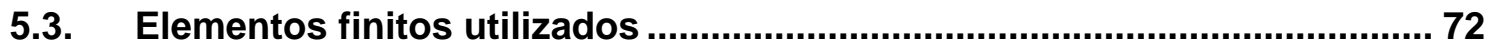

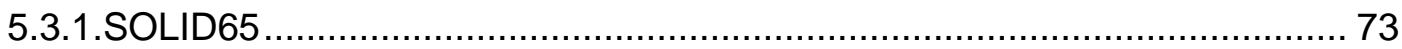

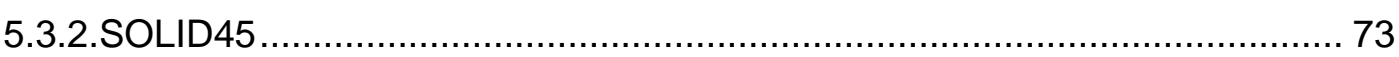

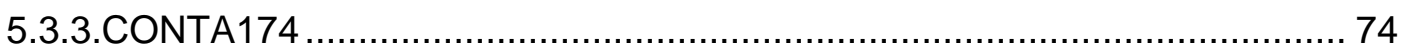

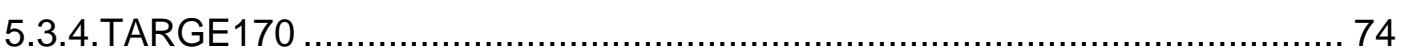

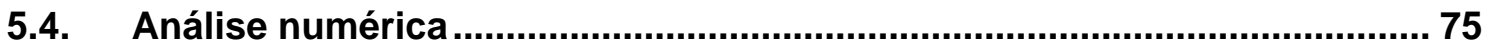

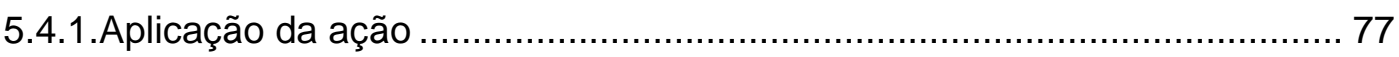

5.4.2.Comportamento dos materiais ............................................................. 77

5.4.3. Valores experimentais adotados na simulação numérica .......................... 78

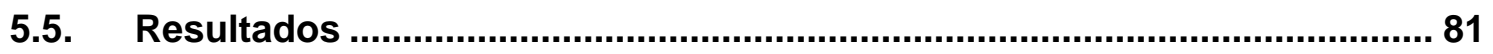

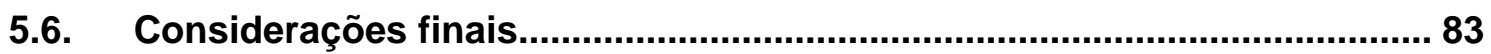

6. ANÁLISE E DISCUSSÃO DOS RESULTADOS ....................................85

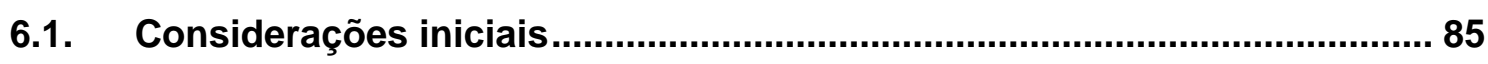

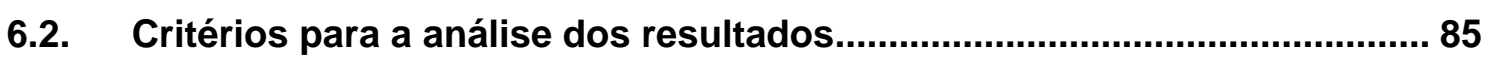

6.3. Parâmetros estatísticos utilizados.............................................................. 86

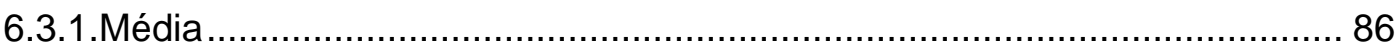

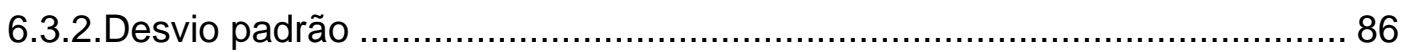

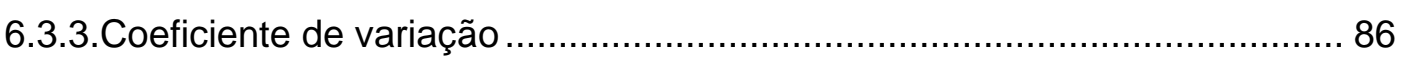

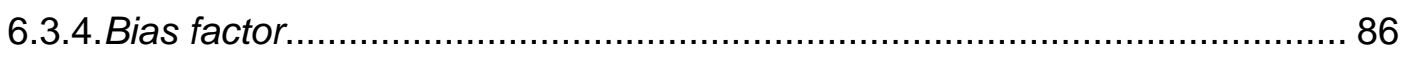

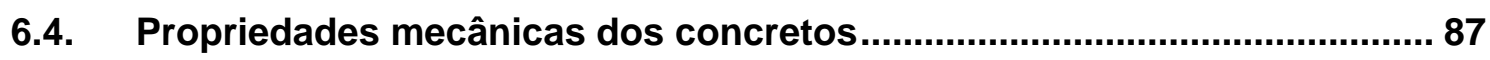


6.5. Propriedades mecânicas das barras de GFRP ........................................89

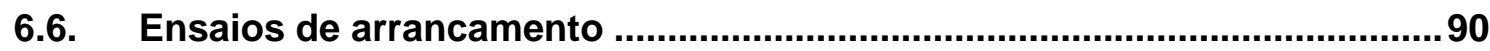

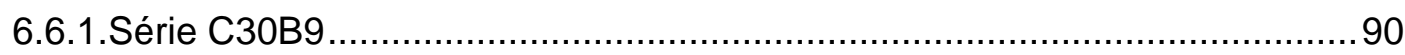

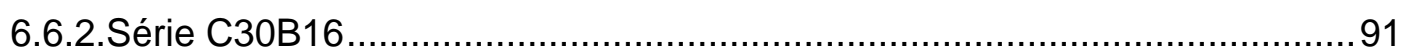

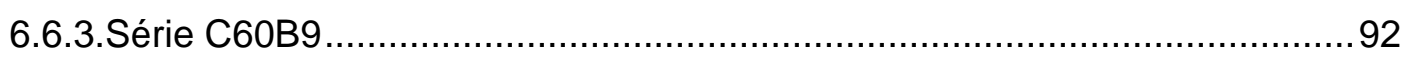

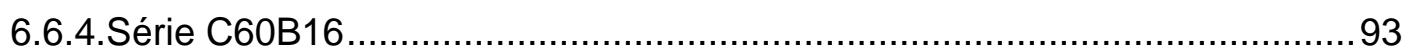

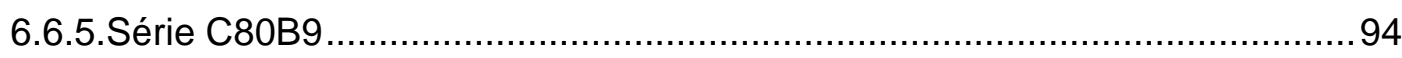

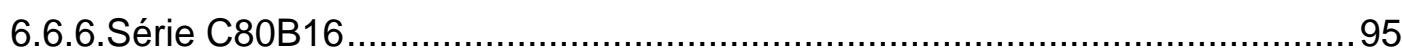

6.6.7.Comparação entre os modelos de arrancamento .....................................96

6.6.7.1. Influência da resistência do concreto no comportamento da

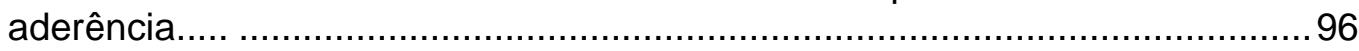

6.6.7.2. Influência do diâmetro da barra no comportamento da aderência.........97

6.6.8.Comparação entre modelos analíticos e experimentais em relação ao comportamento da aderência entre barras de GFRP e o concreto ........................99

6.6.9. Comparação entre a resistência de aderência desenvolvida pelas barras de GFRP e pelas barras de aço........................................................................ 105

6.7. Análise do comprimento de ancoragem básico e da resistência de

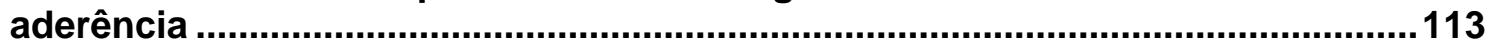

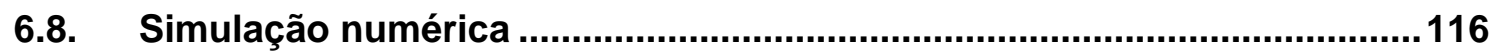

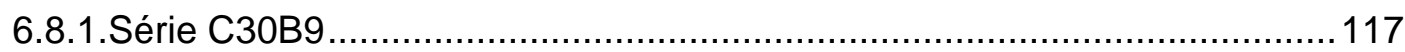

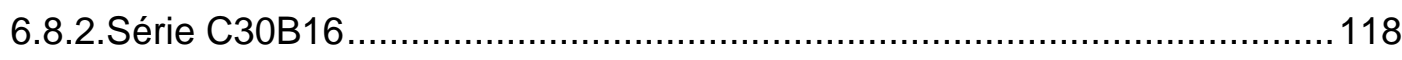

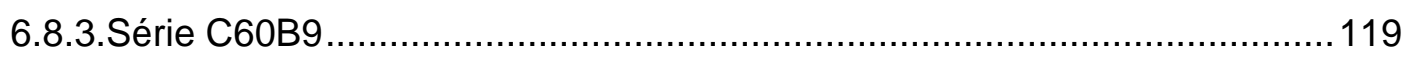

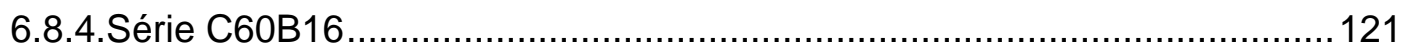

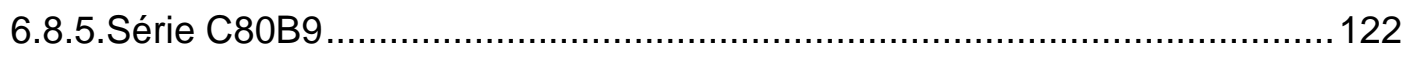

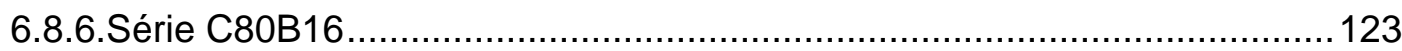

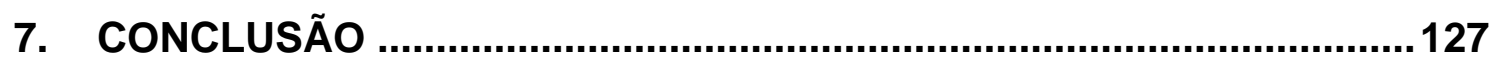

7.1. Propriedades mecânicas das barras de GFRP ...................................... 127

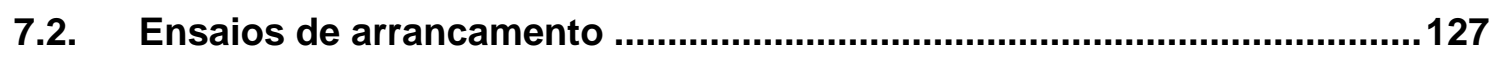

7.3. Influência da resistência do concreto no comportamento da aderência 128

7.4. Influência do diâmetro da barra no comportamento da aderência.......... 128

7.5. Comparação entre modelos analíticos e experimentais em relação ao comportamento da aderência entre barras de GFRP e o concreto........................129

7.6. Comparação entre a resistência de aderência desenvolvida pelas barras de GFRP e pelas barras de aço ........................................................................129

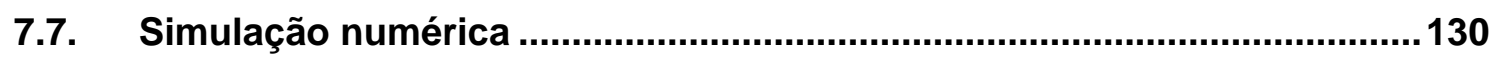

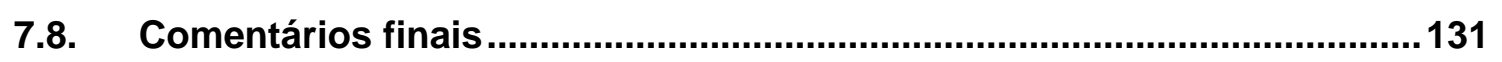

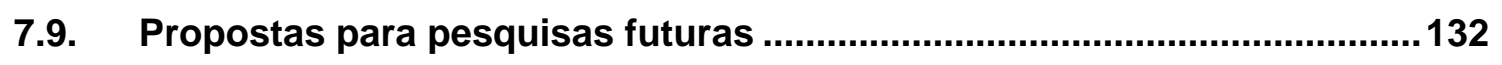

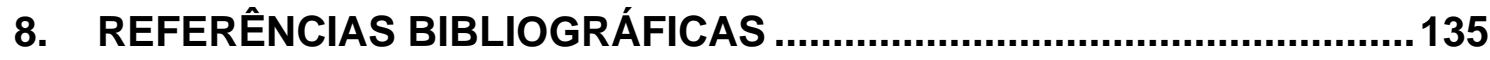




\section{RESUMO}

COUTO, I.A. (2007), "Análise teórica e experimental do comportamento da aderência entre o concreto e barras de fibra de vidro impregnada por polímero" Dissertação de Mestrado, Escola de Engenharia de São Carlos, Universidade de São Paulo, São Carlos-SP.

O uso de novos materiais na construção civil combinado com a alta tecnologia dos processos construtivos pode conduzir à redução de custo e melhoria no comportamento da estrutura. Recentemente, em função da corrosão das barras de aço dentre outros fatores, muitos pesquisadores têm sugerido a utilização de barras não-metálicas como substituição das barras aço nas estruturas em concreto. Além das barras não-metálicas permitirem cobrimentos menores e possibilitarem menor custo de manutenção, outras vantagens no seu uso podem ser citadas, tais como: pequeno peso específico, alta resistência à tração, não condutibilidade elétrica, térmica e magnética, entre outras. Este trabalho analisa o comportamento da aderência entre barras de GFRP (barras de Fibra de Vidro Impregnada por Polímero) e o concreto, por meio de uma revisão bibliográfica e ensaios de arrancamento padronizados, segundo o RILEM-FIP-CEB (1973). Foram consideradas as influências dos parâmetros como a resistência à compressão do concreto e o diâmetro da barra de GFRP. Com base nos resultados experimentais, buscou-se comparar o comportamento de aderência barra de GFRP-concreto e barra de aço-concreto, além da verificação das formulações para previsão da resistência de aderência segundo Códigos Normativos e a literatura técnica, para estruturas armadas com barras de aço e barras de FRP. Posteriormente, realizou-se a análise numérica da aderência, por meio do método dos elementos finitos. Nos modelos experimentais de arrancamento pode-se perceber a influência das propriedades mecânicas e da conformação superficial das barras de GFRP no comportamento da aderência, apresentando menores resistências de aderência quando comparadas às barras de aço de diâmetro similar. O valor da resistência de aderência determinado experimentalmente foi maior que o valor proposto pelos Códigos Normativos. Os modelos numéricos não representaram satisfatoriamente 0 comportamento experimental, visto que se trata de uma simulação numérica linear e o comportamento experimental força $x$ deslocamento é não-linear.

Palavras-chave: barras de GFRP, aderência barra-concreto, concreto, arrancamento, simulação numérica. 


\section{ABSTRACT}

COUTO, I.A. (2007), "Analytical and experimental analysis of bond behavior between concrete and GFRP bars" Dissertação de Mestrado, Escola de Engenharia de São Carlos, Universidade de São Paulo, São Carlos-SP.

The use of new materials in civil construction combined with high technology processes leads to improvements in many aspects, like cost reductions and better structural behavior. Recently, due to corrosion of the steel bars, among other factors, many researchers have been suggesting the use of non-metallic bars as a substitution of the steel reinforcement in concrete structures. Besides, the non-metallic bars allow smaller clear cover and make possible lower maintenance cost, other advantages can be mentioned, such as: low specific weight, high tensile strength, electrical, thermal and magnetic non-conductivities, and others. This work analyzes the bond behavior between GFRP bars (Glass Fiber Reinforced Polymer bars) and concrete, through state-of-art and standard pull-out tests, according to RILEM-FIP-CEB (1973). The influence of some parameters, as compressive concrete strength and GFRP bar diameter, was considered. Based on the experimental results, it was aimed at comparing the bond behavior of the GFRP-concrete bar with the steel-concrete bar, in addition to the verification of bond strength formulations established by the Standards Codes and the bibliography for structures reinforced with steel bars and FRP bars. Further, the bond numerical analysis was carried out through finite elements. In the pull-out tests, the influence of mechanical properties and superficial conformation on the GFRP bars was observed in the bond behavior, presenting smaller bond strength than the steel bars of similar diameter. The value of the experimental bond strength was larger than the value proposed by Standards Codes. The numerical models did not represent well the experimental behavior given that a linear numerical simulation was considered, but, actually, the experimental load x slip behavior is non-linear.

Keywords: GFRP bars, bond, concrete, pull-out, numerical simulation. 


\section{INTRODUÇÃO}

\subsection{Considerações iniciais}

$\mathrm{Na}$ construção civil, as barras de aço são amplamente utilizadas como armadura ativa e passiva nas estruturas em concreto. No entanto, sob certas condições ambientais pode ocorrer a corrosão dessas barras, causando sua deterioração ou até mesmo o colapso progressivo dos elementos estruturais, conduzindo a elevados gastos para reparo e reforço das estruturas deterioradas.

Essa preocupação teve como conseqüência, o desenvolvimento de novas técnicas, como barras cobertas com epóxi, membranas sintéticas ou proteção catódica, com a finalidade de inibir a corrosão, e mais recentemente, a substituição das barras de aço por Barras de Fibras Impregnada por Polímeros, FRP, (Fiber Reinforced Polymer).

A aderência entre as barras de aço e o concreto tem sido estudada há várias décadas, e uma extensa quantidade de trabalhos experimentais e teóricos foram publicados neste sentido. No entanto, as formulações utilizadas nas normas de projeto de estruturas em concreto armado não fazem prescrição ao uso de outros materiais para armadura, senão o aço. A introdução das barras de FRP, utilizadas como armadura para estruturas em concreto, fez surgir a necessidade do desenvolvimento de normas abrangendo o uso de armaduras compostas por diferentes materiais.

As propriedades físicas e mecânicas das barras influenciam no mecanismo de transferência de tensões entre a armadura e o concreto e controlam, conseqüentemente, o espaçamento e a largura das fissuras, a espessura requerida de cobrimento de concreto, e o comprimento de aderência. Parâmetros como o processo de fabricação, a conformação superficial, o tipo e porcentagem das fibras e resinas contidas nas barras afetam as propriedades de aderência entre as barras de FRP e o concreto.

Segundo BAKIS et al. (1998), a aderência entre as barras de FRP e o concreto é controlada pelas propriedades da barra de FRP, diferente da aderência entre as 
barras de aço nervuradas e o concreto, onde a resistência à compressão do concreto é o parâmetro controlador.

Este estudo reflete o início do trabalho de aderência das Barras de Fibra de Vidro Impregnada por Polímeros, GFRP, (Glass Fiber Reinforced Polymer), sob carregamento monotônico, no departamento de Estruturas da Escola de Engenharia de São Carlos.

\subsection{Histórico}

A utilização dos compósitos de FRP se expandiu ao final da Segunda Guerra Mundial. Os compósitos de FRP foram utilizados na indústria eletrônica, aeroespacial e automobilística durante varias décadas, mas sua aplicação na engenharia civil, como armadura para o concreto armado, é relativamente recente (UMOTO et al., 2002).

A expansão do sistema rodoviário nos Estados Unidos, na década de 50, aumentou a necessidade de manutenção anual das estradas, além disso, a aplicação de sal se tornou comum em pontes durante o período de neve. Como resultado disso, a armadura de aço, presente nessas estruturas, ficou submetida à corrosão. Várias pesquisas foram realizadas com a finalidade de solucionar o problema, incluindo cobertura galvanizada, concreto polimérico, cobertura com epóxi e barras de GFRP. No entanto, as barras de GFRP não foram consideradas uma solução economicamente viável até o final da década de 70 (ACI 440 1R, 2003).

A indústria norte-americana "Marshall Vega" desenvolveu barras de GFRP como armadura para estruturas de concreto. Inicialmente, as barras de GFRP foram consideradas uma alternativa de substituição das barras de aço em concretos poliméricos, em virtude da não compatibilidade entre os coeficientes de expansão térmica do concreto polimérico e das barras de aço ( $\mathrm{ACl} 440$ 1R, 2003).

Nos anos 80 ocorreu a demanda de barras não-metálicas na América do Norte, principalmente em obras hospitalares onde são necessários materiais não-condutores magnéticos, com isso, as barras de FRP se tornaram uma solução para este tipo de construção. Em virtude do maior estudo e conhecimento das propriedades das barras não-metálicas, outros tipos de construção começaram a utilizar este tipo de armadura, especialmente, estruturas costeiras, pistas de decolagem dos aeroportos e laboratórios eletrônicos (BROWN e BARTHOLOMEW, 1996* apud ACI 440 1R, 2003).

\footnotetext{
* BROWN, V., e BARTHOLOMEW, C. (1996), "Long-term Deflections of GFRP-Reinforced Concrete Beams," Proceedings of the First International Conference on Composites in Infrastructure (ICCl-96), Tucson, Ariz., pp. 389-400.
} 
Durante a década de 90 houve um crescimento no uso de armaduras nãometálicas em pontes dos Estados Unidos. Em 1991, foi publicado nos EUA o Código Normativo do Instituto Americano de Concreto (ACl), apresentando o Estado da Arte dos Compósitos de FRP (ACl 440 R, 1996). Em 2003, foi publicado o Código Normativo que prevê o dimensionamento de elementos estruturais em concreto armado com barras de FRP (ACl 440 1R, 2003), e em 2004, o Código Normativo contendo os procedimentos de ensaio de estruturas em concreto armado com barras de FRP (ACl 440 3R, 2004).

O Japão é o país que possui o maior número de obras onde se empregaram as armaduras de FRP. Em 1997, a Sociedade dos Engenheiros Civis Japoneses (JSCE) incluiu em suas recomendações de projeto e construção de estruturas o uso de armaduras de FRP.

Na Europa o uso das barras de FRP iniciou-se na Alemanha, em 1986, com a construção de uma ponte rodoviária. Desde a construção desta ponte, têm sido implantados programas para pesquisa e uso de armadura de FRP na Europa. Em 1991, iniciou-se o projeto de pesquisa BRITE/EURAM, e mais recentemente o EUROCONCRETE, dando início aos trabalhos do grupo de pesquisa da FIB (Federação Internacional do Concreto), TASK GROUP 9.3 (FIB TG 9.3), que está finalizando a norma técnica para estruturas em concreto armado com barras de FRP.

No Brasil, alguns pesquisadores têm estudado o uso das barras de FRP como armadura para estruturas em concreto armado. Em 1998 foram publicados dois artigos no III Congresso de Engenharia Civil em Juiz de Fora - MG: Barras de Armação em FRP: Discussão de parâmetros para normalização (ALVES, A. B.; CASTRO, P. F, 1998.) e Comportamento de Vigas de Concreto de Alta Resistência com Armadura Não Metálica Tipo FRP (RAYOL, J. O.; MELO, G. S., 1998). E mais recentemente, em 2006, foi publicada uma dissertação de mestrado na Escola de Engenharia de São Carlos, cujo titulo é: "Análise Teórica e Experimental de Vigas de Concreto Armadas com Barras Não-Metálicas de GFRP" (TAVARES, 2006).

TAVARES estudou o comportamento de vigas armadas com barras de GFRP submetidas à flexão. Foram realizados ensaios para a determinação das propriedades mecânicas das barras de GFRP, das barras de aço e do concreto. As vigas armadas com barras de GFRP foram ensaiadas à flexão em quatro pontos e os resultados comparados com os de uma viga armada com barras de aço CA-50, nas mesmas condições de ensaio. Nos modelos pôde-se perceber a influência das propriedades das barras de GFRP no comportamento geral da estrutura, verificaram-se grandes deformações nas barras longitudinais de GFRP e elevados deslocamentos nas vigas, em virtude do baixo módulo de elasticidade destas barras. 

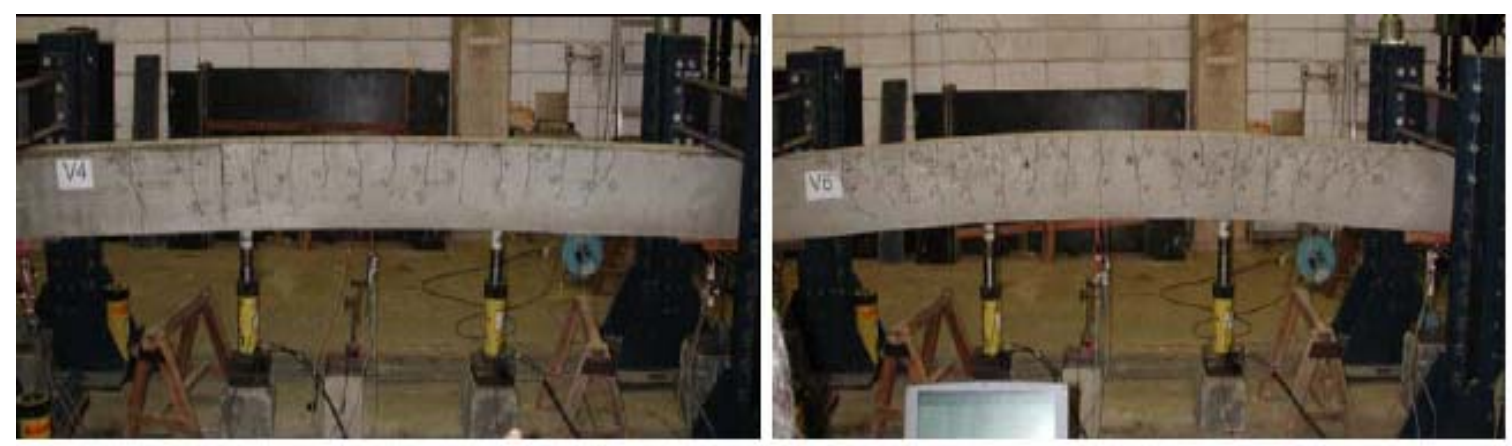

Figura 1.1 - Ensaio das vigas armadas com barras de GFRP

(TAVARES, 2006)

\subsection{Aplicações}

As barras de FRP podem ser utilizadas na construção civil como armadura passiva ou ativa nas estruturas em concreto armado. Em virtude de suas propriedades, estas barras têm se tornado uma alternativa para a substituição das armaduras de aço em determinadas estruturas.

A seguir serão mostradas algumas obras onde se empregaram armaduras de FRP:

Construção de hospital no Texas - EUA, 1985 - foi utilizada armadura de GFRP na construção dos pilares e das vigas. Optou-se por usar este tipo de barra por causa da sua não condutividade magnética.

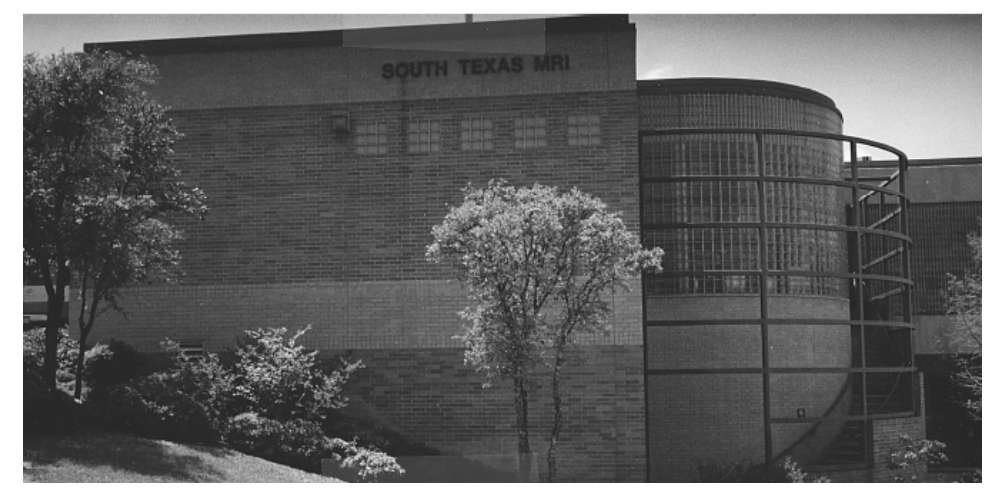

Figura 1.2 - Hospital no Texas

(ACl $440 \mathrm{R}, 1996$ )

Construção da linha de trem no Japão (s.d.) - foi utilizada armadura de GFRP nesta estrutura. Seu uso é justificado pela não condutividade magnética do material. 


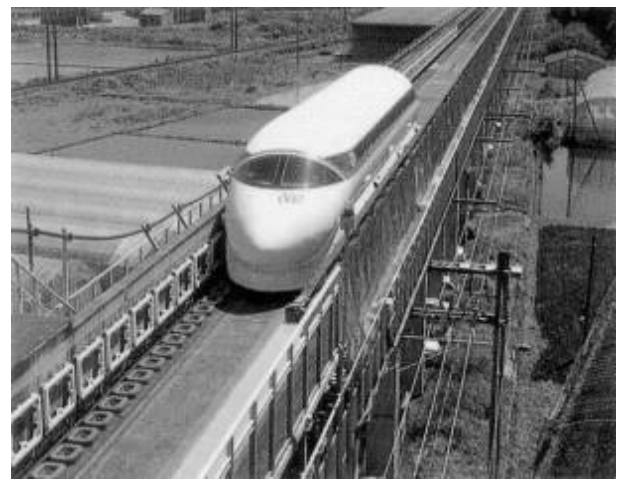

Figura 1.3 - Construção da linha de trem no Japão (PILAKOUTAS e GUADAGNINI, s.d.)

Lajes pré-moldadas na Geórgia - EUA (s.d.) - foi usada armadura de GFRP na confecção de lajes pré-moldadas de um piso. Seu uso é justificado pelo bom comportamento perante meios agressivos, presença de elevada umidade $\mathrm{e}$ temperatura.
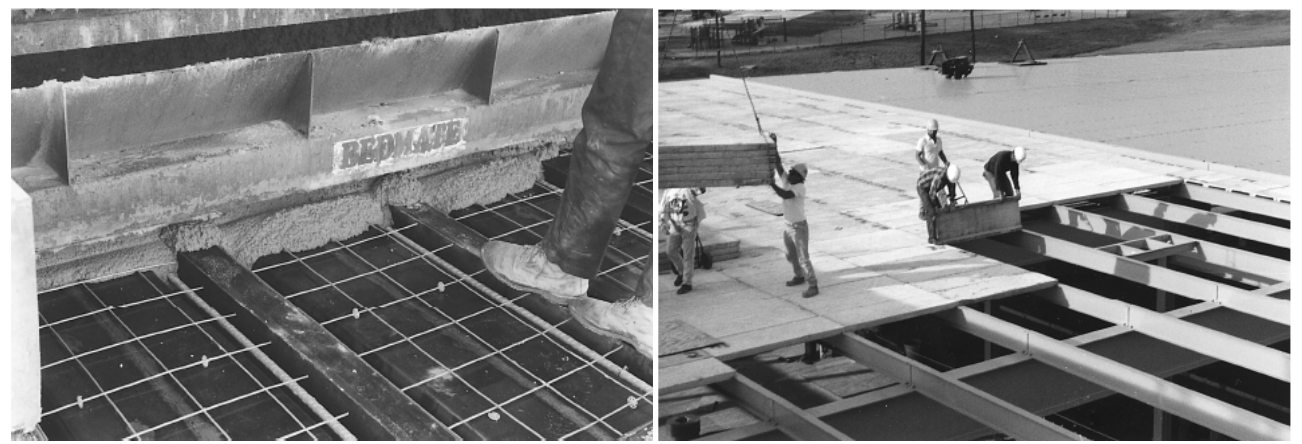

Figura 1.4 - Construção e execução de lajes pré-moldadas na Geórgia (ACl $440 \mathrm{R}, 1996)$

Pontes nos EUA (1999) - foi utilizada armadura de GFRP na construção e na reabilitação de tabuleiros de pontes. O uso da armadura de GFRP se justifica pela sua resistência à corrosão, em virtude do ambiente agressivo e/ou da adição de sal no período de neve.

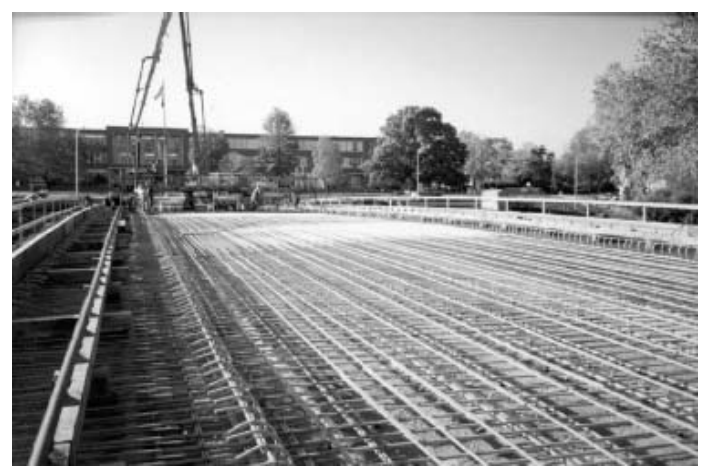

Figura 1.5 - Construção de ponte em Lima - Ohio (ACl 440 1R, 2003) 


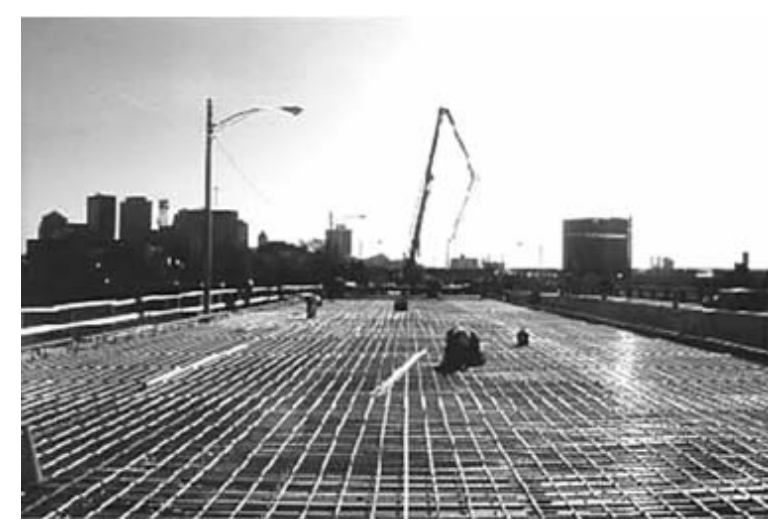

Figura 1.6 - Reabilitação do tabuleiro de ponte em Dayton - Ohio (ACl 440 1R, 2003)

Construção de túnel no Japão (1990) - foi usado tela de GFRP na construção desta estrutura. Seu uso foi justificado por causa de sua pequena massa, resistência à corrosão e fácil construção, pois melhora as condições de montagem da armação.

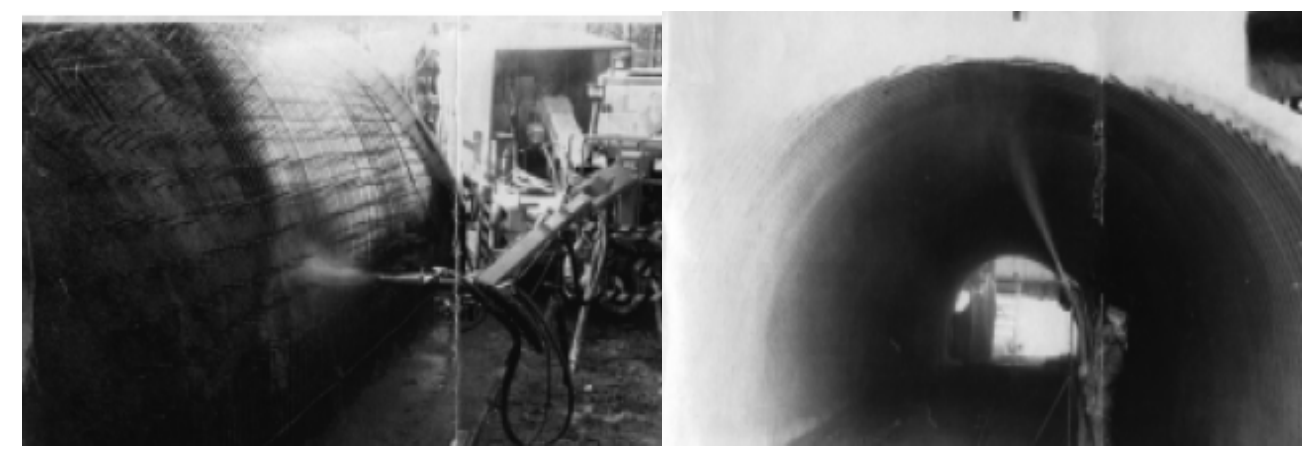

Figura 1.7 - Construção de túnel no Japão

(ACl $440 \mathrm{R}, 1996)$

\subsection{Objetivo}

O objetivo principal desta pesquisa é estudar o comportamento da aderência entre barras de fibra de vidro impregnada por polímero (GFRP) e o concreto, por meio de modelos físicos de arrancamento.

O comportamento da aderência barra de GFRP-concreto é comparado com o comportamento de aderência barra de aço-concreto, de diâmetro similar. Para isto, são analisados a influência do diâmetro e da resistência à compressão do concreto, a forma de ruptura, o comportamento do diagrama tensão de aderência x deslocamento, o deslocamento na ruptura da ligação e a resistência última de aderência.

Os resultados obtidos experimentalmente são comparados com as formulações presentes nos Códigos Normativos para a previsão da resistência última de aderência 
entre as barras de aço e o concreto e com modelos analíticos para a representação do comportamento da aderência entre barras de FRP e o concreto.

É apresentado também, o desenvolvimento de um modelo numérico visando a representação do comportamento da aderência barra de GFRP-concreto obtido por meio dos ensaios de arrancamento.

\subsection{Justificativa}

A indústria da construção civil, em vários países, tem tido crescentes avanços com relação aos novos materiais. São propostos diferentes sistemas construtivos, mistura de diferentes componentes ao concreto, o uso de novos materiais, entre outros, tudo isto visando durabilidade, conforto ao usuário, menor custo de manutenção, além do aspecto arquitetônico.

A substituição da armadura metálica por armadura não-metálica em algumas construções é uma tendência em países como EUA, Japão, Canadá, Inglaterra. No Brasil ainda não existem obras com este tipo de armadura, mas poderia ser uma substituição vantajosa no que diz respeito à crescente corrosão das armaduras no litoral brasileiro, além da corrosão das armaduras por causa das ondas eletromagnéticas nas linhas do metrô.

No entanto, os limitados resultados experimentais das barras de FRP ainda não avaliam exatamente o comportamento dessas barras juntamente com o concreto. São necessários inúmeros estudos a fim de se obter uma norma de projeto de estruturas em concreto armado com armadura não-metálica, já que as normas que tratam de armadura de aço não podem ser usadas diretamente, visto suas diferentes propriedades mecânicas e conformação superficial.

Recentemente, no Brasil, algumas indústrias iniciaram a produção e comercialização de barras e telas de FRP, porém não existem normas brasileiras que abordam o assunto. Em função disto, surge a necessidade de maiores informações a respeito das propriedades deste material e de seu comportamento em relação ao concreto.

Desse modo, a busca de informações a respeito das propriedades das barras não-metálicas e, principalmente, do comportamento da aderência entre estas barras e concreto originou esta pesquisa. 


\subsection{Método empregado}

A primeira etapa deste trabalho consiste em uma revisão bibliográfica a respeito das propriedades das barras de GFRP e do seu comportamento da aderência com o concreto.

A segunda etapa deste trabalho consiste na análise experimental e teórica do comportamento da aderência entre as barras de GFRP e o concreto. A análise experimental consiste nos seguintes ensaios:

- Ensaios de caracterização dos materiais (materiais constituintes do concreto, concreto e barras de GFRP);

- Ensaios de arrancamento em cilindros de concreto armado com barras de GFRP, de acordo com o procedimento de ensaio descrito pela RILEM/FIP/CEB (1973).

A terceira etapa consiste em uma simulação numérica, baseada no Método dos Elementos Finitos, com a finalidade de consolidar um modelo numérico e ainda, comparar os resultados numéricos e experimentais.

\subsection{Estrutura da dissertação}

No primeiro capítulo foi feito uma abordagem geral do assunto, seguido por um histórico da utilização do material na construção civil e algumas obras realizadas em diversos países. Foram apresentados também neste capitulo, o objetivo da pesquisa, a justificativa e a metodologia empregada para o desenvolvimento desta, finalizando com a estrutura da dissertação.

O segundo capítulo trata das propriedades dos compósitos de FRP, com ênfase nas barras de GFRP. São apresentadas propriedades mecânicas das fibras, resinas e barras, além dos fatores que afetam estas propriedades.

O terceiro capítulo descreve o comportamento de aderência, mostrando os principais mecanismos de mobilização. É dado enfoque à aderência entre as barras de GFRP e o concreto,porém, nos casos onde não existem estudos referentes às barras de FRP, recorre-se ao fenômeno da aderência entre as barras de aço e o concreto. A última parte deste capítulo trata de um resumo dos principais ensaios de aderência das barras de aço realizados no meio científico, podendo ser extrapolados para as barras de FRP. 
O quarto capítulo descreve todos os aspectos relativos à análise experimental, como: caracterização dos materiais, metodologia empregada nos ensaios, instrumentação utilizada e preparação dos modelos para os ensaios de arrancamento.

O quinto capítulo será realizado a simulação numérica dos ensaios de arrancamento realizados com a finalidade de representar o comportamento de aderência entre a barra de GFRP e o concreto.

O sexto capítulo se refere a análise e discussão dos resultados obtidos na investigação experimental e teórica.

No sétimo capítulo são apresentadas as conclusões obtidas neste trabalho, bem como, sugestões para trabalhos futuros. 


\section{BARRAS DE FIBRA DE VIDRO IMPREGNADA POR POLÍMERO (GFRP)}

\subsection{Considerações iniciais}

As barras de fibra de vidro impregnada por polímero, GFRP (Glass Fiber Reinforced Polymer), são uma alternativa de armadura para o concreto armado. Estas barras são formadas por um núcleo de fibras (minerais ou sintéticas) estiradas de elevada resistência e impregnadas por uma matriz polimérica (resina), possuindo propriedades anisotrópicas por ter maior resistência longitudinal do que transversal.

As barras de GFRP são fabricadas pelo processo de pultrusão. Podem possuir aparência exatamente igual às das barras de aço entalhadas, mas com propriedades mecânicas diferentes.

Uma particularidade das barras de GFRP é que não podem ser dobradas no canteiro de obras, por causa disto devem ser manufaturadas com a forma final desejada (Figura 2.1).

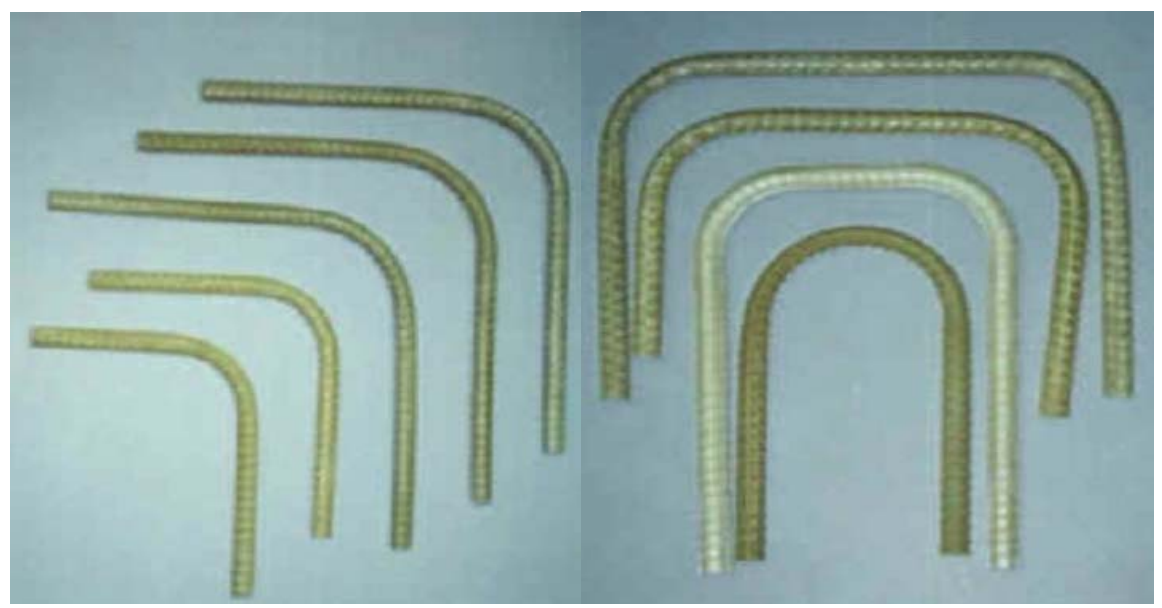

Figura 2.1 - Barras de GFRP com ganchos (RE-BAR CHILE, s.d.) 


\subsection{Compósito de FRP}

Segundo o ACI 440 R (1996), o termo compósito pode ser aplicado a qualquer combinação de dois ou mais materiais separados com uma interface identificável entre eles. Essa interface geralmente recebe um tratamento superficial para melhorar a adesão do componente com a matriz polimérica. As barras de GFRP são compósitos formados por uma matriz polimérica e fibras de vidro, apresentando alta razão entre seu comprimento e o raio. A Figura 2.2 ilustra a seção transversal de um compósito de GFRP.

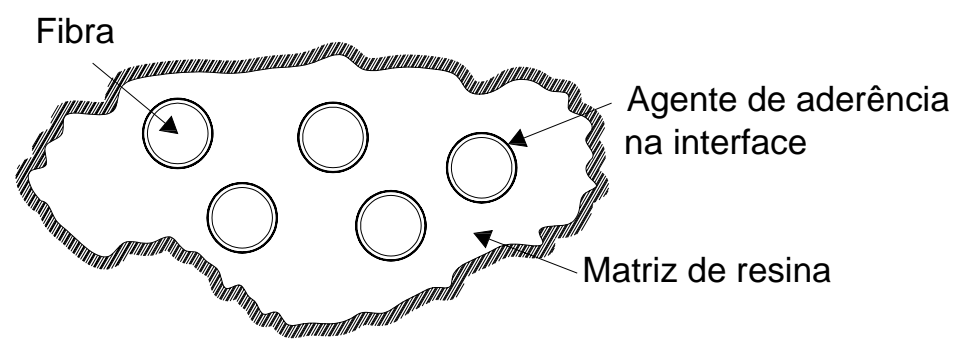

Figura 2.2 - Seção transversal do compósito de GFRP

(ACl $440 \mathrm{R}, 1996)$

Os principais fatores que afetam o desempenho físico dos compósitos de FRP (Fiber Reinforced Polymer) são as propriedades mecânicas das fibras, sua orientação, seu comprimento, seu tipo e sua composição, as propriedades mecânicas da matriz polimérica e a adesão entre as fibras e a matriz.

\subsubsection{Matriz polimérica}

A matriz polimérica é responsável por transferir as tensões entre as fibras da barra e o concreto adjacente e, além disso, proteger as fibras de danos mecânicos e/ou danos causados pelo ambiente.

As resinas geralmente usadas na fabricação das barras de FRP são as termoestáticas. Dentre elas podem ser citadas as de epóxi, vinil éster e poliéster, cujas propriedades estão mostradas na Tabela 2.1. 
Tabela 2.1 - Propriedades das matrizes poliméricas dos compósitos de FRP

(FIB 9.3 TG, 2003)

\begin{tabular}{c|c|c|c}
\hline \multirow{2}{*}{ Propriedades } & \multicolumn{3}{|c}{ Matriz } \\
\cline { 2 - 4 } & Poliéster & Epóxi & Vinil Éster \\
\hline $\begin{array}{c}\text { Massa específica } \\
\left(\mathrm{g} / \mathrm{cm}^{3}\right)\end{array}$ & $1,20-1,40$ & $1,20-1,40$ & $1,15-1,35$ \\
\hline $\begin{array}{c}\text { Resistência à tração } \\
(\mathrm{MPa})\end{array}$ & $34,5-104$ & $55-130$ & $73-81$ \\
\hline $\begin{array}{c}\text { Módulo longitudinal } \\
(\mathrm{GPa})\end{array}$ & $2,1-3,45$ & $2,75-4,10$ & $3,0-3,5$ \\
\hline $\begin{array}{c}\text { coeficiente de } \\
\text { Poisson }\end{array}$ & $0,35-0,39$ & $0,38-0,40$ & $0,36-0,39$ \\
\hline $\begin{array}{c}\text { Coeficiente de dilatação } \\
\text { térmica }\left(10^{-6} /{ }^{\circ} \mathrm{C}\right)\end{array}$ & $55-100$ & $45-65$ & $50-75$ \\
\hline $\begin{array}{c}\text { Teor de umidade } \\
(\%)\end{array}$ & $0,15-0,60$ & $0,08-0,15$ & $0,24-0,30$ \\
\hline \multicolumn{1}{|c|}{}
\end{tabular}

UOMOTO et al. (2002) salientam a importância de se levar em conta à deformação de ruptura das resinas e das fibras. Por exemplo, as resinas epóxi têm baixa capacidade de deformação e trabalham bem em conjunto com fibras de carbono. Mas os resultados não são satisfatórios quando são usadas fibras de aramida ou vidro, que possuem alta capacidade de deformação, neste caso as resinas de vinil éster são mais indicadas.

\subsubsection{Fibras}

As propriedades dos compósitos são influenciadas pela escolha das fibras. $\mathrm{Na}$ construção civil, três tipos de fibras podem ser usadas no processo de fabricação das barras de FRP: fibra de carbono, fibra de aramida ou fibra de vidro. As propriedades de algumas dessas fibras podem ser observadas na Tabela 2.2.

As fibras de vidro são consideradas as mais baratas quando comparadas com as fibras de carbono e aramida. As fibras de vidro comercialmente disponíveis para o uso em construção civil são: Vidro-E, Vidro-S e Vidro álcali resistente.

De acordo com o ACl $440 \mathrm{R}$ (1996), as fibras de vidro reagem com a água e possuem superfície muito ativa. Elas podem ser facilmente danificadas durante 0 manuseio, assim um filme protetor deve ser aplicado imediatamente após o processo de fabricação da fibra. Este filme, além de proteger a fibra contra umidade, também é responsável por aumentar a adesão entre a fibra e matriz polimérica. As fibras de vidro são comercializadas em diversas formas, como está ilustrado na Figura 2.3. 
Tabela 2.2 - Propriedades das fibras usadas em barras de FRP (Adaptado de UOMOTO et al., 2002)

\begin{tabular}{|c|c|c|c|c|c|c|c|c|}
\hline & \multicolumn{4}{|c|}{ Fibra de carbono } & \multicolumn{2}{|c|}{$\begin{array}{l}\text { Fibra de } \\
\text { aramida }\end{array}$} & \multicolumn{2}{|c|}{ Fibra de vidro } \\
\hline & \multicolumn{2}{|c|}{$\begin{array}{l}\text { Carbono Poliacrílico } \\
\text { Nitril }\end{array}$} & \multicolumn{2}{|c|}{ Carbono Pitch } & \multirow[t]{2}{*}{$\begin{array}{c}\text { Kevlar } \\
49 \\
\text { Twaron } \\
\end{array}$} & \multirow[t]{2}{*}{$\begin{array}{l}\text { Tech- } \\
\text { nora }\end{array}$} & \multirow[t]{2}{*}{ Vidro-E } & \multirow[t]{2}{*}{$\begin{array}{c}\text { Vidro } \\
\text { álcali } \\
\text { resistente }\end{array}$} \\
\hline & $\begin{array}{c}\text { Alta } \\
\text { resistência }\end{array}$ & $\begin{array}{c}\text { Alto módulo } \\
\text { de } \\
\text { elasticidade }\end{array}$ & Comum & $\begin{array}{c}\text { Alto módulo } \\
\text { de } \\
\text { elasticidade }\end{array}$ & & & & \\
\hline $\begin{array}{l}\text { Resistência } \\
\text { à tração } \\
(\mathrm{MPa})\end{array}$ & 3430 & $\begin{array}{c}2450- \\
3920\end{array}$ & $\begin{array}{c}764- \\
980\end{array}$ & $\begin{array}{c}2940- \\
3430\end{array}$ & 2744 & 3430 & $\begin{array}{l}3430- \\
3528\end{array}$ & $\begin{array}{c}1764- \\
3430\end{array}$ \\
\hline $\begin{array}{l}\text { Módulo de } \\
\text { deformação } \\
\text { (GPa) }\end{array}$ & $196-235$ & $343-637$ & $37-39$ & $392-784$ & 127 & 72,5 & $\begin{array}{c}72,5- \\
73,5\end{array}$ & $68,6-7$ \\
\hline $\begin{array}{c}\text { Alongamento } \\
(\%)\end{array}$ & $1,3-1,8$ & $0,4-0,8$ & $\begin{array}{c}2,1- \\
2,5\end{array}$ & $0,4-1,5$ & 2,3 & 4,6 & 4,8 & $\begin{array}{l}4-5 \\
2-3\end{array}$ \\
\hline $\begin{array}{c}\text { Massa } \\
\text { específica } \\
\left(\mathrm{g} / \mathrm{cm}^{3}\right)\end{array}$ & $1,7-1,8$ & $1,8-2,0$ & $\begin{array}{c}1,6- \\
1,7\end{array}$ & $1,9-2,1$ & 1,45 & 1,39 & 2,6 & 2,27 \\
\hline $\begin{array}{l}\text { Diâmetro } \\
(\mu \mathrm{m})\end{array}$ & \multicolumn{2}{|c|}{$5-8$} & \multicolumn{2}{|c|}{$9-18$} & \multicolumn{2}{|c|}{12} & \multicolumn{2}{|c|}{$8-12$} \\
\hline
\end{tabular}

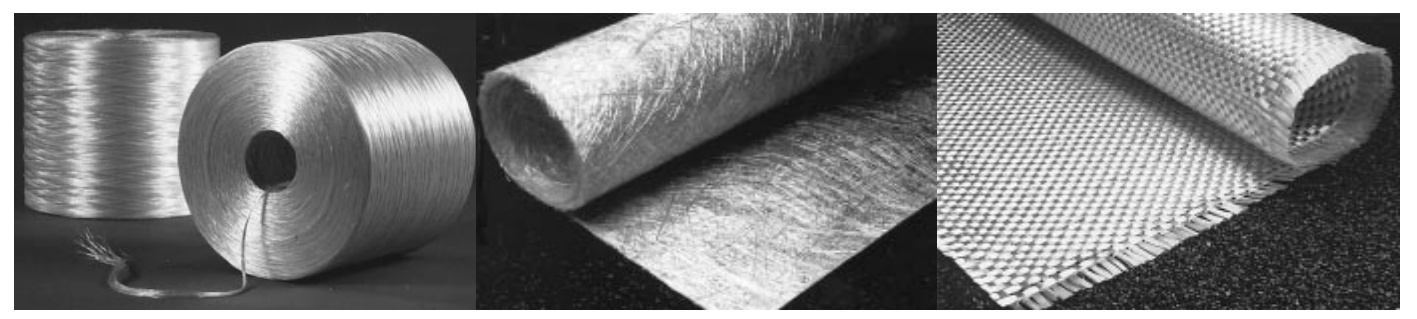

Figura 2.3 - Formas de comercialização da fibra de vidro: a) Fibra de vidro em forma de fio; b) Manta de fibra de vidro distribuída aleatoriamente; c) Tecido de fibra de vidro (ACl $440 \mathrm{R}, 1996)$

\subsection{Processo de fabricação das barras de FRP}

As barras de FRP são geralmente fabricadas pelo processo de Pultrusão (Figura 2.4). Este processo produz barras de seção transversal constante e com comprimento limitado apenas pelo transporte e pelo tamanho do galpão da fábrica. Os filamentos de fibra são submetidos a um banho com resina, catalisador e outros aditivos, as fibras são impregnadas nesse banho e o excesso de resina liquida é removida. Após isto, elas são estiradas para formação do perfil. O processo de pultrusão é realizado a uma velocidade de $0,9 \mathrm{~m} / \mathrm{min}$, dependendo do tamanho da seção transversal da barra (ACl $440 \mathrm{R}, 1996)$. 


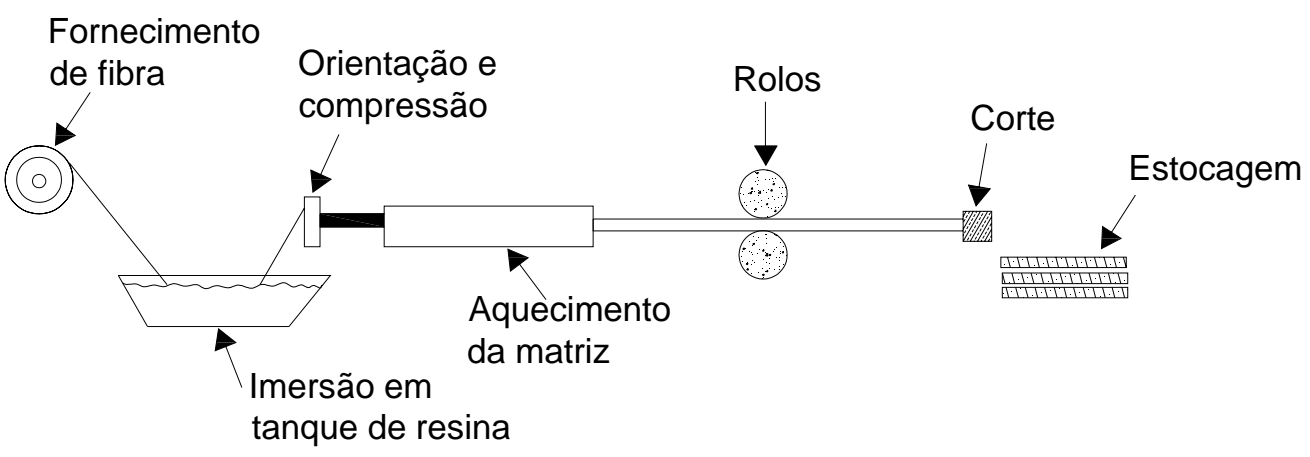

Figura 2.4 - Processo de Pultrusão das barras de FRP (TIGHIOUART et al., 1998)

Segundo BAKIS et al. (2002), para aumentar a aderência com o concreto, deformações superficiais são aplicadas na barra antes do seu endurecimento por alguns desses processos: enrolando filamentos de fibra em forma de hélice ao longo do comprimento da barra; moldando entalhes ao longo do comprimento da barra; enrolando um filme texturizado ao longo do comprimento da barra, com posterior remoção deste; e impregnação de agregados finos na superfície da barra (Figuras 2.5 e 2.6).

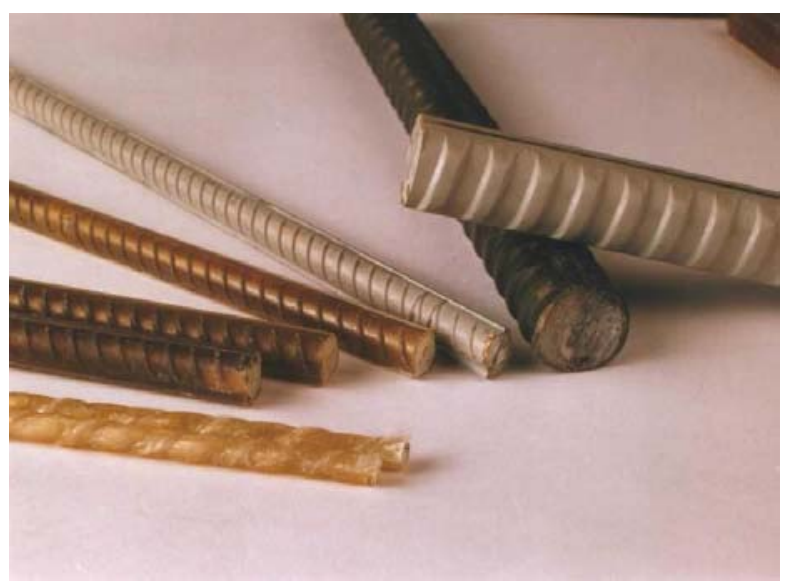

Figura 2.5 - Diferentes conformações superficiais das barras de FRP (RE-BARS CHILE, s.d.)

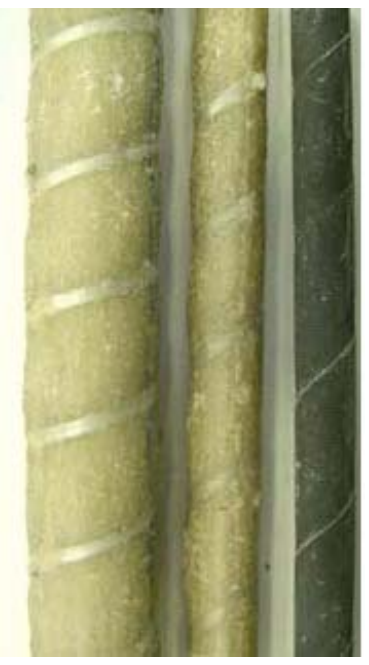

Figura 2.6 - Diferentes conformações superficiais das barras de FRP (BELARBI e WANG, 2004)

\subsection{Propriedades das barras de FRP}

As propriedades mecânicas das barras de FRP variam significativamente com o tipo de resina e fibra, orientação da fibra, efeitos dimensionais e controle de qualidade da produção. Além disso, como todos os materiais estruturais, suas 
propriedades mecânicas também são afetadas pelo tipo e duração do carregamento, pela temperatura e pela umidade ( $\mathrm{ACl} 440$ 1R, 2003).

A Tabela 2.3 faz uma comparação das propriedades mecânicas das barras e cordoalhas de GFRP com as barras e cordoalhas de aço.

Tabela 2.3 - Comparação entre as propriedades das barras e cordoalhas de GFRP e de aço

(Adaptado de ACl $440 \mathrm{R}, 1996)$

\begin{tabular}{c|c|c|c|c}
\hline & Barra de aço & $\begin{array}{c}\text { Cordoalha de } \\
\text { aço }\end{array}$ & $\begin{array}{c}\text { Barra de } \\
\text { GFRP }\end{array}$ & $\begin{array}{c}\text { Cordoalha de } \\
\text { GFRP }\end{array}$ \\
\hline $\begin{array}{c}\text { Resistência à tração } \\
(\mathrm{MPa})\end{array}$ & $483-690$ & $1379-1862$ & $517-1207$ & $1379-1724$ \\
\hline $\begin{array}{c}\text { Tensão de escoamento } \\
(\mathrm{MPa})\end{array}$ & $276-414$ & $1034-1396$ & $\mathrm{NA}^{*}$ & $\mathrm{NA}^{*}$ \\
\hline $\begin{array}{c}\text { Módulo de elasticidade } \\
(\mathrm{GPa})\end{array}$ & 200 & $186-200$ & $41-55$ & $48-62$ \\
\hline $\begin{array}{c}\text { Alongamento máximo } \\
(\mathrm{mm} / \mathrm{mm})\end{array}$ & $>0,10$ & $>0,04$ & $0,035-0,050$ & $0,030-0,045$ \\
\hline $\begin{array}{c}\text { Resistência à } \\
\text { compressão (MPa) }\end{array}$ & $276-414$ & $\mathrm{NA}$ & $310-482$ & $\mathrm{NA}$ \\
\hline $\begin{array}{c}\text { Coeficiente de } \\
\text { dilatação térmica }(10 \\
\left.6 /{ }^{\circ} \mathrm{C}\right)\end{array}$ & 11,7 & 11,7 & 9,9 & 9,9 \\
\hline $\begin{array}{c}\text { Massa específica } \\
\left(\mathrm{g} / \mathrm{cm}^{3}\right)\end{array}$ & 7,9 & 7,9 & $1,5-2,0$ & 2,4 \\
\hline
\end{tabular}

*NA = Não é aplicável

\subsubsection{Massa especifica}

A massa específica das barras e cordoalhas de FRP é obtida pela soma do volume da matriz polimérica e das fibras multiplicado pelas respectivas massas específicas, como mostra a equação 2.1 (FIB TG 9.3, 2003).

$$
\rho_{c}=\rho_{f} \cdot V_{f}+\rho_{m} \cdot V_{m}
$$

Segundo o FIB TG 9.3 (2003) o valor da massa especifica para as barras de FRP varia de $1,7 \mathrm{~g} / \mathrm{cm} 3$ a $2,2 \mathrm{~g} / \mathrm{cm}^{3}$.

Segundo o ACl 440 1R (2003) o valor da massa especifica para as barras de FRP varia de $1,5 \mathrm{~g} / \mathrm{cm}^{3}$ a $2,0 \mathrm{~g} / \mathrm{cm}^{3}$ e para as barras de aço este valor é de $7,9 \mathrm{~g} / \mathrm{cm}^{3}$.

A pequena massa destas barras, quando comparadas com as barras de aço, resulta em redução dos custos de transporte e manuseio no local da obra.

\subsubsection{Dilatação térmica}

Dependendo das proporções da mistura, o coeficiente de dilatação térmica pode assumir valores dentro dos intervalos apresentados na Tabela 2.4. 
Tabela 2.4 - Coeficientes de dilatação térmica (ACl 440 1R, 2003)

\begin{tabular}{c|c|c|c}
\hline Direção & Aço & GFRP & Concreto \\
\hline Longitudinal, $\alpha_{\mathrm{L}}$ & $6,5.10^{-6} /{ }^{\circ} \mathrm{C}$ & $\begin{array}{c}6,0.10^{-6} /{ }^{\circ} \mathrm{C} \text { a } \\
10,0.10^{-6} /{ }^{\circ} \mathrm{C}\end{array}$ & $\begin{array}{c}7,2.10^{-6} /{ }^{\circ} \mathrm{C} \text { a } \\
10,8.10^{-6} /{ }^{\circ} \mathrm{C}\end{array}$ \\
\hline Transversal, $\alpha_{T}$ & $6,5.10^{-6} /{ }^{\circ} \mathrm{C}$ & $\begin{array}{c}21,0.10^{-6} /{ }^{\circ} \mathrm{C} \text { a } \\
23,0.10^{-6} /{ }^{\circ} \mathrm{C}\end{array}$ & $\begin{array}{c}7,2.10^{-6} /{ }^{\circ} \mathrm{C} \mathrm{a} \\
10,8.10^{-6} /{ }^{\circ} \mathrm{C}\end{array}$ \\
\hline
\end{tabular}

\subsubsection{Resistência à tração (longitudinal)}

As barras de FRP alcançam sua resistência última sem apresentar patamar de escoamento. Possuem comportamento elástico-linear e ruptura brusca, sem aviso prévio, como pode ser observado na Figura 2.7. Um grande problema é a padronização da resistência última, pois esta depende da disposição e quantidade de fibras e, ainda, do tipo de resina em cada barra (ACl 440 1R, 2003).

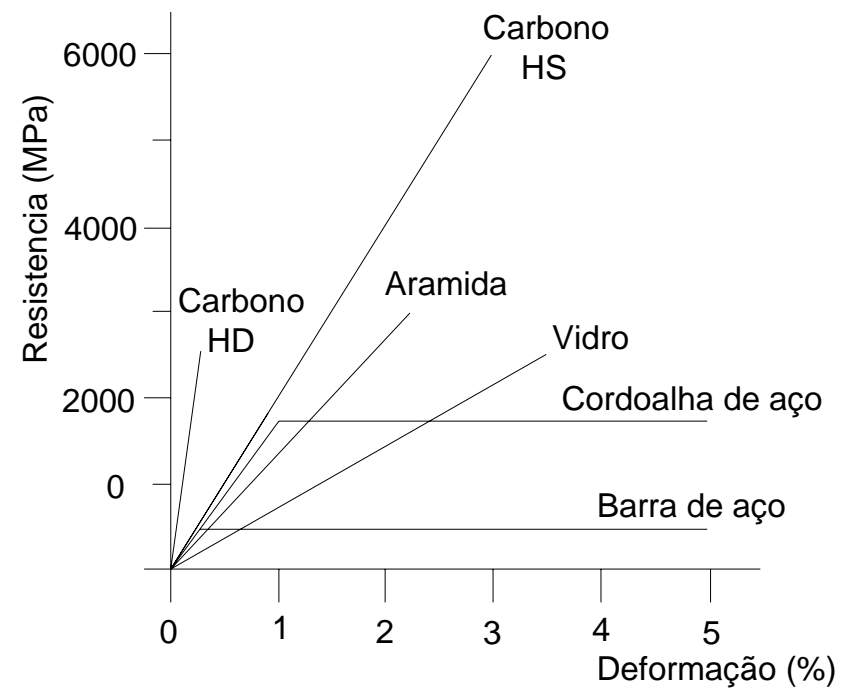

Figura 2.7 - Diagrama tensão x deformação

(Adaptado de ACl $440 \mathrm{R}, 1996$ )

Segundo o $\mathrm{ACl} 440 \mathrm{R}$ (1996), diferente das barras de aço, a resistência à tração das barras de FRP é função do diâmetro. Em virtude do efeito Shear Lag, as fibras localizadas próximas à superfície da barra estão submetidas a maiores tensões que as fibras localizadas próximo ao centro da barra. Este fenômeno resulta na redução de eficiência e resistência das barras com diâmetros maiores, como pode ser observado na Tabela 2.5. 
Tabela 2.5 - Resistência à tração das barras de FRP (JORQUIRA e MAYORGA, 1998)

\begin{tabular}{c|c|c}
\hline Diâmetro $(\mathrm{mm})$ & Seção transversal $\left(\mathrm{mm}^{2}\right)$ & Resistência à tração $(\mathrm{MPa})$ \\
\hline 9 & 71 & 900 \\
\hline 13 & 127 & 740 \\
\hline 16 & 198 & 655 \\
\hline 19 & 285 & 620 \\
\hline 22 & 388 & 585 \\
\hline
\end{tabular}

\subsubsection{Módulo de elasticidade à tração}

Segundo o ACl 440 R (1996), o módulo de elasticidade à tração das barras de GFRP é $75 \%$ menor do que o das barras de aço.

\subsubsection{Resistência à compressão (longitudinal)}

As barras de FRP não se comportam tão bem à compressão quanto à tração. Quando as barras de FRP estão submetidas à compressão, os modelos teóricos para resistência à tração não são válidos. A ruptura, em muitos casos, está associada à microfissuração das fibras. Valores experimentais precisos da resistência à compressão são difíceis de obter, e são altamente dependentes das propriedades dos materiais constituintes e do volume de fibras. A ruptura à compressão pode em função da microfissuração das fibras, da tração transversal em virtude do efeito de Poisson e do cisalhamento entre as fibras (FIB 9.3 TG, 2003).

\subsubsection{Módulo de elasticidade à compressão}

Segundo o $\mathrm{ACl} 440 \mathrm{R}$ (1996), o módulo de elasticidade à compressão das barras de GFRP é aproximadamente $80 \%$ menor que o módulo de elasticidade à tração dessas mesmas barras.

\subsubsection{Resistência ao cisalhamento}

A resistência ao cisalhamento das barras de FRP é determinada pelas propriedades da matriz e pela distribuição local das tensões, e em geral é baixa.

Por exemplo, as barras de FRP podem ser cortadas facilmente com serras comuns na direção perpendicular às fibras. 


\subsubsection{Fadiga}

As barras de FRP possuem uma alta resistência à fadiga. Segundo o $\mathrm{ACl} 440$ R (1996), as barras de GFRP suportam mais que quatro milhões de ciclos de carregamento antes de iniciar a ruptura na zona de ancoragem.

\subsection{Fatores que afetam as propriedades mecânicas das barras de FRP}

As propriedades mecânicas das barras de FRP dependem de muitos fatores, tais como: duração e história do carregamento, temperatura e umidade. Esses fatores são interdependentes, sendo difícil determinar o efeito isolado de cada um $(\mathrm{ACl} 440 \mathrm{R}$, 1996).

\subsubsection{Umidade}

A absorção excessiva de água nas barras de FRP pode resultar em uma diminuição considerável de resistência e rigidez. A resina, ao absorver água pode inchar ou deformar a barra, com isso, deve-se ater às condições climáticas onde sejam utilizados estes produtos. Existem resinas resistentes à umidade, devendo ser utilizadas quando a estrutura encontra-se em contato permanente com água ou em situações de gelo e degelo.

\subsubsection{Fogo e temperatura}

Nos compósitos de FRP, o efeito da alta temperatura é mais visível na resina do que nas fibras, visto que as resinas contêm grandes quantidades de carbono e hidrogênio, que são inflamáveis.

O concreto serve como uma barreira para proteger as barras do contato direto com as chamas. Porém, com o aumento da temperatura no interior do concreto, as propriedades das barras de FRP mudam consideravelmente. É recomendado então, que o usuário tenha conhecimento das propriedades da barra de FRP e o uso de resinas resistentes à alta temperatura, quando julgar necessário. 


\subsubsection{Raios ultravioleta}

Os compósitos podem sofrer danos pela ação dos raios ultravioleta, os quais causam reações químicas na matriz polimérica levando à degradação de suas propriedades, para evitar isto deve-se incorporar à resina aditivos adequados. Porém, este dano não afeta as barras FRP quando são utilizadas no interior de estruturas de concreto armado, já que os raios solares não são incididos de modo direto.

\subsubsection{Corrosão}

Diferente das barras de aço, as barras de FRP não são afetadas pela deterioração eletroquímica, resistem à corrosão pelo efeito dos ácidos, sal, e materiais agressivos sob consideráveis mudanças de temperatura. Porém, as barras de GFRP podem se deteriorar em meio alcalino, daí a importância de resinas resistentes à alcalinidade para proteção das fibras de vidro.

Maiores informações sobre o assunto ver: TAVARES (2006), KAJORNCHEAPPUNNGAM et al. (2002), MICELLI e NANNI (2004), BENMOKRANE et al. (2002), HULATT, HOLLAWAY e THORNE (2002), TANNOUS e SAADATMANESH (1999).

\subsection{Considerações finais}

Este capítulo mostrou, resumidamente, as propriedades das barras de FRP e de seus materiais constituintes, as fibras e as resinas. De acordo com o que foi exposto, percebe-se a dificuldade na determinação das propriedades destas barras, pois elas variam de acordo com os materiais constituintes, processo de fabricação e conformação superficial.

O comportamento mecânico dos compósitos de FRP é diferente do comportamento mecânico das barras de aço. Isto é facilmente notado quando se compara barras de FRP de diferentes diâmetros em relação à sua resistência longitudinal à tração, visto que sua resistência decresce com o aumento do diâmetro.

É necessário um maior estudo desse tipo de material e dos parâmetros que influenciam nas suas propriedades, para posterior análise de seu comportamento em conjunto com o concreto. 


\section{ADERÊNCIA ENTRE O CONCRETO E A ARMADURA}

\subsection{Considerações iniciais}

A existência do concreto armado é decorrente da solidariedade entre seus materiais constituintes, as barras da armadura e o concreto. Essa solidariedade ou aderência impede que haja deslocamento relativo entre a armadura e o concreto adjacente, sendo esta responsável pela transferência das tensões e pela compatibilidade das deformações entre os dois materiais.

O estudo da tensão de aderência é útil para que se possa compreender o comportamento mecânico e o desempenho das estruturas em concreto armado, especialmente sob o ponto de vista da fissuração, condições de trabalho e situações limites. A partir delas, são fixadas as hipóteses de cálculo, as disposições dos elementos construtivos, e demais aspectos construtivos que garantem a segurança das estruturas, como por exemplo, o comprimento de ancoragem (ALCANTARA et al., 2004)

ISA (2004) salientou a importância do estudo da aderência entre o concreto e a armadura, por causa do surgimento de armaduras não metálicas e a introdução crescente de aditivos superplastificantes associados a materiais ultrafinos (adições minerais reativas ou inertes), que densificam a matriz e a zona de transição pasta/agregado, produzindo modificações significativas na estrutura do concreto.

O comportamento mecânico das barras de FRP difere do comportamento mecânico das barras de aço. As barras de GFRP possuem maior resistência longitudinal do que transversal, menor módulo de elasticidade, menor resistência à compressão e ao cisalhamento, etc. Por essa razão, mudanças no dimensionamento devem ser realizadas para o cálculo de estruturas de concreto armado com barras de FRP.

Os compósitos de FRP são anisotrópicos e se caracterizam por sua alta resistência à tração na direção longitudinal das fibras, afetando a resistência ao cisalhamento e o efeito de pino das barras, bem como no comportamento da 
aderência das barras de FRP no concreto. Além disso, os materiais de FRP não exibem patamar de escoamento, possuindo comportamento elástico-linear até a ruptura. Os procedimentos de dimensionamento devem considerar a falta de ductilidade em estruturas de concreto armadas com barras de FRP (ACl 4401 R, 2003).

\subsection{Componentes da aderência}

A solidariedade entre barras da armadura e o concreto é garantida pela existência de aderência entre os dois materiais. Na realidade esta aderência é composta por diversas parcelas, que decorrem de diferentes fenômenos que intervém na ligação entre os dois materiais. De acordo com a literatura técnica, três parcelas possuem grande importância, sendo elas a adesão, o atrito e o engrenamento da ligação ou aderência mecânica (FUSCO, 1995), sendo descritas a seguir.

\subsubsection{Aderência por adesão}

Esta parcela de aderência ocorre em virtude das ligações físico-químicas entre a barra e a pasta de cimento, e se caracteriza por uma resistência de adesão que se opõe à separação dos dois materiais. Para pequenos deslocamentos relativos entre a barra e a massa de concreto que a envolve, essa ligação é destruída.

A Figura 3.1 ilustra um exemplo de ligação por aderência, onde para separar os dois materiais é necessário aplicar uma ação representada pela força $F_{b 1}$.

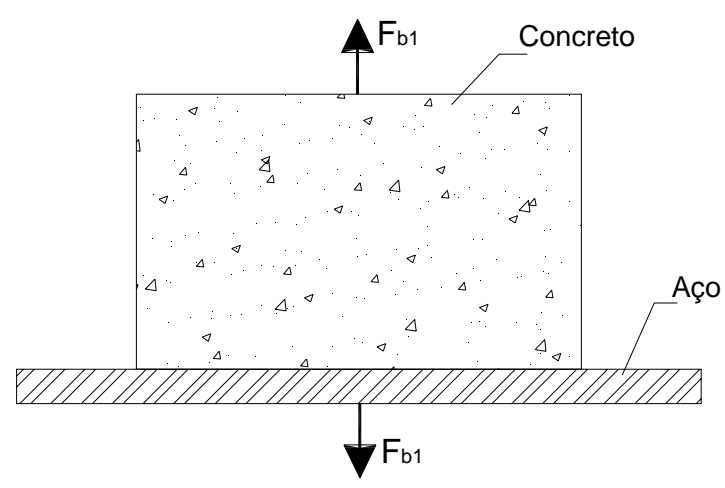

Figura 3.1 - Aderência por adesão

(FUSCO,1995)

\subsubsection{Aderência por atrito}

O atrito se manifesta quando há tendência ao deslocamento relativo entre os materiais, no caso a barra e o concreto. Depende da rugosidade superficial da barra e 
da compressão uniformemente distribuída, exercida pelo concreto sobre a barra, em virtude da retração.

A aderência por atrito pode ser verificada por meio do ensaio de arrancamento, apresentado na Figura 3.2. Verifica-se que a força de arrancamento $F_{b 2}$ é significativamente superior aos limites que podem ser previstos a partir da resistência $F_{b 1}$ obtida no caso anterior. Os ensaios realizados sugerem que esse acréscimo da aderência ocorra por causa das forças de atrito existentes entre os dois materiais (FUSCO,1995).
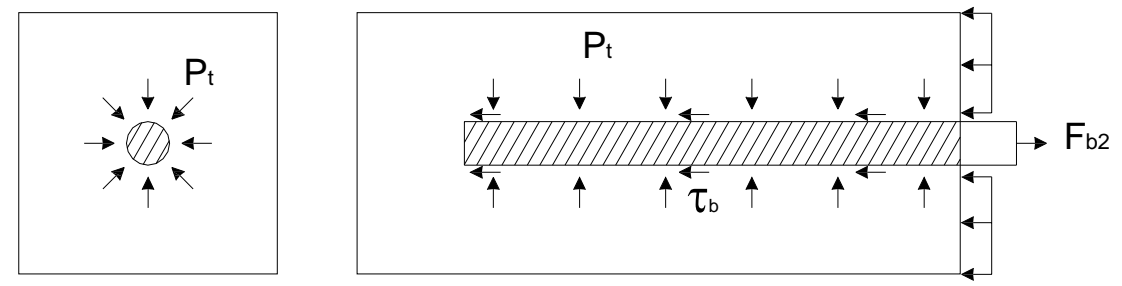

Figura 3.2 - Aderência por atrito

(FUSCO,1995)

\subsubsection{Aderência mecânica}

A aderência mecânica é decorrente da presença de saliências na superfície da barra, que funcionam como peças de apoio, mobilizando tensões de compressão no concreto, Figura 3.3.

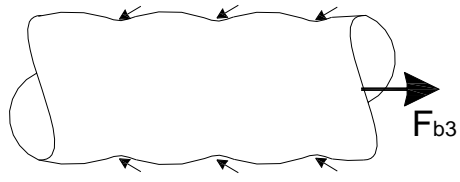

Barras lisas

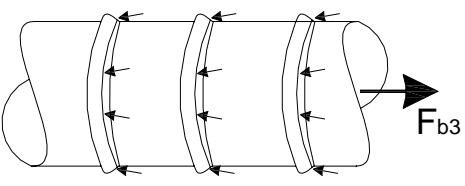

Barras nervuradas

Figura 3.3 - Aderência mecânica

(FUSCO, 1995)

Segundo LEONHARDT \& MÖNNIG (1977), em virtude do engrenamento mecânico, do tipo de encaixe, entre a superfície da barra da armadura e o concreto, formam-se "consolos de concreto" que são solicitados ao corte antes que a barra possa deslizar no concreto (Figura 3.4). A resistência ao corte é o tipo de ligação mais efetiva e confiável, contribuindo de maneira fundamental para a solidarizarão dos dois materiais. 


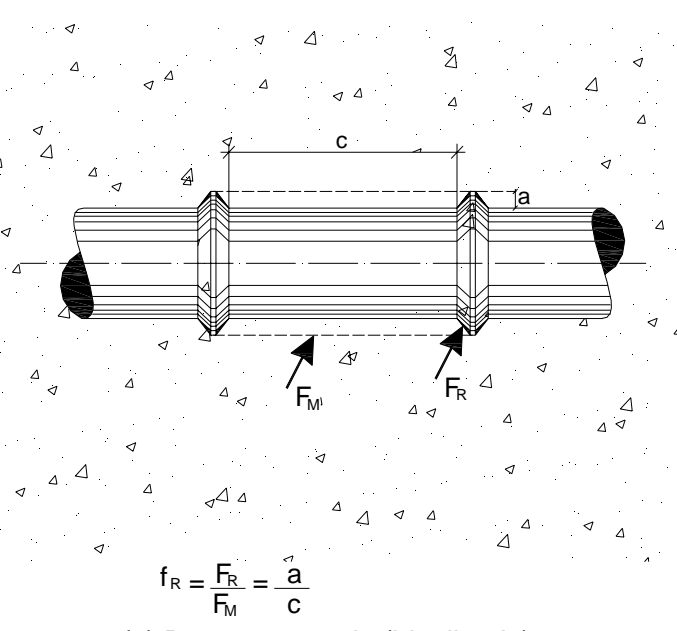

(a) Barra nervurada (idealizada)

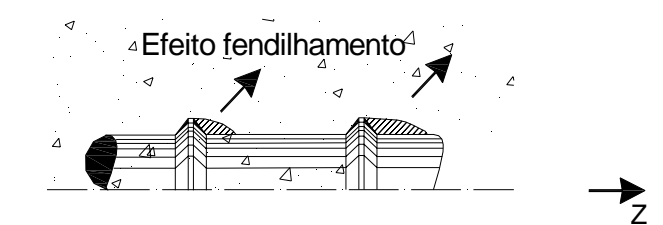

Distância grande entre as nervuras $(\mathrm{fr}<0,10)$

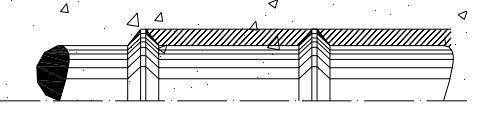

Distância pequena entre as nervuras ( $\mathrm{fr}>0,15)$

(b) Área de ruptura dos consolos de concreto entre as nervuras

Figura 3.4 - Explicação das designações em uma barra ideal com nervuras angulares e áreas possíveis de ruptura dos consolos de concreto entre as nervuras

(LEONHARDT \& MÖNNIG, 1977)

A separação da aderência em três parcelas é esquemática, não sendo possível determinar cada uma delas separadamente. Deste modo, por meio de ensaios, são determinados valores médios globais de aderência, que são suficientes para efeito de projeto.

Nas barras de FRP, a força de aderência é transferida pela resina para as fibras. Diferente das barras de aço, a aderência das barras de FRP não é influenciada significativamente pela resistência à compressão do concreto, provido de adequado confinamento a fim de se evitar o fendilhamento (NANNI et al.,1995; BENMOKRANE, TIGHIOOUART e CHALLAL,1996; KACHLAKEV e LUNDY, 1998 apud ACI 4401 R, 2003).

Nos elementos estruturais em concreto armado submetido à flexão, a tensão de tração é transferida para a barra por meio da aderência entre o concreto e a barra. A aderência entre a barra de FRP e o concreto adjacente à barra é similar ao comportamento encontrado quando se utilizam barras de aço e dependem do tipo de barra de FRP, módulo de elasticidade, conformação superficial e forma da barra (ACI $4401 \mathrm{R}, 2003)$.

NANNI, A., AL-ZAHRANI, M., AL-DULAIJAN, S., BAKIS, C. E., BOOTHBY, T. E. (1995), "Bond of FRP reinforcement to concrete - experimental results", Proceedings of the Second International RILEM Symposium on Non-Metallic Reinforcement for Concrete Structures (FRPRCS-2), Ghent, Belgium, pp135145.

BENMOKRANE, B., TIGHIOOUART, B., e CHALLAL, O. (1996), "Bond strength and load distribution of composite GFRP reinforcing bars in concrete" ACl Materials Journal, v. 93, n. 3, May-June, pp. 246-253.

KACHLAKEV, D. I., e LUNDY, J. R. (1998), "Bond strength study of hollow composite rebars with different micro structure" Proceedings of the Second International Conference on Composites in Infrastructure (ICCI-98), Tucson, Ariz., pp. 1-14. 


\subsection{Comportamento da aderência}

\subsubsection{Barras lisas}

Segundo FIB 9.3 TG (2003), a aderência entre as barras lisas e o concreto é influenciada principalmente pela adesão entre a superfície da barra e o concreto adjacente a ela. Em barras de menor resistência, a resistência ao cisalhamento entre as sucessivas linhas de fibras e a superfície da barra pode influenciar consideravelmente.

A ruptura da aderência ocorre ao longo do perímetro da barra, como se a barra estivesse sendo arrancada do concreto. A resistência de aderência das barras lisas é normalmente muito pequena, apresentando grande variabilidade. Por esta razão, as barras lisas podem ser usadas como armadura no concreto armado providas de outro dispositivo de ancoragem (dobras, ganchos e barras transversais).

\subsubsection{Barras com superfície deformada ou tratada}

Em virtude da pequena resistência de aderência das barras lisas, a maioria das barras de FRP possui superfície rugosa (deformada). O comportamento da aderência entre as barras de FRP e o concreto pode ser descrito por meio da curva de tensão de aderência versus deslocamento de uma barra solicitada monotonicamente (Figura 3.5). O deslocamento é medido na extremidade solicitada da barra, que por sua vez possui pequeno comprimento.

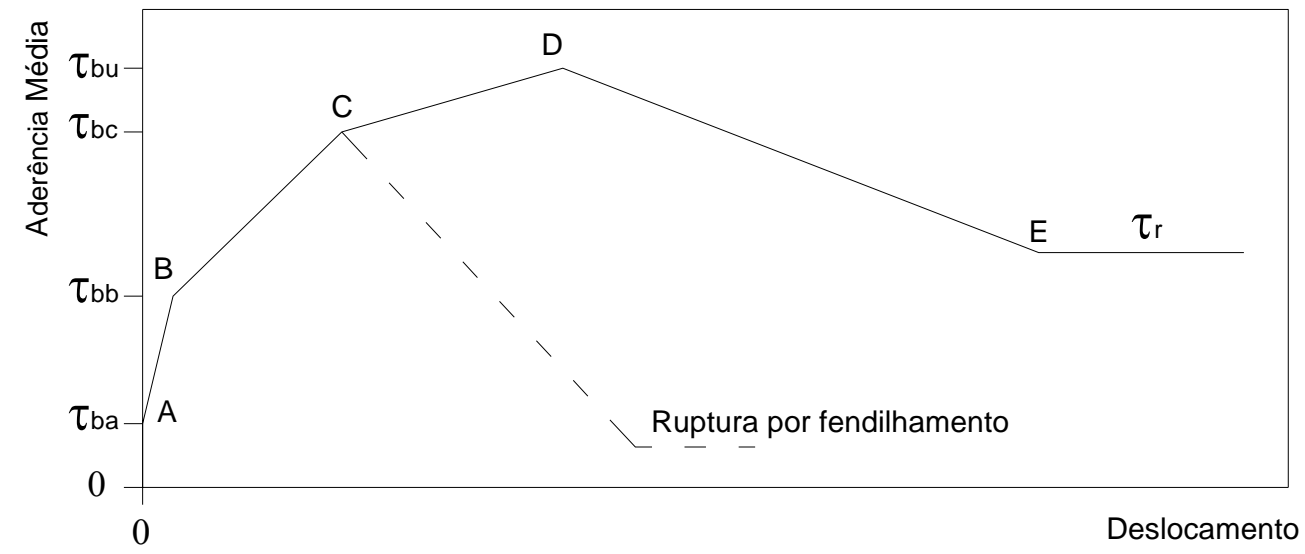

Figura 3.5 - Curva típica de tensão de aderência média versus deslizamento (ACHILLIDES, 1998 apud FIB 9.3 TG,2003)

Trecho 0A: o mecanismo que resiste à ação externa é a adesão química entre os dois materiais. Não é observado deslocamento da barra neste estágio. Resultados experimentais mostraram que o valor da aderência de adesão ( $\left.\tau_{\text {ba }}\right)$ varia entre $0,1 \mathrm{MPa}$ 
a 1,3 MPa, independente do tipo de barra de FRP e do concreto utilizado (ACHILLIDES, 1998 apud FIB 9.3 TG, 2003).

Trecho AB: com o aumento do carregamento ocorre a ruptura da adesão e o mecanismo de aderência muda. O deslocamento na extremidade solicitada da barra aumenta gradualmente, e as deformações superficiais da barra desenvolvem tensões tangenciais em virtude da reação do concreto adjacente. As microfissuras transversais no concreto começam a originar, na ponta da barra, deformações que permite à barra deslocar mais (Figura 3.6). Contudo, como a conformação superficial das barras de FRP é mais amena que as nervuras das barras de aço, o início das microfissuras transversais é relativamente atrasado.

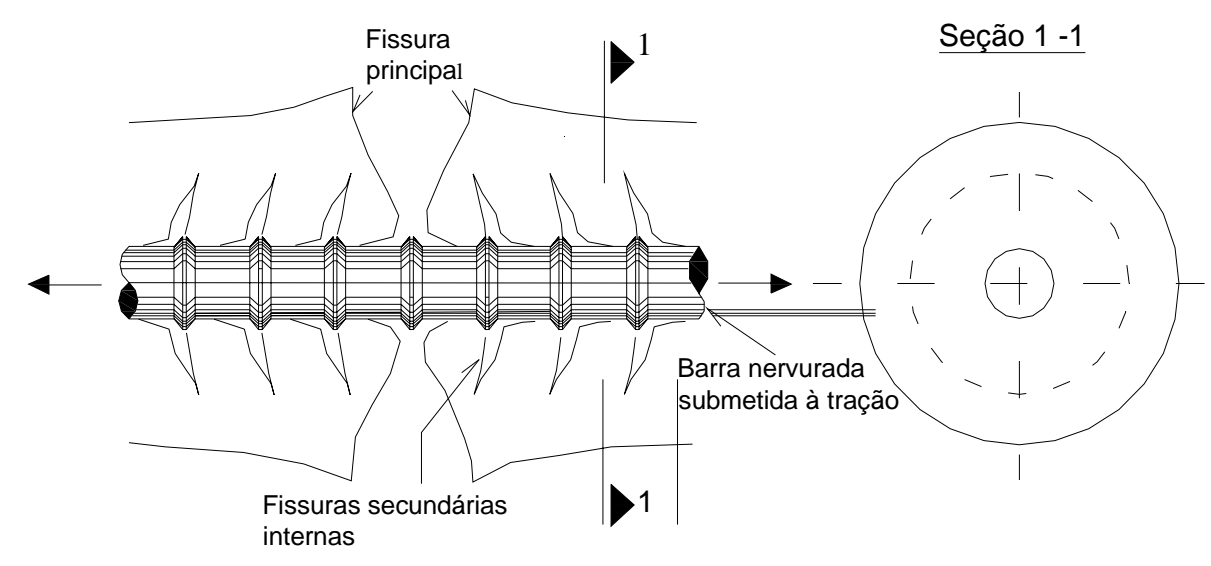

Figura 3.6 - Deformação do concreto após a formação de microfissuras (GOTO, 1971)

Trecho BC: neste estágio a tensão de aderência e o deslocamento na barra aumentam consideravelmente, diminuindo a rigidez da ligação.

Segundo o CEB 151 (1982), nas barras nervuradas a força de tração é transferida ao concreto pelas nervuras. A componente radial da força nas nervuras, que se difunde perpendicularmente ao eixo da barra no concreto, aumenta com o aumento da tensão de aderência $\left(\tau_{b}\right)$, que é igual à componente longitudinal da força de tração nas nervuras. A força resultante forma um ângulo $\alpha$ com a direção do eixo da barra. A Figura 3.7 mostra um esquema das forças entre a barra e o concreto circunvizinho. 


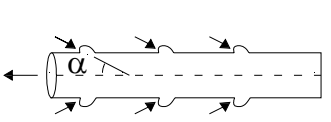

Força de aderência na barra

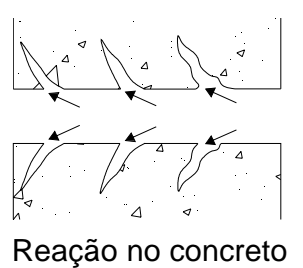

Reação no concreto

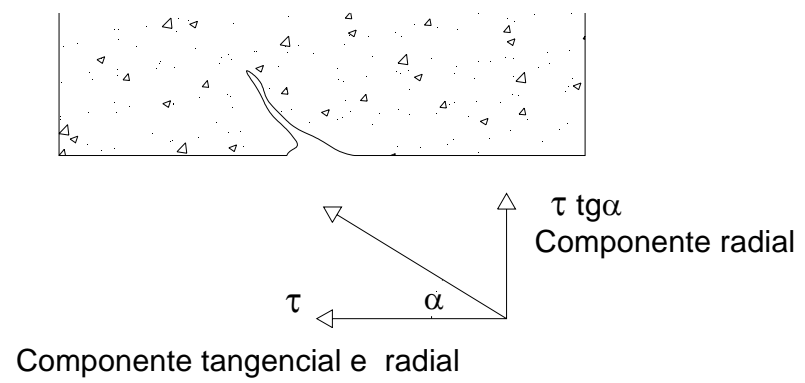

Figura 3.7 - Esquema das forças atuantes entre a barra nervurada e o concreto adjacente

(CEB 151, 1982)

O valor do ângulo $\alpha$ depende do valor do módulo de elasticidade da barra, da resistência ao cisalhamento do concreto no local das microfissuras e da conformação superficial da barra. A componente radial da tensão de aderência é equilibrada com a tensão de tração desenvolvida no concreto adjacente (Figura 3.8).

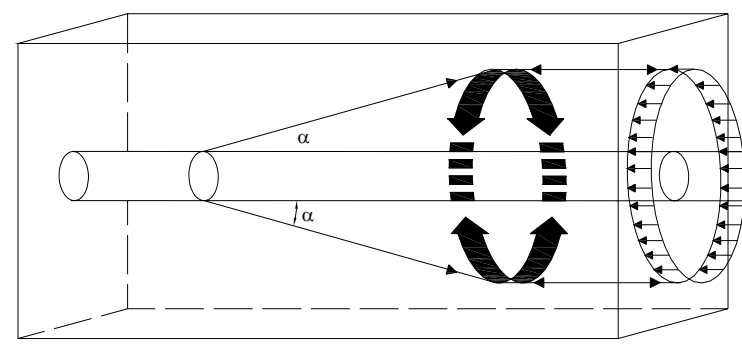

Figura 3.8 - Representação esquemática da componente radial da força de aderência equilibrada diante do anel de tensão de tração no concreto na zona de ancoragem (TEPFERS, 1979)

Se o confinamento da barra não for adequado e o valor da tensão de tração no arco exceder a resistência à tração do concreto, surgirão fissuras no concreto causadas pelo fendilhamento, e vão se desenvolver ao longo do comprimento da barra. Então, o deslocamento entre a barra e o concreto aumenta consideravelmente, resultando na distribuição uniforme da tensão de aderência ao longo do comprimento de ancoragem (TEPFERS e KARLSSON*, 1997 apud FIB 9.3 TG, 2003). A força de aderência radial é agora resistida pela resistência à tração do concreto circunvizinho.

*TEPFERS, R. e KARLSSON, M. (1997), "Pull-out and tensile reinforcement splice tests using FRP C-bars." Proceedings of the 3rd International Symposium on Non-Metallic Reinforcement for Concrete Structures (FRPRCS-3), Japanese Concrete Institute, Sapporo, Japan, vol.2, p. 357-354. 
O modo da fissuração última é determinado pela geometria da seção transversal do elemento estrutural de concreto e depende da localização da fissura (Figura 3.9).

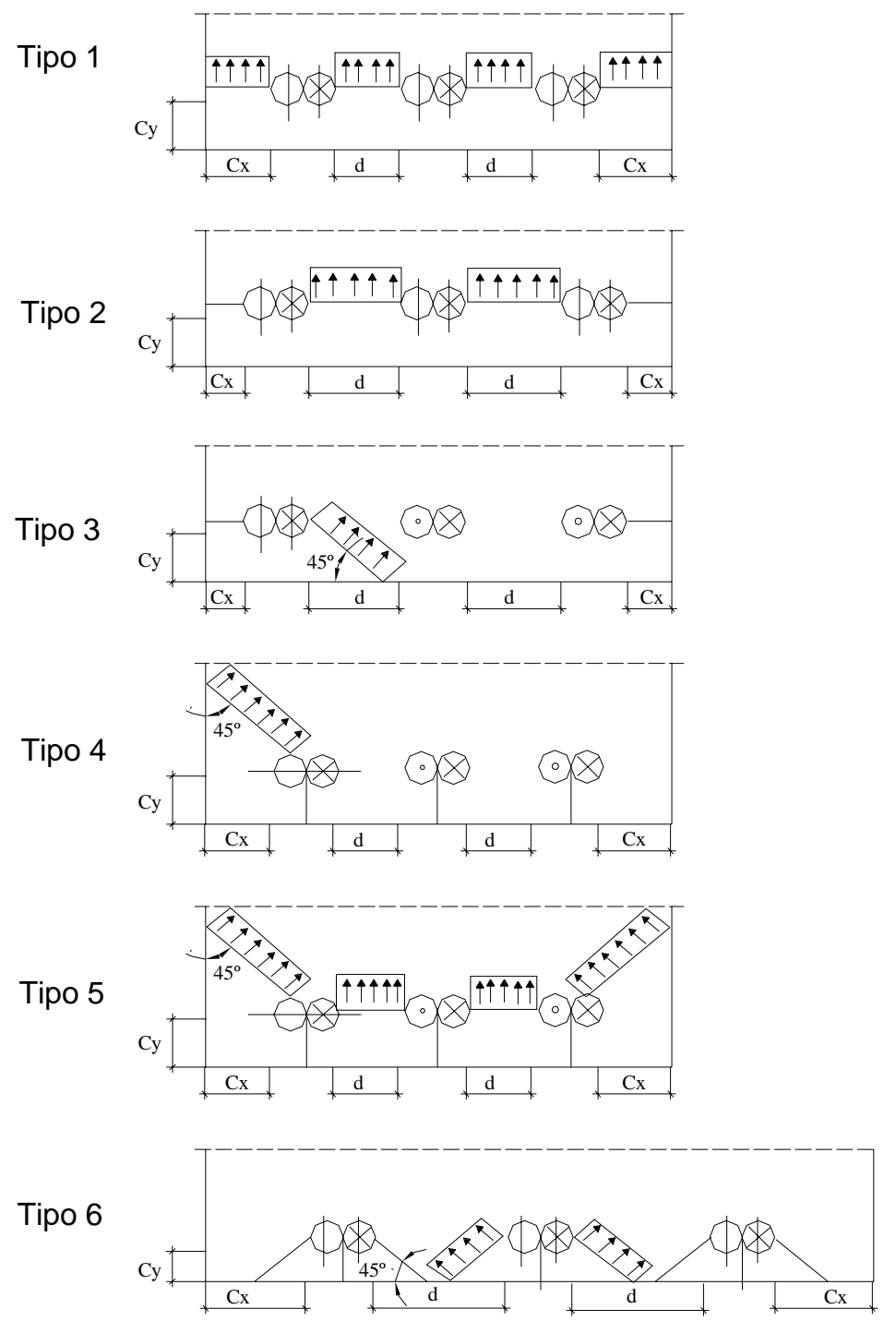

Figura 3.9 - Possíveis formas de ruptura por fendilhamento, no concreto circunvizinho (TEPFERS, 1973)

Trecho CD: se o concreto circunvizinho resistir ao fendilhamento, como por exemplo, no caso de pequenos comprimentos de aderência nos ensaios de arrancamento em cubo de concreto, então, a resistência de aderência pode ser a máxima $\left(\tau_{\mathrm{bu}}\right)$. Neste estágio, ambas as extremidades, carregada e não carregada, se deslocam e a resistência de aderência é significativamente reduzida. Ainda, dependendo da magnitude da resistência do concreto comparado com a resistência ao cisalhamento da rugosidade superficial da barra, quatro modos de ruptura podem ser descritos: 


\section{- Cisalhamento de parte ou de toda a superfície rugosa da barra}

A resistência de aderência das barras de FRP, neste caso, não é controlada pela resistência do concreto, mas pela resistência ao cisalhamento entre as sucessivas linhas de fibras ou pela resistência ao cisalhamento da superfície rugosa da barra. Por esta razão, diferente das barras de aço, um incremento na resistência do concreto não é acompanhado por um correspondente incremento na resistência de aderência entre barras de FRP e o concreto.

\section{- Ruptura por fendilhamento do concreto}

Este modo de ruptura é similar ao das barras de aço nervuradas, o concreto é esmagado pelas deformações na superfície da barra e a resistência de aderência é controlada pela resistência à tração do concreto.

\section{- Ruptura combinada}

Uma combinação dos modos de ruptura mencionados acima é desenvolvida para intensidades de resistência do concreto.

\section{- Arrancamento da barra}

A barra pode esmagar completamente o concreto por causa da sua baixa rigidez na direção radial (transversal). A resistência de aderência é transmitida pelo atrito entre a superfície rugosa da barra e o concreto adjacente. Neste caso, a resistência máxima de aderência poderá depender da geometria das nervuras e da rigidez radial da barra e do confinamento do concreto.

Trecho DE: depois de atingida a máxima tensão de aderência, o mecanismo de resistência entre as deformações superficiais da barra e o concreto se quebra, diminuindo consideravelmente a tensão de aderência. A resistência de aderência residual $\left(\tau_{r}\right)$ depende da resistência de atrito e da interface de ruptura. A rugosidade da interface de ruptura determina a magnitude de $\tau_{\mathrm{r}}$.

\subsection{Modos de ruptura da aderência}

ACHILLIDES \& PILAKOUTAS (2004) investigaram o comportamento da aderência de diferentes barras de FRP por meio de ensaios de arrancamento. Algumas considerações a respeito do modo de ruptura da aderência foram feitas.

Segundo os referidos autores, todas as barras de FRP apresentaram ruptura da aderência por arrancamento da barra. Os cubos de concreto eram providos de adequado confinamento, que possibilitaram avaliar a máxima resistência de aderência. Comparando o modo de ruptura dos modelos com barras de FRP e com barras de aço nervuradas, sob as mesmas condições de ensaio, foi observado que: no ensaio de 
arrancamento da barra de aço, fissuras de cisalhamento se desenvolveram entre as nervuras da barra e o concreto adjacente, durante a ruptura por arrancamento. Quando este tipo de ruptura acontece, a resistência de aderência depende principalmente da resistência do concreto. Entretanto, a resistência de aderência entre as barras de FRP e o concreto não é controlada pela resistência do concreto.

No caso de concretos com resistência superior a $30 \mathrm{MPa}$, a ruptura da aderência ocorre em parte na superfície da barra e em parte no concreto, pelo desprendimento da superfície da barra. A Figura 3.10 mostra a situação de um modelo de arrancamento com barra de GFRP após o ensaio.

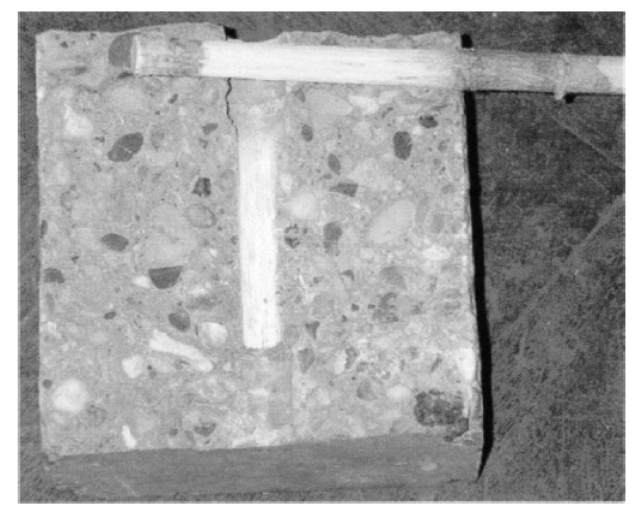

Figura 3.10 - Modelo de arrancamento com barra de GFRP após o ensaio (ACHILLIDES \& PILAKOUTAS, 2004)

O cubo de concreto foi quebrado após a realização do ensaio para posterior avaliação do modo de ruptura da aderência. Na figura, pode-se observar um pó branco (consistindo do esmagamento da resina e do corte das fibras) aderido ao concreto na localização do comprimento de aderência.

A ruptura da aderência pode se desenvolver na interface entre as sucessivas camadas de fibras, como mostra a Figura 3.11. A resistência ao cisalhamento entre as fibras e a resina controla a resistência de aderência entre as barras de FRP e o concreto. A altura da interface de ruptura depende dos valores da resistência ao cisalhamento entre as fibras e a resina e da resistência do concreto.

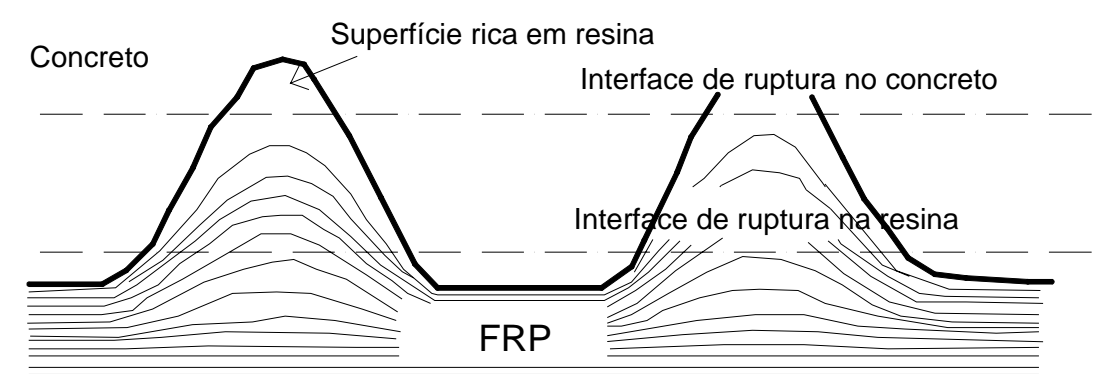

Figura 3.11 - Ruptura por cisalhamento nas camadas das barras de FRP (ACHILLIDES \& PILAKOUTAS, 2004) 
Além disto, observou-se nos ensaios de arrancamento, que a tensão de aderência residual não representa necessariamente o valor real da tensão de atrito desenvolvida na interface de ruptura. Isto, pelo fato de quando a parte danificada da barra se desloca para fora do cubo durante o arrancamento, a parte não danificada da barra entra na zona do comprimento de aderência, aumentando a resistência de aderência (Figura 3.12). Esta ação é conhecida na literatura como ação de cunha exercida pela parte não danificada da barra.

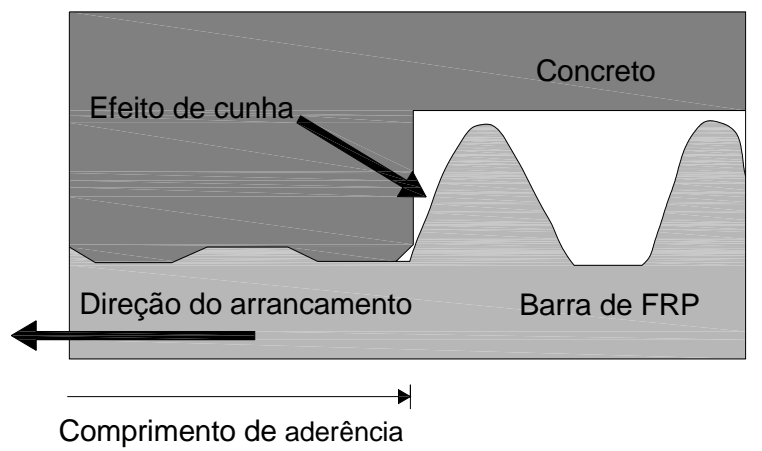

Figura 3.12 - Efeito de cunha exercido pela parte não danificada da barra (ACHILLIDES \& PILAKOUTAS, 2004)

Este fenômeno não é importante para as barras de aço, pois a ruptura da aderência ocorre no concreto adjacente. A parte não aderida da barra entra na zona do comprimento de aderência e não contribui significativamente para a resistência de aderência, porque a interface de ruptura da aderência é aproximadamente a altura das nervuras da barra.

Para concretos com pouca resistência (em torno de $15 \mathrm{MPa}$ ), o modo de ruptura das barras de FRP é semelhante ao modo de ruptura das barras de aço nervuradas. O concreto é esmagado pela rugosidade das barras e a resistência de aderência é controlada pela resistência a tração do concreto.

\subsection{Fatores que influenciam o comportamento da aderência}

O comportamento de aderência das barras de aço depende de muitos parâmetros que influenciam a resistência e ductilidade das ancoragens no concreto armado. Estes parâmetros se comportam de modo diferente nas barras de FRP, por elas possuírem capacidade de resistência anisotrópica e diferentes propriedades mecânicas quando comparadas com as barras de aço. Uma correta avaliação da influência desses fatores no comportamento de aderência é crucial para o seu 
entendimento e para a determinação do comprimento de ancoragem requerido. Os parâmetros mais importantes são:

\subsubsection{Forma da seção transversal da barra}

Segundo ACHILLIDES et al. (1997) ${ }^{1}$ apud FIB T.G. 9.3 (2003), barras de seção quadrada desenvolvem melhores resistências de aderência quando comparadas às barras de seção circular, com boas condições de confinamento, isto porque os ângulos na seção transversal aumentam o efeito de cunha, e consequentemente a resistência de aderência da interface FRP-concreto.

Apesar das barras de seção quadrada desenvolver boa resistência de aderência, elas podem levar ao aumento de forças de fendilhamento no concreto adjacente.

\subsubsection{Conformações superficiais das barras}

As conformações superficiais (rugosidades) das barras de FRP são importantes no desenvolvimento da ancoragem mecânica e na mobilização da pressão lateral. As conformações superficiais podem consistir em apenas resina, em fibras reforçando resinas ou em resinas contendo fibras continuas na direção longitudinal. O último tipo é constituído pelo entrelaçamento das fibras ou pela disposição de forma helicoidal de um filamento de fibra separado na superfície externa da barra. Porém, quando as fibras são posicionadas na direção do eixo da barra pelo entrelaçamento ou por pressionamento longitudinal da fibra, a rigidez axial da barra decresce.

Barras com pequena rugosidade superficial transferem forças de aderência de pequena intensidade. Porém, quando submetidas a tensões elevadas, as barras se tornam mais finas em virtude do efeito de Poisson, e a ruptura por fendilhamento pode se desenvolver no cobrimento de concreto. Sob essas circunstâncias, pequenas deformações superficiais podem levar a perda repentina do contato com o concreto, resultando na ruptura da aderência. Para evitar estes problemas, MALVAR (1995) ${ }^{2}$ apud ACHILLIDES \& PILAKOUTAS (2004) sugeriu que as deformações superficiais de aproximadamente $5,4 \%$ do diâmetro da barra são suficientes para promover adequada aderência com o concreto.

${ }^{1}$ ACHILLIDES, Z., PILAKOUTAS, K., AND WALDRON, P. (1997), "Bond behavior of FRP bars to concrete." Proc., 3rd Int. Symp. on Non-Metallic (FRP) Reinforcement for Concrete Structures, Japan Concrete Society, Sapporo, Japan, pp. 341-348.

${ }^{2}$ MALVAR, J. L. (1995), "Tensile and bond properties of GFRP reinforcing bars." $\mathrm{ACl}$ Materials Journal, v.92, n.3, pp. 276-285. 
O tamanho e inclinação das nervuras não determinam apenas a magnitude da aderência mecânica, mas também a magnitude das forças de tração responsáveis pelo fendilhamento do concreto. As barras com maiores rugosidades possuem grande resistência de aderência sob boas condições de confinamento, e maior tendência à ruptura por fendilhamento do concreto quando comparadas às barras com superfície impregnada por areia (FIB T.G. 9.3, 2003).

\subsubsection{Pequeno módulo de elasticidade na direção longitudinal}

A deformabilidade das barras determina a geometria, o espaçamento e o comprimento das fissuras e consequentemente afeta a transferência de cisalhamento do concreto ao longo das fissuras.

Segundo ACHILLIDES (1998)* apud FIB T.G. 9.3 (2003) e PILAKOUTAS \& GUADAGNINI (s.d), as barras com pequeno módulo de elasticidade (ex. barras de GFRP, E = $45 \mathrm{GPa}$ ) desenvolvem menores resistências de aderência que as barras com maiores módulos de elasticidade (ex. barras de CFRP, E = $115 \mathrm{GPa}$ ).

\subsubsection{Módulo de elasticidade transversal}

O módulo de elasticidade transversal das barras de FRP também influencia a tendência ao fendilhamento. Alguns tipos de barras de FRP apresentam altas resistências à fissuração na aderência, correspondente às barras de aço. Isto, em virtude das barras de FRP possuírem módulo de elasticidade transversal similar ou menor que o concreto.

As barras de FRP são mais deformáveis que as barras de aço, as rugosidades nas barras de FRP não criam intensas concentrações de tensão no concreto, como as barras de aço. A maioria das barras de FRP apresentam menor tendência ao fendilhamento do concreto que as barras de aço. Como mencionado anteriormente, isto também depende da conformação superficial (FIB T.G. 9.3, 2003).

\subsubsection{Efeito do coeficiente de Poisson}

Para a maioria dos materiais de FRP o coeficiente de Poisson é o mesmo para as barras de aço. Em altas deformações longitudinais, a deformação transversal das barras de FRP é maior que a das barras de aço, podendo afetar a aderência (FIB T.G. $9.3,2003)$.

*ACHILLIDES, Z. (1998). "Bond behavior of FRP bars in concrete." PhD thesis, Centre for Cement and Concrete, Dept. of Civil and Structural Engineering, Univ. of Sheffield, Sheffield, U.K. 


\subsubsection{Posição das barras na seção transversal do elemento de concreto}

A posição das barras durante a moldagem do elemento de concreto (topo, fundo, horizontal, inclinada ou vertical) influencia a aderência entre o concreto e a barra de FRP.

Com a exudação da água de amassamento, há acúmulo de água sob as barras posicionadas horizontalmente, ainda, os agregados graúdos, durante o processo de adensamento deslocam-se para a parte inferior da barra, e com a evaporação da água de amassamento surgem vazios na parte inferior das mesmas (Figura 3.13).

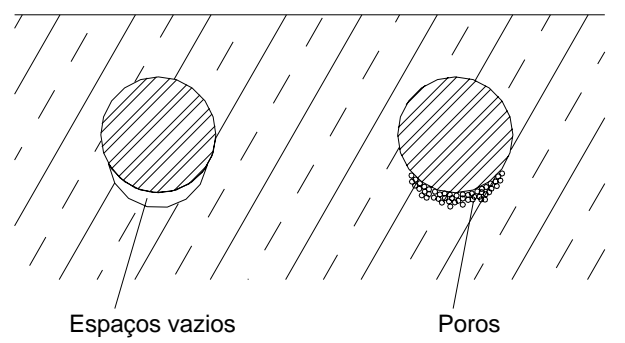

Figura 3.13 - Formação de espaços vazios ou poros sob barras horizontais em virtude da segregação e acúmulo de água

(LEONHARDT \& MÖNNIG, 1977)

A resistência de aderência é maior em barras concretadas na posição vertical e carregadas na direção contraria ao lançamento do concreto e em barras concretadas na posição horizontal, mas não muito acima da face inferior da peça. As barras concretadas na posição vertical e carregadas na direção da concretagem e as barras concretadas na horizontal bem acima da face inferior da peça apresentam resistência de aderência inferior às citadas anteriormente (Figura 3.14).

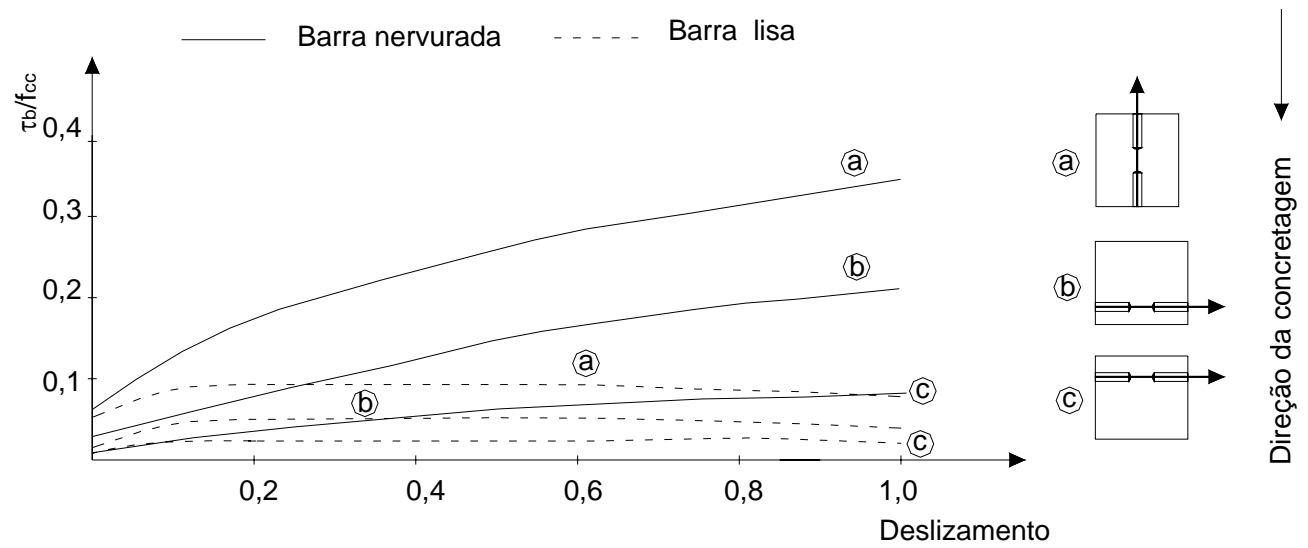

Figura 3.14 - Resultados dos ensaios de arrancamento de barras retas em diferentes posições por ocasião da concretagem.

(LEONHARDT e MÖNNIG, 1977) 
É importante destacar que a influência da posição das barras deve ser determinada para cada tipo de barra de FRP.

TIGHIOUART, BENMOKRANE, GRAO (1998) realizaram ensaios em barras de GFRP com diâmetros de $12,5 \mathrm{~mm}$ e $20,0 \mathrm{~mm}$, em diferentes posições no bloco de concreto (fundo, meio e topo). O fator de modificação variou de 1,09 a 1,14 para barras situadas no meio e de 1,26 a 1,32 para barras situadas no fundo do bloco.

CHALLAL e BENMOKRANE (1993)* apud ACl $4401 \mathrm{R}$ (2003) investigaram o fator de modificação para barras de GFRP de diferentes diâmetros (12,5 mm; 16,0 mm e 20,0 mm) situadas no topo e no fundo da estrutura de concreto. O fator de modificação varia de 1,08 a 1,38 para concreto de resistência normal e de 1,11 a 1,22 para concretos de alta resistência.

\subsubsection{Ancoragem de barras dobradas}

A ancoragem de barras dobradas é afetada pela mudança de direção das fibras na dobra, levando à concentração de tensões laterais e consequentemente baixa resistência axial. A resistência na dobra da barra também depende de como é feito a dobra (FIB T.G. 9.3, 2003).

\subsubsection{Cobrimento do concreto e distância entre barras paralelas}

O cobrimento de concreto requerido para barras de aço é predominantemente controlado pelas condições de agressividade ambiental, este não é o caso das barras de FRP, podendo-se reduzir o cobrimento de concreto para estas barras. Isto é importante quando se tratam de elementos estruturais de pequena espessura em concreto pré-moldado, como painéis de revestimento e itens arquitetônicos.

O cobrimento de concreto é uma importante consideração a ser feita nos projetos com o objetivo de prevenir o fendilhamento, além disto, suficientes cobrimentos de concreto devem ser determinados para condições ambientais e proteção ao fogo das barras de FRP (FIB T.G. 9.3, 2003). 


\subsubsection{Coeficiente de dilatação térmica}

Diferenças no coeficiente de dilatação térmica entre as barras de FRP e concreto, especialmente na direção transversal, influenciam a aderência. A excessiva dilatação térmica das barras causa fissuras de fendilhamento no concreto circunvizinho. No entanto, as barras de FRP não são flexíveis transversalmente o bastante para causar fendilhamento no concreto quando tentam expandir. A dilatação térmica lateral pode ser amenizada pela diminuição da seção transversal das barras em virtude do efeito de Poisson de barras tracionadas. Se a conformação superficial ou as nervuras da barra são de tamanho suficiente, a diferença de deformação térmica entre o concreto e a barra não afeta a aderência (FIB T.G. 9.3, 2003).

\subsubsection{Condições ambientais}

A influência das condições ambientais na aderência entre o concreto e a barra de FRP deve ser levada em consideração. A alta alcalinidade do concreto pode degradar a superfície das barras ou fibras, especialmente em situações de gelo e degelo. Por esta razão, é importante identificar em qual condição a transferência de aderência torna-se crítica e, assim, desenvolver modelos de degradação para ambas as resinas e fibras. As condições ambientais durante a construção, transporte, armazenamento devem ser consideradas. Finalmente, é importante que as barras de FRP estejam protegidas contra a exposição dos raios ultravioleta (FIB T.G. 9.3, 2003).

\subsubsection{Diâmetro da barra}

O diâmetro da barra tem um importante papel no comportamento de aderência das barras de FRP e o concreto. Barras de grandes diâmetros apresentam menores resistências de aderência que barras de pequenos diâmetros.

O desenvolvimento da aderência em barras de FRP é afetado pelo seu diâmetro, em virtude da pequena rigidez da barra ao cisalhamento na direção axial. O valor da rigidez ao cisalhamento das barras de FRP depende principalmente da rigidez ao cisalhamento da resina e da capacidade de resistência da interface resina-fibra. Quando uma barra de FRP é submetida à força axial de arrancamento, podem ocorrer deformações diferenciais entre as fibras situadas no centro da barra e as próximas da superfície, resultando uma distribuição não uniforme de tensões normais na seção transversal da barra (Figura 3.15). 


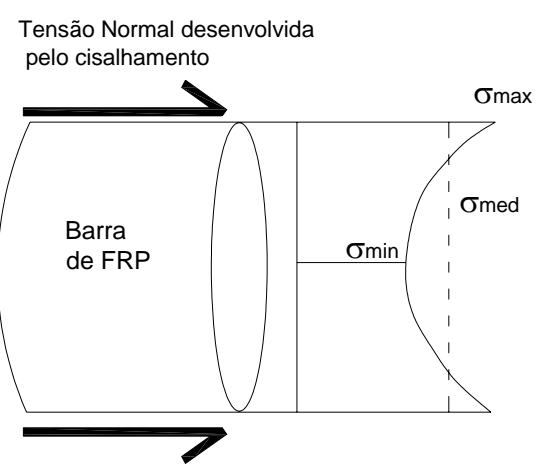

Figura 3.15 - Distribuição da tensão normal desenvolvida na seção transversal de uma barra de FRP sob carregamento axial

(ACHILLIDES \& PILAKOUTAS, 2004)

A resistência de aderência efetiva desenvolvida entre a barra e o concreto é representada pelo valor da tensão normal que age na superfície da barra $\left(\sigma_{\max }\right)$. Por outro lado, a resistência de aderência calculada, designada por resistência de aderência real, é proporcional ao valor da tensão normal média na seção transversal da barra $\left(\sigma_{\text {med }}\right)$. Com o aumento do diâmetro da barra, a diferença entre $\sigma_{\max }$ e $\sigma_{\text {med }}$ aumenta, especialmente quando a rigidez ao cisalhamento axial da barra é relativamente menor, como nas barras de FRP, e a resistência de aderência real das barras decresce (ACHILLIDES \& PILAKOUTAS, 2004). Este efeito, conhecido na literatura como "shear lag", é mais significativo em barras submetidas a maiores tensões normais, o que geralmente acontece em grandes comprimentos de aderência. Para barras de aço este efeito não é importante, por causa da maior resistência do aço ao cisalhamento.

\subsubsection{Resistência à compressão do concreto}

A resistência do concreto circunvizinho está diretamente relacionada com a ruptura da aderência durante o arrancamento. O valor da resistência do concreto comparativamente com a resistência ao cisalhamento da superfície da barra afetam o modo de ruptura das barras de FRP.

A Figura 3.16 mostra o efeito da resistência do concreto na resistência de aderência de barras de FRP. Para os concretos com resistência à compressão maior que $30 \mathrm{MPa}$, a ruptura da aderência ocorre na superfície da barra, consequentemente a resistência de aderência das barras de FRP não depende da resistência do concreto. Porém, para os concretos com menor resistência à compressão (15 MPa) o modo de ruptura da aderência é diferente, neste caso, a ruptura ocorre na matriz de 
concreto e o comportamento de aderência da barra está diretamente relacionado com a resistência do concreto (ACHILLIDES \& PILAKOUTAS, 2004 e FIB T.G. 9.3, 2003).

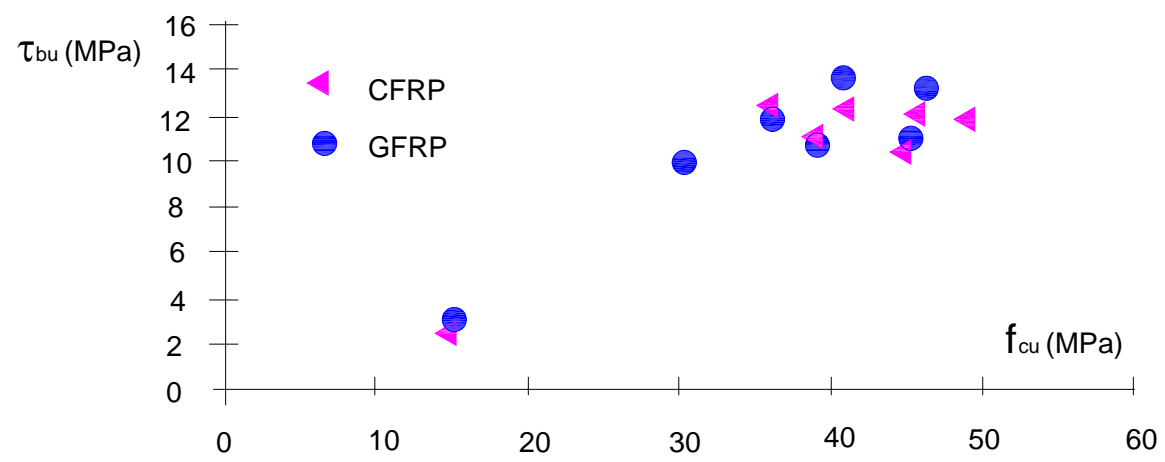

Figura 3.16 - Influência da resistência do concreto na resistência de aderência para as barras de FRP

(ACHILLIDES, 1998 apud FIB T.G. 9.3, 2003)

\subsubsection{Armadura transversal}

ACHILLIDES (1998) apud FIB T.G. 9.3 (2003), investigou a influência da armadura transversal na resistência ao fendilhamento das ancoragens de barras de FRP e regiões de emenda. Observou-se que a armadura transversal pode aumentar a resistência ao fendilhamento do concreto adjacente apenas quando ele está sendo tencionado (por exemplo, quando está localizado na zona de cisalhamento da viga). Caso contrário, o inicio das fissuras de fendilhamento não serão influenciadas pela presença de armadura transversal, por causa da baixa deformação nas quais as fissuras de tração se formam no concreto. Porém, depois de iniciada a fissuração de fendilhamento, a armadura transversal controla a propagação das fissuras e impede futuras aberturas de fissuras, contribuindo para a resistência ao fendilhamento.

\subsubsection{Comprimento das fissuras e retração}

ZHAO, PILAKOUTAS e WALDRON (1997)* apud FIB T.G. 9.3 (2003), investigaram o fenômeno da propagação das fissuras em vigas de concreto armadas com barras de aço e com barras de GFRP. Concluiu-se, que as normas não consideram as propriedades mecânicas do concreto, o efeito das diferentes conformações superficiais e grandes deslocamentos desenvolvidos nos elementos reforçados com FRP. O efeito da retração nos elementos armados com barras de FRP não é tão pronunciado quanto nos elementos armados com barras de aço.

*ZHAO, W.; PILAKOUTAS, K.; AND WALDRON, P. (1997), "FRP Reinforced Concrete Beams: Calculations For Deflection," Proceedings of the Third International Symposium on Non-Metallic (FRP) Reinforcement for Concrete Structures (FRPCS-3), Japan Concrete Institute, Sapporo, Japan, v. 2, pp. 511-518. 


\subsection{Ensaios de aderência}

As propriedades da aderência são complexas e dependem de diversos fenômenos, sendo necessário recorrer-se a analise experimental, com realização de ensaios descritos na literatura técnica.

Existem diversos ensaios para se estimar os valores da tensão de aderência e deslocamento relativo da barra em relação ao concreto e, além disto, verificar a influência de diversos fatores (resistência à compressão do concreto, diâmetro da barra, sentido do carregamento) no comportamento da aderência.

Não existe ensaio padrão para avaliar o comportamento de aderência entre as barras de FRP e o concreto, por isto recorre-se aos ensaios comumente realizados com as barras de aço.

Neste item serão abordados alguns ensaios de arrancamento e ensaios de viga com barras de aço, os quais podem ser utilizados para barras de FRP.

\subsubsection{Ensaio de arrancamento (Pull-out test)}

A determinação da resistência de aderência é normalmente feita por meio do ensaio de arrancamento. Este ensaio consiste em extrair uma barra, geralmente posicionada no centro de um prisma de concreto colocado sobre apoios, em uma máquina de ensaio.

Segundo BARBOSA et al. (2000), as vantagens deste ensaio são: o pequeno custo, a simplicidade do prisma, a possibilidade de se isolarem variáveis que influenciam a aderência e a possibilidade de uma visualização do comprimento mínimo de ancoragem.

É importante analisar a normalização do ensaio, pois alguns itens como forma e dimensões do prisma, comprimento de ancoragem e direção da concretagem podem alterar substancialmente os resultados.

O tamanho e a forma do prisma, bem como a posição e o comprimento do trecho de aderência da barra influenciam consideravelmente os resultados do ensaio. O prisma apresentado na Figura 3.17-a é inadequado, visto que por causa do impedimento à deformação transversal da placa de apoio e, em virtude da compressão por efeito de arco, exerce uma compressão transversal sobre a barra, provocando aderência adicional por atrito. Considerando trechos sem aderência, essas influências nos prismas b e c são diminuídas (LEONHARDT \& MÖNNIG, 1977). 
Trajetórias principais de compressão

Pressão transversal devido à deformação transversal impedida

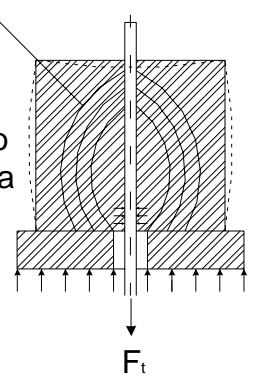

a) Prisma inadequado com a indicação esquemática da compressão por efeito de arco e de compressão transversal.

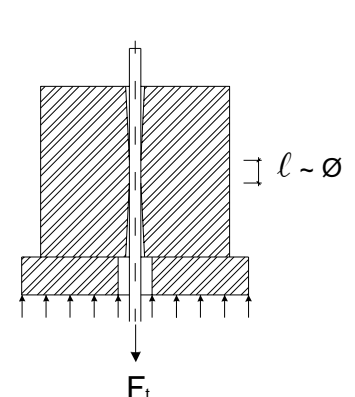

b) Prisma segundo REHM

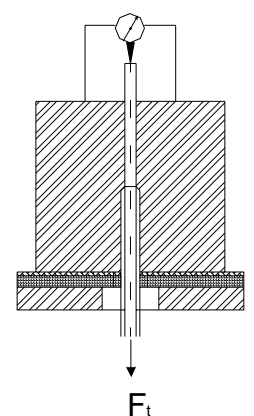

c) Prisma de acordo com as recomendações da RILEM/CEB/FIP (1973)

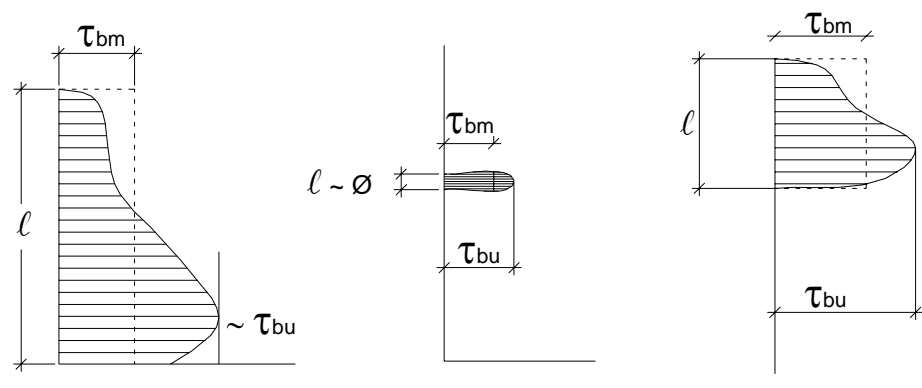

Figura 3.17 - Prismas para ensaio de arrancamento e respectivas variações da tensão de aderência ao longo do comprimento

(LEONHARDT \& MÖNNIG, 1977)

Durante o ensaio de arrancamento, determinando-se os deslocamentos da seção inicial $A$ da barra e da seção terminal $B$, obtém-se os resultados representados na Figura 3.18 (FUSCO, 1995).

B

Seção de saída Seção de entrada

A

$\mathrm{Ft}$
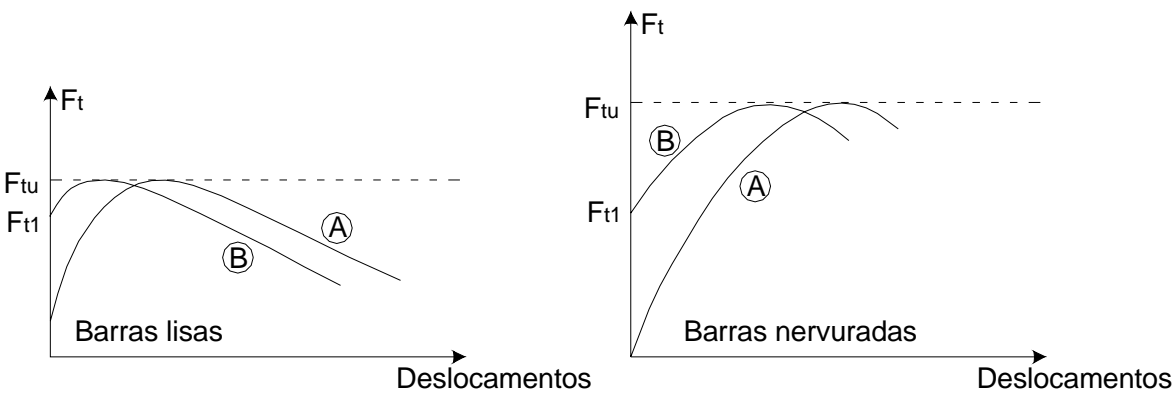

Figura 3.18 - Comportamento das barras lisas e das barras nervuradas (FUSCO, 1995) 
Desde o inicio do ensaio foram observados deslocamentos da seção inicial de ancoragem, e o escorregamento total da barra se dá somente a partir de uma força $F_{t 1}$. Depois de iniciado o escorregamento de toda a barra, a força de aderência pode aumentar. Esse aumento é maior em barras nervuradas, em virtude da capacidade de mobilização de aderência mecânica.

A tensão de aderência medida no ensaio de arrancamento é a tensão média, visto a dificuldade em medir a variação desta ao longo do comprimento de ancoragem, e pode ser escrita da seguinte maneira:

$$
\tau_{b}=\frac{F_{t}}{u \cdot \ell}
$$

Sendo:

$\tau_{\mathrm{b}}$ - Tensão de aderência média;

$\mathrm{F}_{\mathrm{t}}$ - Intensidade da força que solicita a barra;

u - Perímetro da barra;

$\ell$ - Comprimento de ancoragem.

Segundo LEONHARDT e MÖNNIG (1977), define-se como valor de cálculo para resistência de aderência $f_{b d}$, a tensão de aderência para o qual ocorre um deslocamento da extremidade livre da barra de $0,1 \mathrm{~mm}$ em relação ao concreto. A resistência de aderência de cálculo pode ser escrita da seguinte maneira:

$$
f_{b d}=\frac{F_{t}(s=0,1 \mathrm{~mm})}{u \cdot \ell}
$$

Na realidade, a resistência efetiva, ou seja, a tensão última de aderência $\left(\tau_{\text {bu }}\right)$ é muito maior que o valor de cálculo, especialmente nos casos de barras com aderência mecânica, alcançando até o dobro desse valor e deslocamentos de até $1 \mathrm{~mm}$. Tendo em vista a grande dispersão dos valores de aderência, recomenda-se para o dimensionamento um valor bastante afastado da resistência efetiva.

\subsubsection{Ensaio de arrancamento RILEM-FIP-CEB (1973)}

Neste ensaio as duas extremidades da barra são projetadas para fora do prisma de concreto (Figura 3.19). A barra é tracionada em um dos extremos e os deslocamentos relativos entre a barra e o prisma de concreto são medidos no outro extremo.

O prisma é moldado com a barra na posição horizontal, a compactação é realizada com um vibrador de imersão e após três dias o prisma é desmoldado. A resistência do concreto precisa estar no intervalo de 27 MPa a 33 MPa. 


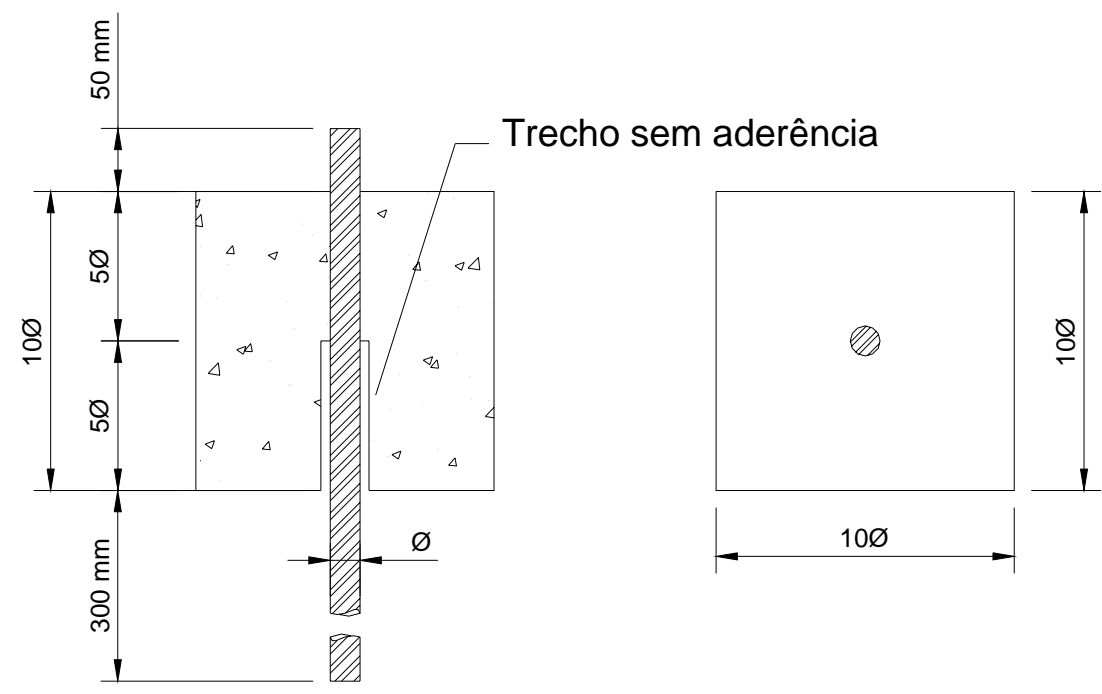

Figura 3.19 - Prisma para o ensaio de arrancamento (RILEM-FIP-CEB, 1973)

A velocidade de aplicação de força é calculada de acordo com a seguinte expressão:

$v_{p}=5 \cdot \phi^{2}(\mathrm{kgf} / \mathrm{s})$

Sendo:

$\phi$ - diâmetro da barra em cm.

A tensão de aderência é obtida com base em um concreto de resistência de 30 MPa, e pode ser obtida de acordo com a seguinte expressão:

$\tau_{b}=0,0637 \cdot \frac{F_{t}}{\phi^{2}} \cdot \frac{30}{f_{c m}}$

Sendo:

$\tau_{\mathrm{b}}$ - tensão de aderência em MPa;

$\mathrm{F}_{\mathrm{t}}$ - força de tração em kN;

$\phi$ - diâmetro da barra em mm;

$\mathrm{f}_{\mathrm{cm}}$ - resistência média à compressão do concreto em MPa.

\subsubsection{Ensaio de arrancamento ASTM C-234 (1991)}

Os prismas deste ensaio podem ser de dois tipos: o primeiro com o concreto moldado na direção da barra, similar ao ensaio segundo a RILEM-FIP-CEB, o segundo com o concreto moldado na direção transversal às barras.

O primeiro tipo de prisma tem formato cúbico, com $150 \mathrm{~mm}$ em cada face, com uma barra posicionada verticalmente ao longo do eixo central. A extremidade superior 
da barra deve ter um comprimento tal que permita atravessar os blocos de apoio do dispositivo de ensaio e fique ligada às garras da máquina de ensaio, como mostra a Figura 3.20.
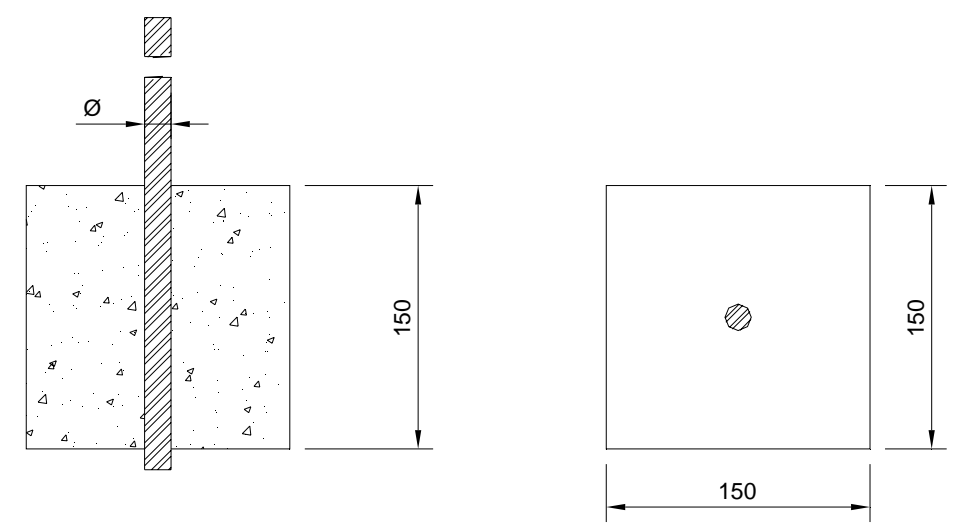

Figura 3.20 - Prisma para o ensaio de arrancamento com barra vertical (ASTM C-234, 1991)

O segundo tipo de prisma tem dimensões de $150 \mathrm{~mm} \times 150 \mathrm{~mm} \times 300 \mathrm{~mm}$, com o maior eixo na direção vertical. As duas barras devem ser embutidas em cada prisma, perpendicular ao maior eixo e paralelas e eqüidistantes das faces. Na direção vertical, uma barra precisa ser localizada com seu eixo a $75 \mathrm{~mm}$ do fundo do prisma e a outra com seu eixo a $225 \mathrm{~mm}$ do fundo do prisma. Ambas as barras precisam ter comprimento tal que suas extremidades fiquem para fora das faces dos prismas, permitindo atravessar os blocos de apoio do dispositivo de ensaio e sejam ancoradas nas garras da máquina de ensaio, como mostra a Figura 3.21. Uma ranhura precisa ser feita em cada uma das faces opostas do prisma, paralelas às barras e na metade do prisma. Essas ranhuras têm no mínimo $13 \mathrm{~mm}$ de profundidade, e servem para facilitar o rompimento do prisma em duas partes passando pelo plano de enfraquecimento.
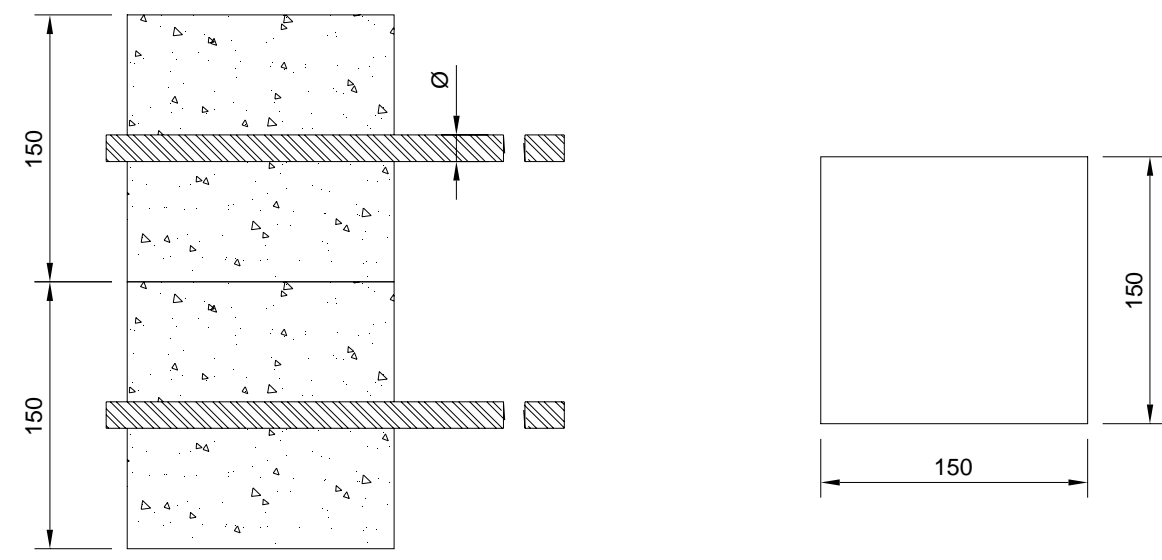

Figura 3.21 - Prismas para o ensaio de arrancamento com barras horizontais (ASTM C-234, 1991) 
De acordo com a ASTM Practices E 4 (s.d.), a velocidade de aplicação da força não pode ser maior do que $20 \mathrm{kN} / \mathrm{min}$ ou controlando-se o deslocamento em 1,3 $\mathrm{mm} / \mathrm{min}$.

\subsubsection{Ensaio de arrancamento segundo RHEM}

O prisma para este ensaio de arrancamento consiste em um cubo de concreto com uma barra centrada, possuindo dois trechos sem aderência (nas duas extremidades do prisma), com está ilustrado na Figura 3.22. O valor do comprimento de aderência é uma vez o diâmetro da barra.

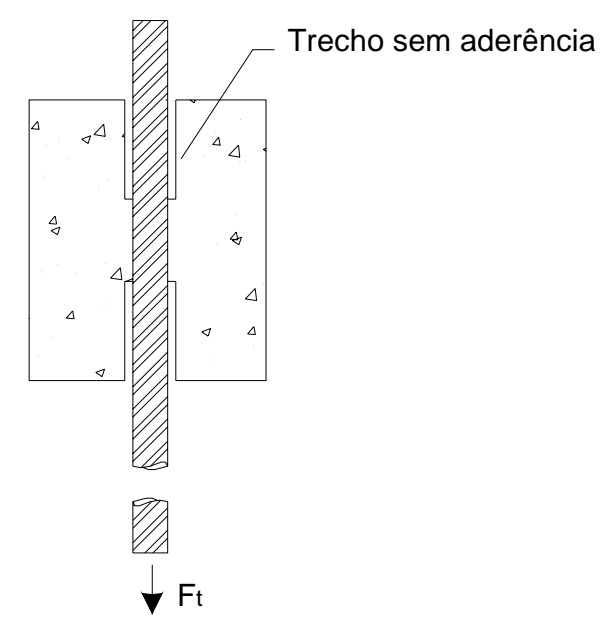

Figura 3.22 - Prisma para o ensaio de arrancamento (REHM, 1979)

\subsubsection{Ensaio de viga (Beam test)}

No ensaio de arrancamento existe uma compressão longitudinal do concreto. Essa compressão não existe na zona de ancoragem da armadura de tração em vigas fletidas. Por essa razão pode-se proceder ao ensaio de viga para determinação da capacidade de ancoragem das barras.

O ensaio de viga consiste em dois blocos retangulares de concreto armado, ligados no topo por um perfil de aço, e no fundo por barras, sendo testadas a aderência destas barras ao concreto. As dimensões das vigas estão mostradas na Figura 3.23. 

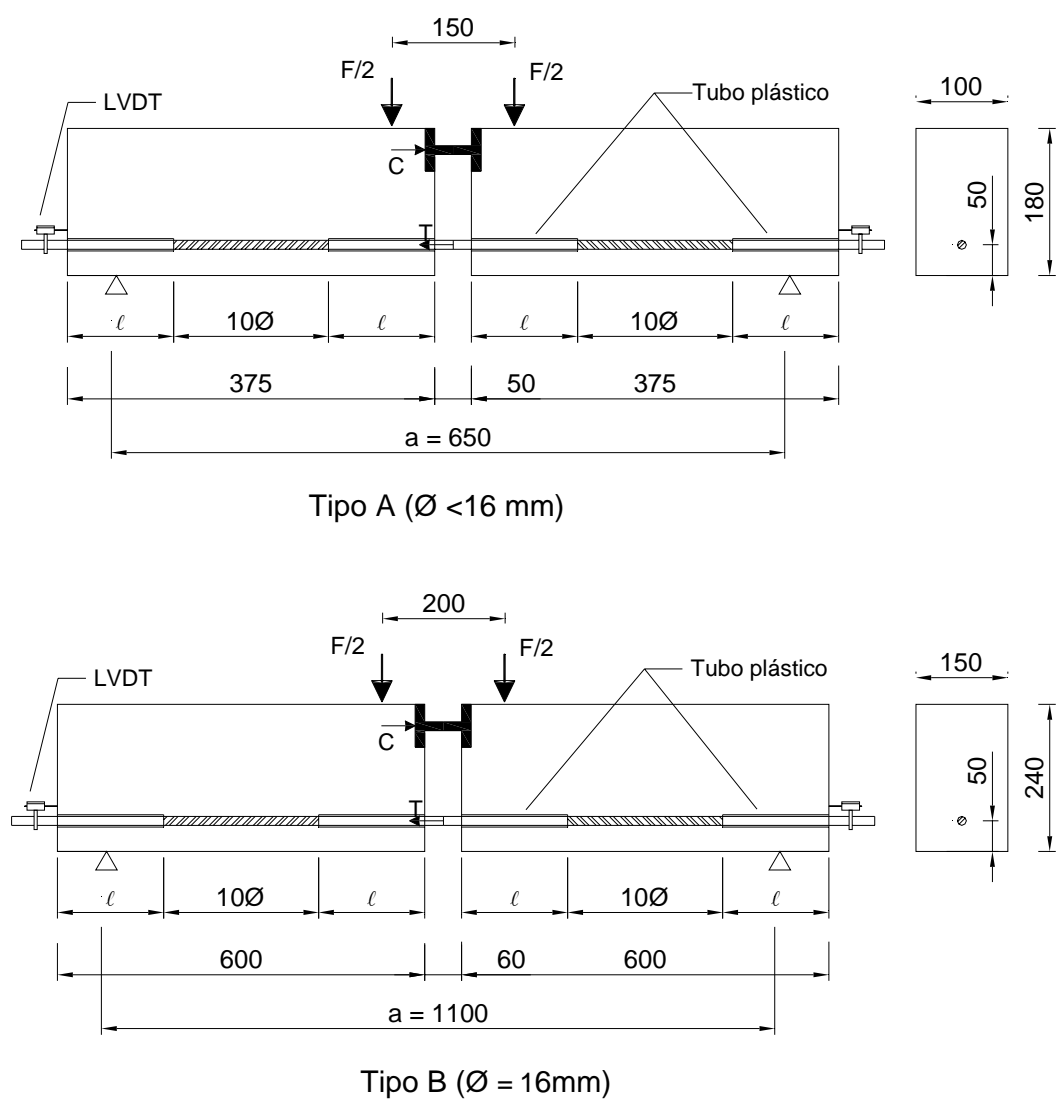

Figura 3.23 - Viga para o ensaio de flexão em vigas (RILEM-FIP-CEB, 1973)

Neste ensaio são aplicadas duas forças iguais e simétricas em relação ao perfil de aço. Os deslocamentos de cada extremidade livre das barras são medidos após cada incremento de força por um LVDT. A resistência de aderência pode ser calculada de acordo com a seguinte expressão:

$$
\tau_{b}=\frac{R_{s t}}{\pi \cdot \phi \cdot \ell}(M P a)
$$

Sendo:

$\mathrm{R}_{\mathrm{st}}$ - força de tração na armadura em Newton $\left(R_{s t}=\frac{F}{4} \cdot \frac{a}{\mathrm{z}}\right)$;

a - comprimento da viga;

z - distancia entra a resultante de tração e a resultante de compressão;

$\phi$ - diâmetro em mm;

$\ell$ - comprimento de aderência em $\mathrm{mm}$. 


\subsubsection{Ensaio de extremo de viga}

Este ensaio consiste em uma barra tracionada, situada na parte inferior de uma viga de concreto. A reação que simula a zona de compressão na viga é aplicada na parte superior, o momento criado é equilibrado por um par de forças que simulam a reação de apoio e a força cortante que será transmitida pelo concreto (Figura 3.24).

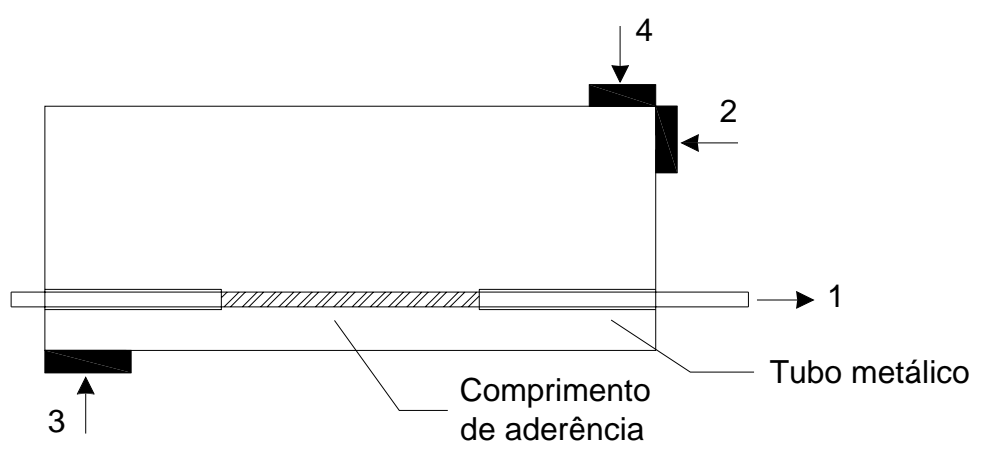

(1) força de tração na barra;

(2) placa de reação que simula azona de compressão na viga;

(3) placa de reação de apoio;

(4) placa de reação que simula a força cortante que seria transmitida pelo concreto.

Figura 3.24 - Corpo-de-prova do ensaio de extremo de viga (CLARK e JOHNSTON, 1983)

Segundo RIBEIRO (1985) apud BARBOSA (2001) este tipo de ensaio fornece as mesmas informações do ensaio de viga, com a vantagem de redução do tamanho da viga.

\subsection{Considerações finais}

De acordo com a revisão da literatura técnica, o comportamento da aderência entre as barras de FRP e as barras de aço é diferente. As barras de FRP possuem propriedades anisotrópicas e, além disto, propriedades mecânicas distintas das barras de aço, influenciando muito o comportamento da aderência.

A ruptura da aderência para as barras de FRP pode se desenvolver na interface das sucessivas camadas de fibra, podendo ocorrer cisalhamento de toda ou de parte da superfície rugosa da barra. Por esta razão, o incremento da resistência do concreto não influencia de maneira significativa a resistência de aderência, esta passa a depender das propriedades da barra. 
O comportamento da aderência entre este tipo de barra e o concreto ainda não está completamente estudado, salientando a quantidade de parâmetros que influenciam no seu comportamento.

Os ensaios para avaliação da aderência utilizados em barras de FRP são os mesmos utilizados em barras de aço. É necessário um ensaio padrão de aderência, assim os resultados poderão avaliar adequadamente a resistência de aderência, visto que, muitos ensaios não conseguem representar de forma adequada o comportamento da aderência. 


\section{INVESTIGAÇÃO EXPERIMENTAL DA ADERÊNCIA}

\subsection{Considerações iniciais}

A investigação experimental do comportamento da aderência entre as barras de GFRP e o concreto foi realizada utilizando ensaios de arrancamento padronizados pela RILEM/FIP/CEB (1973), com adaptação do modelo cúbico padrão para o modelo cilíndrico, para uma adequação das formas já existentes. Este ensaio foi escolhido por ser de simples realização e comumente usado no meio técnico.

Foram utilizados concretos com resistência à compressão de $30 \mathrm{MPa}, 60 \mathrm{MPa}$ e $80 \mathrm{MPa}$ e barras de GFRP com diâmetros de $9 \mathrm{~mm}$ e $16 \mathrm{~mm}$. Os deslocamentos nas barras foram medidos por transdutores de deslocamento. Todos os ensaios foram realizados no Laboratório de Engenharia de Estruturas da Escola de Engenharia de São Carlos - USP.

\subsection{Investigação experimental}

A investigação experimental foi dividida nas seguintes etapas:

- Ensaios preliminares para determinar as propriedades dos materiais constituintes do concreto;

- Estudo de dosagem dos materiais para obtenção dos traços de concretos, com classes de resistência à compressão de $30 \mathrm{MPa}, 60$ MPa e $80 \mathrm{MPa}$;

- Ensaios de arrancamento das barras de GFRP em cilíndros de concreto;

- Ensaios de determinação das propriedades do concreto, simultaneamente à etapa anterior;

- Ensaio de determinação das propriedades das barras de GFRP. 


\subsection{Concreto}

\subsubsection{Propriedades dos materiais constituintes do concreto}

\subsubsection{Cimento}

Para a dosagem do concreto foi utilizado o cimento do tipo CP $\vee$ ARI Plus (Cimento portland de Alta Resistência Inicial), da marca Ciminas, da empresa Holcim, cujas propriedades, fornecidas pelo fabricante, se encontram na Tabela 4.1.

Tabela 4.1 - Propriedades do cimento CPV ARI Plus (http://www.holcim.com.br, 2006)

\begin{tabular}{c|c|c}
\hline \multicolumn{2}{c}{ Propriedades do cimento } \\
\hline Superfície Blaine & \multicolumn{2}{|c}{$4500 \mathrm{~g} / \mathrm{cm}$} \\
\hline \#325 & \multicolumn{2}{|c}{$3 \%$} \\
\hline Tempo de pega & \multicolumn{2}{|c}{$130 \mathrm{~min}$} \\
\hline \multirow{3}{*}{ Resistência à compressão } & 3 dia & $26,0 \mathrm{MPa}$ \\
\cline { 2 - 3 } & 7 dias & $41,0 \mathrm{MPa}$ \\
\cline { 2 - 3 } & 28 dias & $53,0 \mathrm{MPa}$ \\
\cline { 2 - 3 } & & \\
\hline
\end{tabular}

\subsubsection{Sílica ativa}

Foi utilizada sílica ativa Silmix, da marca Cauê - Grupo Camargo Correa cujas propriedades, fornecidas pelo fabricante, se encontram na Tabela 4.2.

Tabela 4.2 - Propriedades da sílica ativa Silmix (http://www.caue.com.br, 2006)

\begin{tabular}{c|c}
\hline \multicolumn{2}{c}{ Propriedades da sílica ativa } \\
\hline Massa específica & $2220 \mathrm{~kg} / \mathrm{m}^{3}$ \\
\hline Superfície específica & $20000 \mathrm{~m}^{2} / \mathrm{kg}$ \\
\hline Formato da partícula & esférico \\
\hline Diâmetro médio & $0,2 \mu \mathrm{m}$ \\
\hline Teor de $\mathrm{SiO}_{2}$ & Mín. $85 \%$ \\
\hline
\end{tabular}

\subsubsection{3. Água}

A água empregada na mistura é proveniente da rede púbica de abastecimento de São Carlos - SP. 


\subsubsection{Superplastificante}

Foi utilizado o superplastificante Glenium 51, da marca Degussa, cujas propriedades, fornecidas pelo fabricante, estão descritas na Tabela 4.3.

Tabela 4.3 - Propriedades do superplastificante Glenium 51 (http://www.degussa-cc.com.br, 2006)

\begin{tabular}{c|c}
\hline \multicolumn{2}{c}{ Propriedades do superplastificante } \\
\hline Base química: & Policarboxilatos \\
\hline Aspécto: & Líquido viscoso \\
\hline Cor: & Bege \\
\hline Densidade: & 1,067 a $1,107 \mathrm{~g} / \mathrm{cm}^{3}$ \\
\hline $\mathrm{pH}:$ & 5 a 7 \\
\hline Sólidos: & 28,5 a $31,5 \%$ \\
\hline Viscosidade: & 95 a $160 \mathrm{cps}$ \\
\hline
\end{tabular}

\subsubsection{Agregados}

O agregado miúdo empregado consistiu em uma areia fina quartzosa proveniente do Rio Mogi-Guaçu - município de Rincão - SP, cuja composição granulométrica está representada na Tabela 4.4 (de acordo com as especificações da NBR 7217: 1987 - "Agregados: Determinação da composição granulométrica").

Tabela 4.4 - Análise granulométrica do agregado miúdo.

\begin{tabular}{c|c|c}
\hline Peneira (mm) & Porcentagem retida & $\begin{array}{c}\text { Porcentagem } \\
\text { acumulada }\end{array}$ \\
\hline 9,5 & 0 & 0 \\
\hline 6,3 & 0 & 0 \\
\hline 4,8 & 1 & 1 \\
\hline 2,4 & 5 & 4 \\
\hline 1,2 & 12 & 43 \\
\hline 0,6 & 25 & 79 \\
\hline 0,3 & 36 & 98 \\
\hline 0,15 & 19 & 100 \\
\hline Fundo & 2 & $2,4 \mathrm{~mm}$ \\
\hline \multicolumn{2}{c|}{ Dimensão máxima característica } & \\
\hline \multicolumn{2}{c|}{ Módulo de finura } & \\
\hline
\end{tabular}

O agregado graúdo utilizado foi de origem basáltica, proveniente da Pedreira Morada do Sol - município de Araraquara - SP, cuja composição granulométrica está representada na Tabela 4.5 (de acordo com as especificações da NBR 7217: 1987). 
Tabela 4.5 - Análise granulométrica do agregado graúdo.

\begin{tabular}{|c|c|c|}
\hline Peneira $(\mathrm{mm})$ & Porcentagem retida & $\begin{array}{c}\text { Porcentagem } \\
\text { acumulada }\end{array}$ \\
\hline 25 & 0 & 0 \\
\hline 19 & 0 & 0 \\
\hline 12,5 & 21 & 21 \\
\hline 9,5 & 34 & 55 \\
\hline 6,3 & 43 & 98 \\
\hline 4,8 & 1 & 99 \\
\hline 2,4 & 1 & 100 \\
\hline 1,2 & 0 & 100 \\
\hline 0,6 & 0 & 100 \\
\hline 0,3 & 0 & 100 \\
\hline 0,15 & 0 & 100 \\
\hline Fundo & 0 & 100 \\
\hline \multicolumn{2}{|c|}{ Dimensão máxima característica } & $19 \mathrm{~mm}$ \\
\hline \multicolumn{2}{|c|}{ Módulo de finura } & 6,54 \\
\hline
\end{tabular}

As principais propriedades dos agregados miúdos e graúdos estão reunidas na Tabela 4.6, conforme as seguintes normas técnicas:

- NBR 7211:1983 - "Agregados para concreto";

- NBR 9776:1987 - "Agregados - determinação da massa específica de agregados miúdos por meio do Frasco de Chapmam";

- NBR 7251:1982 - "Agregado no estado solto: determinação da massa unitária";

- NBR 9937:1987 - "Agregados - determinação da absorção e da massa específica de agregados graúdos".

Tabela 4.6 - Propriedades dos agregados miúdos e graúdos.

\begin{tabular}{|c|c|}
\hline Material & \\
\hline Agregado miúdo & $\begin{array}{l}\text { Dimensão máxima característica }=2,4 \mathrm{~mm} \\
\text { Módulo de finura }=2,43 \\
\text { Massa específica }=2,630 \mathrm{~g} / \mathrm{cm}^{3}\end{array}$ \\
\hline Agregado graúdo & $\begin{array}{l}\text { Dimensão máxima característica }=19 \mathrm{~mm} \\
\text { Módulo de finura }=6,54 \\
\text { Massa específica na condição seca }=2,828 \mathrm{~g} / \mathrm{cm}^{3} \\
\text { Massa específica na condição SSS }=2,786 \mathrm{~g} / \mathrm{cm}^{3} \\
\text { Índice de absorção do agregado }=1,71 \%\end{array}$ \\
\hline
\end{tabular}

* condição SSS - condição saturada e superfície seca 


\subsubsection{Dosagem dos materiais}

A dosagem dos materiais foi realizada segundo o método descrito por HELENE e TERZIAN (1992). O teor de argamassa foi fixado em $57 \%$ para as três classes de resistência à compressão do concreto $(30 \mathrm{MPa}, 60 \mathrm{MPa}$ e $80 \mathrm{MPa})$.

Para o concreto com resistência à compressão de $80 \mathrm{MPa}$, foi adicionado ao traço $0,8 \%$ de superplastificante e $10 \%$ de sílica ativa, ambos em relação à massa de cimento.

O consumo dos materiais por metro cúbico de concreto e os respectivos traços, em massa, estão resumidos na Tabela 4.7.

Tabela 4.7 - Consumo dos materiais e traços dos concretos.

\begin{tabular}{c|c|c|c}
\hline $\begin{array}{c}\text { Consumo de } \\
\text { material por } \mathrm{m}^{3} \text { de } \\
\text { concreto }\left(\mathrm{kg} / \mathrm{m}^{3}\right)\end{array}$ & 30 & 60 & 80 \\
\cline { 2 - 4 } & 365 & 488 & 564 \\
\hline Cimento & 884 & 767 & 704 \\
\hline Areia & 942 & 942 & 958 \\
\hline Brita & 256 & 227 & 198 \\
\hline Água & - & - & 4,51 \\
\hline Superplastificante & - & - & 56,4 \\
\hline Sílica ativa & $1: 1,42: 2,58: 0,7$ & $1: 1,57: 1,93: 0,465$ & $1: 1,25: 1,70: 0,35:$ \\
\hline Traço em massa & & & $0,8 \%$ SP+10\% SA \\
\hline
\end{tabular}

\subsubsection{Mistura}

A mistura foi feita em betoneira de eixo inclinado, e os materiais foram adicionadas na seguinte ordem:

- Mistura, por 3 minutos, de 2/3 da brita e da água com o cimento e sílica ativa;

- Adição da areia, restante da água e da brita e superplastificante, misturando por mais 3 minutos.

\subsubsection{Ensaios de determinação das propriedades do concreto}

Para analisar as propriedades do concreto foram realizados ensaios de abatimento de tronco de cone (Slump test), compressão axial, tração por compressão 
diametral e módulo de elasticidade, todos estes de acordo com as respectivas normas de ensaios:

- NBR 7223:1982 - "Determinação da consistência do concreto pelo abatimento do tronco de cone - ensaio de abatimento";

- NBR 5739:1980 - "Ensaio de compressão de corpos-de-prova cilíndricos de concreto";

- NBR 7222:1983 - "Argamassas e concretos - determinação da resistência à tração por compressão diametral de corpos-de-prova cilíndricos";

- NBR 8522:1984 - "Concreto - determinação do módulo de deformação estática e diagrama tensão x deformação".

Para cada concreto produzido foram moldados doze corpos-de-prova cilíndricos de $10 \mathrm{~cm}$ x $20 \mathrm{~cm}$ para a determinação da resistência à compressão, três corpos-de-prova para determinação da resistência à tração por compressão diametral e três corpos-de-prova para determinação do módulo de elasticidade.

Os corpos-de-prova foram moldados na posição vertical e o adensamento realizado em mesa vibratória. Foram desmoldados 24 horas após a concretagem e levados para a câmara úmida, onde permaneceram até a data do ensaio.

A Tabela 4.8 mostra as propriedades obtidas, no estado fresco e no estado endurecido, dos concretos analisados.

Tabela 4.8 - Propriedades dos concretos aos 28 dias de idade

\begin{tabular}{c|c|c|c|c|c}
\hline $\begin{array}{c}\text { Classe de resistência } \\
\text { do concreto }\end{array}$ & $\begin{array}{c}\text { Abatimento } \\
(\mathrm{cm})\end{array}$ & $f_{c}(\mathrm{MPa})$ & $f_{c t, s p}(\mathrm{MPa})$ & $f_{t}(\mathrm{MPa})$ & $E_{c}(\mathrm{GPa})$ \\
\hline C30 & 21,0 & 34,6 & 2,6 & 2,2 & 32,53 \\
\hline C60 & 13,0 & 55,2 & 4,5 & 3,8 & 39,93 \\
\hline C80 & 15,0 & 81,3 & 6,4 & 5,4 & 40,6 \\
\hline
\end{tabular}

Sendo que, $\mathrm{f}_{\mathrm{c}}$ é a resistência à compressão do concreto, $\mathrm{f}_{\mathrm{ct}, \mathrm{sp}}$ é a resistência à tração indireta do concreto, $\mathrm{f}_{\mathrm{t}}$ é a resistência à tração do concreto, e $\mathrm{E}_{\mathrm{c}}$ é o módulo de elasticidade tangente do concreto, todos ensaiados aos 28 dias de idade.

Como o plano de ruptura imposto pelo arranjo do ensaio de compressão diametral não se constitui obrigatoriamente no plano de menor resistência, os resultados desse ensaio, conforme LOBO CARNEIRO* (1949) apud FUSCO (1995), são maiores que os resultados do ensaio de tração pura. Portanto, a resistência à tração do ensaio de compressão diametral é multiplicada por 0,85.

* LOBO CARNEIRO, F.L. (1949), Résistence à la traction des bétons. Rio de Janeiro, Instituto Nacional de Tecnologia. 
A Figura 4.1 ilustra a evolução da resistência à compressão em relação ao tempo e o módulo de elasticidade longitudinal dos concretos utilizados na pesquisa.
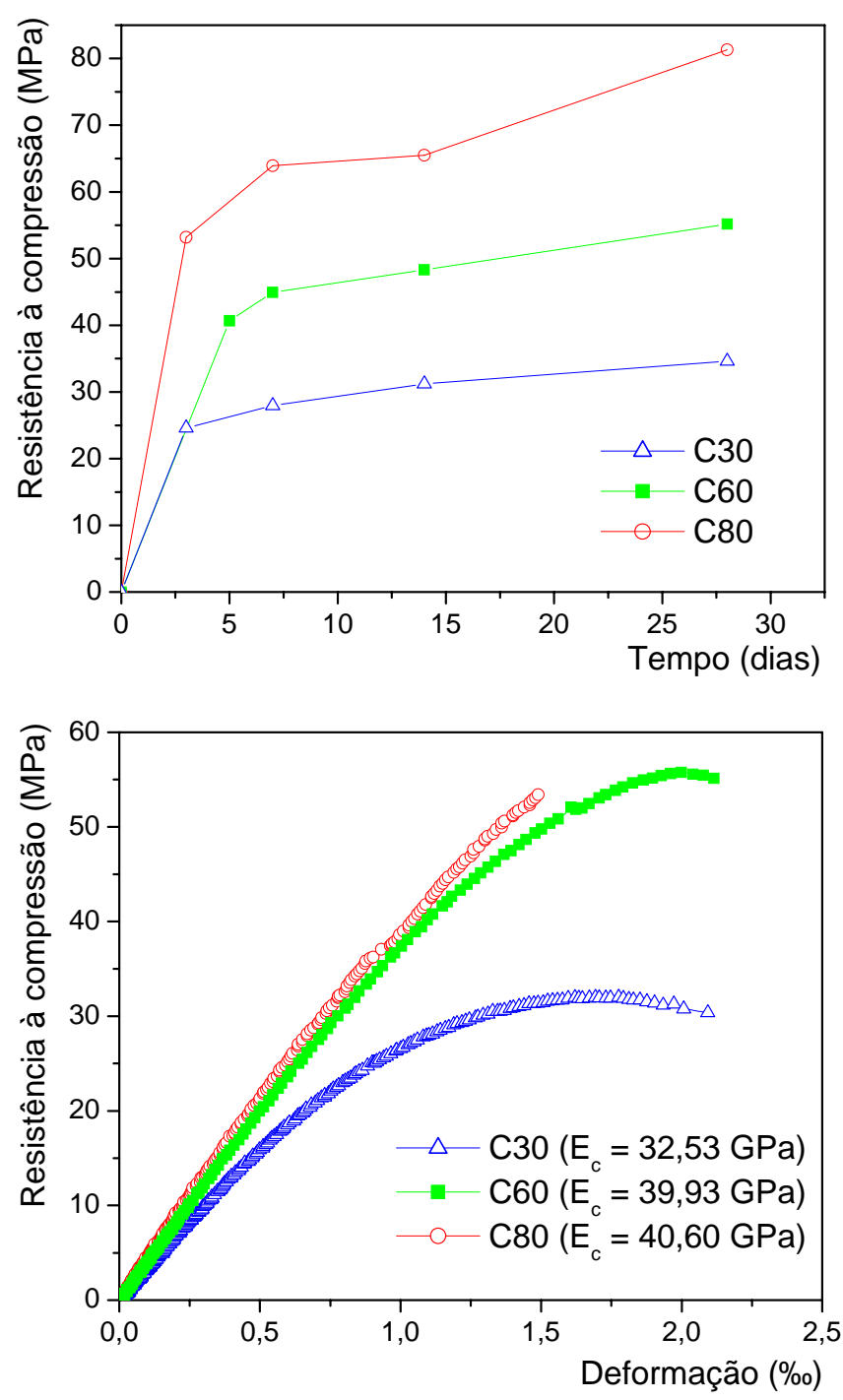

Figura 4.1 - a) Evolução da resistência à compressão dos concretos C30, C60 e C80.

b) Variação do módulo de elasticidade longitudinal dos concretos C30, C60 e C80

\subsection{Barras de GFRP}

Para a realização da investigação experimental foram utilizadas barras de GFRP Aslan 100, da empresa Hughes Brothers, com diâmetros de 9 mm e 16 mm. Estas barras foram fabricadas pelo processo de pultrusão, compostas por fibras de vidro e matriz polimérica de vinil-éster. A conformação superficial destas barras foi obtida por meio de fibras de vidro dispostas de forma helicoidal e uma camada de areia, como pode ser visto na Figura 4.2. 


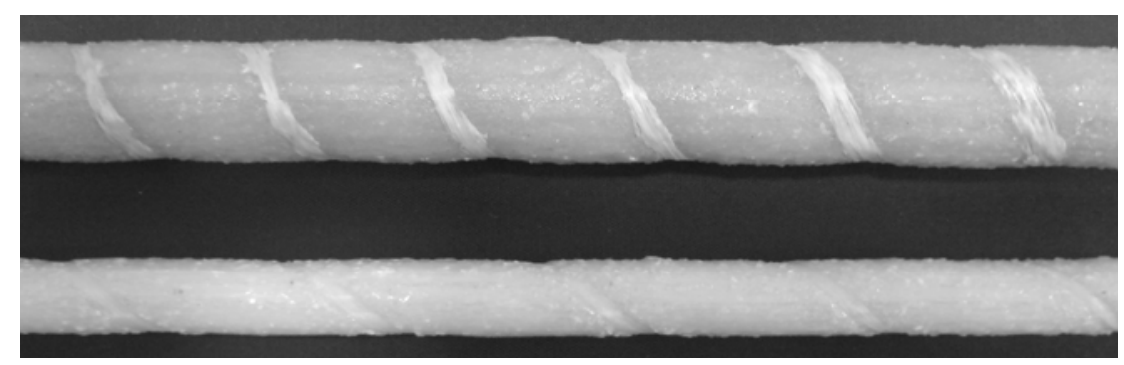

Figura 4.2 - Barras de GFRP Aslan 100

As propriedades mecânicas das barras de GFRP, fornecidas pelo fabricante, estão apresentadas Tabela 4.9.

Tabela 4.9 - Propriedades mecânicas das barras de GFRP (hpt://www.hughesbros.com, 2006)

\begin{tabular}{c|c|c|c|c}
\hline $\begin{array}{c}\text { Diâmetro da } \\
\text { barra }(\mathrm{mm})\end{array}$ & Área $\left(\mathrm{mm}^{2}\right)$ & $\begin{array}{c}\text { Diâmetro nominal } \\
(\mathrm{mm})\end{array}$ & $\begin{array}{c}\text { Resistência à } \\
\text { tração }(\mathrm{MPa})\end{array}$ & $\begin{array}{c}\text { Módulo de } \\
\text { elasticidade } \\
(\mathrm{GPa})\end{array}$ \\
\hline 9 & 84,32 & 9,53 & 760 & 40,8 \\
\hline 16 & 217,56 & 15,88 & 655 & 40,8 \\
\hline
\end{tabular}

Para a determinação da resistência à tração e módulo de elasticidade das barras de GFRP foram realizados ensaios de tração direta nessas barras segundo a norma americana ASTM D 3916 - 02 (2002).

Esta norma prevê a utilização de um dispositivo de alumínio para a fixação da barra na prensa durante o ensaio, como pode ser observado na Figura 4.3.

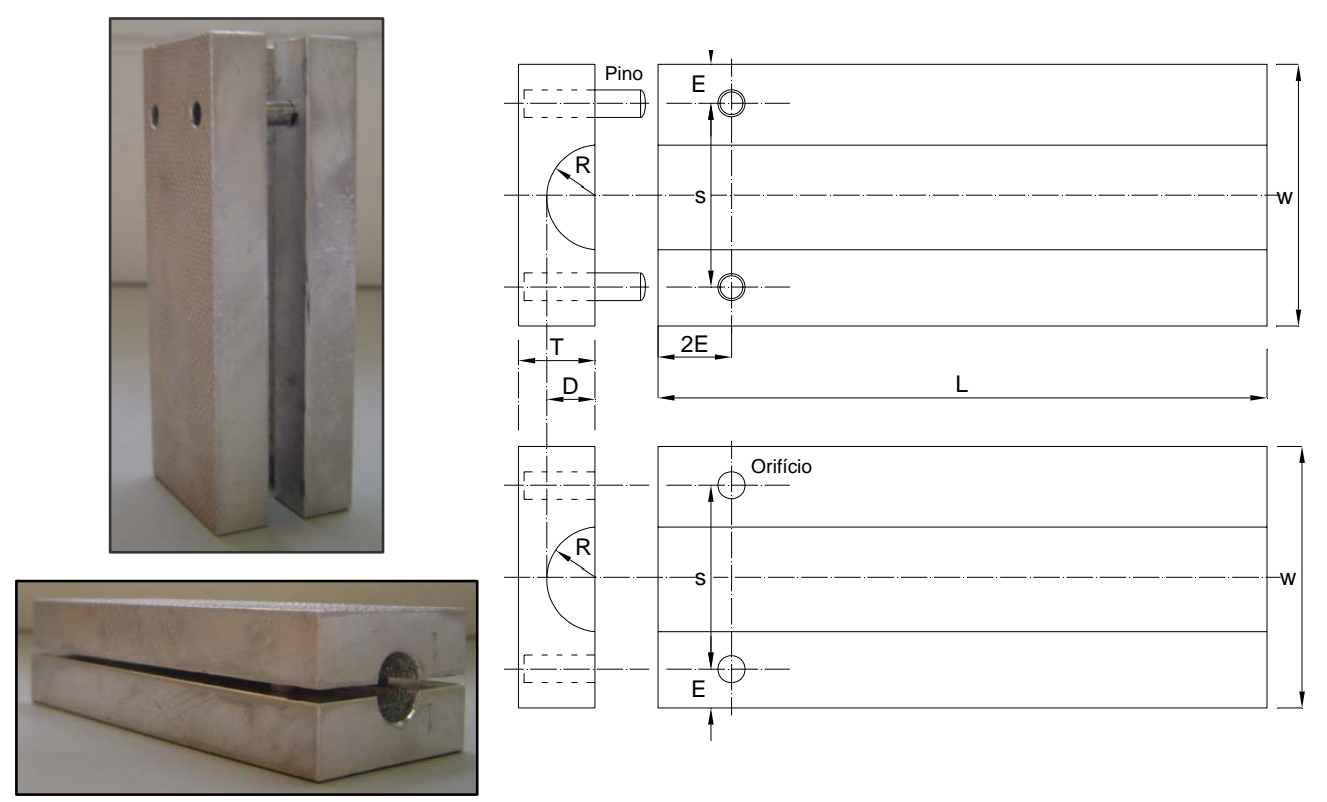

Figura 4.3 - Dispositivo de alumínio para o ensaio de tração das barras de FRP (ASTM D 3916 - 02, 2002) 
O uso deste procedimento de ensaio é justificado pela pequena resistência transversal das barras de FRP. A combinação da alta resistência à tração axial e da baixa resistência à compressão transversal nas barras fabricadas pelo processo de pultrusão, apresentam problemas na determinação da resistência à tração quando são realizados ensaios de tração com garras convencionais. A alta força de compressão transversal gerada no método convencional esmaga a barra, podendo causar sua ruptura prematura. Neste método, o dispositivo de alumínio envolve a superfície da barra, reduzindo a ação da força de compressão sobre a barra, determinando-se assim, as propriedades de tração das barras de FRP com maior precisão.

De acordo com a norma ASTM D 3916 - 02 (2002) foram ensaiados cinco corpos-de-prova para cada diâmetro estudado. As dimensões dos corpos-de-prova estão representadas na Tabela 4.10 .

Tabela 4.10 - Dimensões dos corpos-de-prova de GFRP.

\begin{tabular}{c|c}
\hline Diâmetro da barra $(\mathrm{mm})$ & Comprimento $(\mathrm{mm})$ \\
\hline 9 & 800 \\
\hline 16 & 1000 \\
\hline
\end{tabular}

Para a realização deste ensaio foi utilizada uma máquina de ensaio servohidráulica com sistema de aquisição de dados. A velocidade de carregamento foi de $0,083 \mathrm{~mm} / \mathrm{s}$. As forças foram aplicadas à velocidade constante até a ruptura do corpode-prova. Para determinar o módulo de elasticidade foi instalado um extensômetro removível na barra, como pode ser visto na Figura 4.4.
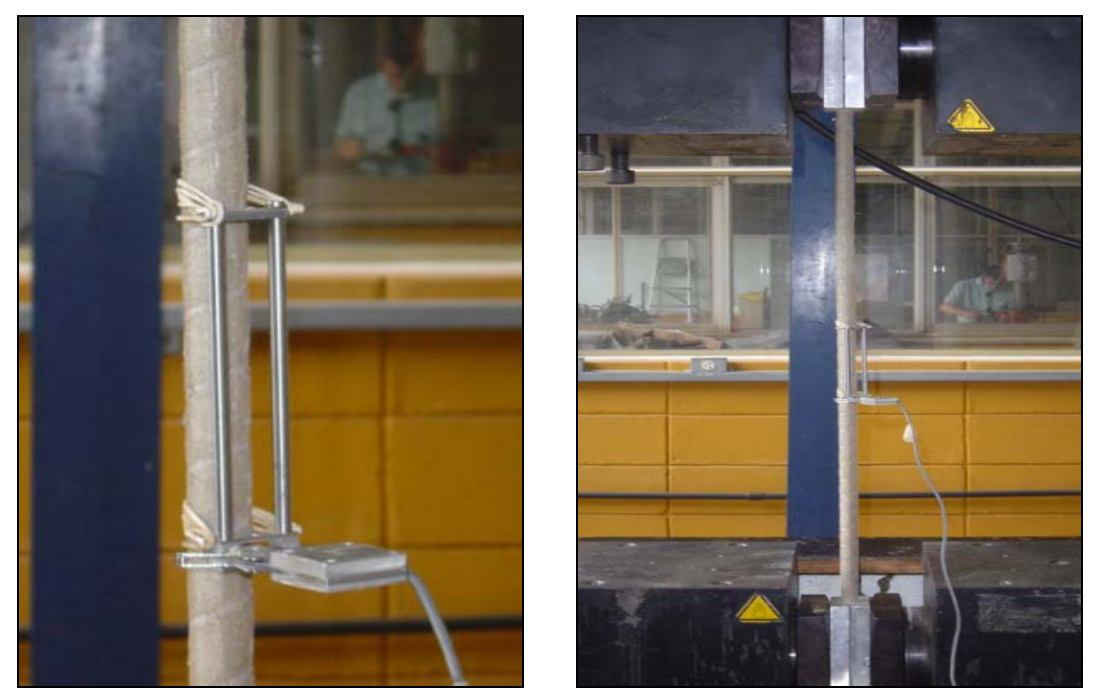

Figura 4.4 - Ensaio de tração direta nas barras de GFRP 
$\mathrm{Na}$ Tabela 4.11 estão apresentadas as propriedades obtidas experimentalmente das barras de GFRP ( $\phi 9 \mathrm{~mm}$ e $\phi 16 \mathrm{~mm})$ utilizadas nos ensaios de arrancamento.

Tabela 4.11 - Propriedades das barras de GFRP.

\begin{tabular}{c|c|c}
\hline & $\phi 9$ & $\phi 16$ \\
\hline Diâmetro nominal experimental (mm) & 9,56 & 15,90 \\
\hline Módulo de elasticidade longitudinal (GPa) & 42,73 & 44,86 \\
\hline Resistência última (MPa) & 714 & 624 \\
\hline
\end{tabular}

O diâmetro nominal experimental foi obtido por meio da imersão em água de três amostras de cada barra, com comprimento de aproximadamente $25 \mathrm{~cm}$. Foi medido o deslocamento de água provocado pela imersão da amostra, e em seguida calculado o diâmetro nominal da barra, considerando-a perfeitamente circular.

A Figura 4.5 ilustra o comportamento elástico-linear dos diagramas tensão $x$ deformação para as respectivas barras de GFRP.
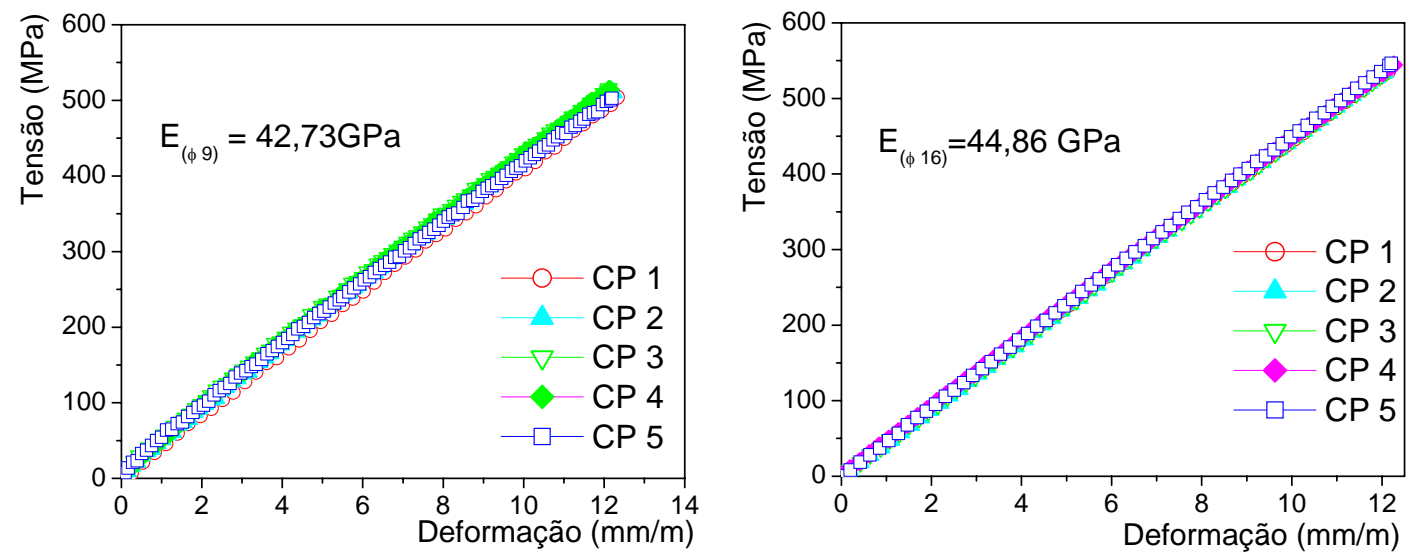

Figura 4.5 - a) Diagrama tensão x deformação das barras de GFRP com $\phi 9,5 \mathrm{~mm}$. b)

Diagrama tensão $x$ deformação das barras de GFRP com $\phi 16 \mathrm{~mm}$

A Figura 4.6 ilustra a ruptura desenvolvida pelas barras de GFRP. 

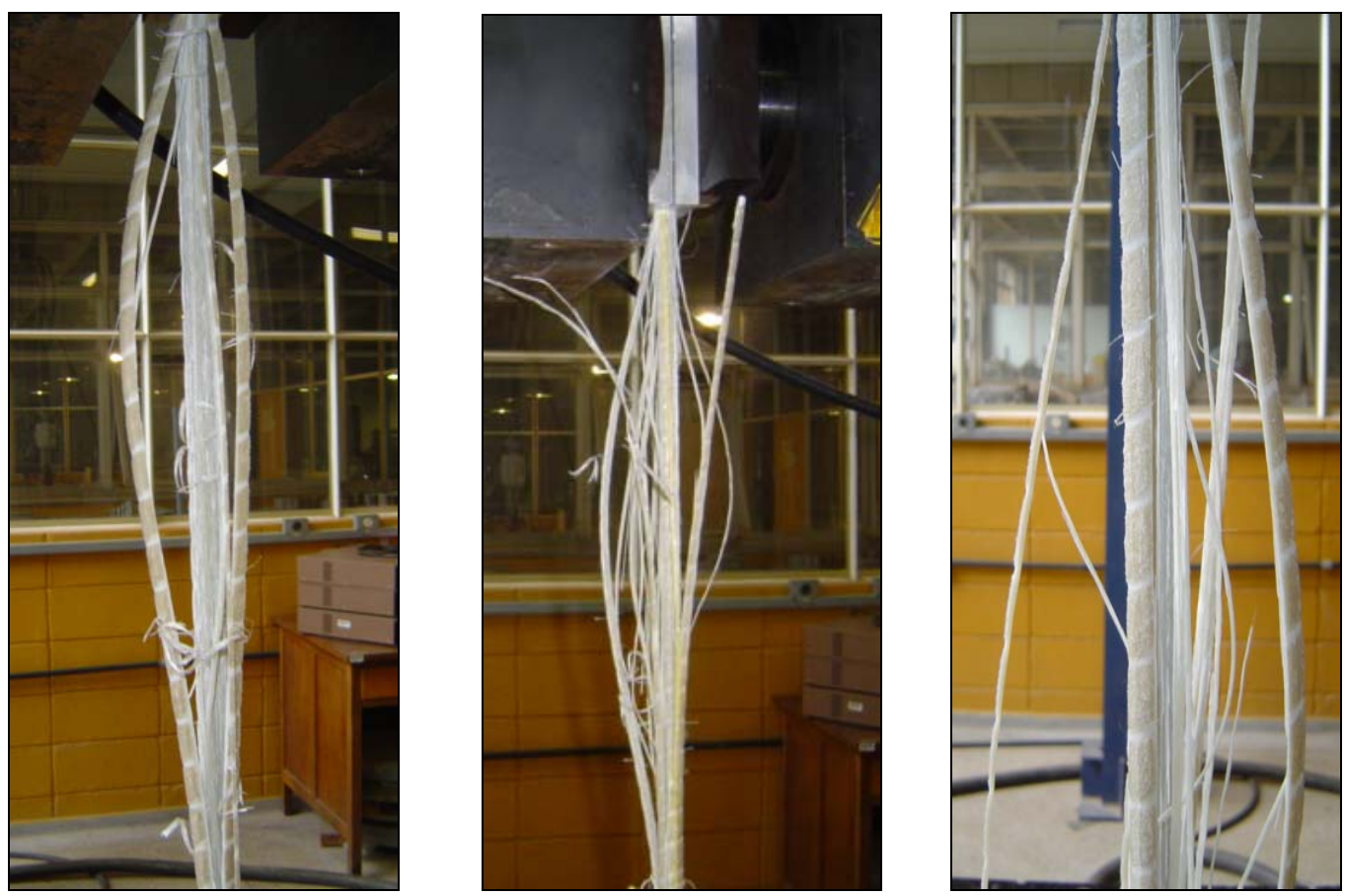

Figura 4.6 - Ruptura desenvolvida pelas barras de GFRP

\subsection{Ensaios de arrancamento}

Como dito anteriormente, os ensaios de arrancamento foram realizados de acordo com os procedimentos descritos pela RILEM/FIP/CEB (1973). Os modelos de arrancamento foram ensaiados 28 dias após sua concretagem, para cada classe de resistência do concreto foram ensaiados cinco modelos, totalizando 30 ensaios. A Tabela 4.12 traz um resumo dos ensaios realizados.

Tabela 4.12 - Ensaios de arrancamento realizados na investigação experimental

\begin{tabular}{c|c|c|c}
\hline \multirow{2}{*}{ Nomenclatura } & $\begin{array}{c}\text { Resistência do concreto } \\
\text { aos 28 dias }(\mathrm{MPa})\end{array}$ & $\begin{array}{c}\text { Diâmetro da barra de } \\
\text { GFRP }(\mathrm{mm})\end{array}$ & $\begin{array}{c}\text { Número de } \\
\text { repetições }\end{array}$ \\
\hline \multirow{2}{*}{ C30B9 } & \multirow{2}{*}{30} & 9 & 5 \\
\cline { 1 - 3 } C30B16 & \multirow{2}{*}{60} & 16 & 5 \\
\hline C60B9 & \multirow{2}{*}{80} & 9 & 5 \\
\hline C60B16 & & 9 & 5 \\
\hline C80B9 & & 16 & 5 \\
\hline C80B16 & & &
\end{tabular}

Sendo que, C30, C60 e C80 correspondem a classe de resistência do concreto (30 MPa, $60 \mathrm{MPa}$ e $80 \mathrm{MPa}$ ) e B9, B16 correspondem aos diâmetros das barras (9 $\mathrm{mm}$ e $16 \mathrm{~mm})$. 


\subsubsection{Fôrmas}

Para a moldagem dos modelos de arrancamento foram utilizadas fôrmas cilíndricas de tubos de PVC, com um corte longitudinal para facilitar e desfôrma. O fundo era constituído por uma base de madeira com um orifício central, presa ao tubo de PVC por parafusos radiais. Na parte superior, foi fixado um sarrafo de madeira para garantir o posicionamento da barra. O trecho não aderente da barra foi obtido pela introdução de uma mangueira de plástico. O detalhamento da fôrma pode ser observado na Figura 4.7.

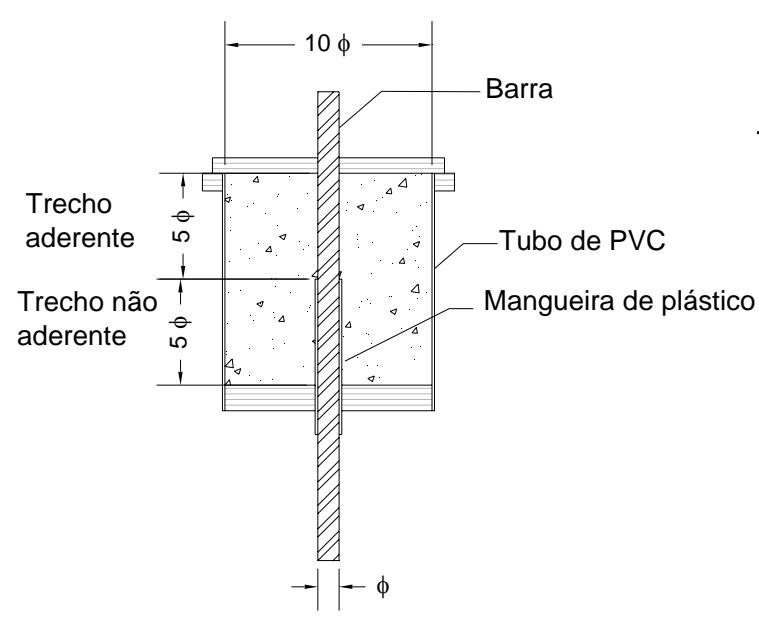

Corte AA

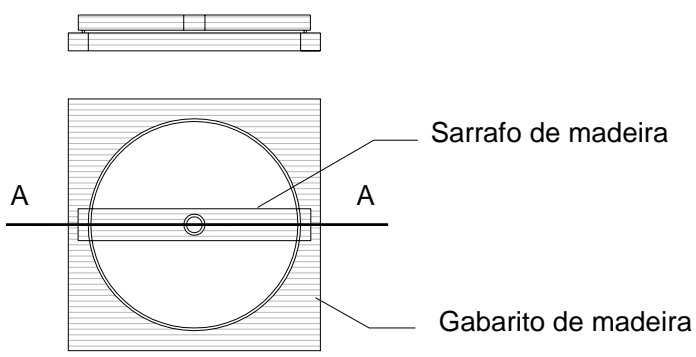

Vista superior

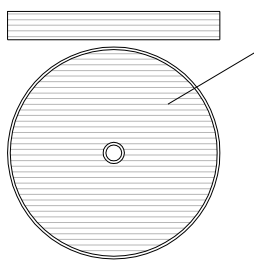

Vista inferior
Fundo de madeira com orifício central

Figura 4.7 - Detalhamento da fôrma dos modelos de arrancamento.

A Figura 4.8 ilustra as fôrmas utilizadas nos modelos de arrancamento para as barras de $9 \mathrm{~mm}$ e $16 \mathrm{~mm}$.
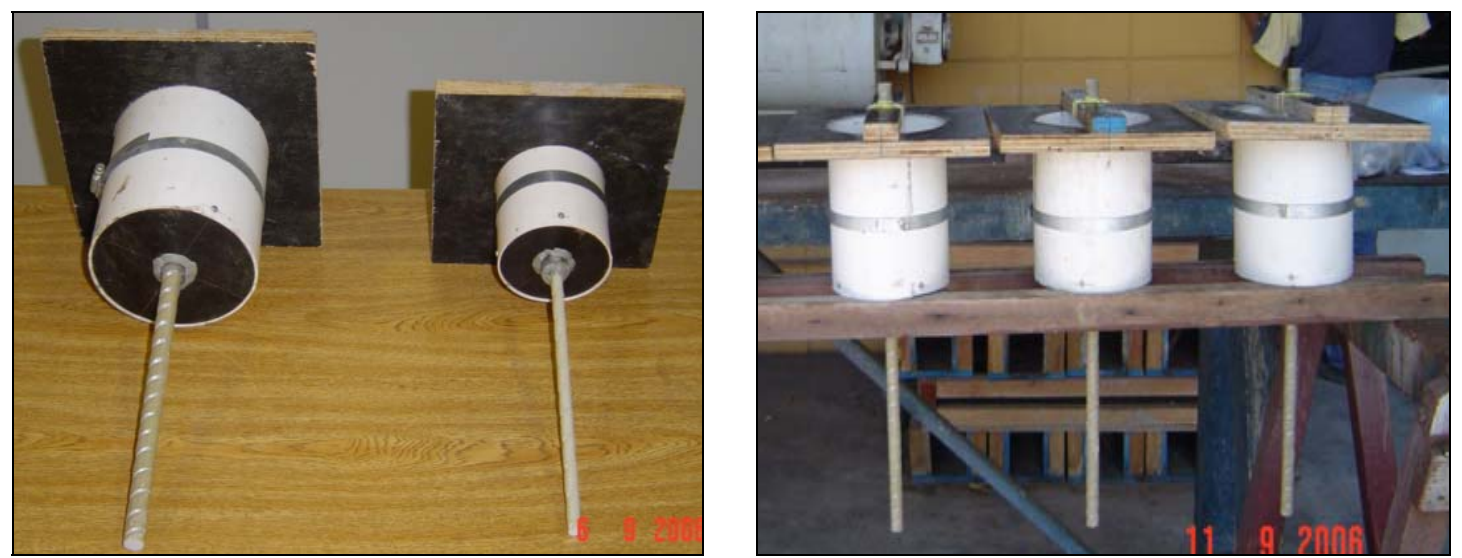

Figura 4.8 - Fôrmas utilizadas nos modelos de arrancamento. 


\subsubsection{Moldagem e cura dos modelos}

Os cilindros de concreto foram moldados na direção vertical. O concreto foi lançado em três camadas e adensado externamente. Após um dia da moldagem, os modelos foram desmoldados e em seguida armazenados em câmara úmida até a data do ensaio. A Figura 4.9 ilustra a moldagem e adensamento dos modelos de arrancamento para o ensaio de aderência.
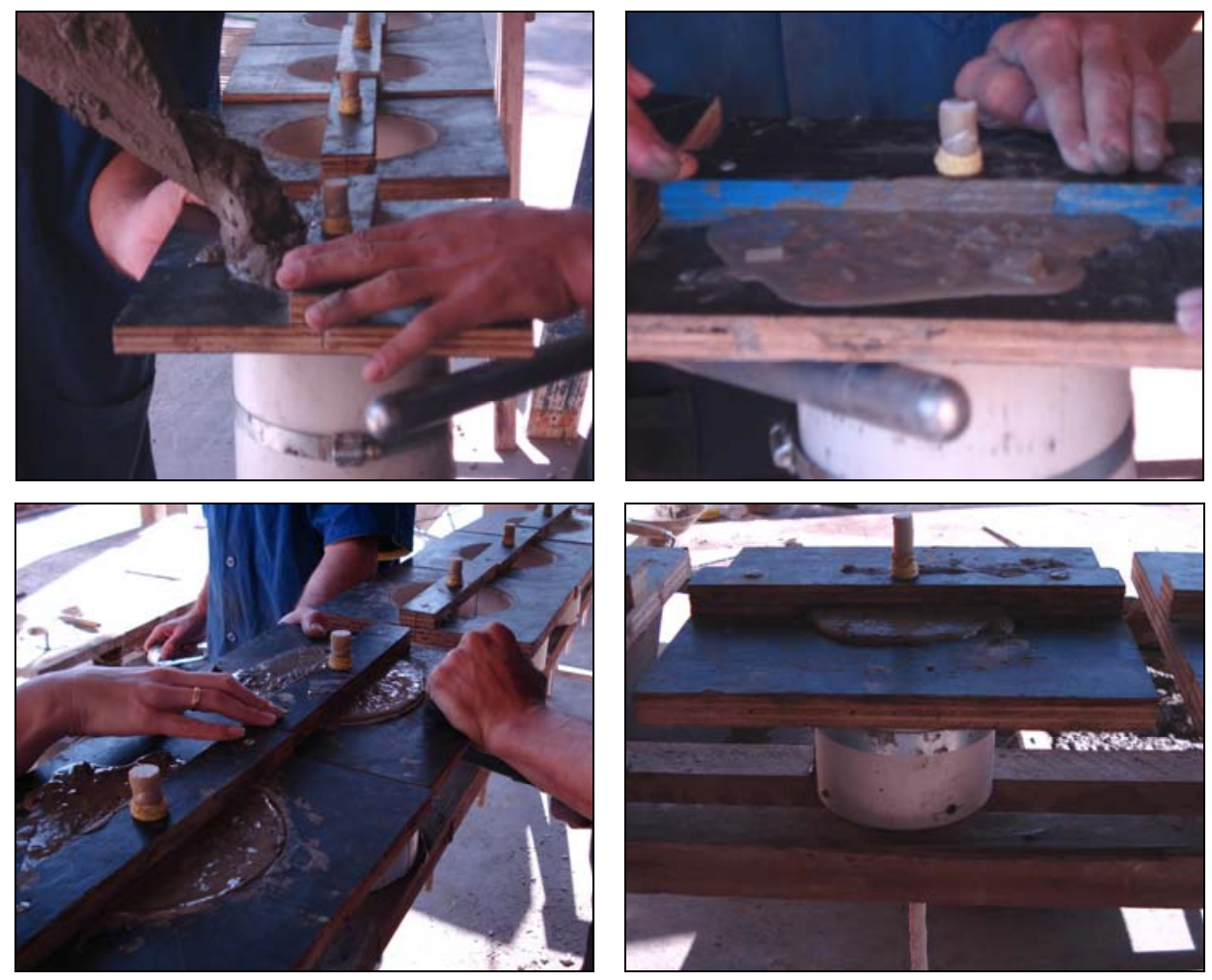

Figura 4.9 - Moldagem e adensamento dos modelos de arrancamento.

\subsubsection{Realização do ensaio}

Os ensaios de arrancamento foram realizados aos 28 dias de idade do concreto. O cilindro de concreto foi apoiado em uma placa metálica, com orifício central que permitia a passagem da barra, e esta por sua vez foi presa pelo dispositivo de alumínio encaixado na garra da máquina INSTRON. A placa metálica está ligada à INSTRON por quatro hastes metálicas. Na Figura 4.10 está ilustrado o esquema do ensaio de arrancamento. 


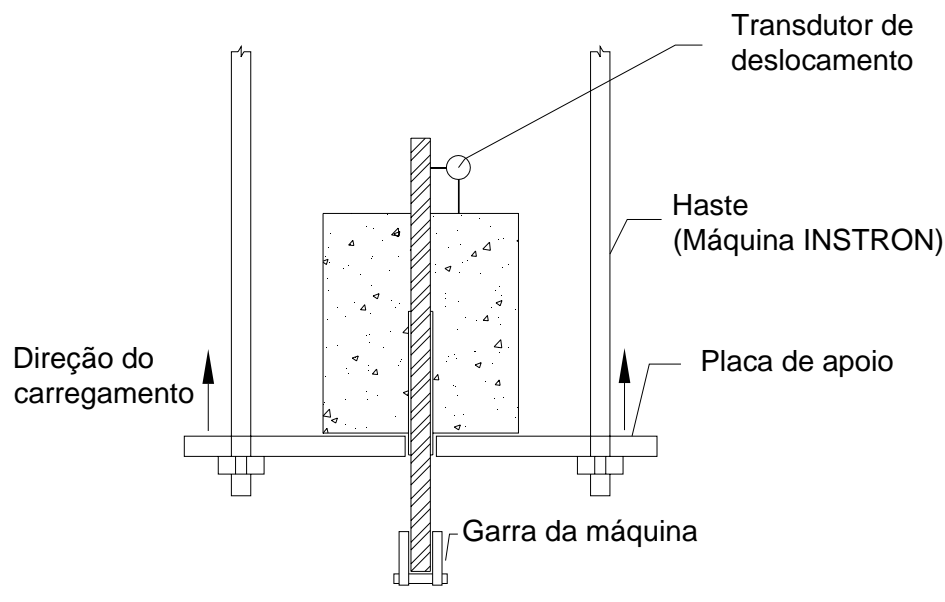

Figura 4.10 - Esquema do ensaio de arrancamento.

Os ensaios foram realizados com controle de deslocamento e o deslocamento da barra foi medido em sua extremidade não solicitada por meio de um transdutor de deslocamento.

A velocidade de aplicação da força foi calculada de acordo com o diâmetro a barra ensaiada. No caso dos modelos com barras de $9 \mathrm{~mm}$, a velocidade adotada foi de $0,010 \mathrm{~mm} / \mathrm{s}$, e no caso dos modelos com barras de $16 \mathrm{~mm}$, a velocidade adotada foi de $0,016 \mathrm{~mm} / \mathrm{s}$ (FERNANDES, 2000 e CASTRO, 2002). A Figura 4.11 ilustra o dispositivo de ensaio utilizado para os ensaios de arrancamento.

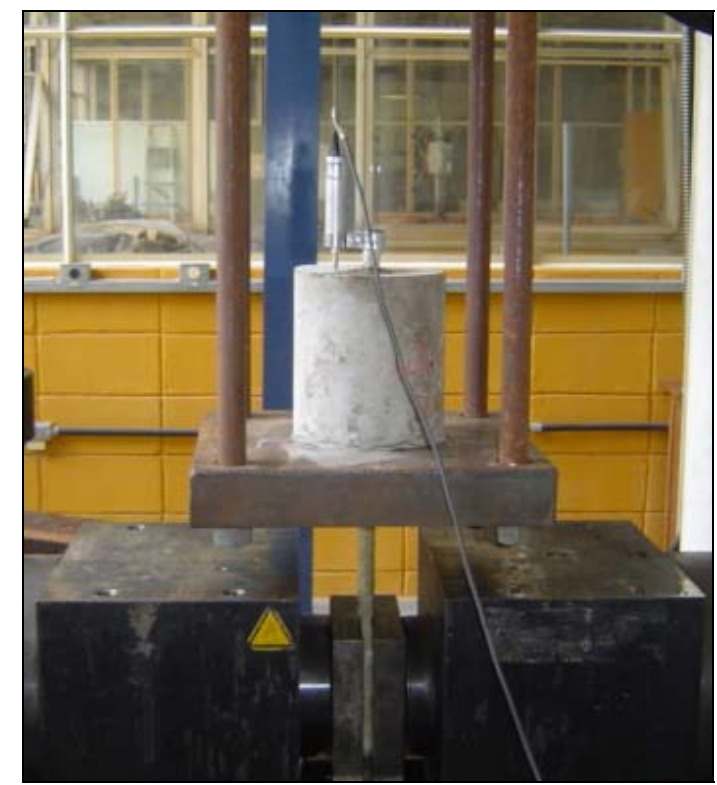

Figura 4.11 - Ensaio de arrancamento. 
As Figuras 4.12, 4.14 e 4.15 ilustram o comportamento das curvas tensão $x$ deslocamento para os modelos de arrancamento das séries C30, C60 e C80, respectivamente.
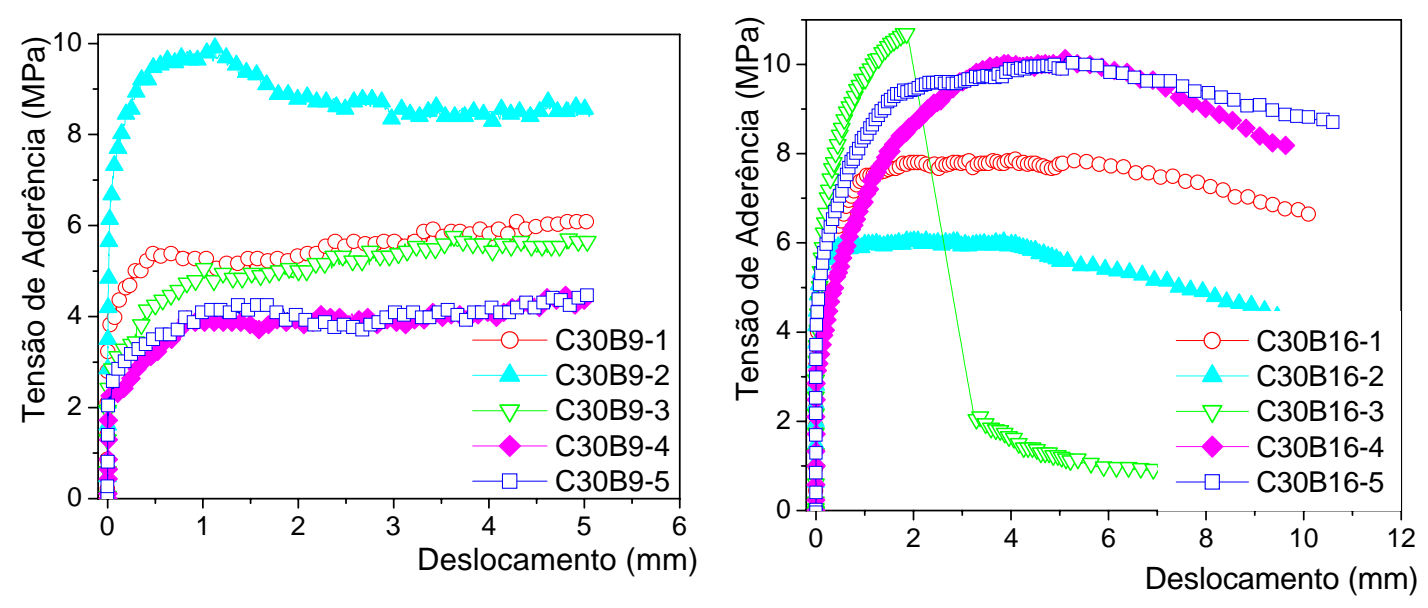

Figura 4.12- a)Comportamento dos modelos de arrancamento da série C30B9;

b)Comportamento dos modelos de arrancamento da série .C30B16

O modelo C30B9-1 (Figura 4.12-a) apresentou comportamento atípico comparado aos demais modelos da mesma série. Isto pode ser atribuído à pequena dimensão dos modelos com barras de $9 \mathrm{~mm}$ e do comprimento de ancoragem, pois uma pequena variação no comprimento de ancoragem pode acarretar grande variação dos resultados (ALMEIDA FILHO, 2006)

O modelo C30B16-3 (Figura 4.12-b) apresentou fissura por fendilhamento, o que não comprometeu o modelo (sem explosão do mesmo) e sim a ligação barraconcreto, como está ilustrado na Figura 4.13. Portanto, este modelo não foi considerado na análise dos resultados.

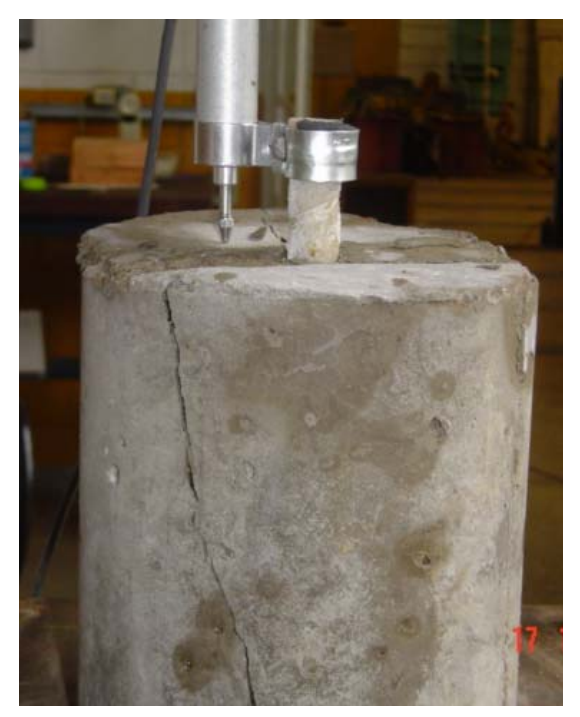

Figura 4.13 - Fendilhamento do cilindro de concreto 

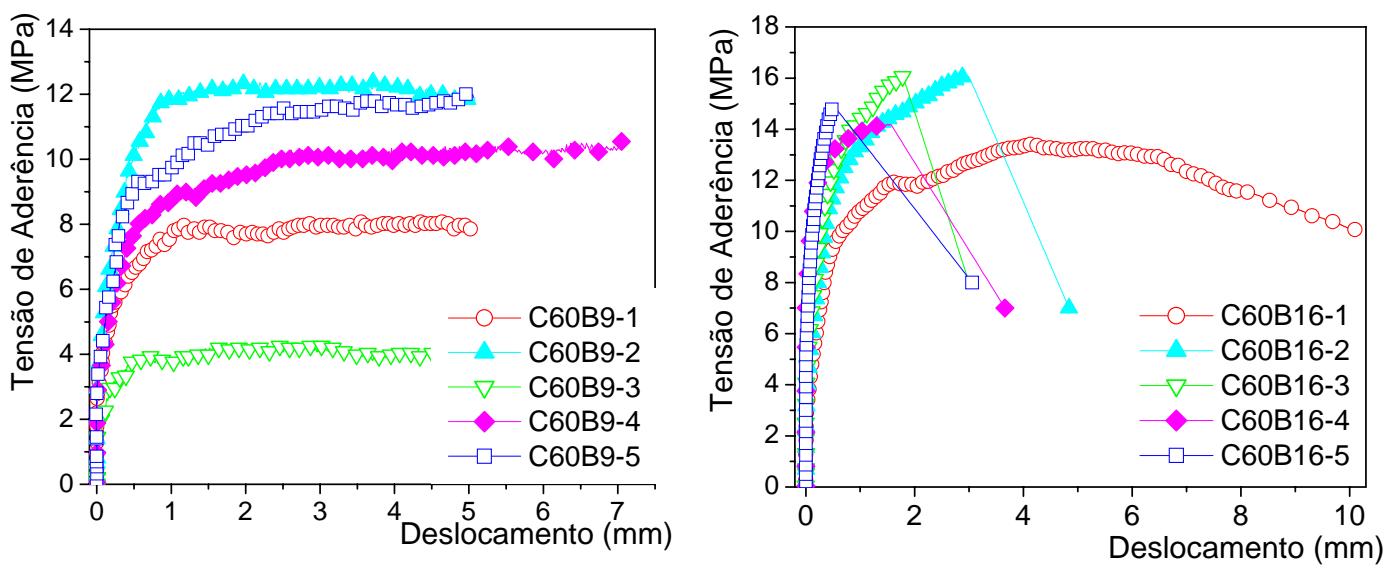

Figura 4.14 - a)Comportamento dos modelos de arrancamento da série C60B9; b)Comportamento dos modelos de arrancamento da série .C60B16

Na Figura 4.14-a pode ser observado grande variação nas curvas tensão de aderência $x$ deslocamento. Isto pode ser atribuído ao mesmo fato explicado anteriormente para a Figura 4.12-a. Nesta série será descartado o modelo C60B9-3, por apresentar resistência de aderência significativamente inferior aos demais modelos.

O modelo C60B16-1 (Figura 4.14-b) apresentou ruptura por arrancamento da barra, enquanto os demais modelos apresentaram ruptura da superfície da barra e posterior fendilhamento do concreto (ruptura combinada). Em virtude do comportamento atípico do modelo C60B16-1, ele não foi considerado na análise dos resultados.
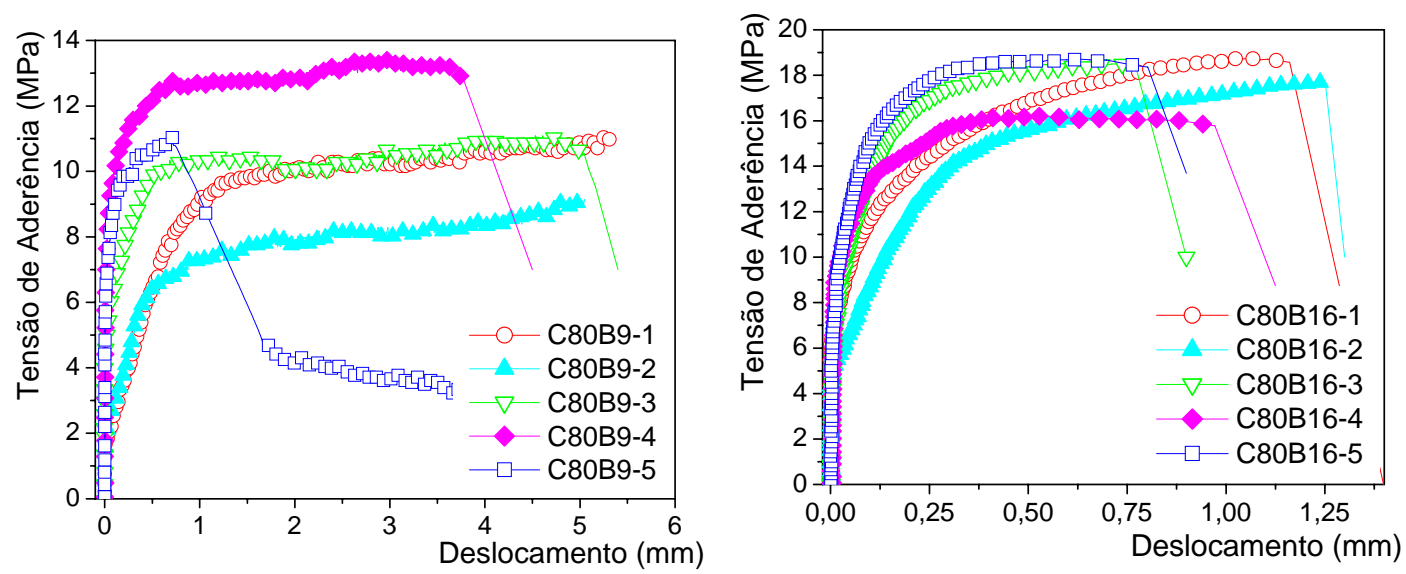

Figura 4.15 - a)Comportamento dos modelos de arrancamento da série C80B9;

b) Comportamento dos modelos de arrancamento da série C80B16

Na Figura 4.15-a, o modelo C80B9-5 apresentou o mesmo comportamento do modelo C30B9-3, assim, ele não será considerado na análise dos resultados. 
Os modelos da série C80B16 tiveram comportamentos similares, com ruptura combinada em todos os casos (Figura 4.16). A ruptura ocorrida na superfície da barra também foi observada por PILAKOUTAS \& ACHILIDES (2004) em ensaios de arrancamento.
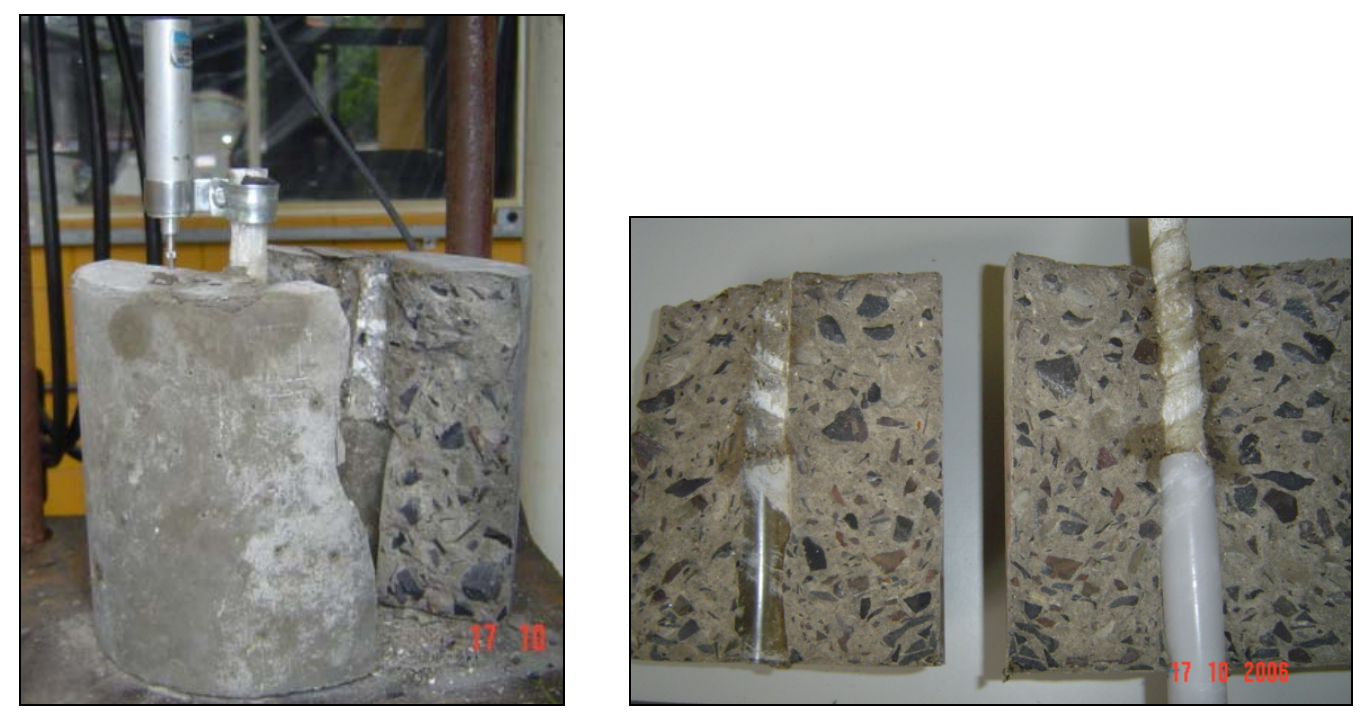

Figura 4.16 - Ruptura combinada durante ensaio de arrancamento

É importante salientar que o concreto também contribuiu bastante para a variabilidade encontrada entre os modelos de arrancamento de uma mesma série, visto que o concreto é um material heterogêneo.

\subsection{Instrumentos e equipamentos utilizados}

Os instrumentos e equipamentos utilizados na investigação experimental estão indicados na Tabela 4.13. 
Tabela 4.13 - Instrumentos e equipamentos utilizados na investigação experimental.

\begin{tabular}{|c|c|c|c|c|}
\hline Instrumento & Tipo & Marca & Características & Finalidade \\
\hline $\begin{array}{c}\text { Máquina de } \\
\text { ensaio servo- } \\
\text { hidráulica }\end{array}$ & Modelo 8506 & INSTRON & $\begin{array}{c}\text { Controle de } \\
\text { deslocamento do } \\
\text { pistão }\end{array}$ & $\begin{array}{c}\text { Aplicação da força no } \\
\text { ensaio de } \\
\text { arrancamento }\end{array}$ \\
\hline $\begin{array}{l}\text { Sistema de } \\
\text { aquisição de } \\
\text { dados }\end{array}$ & $\begin{array}{c}\text { Vishay } \\
\text { Measurements } \\
\text { Group }\end{array}$ & $\begin{array}{l}\text { SYSTEM } \\
5000\end{array}$ & - & $\begin{array}{c}\text { Aquisição automática } \\
\text { de dados }\end{array}$ \\
\hline $\begin{array}{c}\text { Máquina } \\
\text { hidráulica } \\
\text { automática }\end{array}$ & $\begin{array}{c}\text { Modelo } \\
\text { Autotest } 2000\end{array}$ & ELE & Controle de força & $\begin{array}{c}\text { Ensaios nos corpos-de- } \\
\text { prova de concreto }\end{array}$ \\
\hline $\begin{array}{l}\text { Extensômetro } \\
\text { removível }\end{array}$ & - & MSI & $\begin{array}{l}\text { Base de medida: } \\
\qquad 100 \text { mm } \\
\text { Resolução: } \\
\text { 0,001 mm }\end{array}$ & $\begin{array}{c}\text { Medição das } \\
\text { deformaçoes no } \\
\text { concreto e na barra } \\
\text { para determinação do } \\
\text { módulo de elasticidade }\end{array}$ \\
\hline $\begin{array}{l}\text { Transdutor de } \\
\text { deslocamento }\end{array}$ & DTH- A-10 & KYOWA & $\begin{array}{l}\text { Curso : 10mm } \\
\text { Resolução: } \\
\text { 0,001 mm }\end{array}$ & $\begin{array}{c}\text { Medição dos } \\
\text { deslocamentos nos } \\
\text { ensaios de } \\
\text { arrancamento }\end{array}$ \\
\hline
\end{tabular}

\subsection{Considerações finais}

Este capítulo tratou do programa experimental realizado, incluindo as análises das propriedades dos materiais (concreto e barra) e ensaios de arrancamento.

Com relação a caracterização das barras de GFRP pode-se concluir que:

- O dispositivo de alumínio empregado para minimizar as tensões causadas pela ancoragem da barra na máquina de ensaio não se comportou adequadamente, pois as barras apresentaram ruptura prematura e próxima das garras da máquina;

- As barras apresentaram comportamento elástico-linear, com ruptura frágil.

Com relação aos ensaios de arrancamento pode-se concluir que:

- Os modelos de arrancamento foram adequados para a medida do deslocamento da barra de GFRP em relação ao cilindro de concreto;

- Em relação à resistência à compressão dos concretos, pode-se verificar que a resistência de aderência não apresentou variação significativa 
entre os modelos das séries com concreto de resistência à compressão de $60 \mathrm{MPa}$ e de $80 \mathrm{MPa}$; o que não ocorreu nos modelos das séries com concreto de resistência à compressão de $30 \mathrm{MPa}$;

- A resistência de aderência é sensivelmente superior nos modelos onde se utilizaram os concretos de alta resistência quando comparados aos modelos com o concreto de resistência à compressão de $30 \mathrm{MPa}$

- A resistência de aderência foi maior, em todos os modelos, quando se utilizou barra de $16 \mathrm{~mm}$;

- Nos modelos com barras de $9 \mathrm{~mm}$, ocorreu ruptura por arrancamento da barra. Em alguns casos, quando se utilizou concreto de resistência à compressão de $80 \mathrm{MPa}$ ocorreu ruptura combinada;

- A série C30B16 se caracterizou pela ruptura por arrancamento da barra, já as séries C60B16 e C80B16 se caracterizaram pela ruptura combinada. 


\section{SIMULAÇÃO NUMÉRICA DA ADERÊNCIA}

\subsection{Considerações iniciais}

A análise numérica do comportamento da aderência entre a barra de GFRP e o concreto constituiu da simulação numérica dos modelos de arrancamento utilizados na investigação experimental por meio do programa computacional Ansys versão 9.0, baseado no método dos elementos finitos.

O modelo numérico de aderência barra-concreto é definido por um problema de contato, o qual envolve a não linearidade física da estrutura, apresentando, portanto algumas dificuldades para sua solução, dependendo da ação, do material, condições de contorno e outros fatores, determinadas regiões do modelo podem entrar e sair do contato bruscamente (FERNANDES, 2000)

Para a representação numérica do comportamento da aderência foi realizado um estudo experimental preliminar, a fim de parametrizar e calibrar o modelo numérico de acordo com as propriedades dos materiais constituintes. Posteriormente, efetuouse a análise dos resultados obtidos pelo estudo numérico, comparando-os com os resultados obtidos na investigação experimental.

A simulação numérica foi realizada levando em consideração o comportamento elástico-linear dos materiais, buscando representar, de maneira satisfatória, o primeiro trecho do diagrama força $x$ deslocamento obtido nos modelos experimentais de arrancamento.

\subsection{Materiais}

Os modelos numéricos utilizados neste trabalho foram baseados nos modelos desenvolvidos por ALMEIDA FILHO (2006). Assim, foram realizadas considerações com relação aos materiais utilizados na investigação numérica da aderência, que são apresentadas a seguir. 
É importante ressaltar a ausência de trabalhos publicados no que diz respeito à análise numérica do comportamento da aderência entre barras de FRP e o concreto. Posto isto, a consideração a respeito das propriedades mecânicas dos materiais e da geometria do modelo foi realizada com base na investigação experimental da aderência (Capítulo 4).

\subsubsection{Concreto}

O concreto é um material que possui grande resistência à compressão, quando comparado com sua resistência à tração. A partir desta consideração, foram propostos diversos modelos matemáticos com a finalidade de simular o comportamento do diagrama tensão $x$ deformação deste material, como o modelo desenvolvido por KENT e PARK e modificado por SCOTT et al. (1982).

O modelo de SCOTT et al. (1982), representa o diagrama tensão x deformação do concreto submetido à compressão dividido em três regiões (Figura 5.1-a). E para o caso do concreto submetido à tração (Figura 5.1-b), o diagrama é representado pelo comportamento elástico-linear até o limite estabelecido para resistência à tração do concreto, com inclinação igual a $\mathrm{E}_{\mathrm{b} 1}$, em função do módulo de elasticidade longitudinal $\left(E_{c}\right)$ e a inclinação $E_{b 2}$, em função do módulo de elasticidade transversal $(G)$.

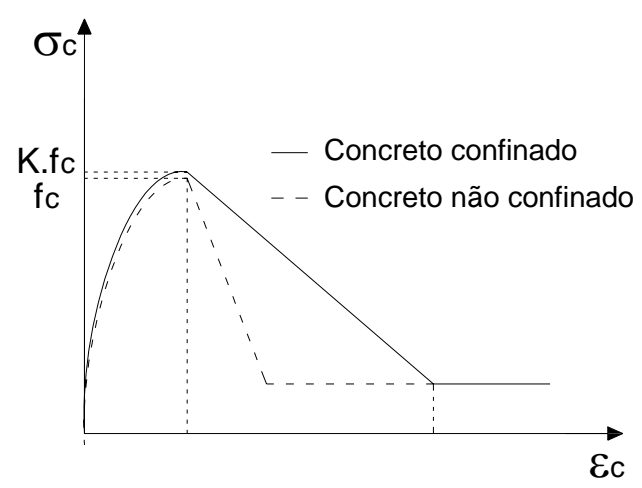

(a)

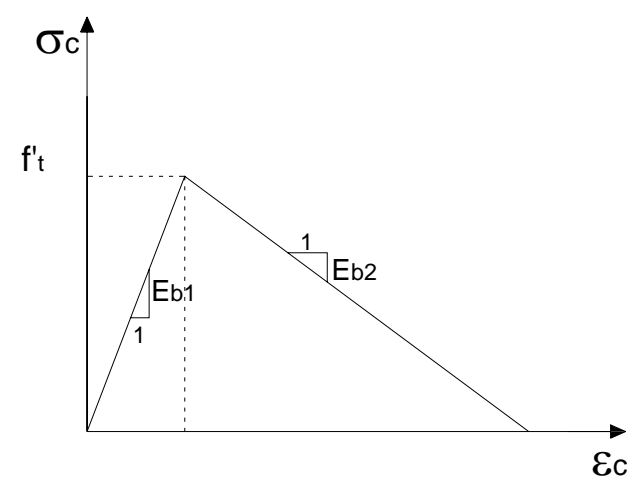

(b)

Figura 5.1 - Diagramas tensão x deformação para o concreto; a) Região de compressão; b) Região de tração

(KWAK e KIM, 2001)

Porém, para o presente trabalho foram utilizados os resultados da investigação experimental realizada, cujas principais propriedades mecânicas do concreto estão representadas na Tabela 5.3. 


\subsubsection{Barra de GFRP}

CHAMIS (1984) propôs um modelo micromecânico para simular o comportamento dos compósitos de FRP, onde as propriedades mecânicas do material são consideradas transversalmente isotrópicas. As equações propostas por CHAMIS (1984) para o cálculo das propriedades mecânicas (Módulo de elasticidade longitudinal, módulo de elasticidade transversal e coeficiente de Poisson) dos compósitos de FRP são apresentadas a seguir.

Módulo de Elasticidade longitudinal $\left(E_{11}\right)$ :

$$
E_{11}=E_{f} \cdot V_{f}+E_{m} \cdot V_{m}
$$

Módulo de elasticidade transversal nos eixos 2 e $3\left(E_{22}\right.$ e $\left.E_{33}\right)$ :

$$
E_{22}=E_{33}=\frac{E_{m}}{1-\sqrt{V_{f}} \cdot\left(1-E_{m} / E_{f}\right)}
$$

Módulo de cisalhamento nos planos 1-2, 1-3 e 2-3 ( $\mathrm{G}_{12}, \mathrm{G}_{13}$ e $\left.\mathrm{G}_{23}\right)$ :

$$
G_{12}=G_{13}=G_{23}=\frac{G_{m}}{1-\sqrt{V_{f}} \cdot\left(1-G_{m} / G_{f}\right)}
$$

Coeficiente de Poisson nos planos 1-2, 1-3 e 2-3 ( $v_{12}, v_{13}$ e $\left.v_{23}\right)$ :

$$
\begin{aligned}
& v_{12}=v_{13}=v_{f} \cdot V_{f}+v_{m} \cdot V_{m} \\
& v_{23}=\frac{E_{22}}{2 \cdot G_{23}}-1
\end{aligned}
$$

Sendo:

$V_{f}-$ volume de fibras;

$\mathrm{V}_{\mathrm{m}}$ - volume da matriz polimérica;

$E_{f}, G_{f}$ e $v_{f}$ - propriedades elásticas da fibra;

$E_{m}, G_{m}$ e $v_{m}$ - propriedades elásticas da matriz. Sistema de coordenadas

BAKIS et al. (1998) realizou a simulação numérica de modelos de arrancamento com barras de GFRP e CFRP, utilizando o modelo proposto por CHAMIS (1984) para o cálculo das propriedades mecânicas das barras. Os resultados obtidos com a simulação numérica representaram adequadamente o comportamento experimental do diagrama tensão de aderência $x$ deslocamento dos modelos de arrancamento analisados. 
Porém, neste trabalho não será utilizado o modelo proposto por CHAMIS (1984), pois o fabricante das barras de GFRP não disponibilizou as propriedades mecânicas das fibras e das resinas constituintes, apenas da barra. Assim, o comportamento do diagrama tensão $x$ deformação das barras de GFRP utilizado para a simulação numérica foi obtido por meio da investigação experimental (Capítulo 4). As propriedades mecânicas da barra de GFRP estão apresentadas na Tabela 5.3.

\subsubsection{Interface barra-concreto}

Para representar a interface barra-concreto foi adotado o modelo de MohrCoulomb modificado do programa Ansys, como está representado na Figura 5.2. A tensão cisalhante $(\tau)$ é definida como uma parcela da pressão de contato $(p)$, considerando o coeficiente de atrito $(\mu)$.

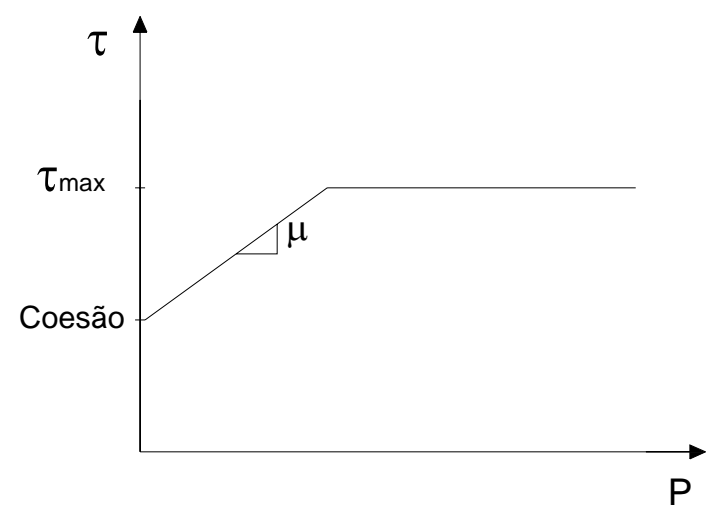

Figura 5.2 - Modelo de atrito Mohr-Coulomb modificado, adotado pelo programa Ansys

No modelo de Mohr-Coulomb modificado, duas superfícies inicialmente em contato irão deslocar uma em relação à outra após ultrapassada a tensão de coesão entre os materiais. Depois de atingida a tensão de coesão, o deslocamento avança de acordo com o coeficiente de atrito até atingir o valor referente a tensão máxima $\left(\tau_{\max }\right)$, e a partir daí, ocorre a separação dos materiais.

\subsection{Elementos finitos utilizados}

Os modelos numéricos desenvolvidos foram elaborados com base em elementos pré-definidos, disponibilizados na biblioteca interna do Ansys, os quais serão apresentados a seguir. A escolha dos elementos foi feita levando-se em consideração aspectos como número de graus de liberdade, esforço computacional e, principalmente, representatividade perante o comportamento a ser simulado. 


\subsubsection{SOLID65}

O elemento finito SOLID65 é utilizado para a modelagem tridimensional de materiais sólidos. Este elemento é capaz de simular o comportamento de materiais como o concreto, ou seja, permite fissuração na tração, esmagamento na compressão, deformação plástica e fluência.

O elemento SOLID65 possui oito nós, cada um com três graus de liberdade, sendo eles translações segundo os eixos x, y e z (Figura 5.3).

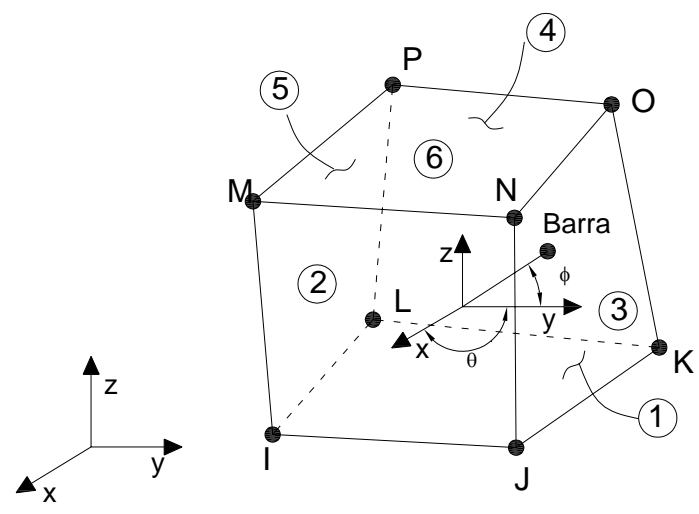

Figura 5.3 - Elemento finito SOLID65

\subsubsection{SOLID45}

O elemento finito SOLID45 é utilizado para a modelagem tridimensional de materiais sólidos. Este elemento permite plasticidade, fluência, dilatação térmica, rigidez a tração, grandes deflexões e deformações.

O elemento SOLID45 possui oito nós, cada um com três graus de liberdade, sendo eles translações segundo os eixos x, y e z (Figura 5.4).

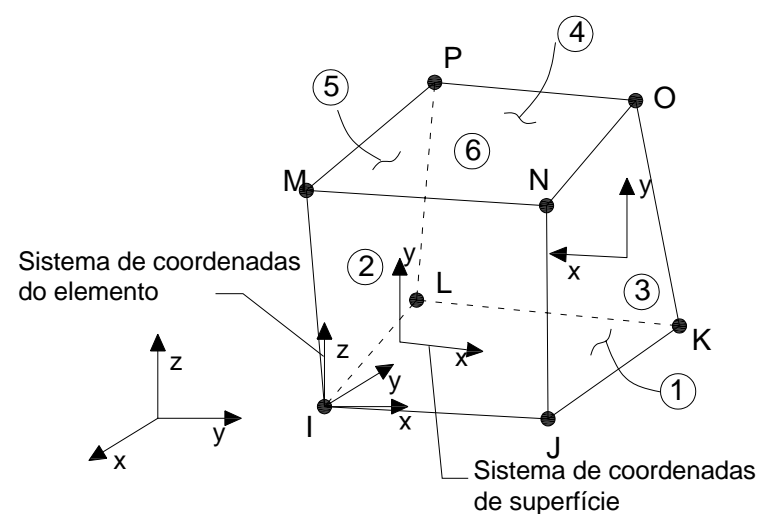

Figura 5.4 - Elemento finito SOLID45 


\subsubsection{CONTA174}

O elemento finito CONTA174 é utilizado, em análises tridimensionais, para representar o contato e o deslocamento entre a superfície rígida e a superfície deformável definida. As propriedades geométricas deste elemento variam de acordo com o tipo de elemento sobre o qual ele está aplicado.

O elemento CONTA174 possui três graus de liberdade em cada nó, sendo eles translações segundo os eixos $x, y$ e $z$.

\subsubsection{TARGE170}

O elemento finito TARGE170 é utilizado para representar várias superfícies rígidas tridimensionais associadas com os elementos de contato (CONTA 174). Os elementos de contato revestem os elementos sólidos (descrevendo o contorno do corpo deformável) e estão potencialmente ligados à superfície rígida. Esta superfície é discretizada pelos elementos TARGE170, formando par com a superfície de contato (CONTA174). O par de contato utilizado permite a consideração de atrito e coesão (adesão) entre as partes.

O elemento TARGE170 possui três graus de liberdade em cada nó, sendo eles translações segundo os eixos $x, y$ e $z$.

É importante ressaltar que as direções dos vetores normais às superfícies dos elementos finitos CONTA174 e TARGE170 devem estar em sentido contrário (Figura $5.5)$.

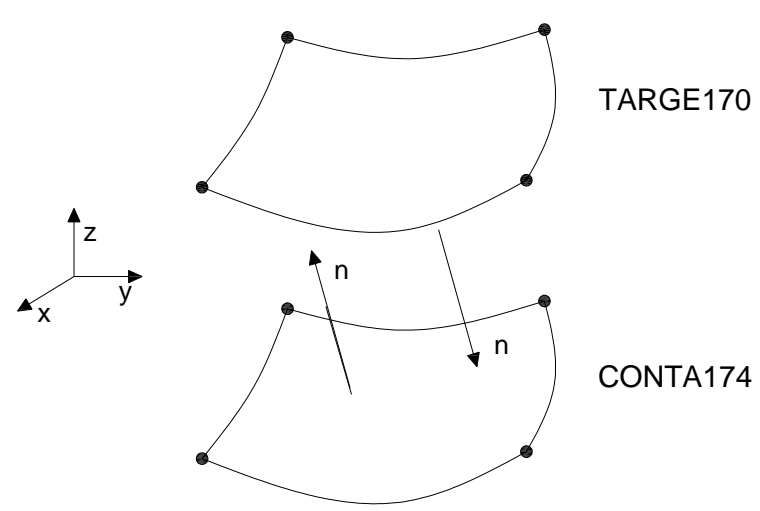

Figura 5.5 - Elementos finitos TARGE170 e CONTA174 


\subsection{Análise numérica}

Neste item será apresentada a simulação numérica referente aos ensaios de arrancamento realizados conforme as prescrições da RILEM-FIP-CEB (1973). Os modelos numéricos desenvolvidos foram divididos conforme a Tabela 5.1

Tabela 5.1 - Modelos de arrancamento utilizados na simulação numérica

\begin{tabular}{c|c|c}
\hline Modelo & $\begin{array}{c}\text { Diâmetro da barra } \\
(\mathrm{mm})\end{array}$ & $\begin{array}{c}\text { Resistência à compressão } \\
\text { do concreto (MPa) }\end{array}$ \\
\hline C30B9 & 9 & 30 \\
\hline C30B16 & 16 & 30 \\
\hline C60B9 & 9 & 60 \\
\hline C60B16 & 16 & 60 \\
\hline C80B9 & 9 & 80 \\
\hline C80B16 & 16 & 80 \\
\hline
\end{tabular}

Sendo que, C30, C60 e C80 correspondem a classe de resistência à compressão do concreto (30 MPa, $60 \mathrm{MPa}$ e $80 \mathrm{MPa}$, respectivamente) e B9 e B16 correspondem ao diâmetro da barra (9 $\mathrm{mm}$ e $16 \mathrm{~mm}$, respectivamente).

As Figuras 5.6 e 6.7 ilustram a discretização adotada para os modelos numéricos, bem como o ponto de medição de deslocamento e força (Ponto 11). Em virtude da simetria do modelo de arrancamento, utilizou-se para a simulação numérica, $1 / 4$ do modelo.

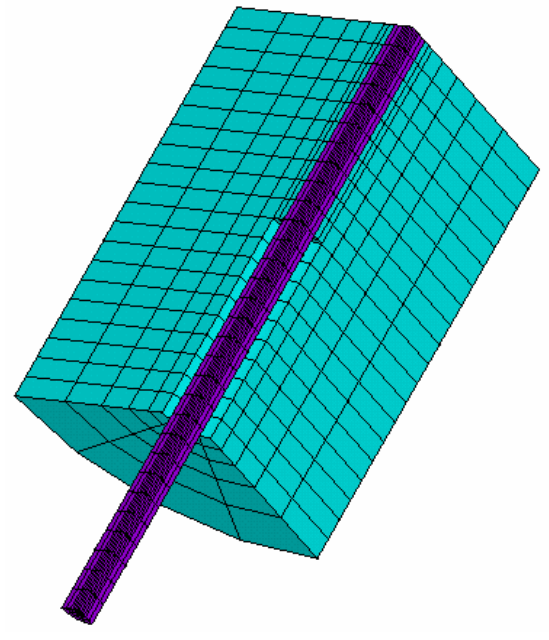

a) Modelo completo
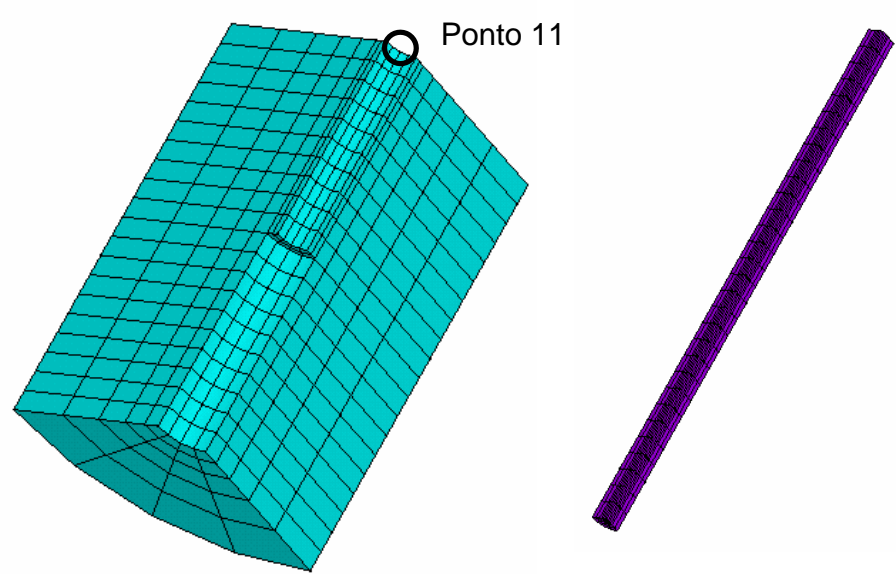

Figura 5.6 - Discretização dos modelos numéricos com barra de $9 \mathrm{~mm}$ 


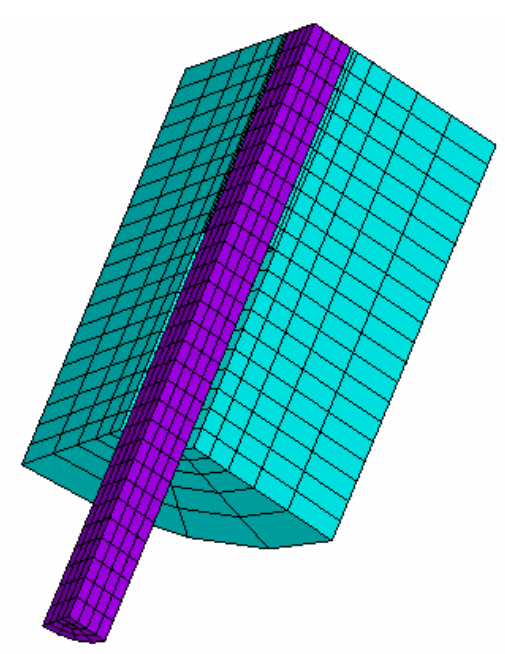

$\begin{array}{lll}\text { a) Modelo completo } & \text { b) Prisma de concreto } & \text { c) Barra de GFRP }\end{array}$
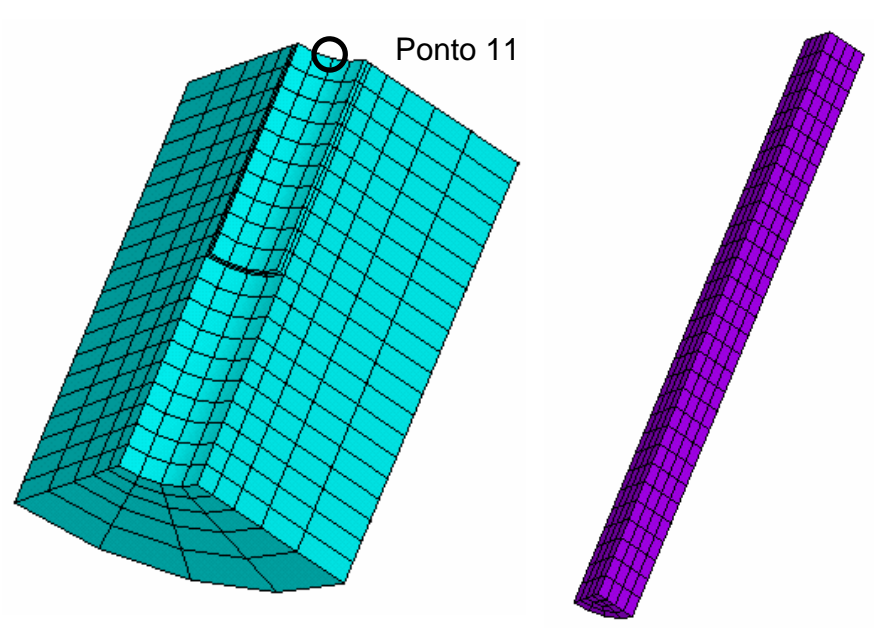

Figura 5.7 - Discretização dos modelos numéricos com barra de 16 mm

Os elementos finitos empregados no desenvolvimento dos modelos numéricos estão resumidos na Tabela 5.2, bem como a quantidade utilizada para cada modelo.

Tabela 5.2 - Quantidade de elementos finitos utilizados por modelo numérico

\begin{tabular}{c|c|c}
\hline \multirow{2}{*}{ Elemento } & \multicolumn{2}{|c}{ Modelo } \\
\cline { 2 - 3 } & C30B9, C60B9 e C80B9 & C30B16, C60B16 e C80B16 \\
\hline SOLID65 & 480 unid./modelo & 480 unid./modelo \\
\hline SOLID45 & 600 unid./modelo & 360 unid./modelo \\
\hline CONTA174 & 40 unid./modelo & 40 unid./modelo \\
\hline TARGE170 & 40 unid./modelo & 40 unid./modelo \\
\hline
\end{tabular}

Para a simulação numérica foi utilizado o modelo de contato Bonded, presente no programa computacional Ansys, onde a superfície de contato possui aderência em todas as direções (uma vez que o contato seja estabelecido) para o restante da análise.

ALMEIDA FILHO et al. (2004) realizou um estudo paramétrico com o objetivo de avaliar o grau de influência das variáveis na interface aço-concreto presentes no programa Ansys, são elas: o parâmetro FKN (normal contact stiffness factor), a coesão (c), o coeficiente de atrito $(\mu)$ e a malha de elementos finitos. Concluiu-se então, que para o modelo de contato Bonded, independente do valor do coeficiente de atrito e da coesão, os valores se mantiveram inalterados, somente tendo como parâmetro de influência o FKN e a malha.

O valor do coeficiente de atrito e da coesão adotados neste trabalho foi de 0,75 e $0,75 \mathrm{kN} / \mathrm{cm}^{2}$, respectivamente. 


\subsubsection{Aplicação da ação}

O modelo numérico desenvolvido neste trabalho tem a finalidade de representar os resultados obtidos pelo ensaio de arrancamento. Para isto, foi aplicado um deslocamento no modelo correspondente ao deslocamento do pistão durante o ensaio, como mostra a Figura 5.8.

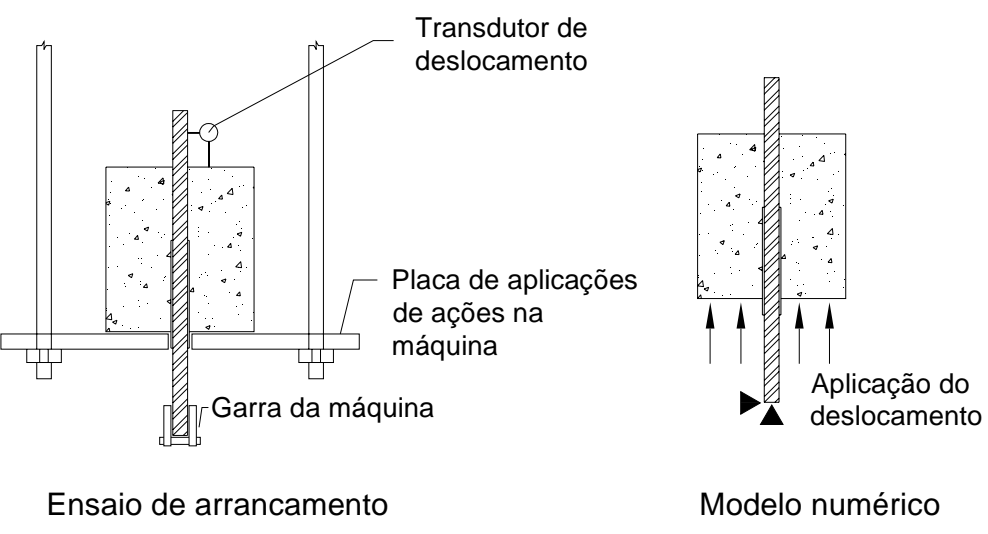

Figura 5.8 - Esquema do ensaio e aplicação do deslocamento no modelo numérico (Adaptado de ALMEIDA FILHO, 2006)

\subsubsection{Comportamento dos materiais}

Foi realizada a análise numérica linear do comportamento da aderência, com isto as propriedades mecânicas dos materiais constituintes foram consideradas elástico-lineares. A Tabela 5.3 mostra as propriedades dos materiais constituintes e a Figura 5.9 ilustra o comportamento das curvas tensão $x$ deformação para os concretos e as barras utilizadas.

Tabela 5.3 - Propriedades dos materiais constituintes utilizadas na analise numérica

\begin{tabular}{c|c|c|c}
\hline \multicolumn{5}{c}{ Barra } \\
\hline Diâmetro da barra (mm) & $\begin{array}{c}\text { Diâmetro nominal } \\
(\mathrm{mm})\end{array}$ & $\begin{array}{c}\text { Módulo de Elasticidade } \\
\text { longitudinal (MPa) }\end{array}$ & $\begin{array}{c}\text { Coeficiente de } \\
\text { Poisson }\end{array}$ \\
\hline 9 & 9,56 & 42,70 & 0,3 \\
\hline 16 & 15,88 & 44,90 & 0,3 \\
\hline \multicolumn{4}{|c|}{ Concreto } \\
Classe de resistência à & $\begin{array}{c}\text { Resistência à } \\
\text { compressão (MPa) }\end{array}$ & $\begin{array}{c}\text { Módulo de Elasticidade } \\
(\mathrm{MPa})\end{array}$ & $\begin{array}{c}\text { Coeficiente de } \\
\text { Poisson }\end{array}$ \\
\hline 30 & 34,6 & 32,53 & 0,2 \\
\hline 60 & 55,2 & 39,93 & 0,2 \\
\hline 80 & 81,3 & 40,50 & 0,2 \\
\hline
\end{tabular}



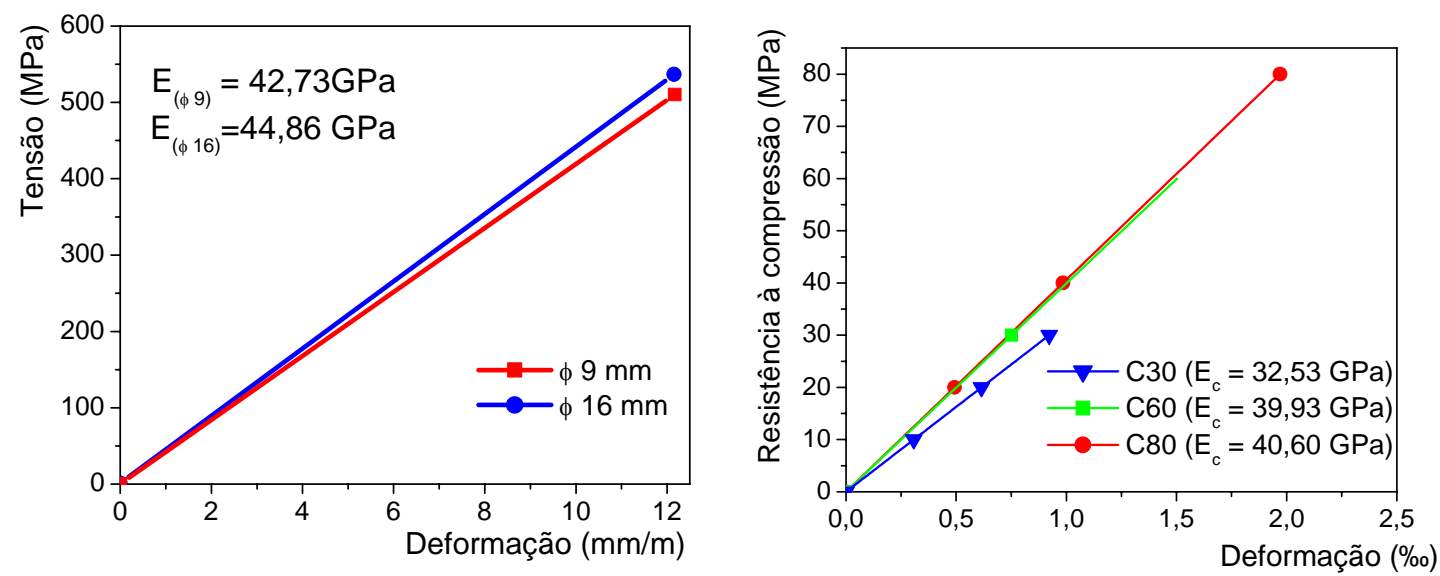

Figura 5.9 - a) Curva tensão x deformação das barras utilizadas na análise numérica;

b) Curva tensão $x$ deformação dos concretos utilizados na análise numérica.

\subsubsection{Valores experimentais adotados na simulação}

\section{numérica}

Os tipos de ruptura desenvolvidos por modelos de arrancamento, considerando os materiais aço e concreto, são: a ruptura por arrancamento da barra ou a ruptura por fendilhamento do concreto. A Figura 5.10 ilustra uma curva típica de tensão de aderência $\mathrm{x}$ deslocamento obtida por meio do ensaio de arrancamento em barra de aço e concreto de baixa resistência à compressão. Pode-se observar também a variação da resistência de aderência, do deslocamento relativo da barra, das tensões na barra de aço e os limites referentes à adesão, resistência ao atrito e o pós-pico até o arrancamento da barra.

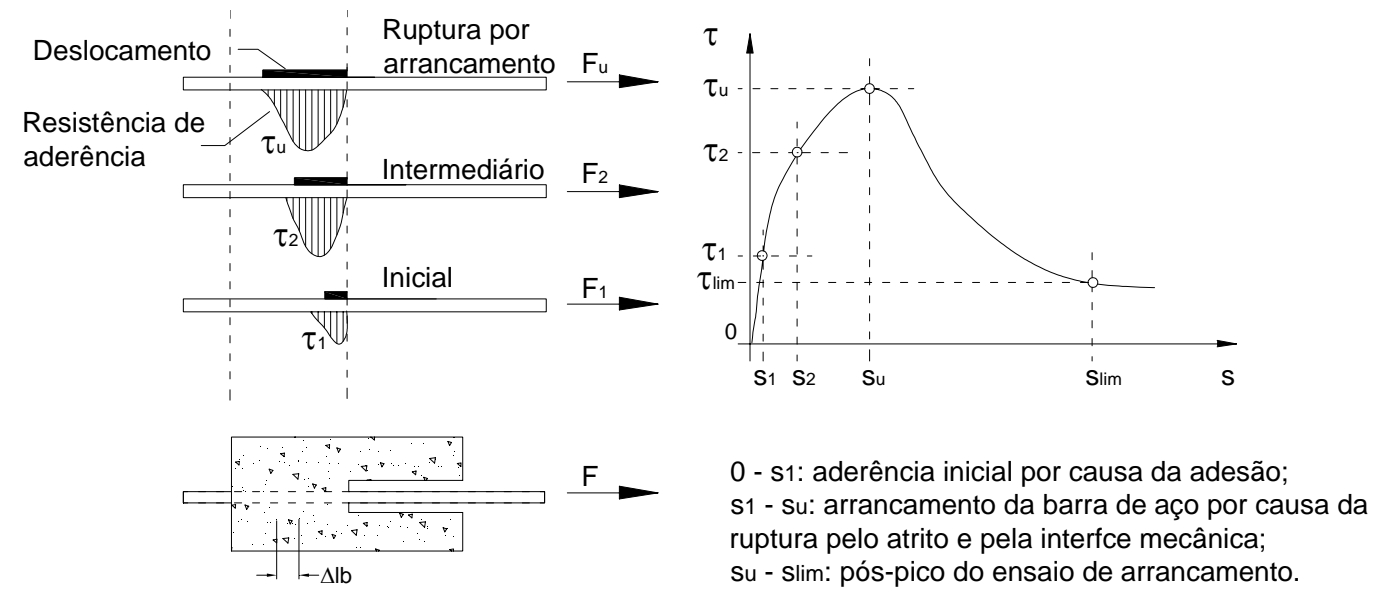

Figura 5.10 - Comportamento da resistência de aderência e do deslocamento no ensaio de arrancamento de modelos com barra de aço e concreto de baixa resistência à compressão

(ALMEIDA FILHO 2006) 
FERNANDES (2000) realizou a simulação numérica linear, por meio do programa computacional Ansys, do ensaio de arrancamento de uma barra de aço em um cilindro de concreto, conforme a recomendação da RILEM-FIB-CEB (1973). Para isto, foi levado em consideração o comportamento linear dos materiais e não-linear do contato. A Figura 5.11 mostra a comparação entre o resultado obtido experimentalmente e o resultado obtido na simulação numérica.

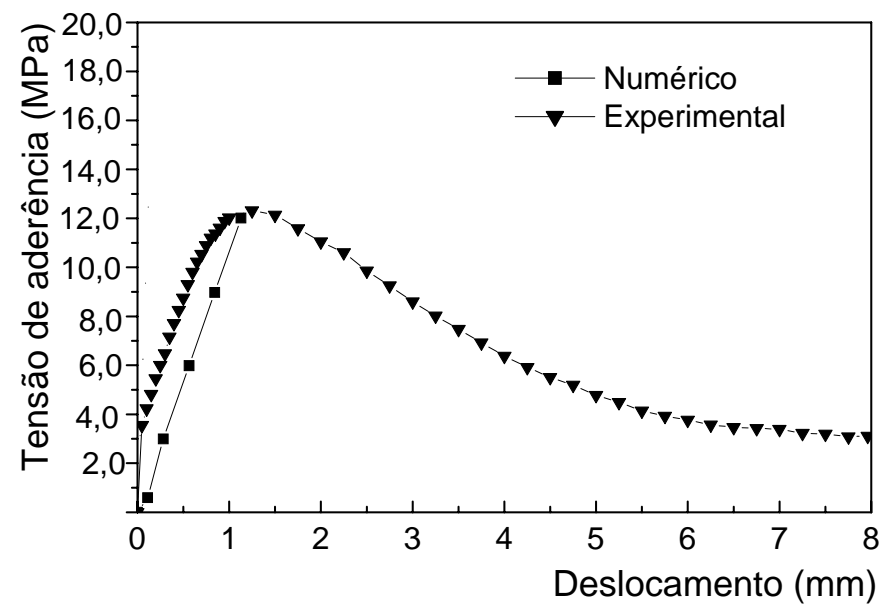

Figura 5.11 - Curva tensão de aderência x deslocamento para o modelo de arrancamento segundo FERNANDES (2000)

Para a simulação numérica do modelo de arrancamento, FERNANDES (2000) considerou o deslocamento último, $\mathrm{s}_{u}$, igual a 1,25 mm. Então, a resistência última de aderência obtida numericamente foi comparada com a resistência última de aderência obtida experimentalmente.

O comportamento da curva tensão de aderência $x$ deslocamento encontrado para os modelos de arrancamento com barra de GFRP foi diferente do comportamento conhecido para os modelos de arrancamento com barra de aço (Figura 5.10). Nos modelos com barra de GFRP ocorreu ruptura combinada, não foi observado um pico no diagrama tensão de aderência $\mathrm{x}$ deslocamento, o qual representaria a resistência última de aderência e o deslocamento último (Figura 5.12).

A simulação numérica linear não consegue representar de maneira satisfatória a ruptura combinada desenvolvida nos modelos com barra de GFRP (Figura 5.12-a). Assim, buscou-se por meio da simulação numérica representar o primeiro trecho do diagrama força $x$ deslocamento, adotando o deslocamento referente ao ponto 1 do gráfico. A força obtida experimentalmente é então comparada com o valor da força última encontrado na simulação numérica (Figura 5.12-b). 


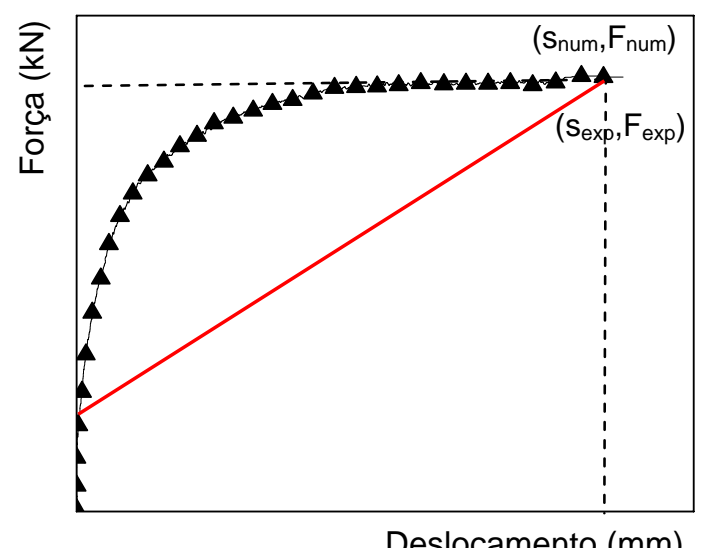

(a)

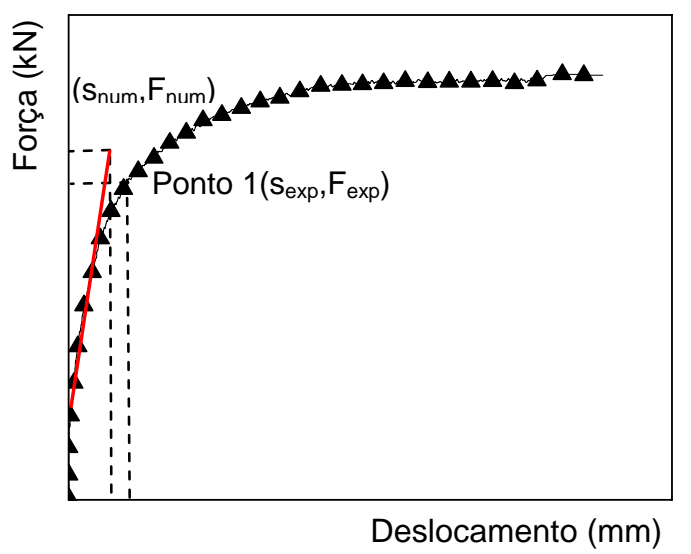

(b)

Figura 5.12 - Comportamento experimental e numérico para o modelo de arrancamento com barra de GFRP

A Tabela 5.4 mostra os resultados obtidos nos ensaios de arrancamento, os quais foram adotados para a realização da simulação numérica.

Tabela 5.4 - Resultados obtidos nos ensaios de arrancamento

\begin{tabular}{c|c|c|c}
\hline Modelo & $F_{\text {exp }}(\mathrm{kN})$ & $\tau_{\exp }(\mathrm{MPa})$ & $S_{\text {exp }}(\mathrm{mm})$ \\
\hline C30B9 & 4,75 & 3,31 & 0,21 \\
\hline C30B16 & 24,96 & 6,30 & 0,44 \\
\hline C60B9 & 11,10 & 7,73 & 0,48 \\
\hline C60B16 & 44,87 & 11,33 & 0,30 \\
\hline C80B9 & 12,97 & 9,04 & 0,34 \\
\hline C80B16 & 61,24 & 15,46 & 0,28 \\
\hline
\end{tabular}

Sendo que, " $F_{\exp }$ " corresponde ao valor da força referente ao Ponto 1 do gráfico força $x$ deslocamento, " $\tau_{\exp }$ " a resistência aderência no Ponto 1 e "s" o deslocamento da barra em relação ao concreto também no Ponto 1.

Por fim, para calibrar os resultados experimentais foi necessário ajustar as constantes do contato FKT e FKN (responsáveis pela influência da superfície normal e tangencial do contato) de modo que os valores encontrados na simulação numérica para tensão de aderência representassem, de maneira satisfatória, os resultados obtidos experimentalmente. 


\subsection{Resultados}

Inicialmente, foi realizado um estudo paramétrico com diferentes valores para os coeficientes FKT e FKN, que correspondem às constantes do contato, com a finalidade de avaliar a influência destes parâmetros nos resultados obtidos (Figuras $5.13,5.14$ e 5.15$)$.

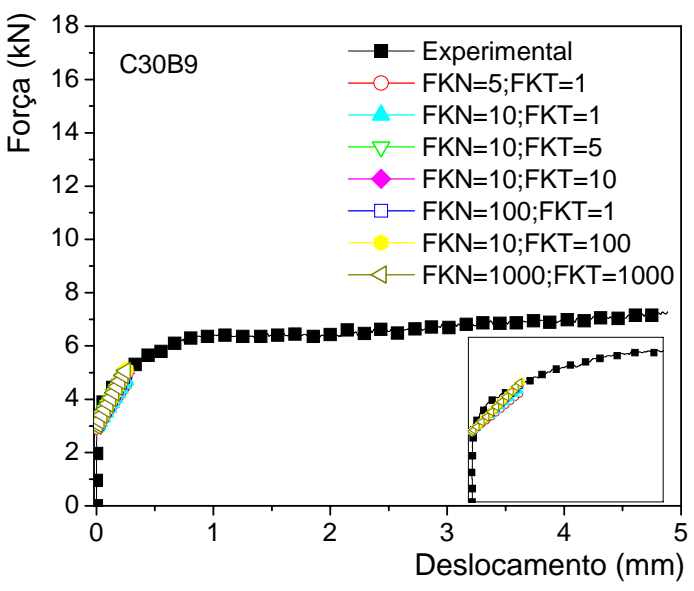

(a)

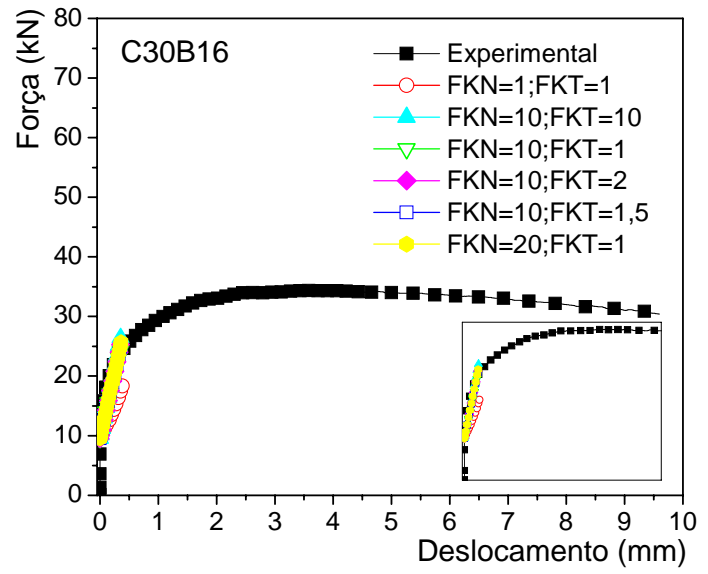

(b)

Figura 5.13 - Comparação entre o resultado numérico e o experimental para os modelos de arrancamento das séries C30B9 e C30B16

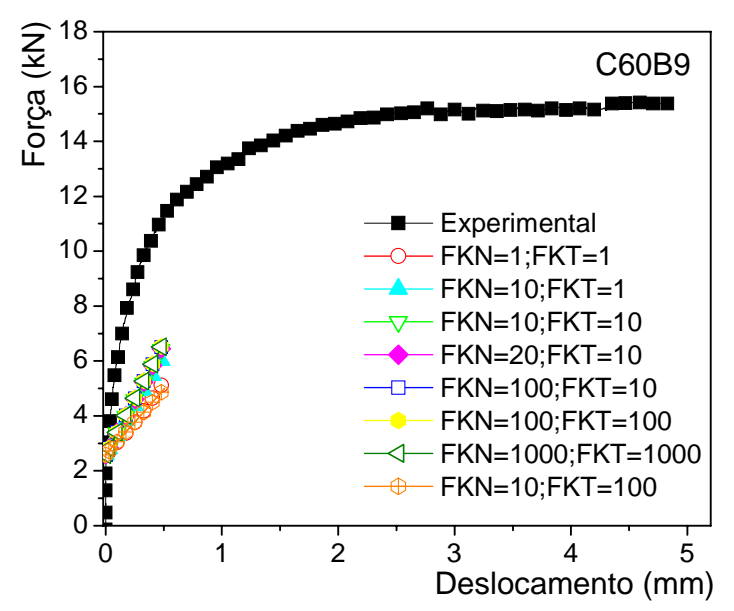

(a)

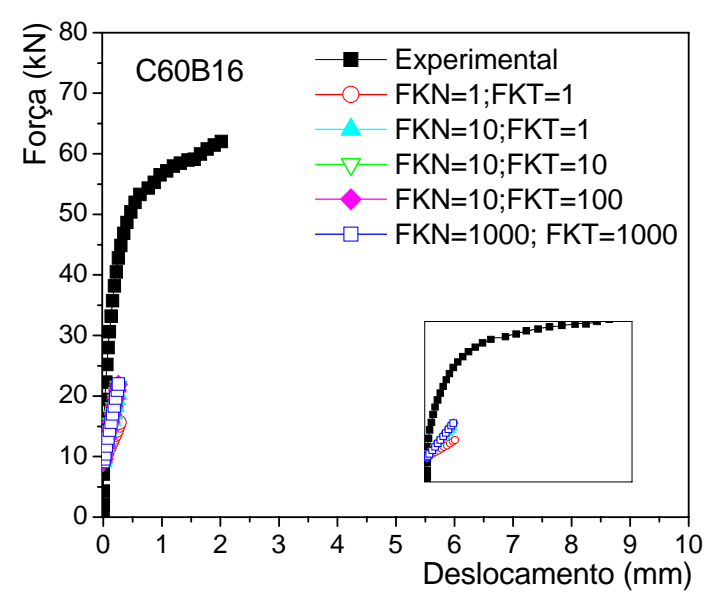

(b)

Figura 5.14 - Comparação entre o resultado numérico e o experimental para os modelos de arrancamento das séries C60B9 e C60B16. 


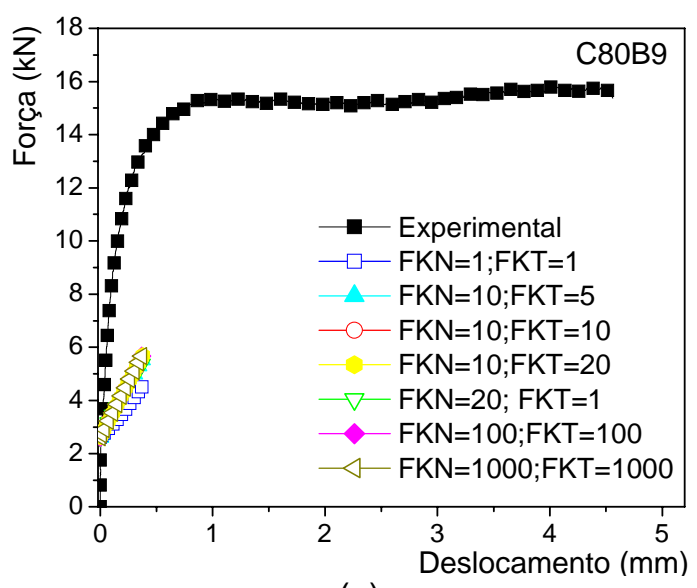

(a)

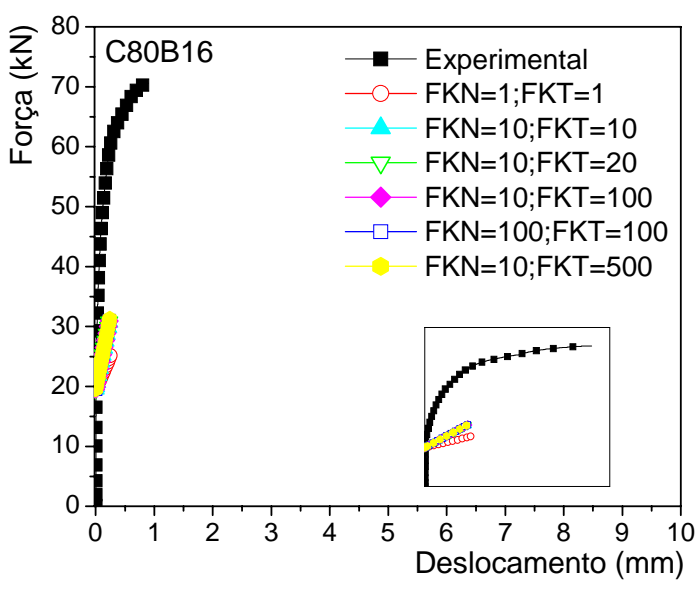

(b)

Figura 5.15 - Comparação entre o resultado numérico e o experimental para os modelos de arrancamento das séries C80B9 e C80B16.

Com base no estudo paramétrico percebeu-se que os valores das constantes FKT e FKN exercem influência nos resultados encontrados para a resistência última de aderência onde se utilizou concreto de resistência à compressão de $30 \mathrm{MPa}$.

Nas séries onde se utilizaram concretos de alta resistência à compressão (60 MPa e $80 \mathrm{MPa}$ ) a simulação numérica linear não representou, de maneira satisfatória, o valor para resistência última de aderência, ficando bem abaixo do valor encontrado na investigação experimental (Figuras 5.15 e 5.16), ou seja, os modelos numéricos utilizados não foram aplicáveis para concretos de alta resistência à compressão. Isto pode ser explicado pelo fato do módulo de elasticidade dos concretos em questão serem próximos do módulo de elasticidade da barra de GFRP (o comportamento do modelo passa de heterogêneo para homogêneo), com isto, os valores dos parâmetros FKT e FKN não são suficientes para aumentar a inclinação da reta força $x$ deslocamento, obtendo assim melhor representatividade dos resultados.

Os diagramas força $x$ deslocamento obtidos por meio da simulação numérica não representaram comportamento encontrado na investigação experimental, não foi possível representar a ruptura combinada desenvolvida pelos modelos. Para uma melhor representação do comportamento da aderência seria necessária a realização da analise numérica não linear.

Os resultados numéricos que melhor se aproximaram dos experimentais estão resumidos na Tabela 5.5. 
Tabela 5.5 - Comparação entre os valores obtidos experimentalmente e numericamente

\begin{tabular}{c|c|c|c|c|c|c|c|c}
\hline \multirow{2}{*}{ Série } & \multirow{2}{*}{$F K N$} & \multirow{2}{*}{$F K T$} & \multicolumn{3}{|c|}{$F(k N)$} & \multicolumn{3}{c}{$s(\mathrm{~mm})$} \\
\cline { 4 - 9 } & & & Exp. & Num. & $\lambda$ & Exp. & Num. & $\lambda$ \\
\hline C30B9 & 10 & 1 & 4,75 & 4,78 & 0,994 & 0,210 & 0,25 & 0,826 \\
\hline C30B16 & 10 & 1 & 24,96 & 24,70 & 1,010 & 0,440 & 0,36 & 1,211 \\
\hline C60B9 & 20 & 10 & 11,10 & 6,67 & 1,664 & 0,475 & 0,51 & 0,935 \\
\hline C60B16 & 10 & 100 & 44,87 & 22,29 & 2,013 & 0,301 & 0,27 & 1,134 \\
\hline C80B9 & 10 & 20 & 12,97 & 5,71 & 2,274 & 0,340 & 0,38 & 0,893 \\
\hline C80B16 & 10 & 500 & 61,24 & 31,27 & 1,959 & 0,28 & 0,24 & 1,166 \\
\hline
\end{tabular}

Sendo que, FKN e FKT correspondem a constantes do contato, $\tau_{\mathrm{u}}$ corresponde a resistência última de aderência e $\lambda$ corresponde a relação entre 0 resultado experimental e o resultado numérico.

De acordo com a Tabela 5.5, os valores de força obtidos numericamente para as séries C30B9 e C30B16 foram próximos dos valores obtidos experimentalmente (variando aproximadamente 1\%). O mesmo não foi observado para o deslocamento, que apresentou variação de aproximadamente $20 \%$ nas duas séries de arrancamento.

Para as séries com concreto de alta resistência à compressão (C60B9, C60B16, C80B9 e C80B16), os valores de força obtidos numericamente não foram representativos dos valores encontrados na investigação experimental, apresentado variação no resultado em mais de $100 \%$. Para o deslocamento, a variação dos resultados numéricos em relação aos resultados experimentais foi menor (aproximadamente 7\% para a série C60B9 e 17\% para a série C80B16).

\subsection{Considerações finais}

Este capítulo tratou da análise numérica realizada para avaliação da força de aderência. Pode-se concluir parcialmente que:

- Os valores das constantes FKN e FKT exerceram influência nos resultados obtidos numericamente, porém quando se consideram concretos de alta resistência à compressão esta influência não é muito significativa;

- Encontrou-se boa aproximação entre os resultados obtidos por meio da simulação numérica e os ensaios de arrancamento quando utilizou concreto de resistência à compressão de $30 \mathrm{MPa}$; 
- Para as séries com concreto de resistência à compressão de 60 MPa e $80 \mathrm{MPa}$, não obteve boa aproximação entre os resultados obtidos numericamente e experimentalmente para 0 valor da força de aderência;

- Para melhor representação do comportamento da aderência entre as barras de GFRP e o concreto é justificado o desenvolvimento da simulação numérica não linear. 


\section{ANÁLISE E DISCUSSÃO DOS RESULTADOS}

\subsection{Considerações iniciais}

Neste capítulo serão analisados e discutidos os resultados obtidos por meio da investigação experimental e numérica. Os resultados experimentais serão comparados com os resultados obtidos por outros autores e por formulações provenientes de algumas normas.

Será analisada a influência da resistência do concreto e do diâmetro da barra de GFRP no comportamento da aderência, além disto, será realizada a comparação dos resultados obtidos com modelos de arrancamento de barras de GFRP com modelos de arrancamento de barras de aço disponíveis na literatura técnica.

Por fim, os modelos experimentais de arrancamento serão confrontados com os respectivos modelos numéricos.

\subsection{Critérios para a análise dos resultados}

Para a avaliação da variabilidade encontrada nos resultados experimentais, dois critérios foram utilizados na análise dos resultados: o desvio padrão (D.P.) e o coeficiente de variação (C.V.).

O coeficiente de variação $(\mathrm{CV})$ é uma análise estatística preliminar que pretende avaliar a variação dos resultados de um experimento. Esse procedimento é empregado quando se deseja comparar a variabilidade de várias amostras com o seu valor médio.

BARBOSA (2001) E FRANÇA (2004); realizaram a análise estatística dos resultados experimentais da aderência barra de aço-concreto e adotaram como valor limite do coeficiente de variação igual a $25 \%$, ou seja, se o valor de CV é menor que $25 \%$ a amostra será aceita.

ALMEIDA FILHO (2006) estabeleceu três valores limites para o coeficiente de variação, visando maior controle de qualidade das amostras estudadas. Para a classe 
de qualidade $A$ (excelente), o limite aceito para o coeficiente de variação foi de $10 \%$, para a classe $B$ (médio) o limite de CV foi de $15 \%$ e para a classe $C$ (pobre) o limite de CV foi de $20 \%$.

Neste trabalho, será adotado como critério de qualidade os valores limites de coeficiente de variação estabelecidos por ALMEIDA FILHO (2006), pois o controle de qualidade assegurado é mais rigoroso.

\subsection{Parâmetros estatísticos utilizados}

Os parâmetros estatísticos utilizados na análise dos resultados foram: média, desvio padrão (D.P.), coeficiente de variação (C.V.) e Bias Factor ( $\lambda$ ).

\subsubsection{Média}

A media consiste na relação entre e a soma dos valores obtidos e o número de amostras.

$$
M=\frac{\sum_{1}^{n} x_{i}}{n}
$$

\subsubsection{Desvio padrão}

O desvio padrão consiste na relação entre o valor da amostra e a média da população e o tamanho da população menos um.

$$
D P=\sqrt{\frac{\sum_{1}^{n}\left(x_{i}-M\right)^{2}}{(n-1)}}
$$

\subsubsection{Coeficiente de variação}

O coeficiente de variação consiste na relação entre o desvio padrão e a média.

$$
C V=\frac{D P}{M}
$$

\subsubsection{Bias Factor}

O Bias Factor consiste na relação entre o valor médio experimental e o valor previsto (V.P.) por uma formulação.

$$
\lambda=\frac{M}{V P}
$$




\subsection{Propriedades mecânicas dos concretos}

As propriedades mecânicas dos concretos desenvolvidos neste trabalho (Capítulo 4) foram comparadas com as especificações disponíveis nos Códigos Normativos: NBR 6118:2003, EUROCODE (2002) e ACI 318 (1999).

A Tabela 6.1 resume as propriedades mecânicas dos concretos utilizados.

Tabela 6.1 - Propriedades mecânicas dos concretos

\begin{tabular}{c|c|c|c}
\hline $\begin{array}{c}\text { Classe de resistência } \\
\text { do concreto }\end{array}$ & $f_{c}(\mathrm{MPa})$ & $f_{t}(\mathrm{MPa})$ & $E_{c}(\mathrm{GPa})$ \\
\hline C30 & 34,6 & 2,2 & 32,53 \\
\hline C60 & 55,2 & 3,8 & 39,93 \\
\hline C80 & 81,3 & 5,4 & 40,60 \\
\hline
\end{tabular}

A Tabela 6.2 mostra as formulações para previsão do módulo de elasticidade tangente $\left(E_{c}\right)$ e resistência à tração $\left(f_{t}\right)$ do concreto de acordo com os códigos normativos.

Tabela 6.2 - Formulações para previsão de módulo de elasticidade e resistência à tração do concreto

\begin{tabular}{c|c|c}
\hline & $E_{c}(\mathrm{GPa})$ & $f_{t}(\mathrm{MPa})$ \\
\hline NBR 6118:2003 & $E_{c}=5,6 \cdot \sqrt{f_{c}}$ & $f_{t}=0,3 \cdot f_{c}^{2 / 3}$ \\
\hline $\begin{array}{c}\text { EUROCODE } \\
(2002)\end{array}$ & $E_{c}=22 \cdot \sqrt[3]{f_{c} / 10}$ & $f_{t}=0,3 \cdot\left(f_{c}-8\right)^{2 / 3} \rightarrow f_{c k} \leq 60$ \\
$f_{t}=2,12 \cdot \ln \left(1+\frac{f_{c}}{10}\right) \rightarrow f_{c k}>60$ \\
\hline $\mathrm{ACl} 318(1999)$ & $E_{c}=4,7 \cdot \sqrt{f_{c}}$ & $f_{t}=0,56 \cdot \sqrt{f_{c}}$ \\
\hline
\end{tabular}

A Tabela 6.3 e a Figura 6.1 apresentam as comparações dos resultados experimentais com as previsões dos códigos normativos para módulo de elasticidade e resistência à tração para concretos estudados.

Vale ressaltar que a NBR 6118:2003 não apresenta uma formulação para a previsão do módulo de elasticidade de concretos com resistência à compressão maior do que $50 \mathrm{MPa}$. Com isto, os valores do módulo de elasticidade apresentado na Tabela 6.3, de acordo com a NBR 6118:2003, para os concretos da classe de resistência à compressão C60 e C80 foram considerados apenas como ilustração. 
Tabela 6.3 - Comparação do módulo de elasticidade e resistência à tração entre os resultados experimentais e os valores previstos pelos códigos normativos (Bias Factor)

\begin{tabular}{c|c|c|c|c|c}
\hline \multirow{2}{*}{ Códigos Normativos } & \multirow{2}{*}{$f_{c}(\mathrm{MPa})$} & \multicolumn{2}{|c|}{$E_{c}(\mathrm{GPa})$} & \multicolumn{2}{c}{$f_{t}(\mathrm{MPa})$} \\
\cline { 3 - 6 } & & V.P. & $\lambda$ & V.P. & $\lambda$ \\
\hline \multirow{3}{*}{ NBR 6118:2003 } & 34,6 & 32,94 & 0,99 & 3,2 & 0,69 \\
\cline { 2 - 6 } & 55,2 & 41,61 & 0,96 & 4,3 & 0,87 \\
\cline { 2 - 6 } & 81,3 & 50,49 & 0,80 & 5,6 & 0,96 \\
\hline \multirow{3}{*}{ EUROCODE (2002) } & 34,6 & 33,27 & 0,98 & 2,7 & 0,82 \\
\cline { 2 - 6 } & 55,2 & 38,88 & 1,03 & 3,9 & 0,97 \\
\cline { 2 - 6 } & 81,3 & 44,24 & 0,92 & 4,7 & 1,15 \\
\hline \multirow{3}{*}{ ACI 318 (1999) } & 34,6 & 27,65 & 1,18 & 3,3 & 0,67 \\
\cline { 2 - 6 } & 55,2 & 34,92 & 1,14 & 4,2 & 0,91 \\
\cline { 2 - 6 } & 81,3 & 42,38 & 0,96 & 5,0 & 1,07 \\
\hline
\end{tabular}
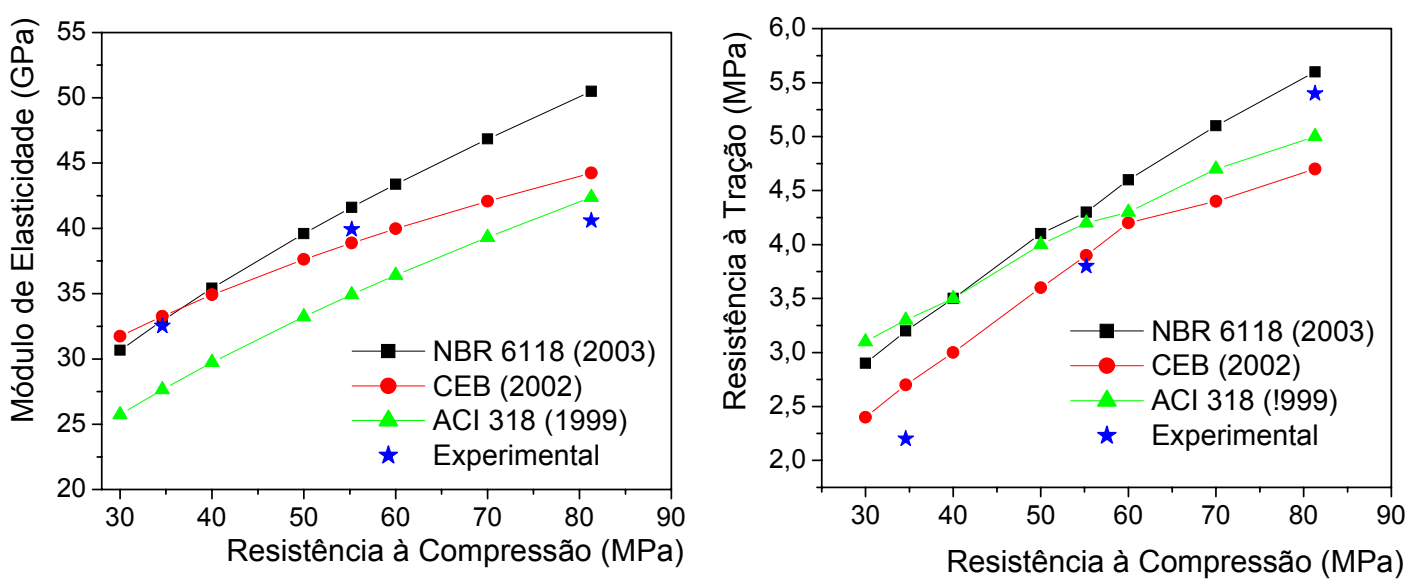

Figura 6.1 - Comparação do módulo de elasticidade e resistência à tração entre os resultados experimentais e os códigos normativos

De acordo com os valores apresentados na Tabela 6.3 e Figura 6.1, observouse que alguns códigos normativos estimaram para maior os valores do módulo de elasticidade e resistência à tração dos concretos estudados, apresentando valores contra a segurança. Porém, para melhor avaliação dos resultados experimentais e consequentemente, das formulações fornecidas pelos códigos, é necessário uma maior quantidade de repetições para a obtenção de um valor médio mais confiável.

Com relação ao módulo de elasticidade, a NBR 6118:2003 apresentou resultados contra a segurança para as três classes de resistência do concreto estudadas. O ACI 318 (1999) apresentou os melhores resultados para o módulo de elasticidade, com os valores a favor da segurança, exceto no caso do concreto com resistência à compressão de $80 \mathrm{MPa}$.

No caso da resistência à tração, os códigos apresentaram valores estimados para maior, contra a segurança, exceto para o concreto de $80 \mathrm{MPa}$, onde no 
EUROCODE (2002) e no ACl (1999) os valores foram menores que os encontrados experimentalmente.

\subsection{Propriedades mecânicas das barras de GFRP}

A Figura 6.2 ilustra o comportamento médio das curvas tensão $x$ deformação para as barras de GFRP utilizadas na investigação experimental.
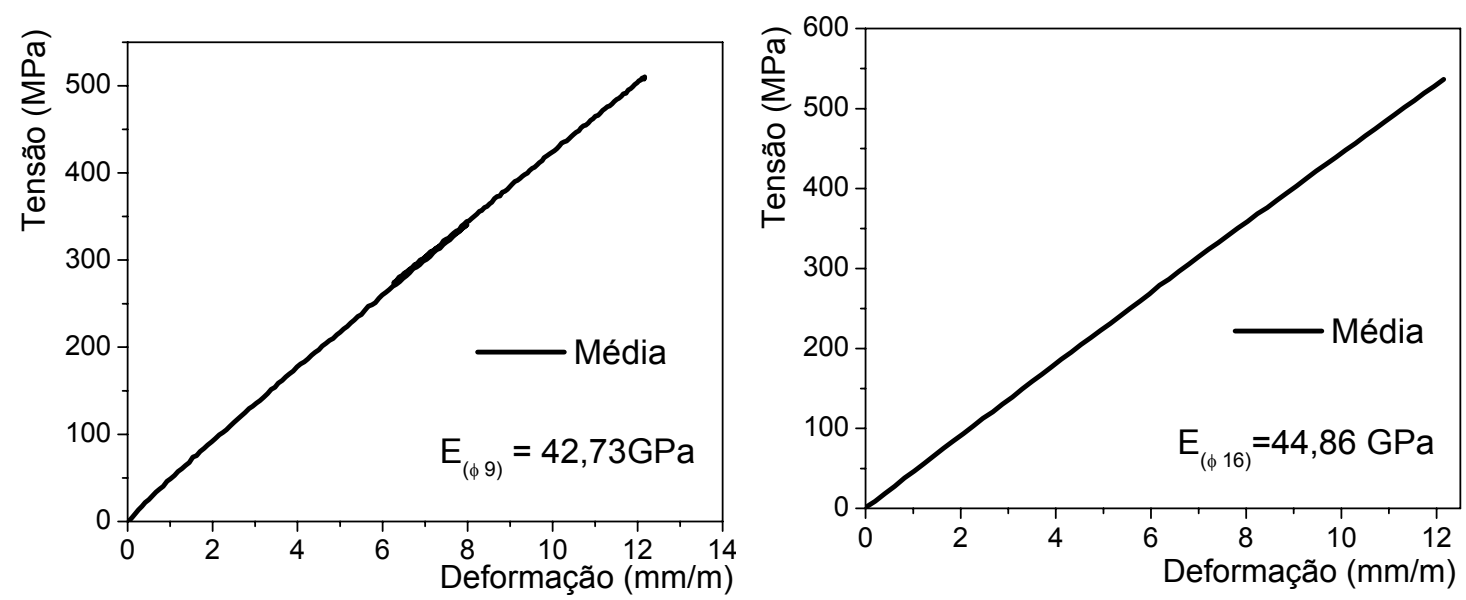

Figura 6.2 - a) Comportamento médio das barras de GFRP com diâmetro de 9 mm; b) Comportamento médio das barras de GFRP com diâmetro de $16 \mathrm{~mm}$

Como comentado no Capítulo 4, as barras ensaiadas não alcançaram a resistência última fornecida pelo fabricante, em virtude da ruptura prematura da barra junto ao dispositivo de ancoragem. O ACl 440 1R (2003) relata a dificuldade na realização deste ensaio e que as propriedades mecânicas das barras de FRP podem ser obtidas de acordo com o fabricante.

A comparação dos resultados obtidos experimentalmente com os valores fornecidos pelo fabricante das barras está representada na Tabela 6.4.

Tabela 6.4 - Comparação das propriedades mecânicas das barras de GFRP

\begin{tabular}{c|c|c|c|c|c|c}
\hline Diâmetro da barra & \multicolumn{3}{|c|}{$9 \mathrm{~mm}$} & \multicolumn{3}{c}{$16 \mathrm{~mm}$} \\
\hline $\begin{array}{c}\text { Diâmetro nominal } \\
(\mathrm{mm})\end{array}$ & Exp. & Fab. & $\lambda$ & Exp. & Fab. & $\lambda$ \\
\hline $\begin{array}{c}\text { Módulo de elasticidade } \\
\text { longitudinal (GPa) }\end{array}$ & 4,56 & 9,53 & 1,00 & 15,90 & 15,88 & 1,00 \\
\hline $\begin{array}{c}\text { Resistência última } \\
(\mathrm{MPa})\end{array}$ & 714 & 760 & 0,94 & 624 & 655 & 0,95 \\
\hline
\end{tabular}


De acordo com a Tabela 6.4, o módulo de elasticidade obtido experimentalmente foi maior $5 \%$ e $10 \%$ quando comparado aos valores fornecidos pelo fabricante para as barras com diâmetro de $9 \mathrm{~mm}$ e $16 \mathrm{~mm}$, respectivamente. Com relação à resistência última, as barras tiveram variações de $-6 \%$ e $-5 \%$ quando comparados aos valores fornecidos pelo fabricante para os diâmetros de $9 \mathrm{~mm}$ e 16 $\mathrm{mm}$, respectivamente.

\subsection{Ensaios de arrancamento}

\subsubsection{Série C30B9}

A Figura 6.3 ilustra o comportamento das curvas tensão de aderência $x$ deslocamento para os modelos de arrancamento da série C30B9.

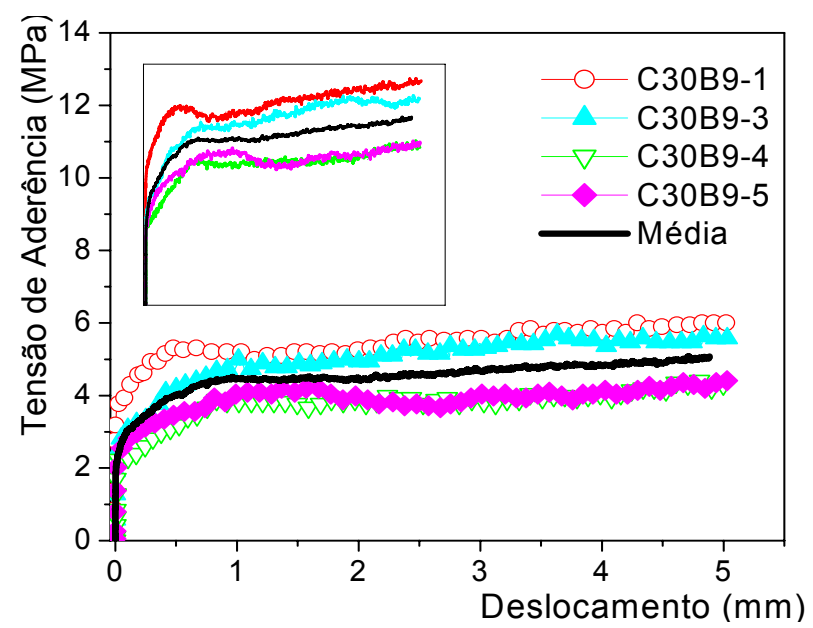

Figura 6.3 - Comportamento dos modelos de arrancamento da série C30B9

A Tabela 6.5 mostra a variação dos resultados obtidos nos ensaios de arrancamento.

Tabela 6.5 - Resultados obtidos nos ensaios de arrancamento da série C30B9

\begin{tabular}{c|c|c|c|c|c|c|c|c}
\hline Modelo & $\begin{array}{c}F_{u} \\
(\mathrm{kN})\end{array}$ & $\begin{array}{c}\mathrm{s}_{u} \\
(\mathrm{~mm})\end{array}$ & $\begin{array}{c}\tau_{0,01} \\
(\mathrm{MPa})\end{array}$ & $\begin{array}{c}\tau_{0,1} \\
(\mathrm{MPa})\end{array}$ & $\begin{array}{c}\tau_{1,0} \\
(\mathrm{MPa})\end{array}$ & $\begin{array}{c}\tau_{u} \\
(\mathrm{MPa})\end{array}$ & $\begin{array}{c}\tau_{m} \\
(\mathrm{MPa})\end{array}$ & Ruptura \\
\hline C30B9-1 & 8,85 & 4,85 & 3,56 & 4,20 & 5,16 & 6,17 & 4,31 & $\mathrm{~A}^{*}$ \\
\hline C30B9-3 & 8,16 & 4,92 & 2,39 & 3,03 & 4,84 & 5,69 & 3,42 & $\mathrm{~A}$ \\
\hline C30B9-4 & 6,41 & 4,96 & 2,13 & 2,29 & 4,04 & 4,46 & 2,82 & $\mathrm{~A}$ \\
\hline C30B9-5 & 6,41 & 4,91 & 2,18 & 2,55 & 4,04 & 4,46 & 2,92 & $\mathrm{~A}$ \\
\hline Média & 7,46 & 4,91 & 2,56 & 3,02 & 4,52 & 5,20 & 3,37 & \\
\hline D. P. & 1,243 & 0,046 & 0,674 & 0,846 & 0,567 & 0,866 & 0,679 & \\
\hline C. V. & $16,67 \%$ & $0,93 \%$ & $26,29 \%$ & $28,06 \%$ & $12,56 \%$ & $16,67 \%$ & $20,17 \%$ & \\
\hline
\end{tabular}

*- ruptura por arrancamento da barra. 
De acordo com a Tabela 6.5, pode-se observar grande variabilidade nos resultados, principalmente nas tensões de aderência correspondentes a $\tau_{0,01}, \tau_{0,1}$ e $\tau_{m}$ (26,29\%, $28,06 \%$ e $20,17 \%$, respectivamente).

A variabilidade dos resultados pode ser atribuída à pequena dimensão dos modelos de arrancamento e do comprimento de aderência, pois a menor variação em seu comprimento de ancoragem pode acarretar grande variação dos resultados (ALMEIDA FILHO, 2006).

\subsubsection{Série C30B16}

A Figura 6.4 representa o comportamento das curvas tensão de aderência $x$ deslocamento para os modelos de arrancamento da série C30B16

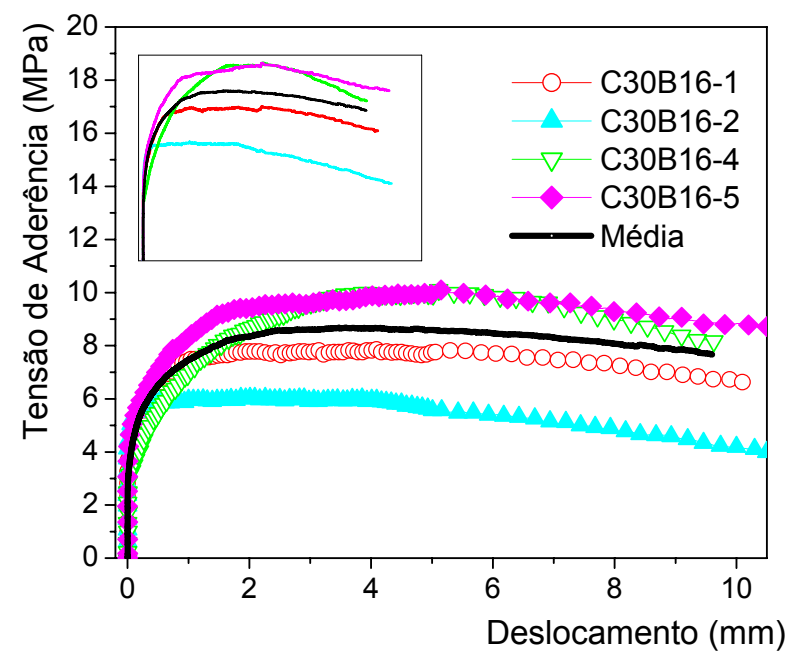

Figura 6.4 - Comportamento dos modelos de arrancamento da série C30B9

A Tabela 6.6 mostra a variação dos resultados obtidos nos ensaios de arrancamento para a série C30B16.

Tabela 6.6 - Resultados obtidos nos ensaios de arrancamento da série C30B16

\begin{tabular}{c|c|c|c|c|c|c|c|c}
\hline Modelo & $\begin{array}{c}F_{u} \\
(\mathrm{kN})\end{array}$ & $\begin{array}{c}\mathrm{s}_{u} \\
(\mathrm{~mm})\end{array}$ & $\begin{array}{c}\tau_{0,01} \\
(\mathrm{MPa})\end{array}$ & $\begin{array}{c}\tau_{0,1} \\
(\mathrm{MPa})\end{array}$ & $\begin{array}{c}\tau_{1,0} \\
(\mathrm{MPa})\end{array}$ & $\begin{array}{c}\tau_{u} \\
(\mathrm{MPa})\end{array}$ & $\begin{array}{c}\tau_{m} \\
(\mathrm{MPa})\end{array}$ & Ruptura \\
\hline C30B16-1 & 31,36 & 5,10 & 3,69 & 4,61 & 7,46 & 7,90 & 5,25 & $\mathrm{~A}^{*}$ \\
\hline C30B16-2 & 42,50 & 1,82 & 3,50 & 5,36 & 9,66 & 10,70 & 6,17 & $\mathrm{~A}$ \\
\hline C30B16-4 & 40,14 & 5,11 & 2,98 & 3,57 & 6,97 & 10,11 & 4,51 & $\mathrm{~A}$ \\
\hline C30B16-5 & 40,21 & 5,10 & 4,15 & 5,30 & 8,36 & 10,13 & 5,94 & $\mathrm{~A}$ \\
\hline Média & 38,55 & 4,28 & 3,58 & 4,71 & 8,11 & 9,71 & 5,47 & \\
\hline D. P. & 4,918 & 1,640 & 0,485 & 0,832 & 1,183 & 1,239 & 0,749 & \\
\hline C. V. & $12,76 \%$ & $38,29 \%$ & $13,56 \%$ & $17,65 \%$ & $14,58 \%$ & $12,76 \%$ & $13,71 \%$ & \\
\hline
\end{tabular}

* - ruptura por arrancamento da barra. 
De acordo com a Tabela 6.6, os valores de deslocamento último apresentaram grande variação nos resultados $(38,29 \%)$. Com relação aos demais valores, a variabilidade dos resultados foi considerada, de acordo com os limites estabelecidos para o critério de qualidade, com média qualidade.

\subsubsection{Série C60B9}

A Figura 6.5 ilustra o comportamento das curvas tensão de aderência $\mathrm{x}$ deslocamento para os modelos de arrancamento da série C60B9.

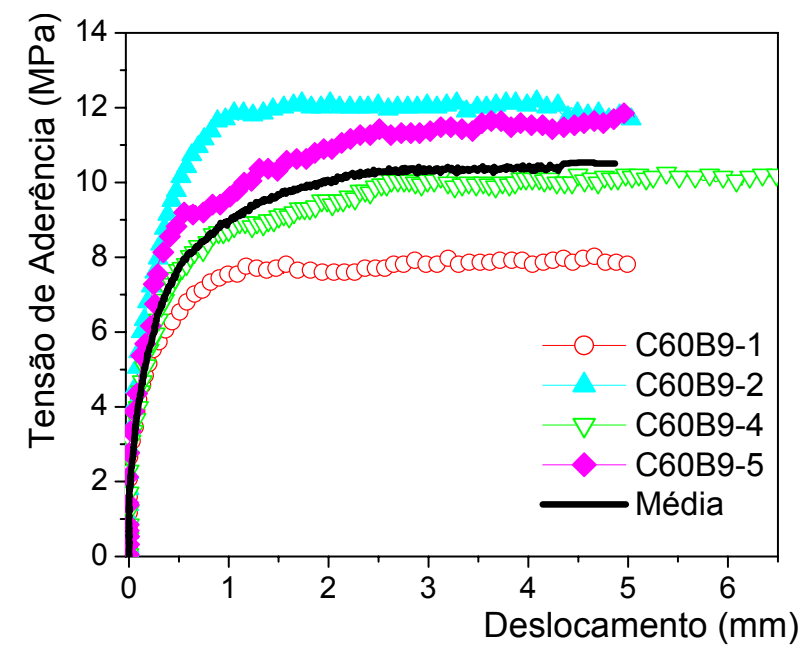

Figura 6.5 - Comportamento dos modelos de arrancamento da série C60B9

A Tabela 6.7 mostra a variação dos resultados obtidos nos ensaios de arrancamento.

Tabela 6.7 - Resultados obtidos nos ensaios de arrancamento da série C60B9

\begin{tabular}{c|c|c|c|c|c|c|c|c}
\hline Modelo & $\begin{array}{c}F_{u} \\
(\mathrm{kN})\end{array}$ & $\begin{array}{c}\mathrm{S}_{u} \\
(\mathrm{~mm})\end{array}$ & $\begin{array}{c}\tau_{0,01} \\
(\mathrm{MPa})\end{array}$ & $\begin{array}{c}\tau_{0,1} \\
(\mathrm{MPa})\end{array}$ & $\begin{array}{c}\tau_{1,0} \\
(\mathrm{MPa})\end{array}$ & $\begin{array}{c}\tau_{u} \\
(\mathrm{MPa})\end{array}$ & $\begin{array}{c}\tau_{m} \\
(\mathrm{MPa})\end{array}$ & Ruptura \\
\hline C60B9-1 & 11,60 & 4,61 & 2,71 & 4,36 & 7,44 & 8,08 & 4,84 & $\mathrm{~A}^{*}$ \\
\hline C60B9-2 & 17,63 & 3,60 & 3,30 & 5,42 & 11,85 & 12,28 & 6,86 & $\mathrm{~A}$ \\
\hline C60B9-4 & 14,96 & 7,05 & 2,87 & 4,09 & 8,72 & 10,42 & 5,23 & $\mathrm{~A}$ \\
\hline C60B9-5 & 17,02 & 5,05 & 3,14 & 4,84 & 9,73 & 11,85 & 5,90 & $\mathrm{~A}$ \\
\hline Média & 15,30 & 5,08 & 3,00 & 4,68 & 9,43 & 10,66 & 5,70 & \\
\hline D. P. & 2,719 & 1,450 & 0,262 & 0,584 & 1,864 & 1,894 & 0,884 & \\
\hline C. V. & $17,77 \%$ & $28,57 \%$ & $8,73 \%$ & $12,48 \%$ & $19,76 \%$ & $17,77 \%$ & $15,50 \%$ & \\
\hline
\end{tabular}

* - ruptura por arrancamento da barra.

Os modelos de arrancamento desta série apresentaram variação dos resultados, principalmente nos valores de deslocamento último e tensão de aderência referente ao deslocamento de $1 \mathrm{~mm}(28,57 \%$ e $19,76 \%$, respectivamente). Isto pode 
ser atribuído à pequena dimensão dos modelos e comprimento de aderência, como comentado no item 6.6.1.

\subsubsection{Série C60B16}

A Figura 6.6 ilustra o comportamento das curvas tensão de aderência $x$ deslocamento para os modelos de arrancamento da série C60B16.

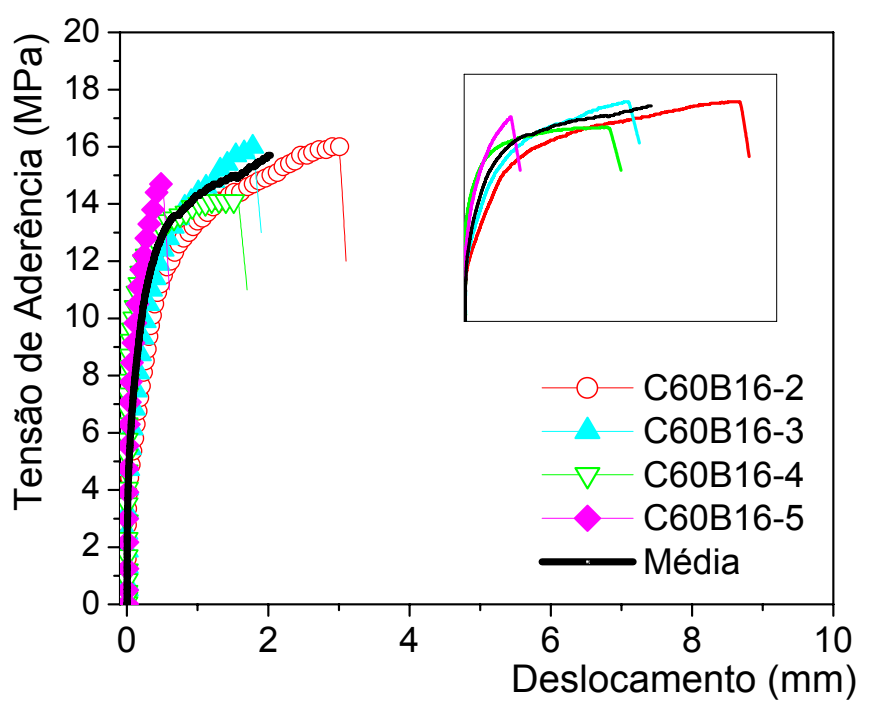

Figura 6.6 - Comportamento dos modelos de arrancamento da série C60B16

A Tabela 6.8 mostra a variação dos resultados obtidos nos ensaios de arrancamento.

Tabela 6.8 - Resultados obtidos nos ensaios de arrancamento da série C60B16

\begin{tabular}{c|c|c|c|c|c|c|c|c}
\hline Modelo & $\begin{array}{c}F_{u} \\
(\mathrm{kN})\end{array}$ & $\begin{array}{c}\mathrm{S}_{u} \\
(\mathrm{~mm})\end{array}$ & $\begin{array}{c}\tau_{0,01} \\
(\mathrm{MPa})\end{array}$ & $\begin{array}{c}\tau_{0,1} \\
(\mathrm{MPa})\end{array}$ & $\begin{array}{c}\tau_{1,0} \\
(\mathrm{MPa})\end{array}$ & $\begin{array}{c}\tau_{u} \\
(\mathrm{MPa})\end{array}$ & $\begin{array}{c}\tau_{m} \\
(\mathrm{MPa})\end{array}$ & Ruptura \\
\hline C60B16-2 & 63,71 & 2,97 & 3,44 & 5,73 & 13,28 & 16,04 & 7,48 & $\mathrm{C}^{1}$ \\
\hline C60B16-3 & 63,71 & 1,79 & 4,05 & 6,65 & 14,35 & 16,04 & 8,35 & $\mathrm{C}$ \\
\hline C60B16-4 & 56,24 & 1,54 & 7,28 & 10,03 & 13,89 & 14,16 & 10,40 & $\mathrm{C}$ \\
\hline C60B16-5 & 59,36 & 0,50 & 5,44 & 9,40 & & 14,95 & 7,42 & $\mathrm{~F}^{2}$ \\
\hline Média & 60,76 & 1,70 & 5,05 & 7,95 & 13,84 & 15,30 & 8,41 & \\
\hline D. P. & 3,645 & 1,011 & 1,705 & 2,086 & 0,540 & 0,918 & 1,393 & \\
\hline C. V. & $6,00 \%$ & $59,54 \%$ & $33,74 \%$ & $26,24 \%$ & $3,90 \%$ & $6,00 \%$ & $16,56 \%$ & \\
\hline
\end{tabular}

1 - ruptura combinada (ruptura da superfície da barra e posterior fendilhamento do concreto)

2 - ruptura por fendilhamento do concreto

Os valores referentes ao deslocamento último, tensão de aderência correspondente ao deslocamento de $0,01 \mathrm{~mm}$ e $0,1 \mathrm{~mm}$ apresentaram alta variabilidade nos resultados $(59,54 \%, 33,74 \%$ e $26,24 \%$, respectivamente). Isto pode ser atribuído ao tipo de ruptura desenvolvido nos modelos. 
Os modelos em que ocorreram a ruptura combinada apresentaram maior variabilidade nos resultados de deslocamento último quando comparados aos modelos com ruptura por arrancamento. Isto pode ser explicado pelo fato da ruptura por fendilhamento do concreto ser brusca (sem aviso prévio), o que pode favorecer a variabilidade dos resultados quanto ao deslocamento último.

\subsubsection{Série C80B9}

A Figura 6.7 ilustra o comportamento das curvas tensão de aderência $\mathrm{x}$ deslocamento para os modelos de arrancamento da série C80B9.

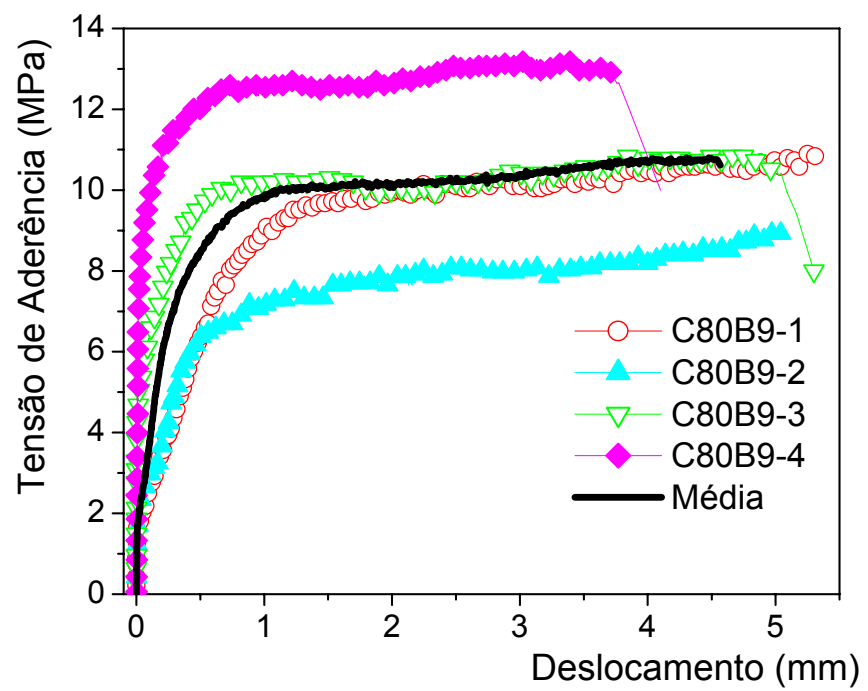

Figura 6.7 - Comportamento dos modelos de arrancamento da série C80B9

A Tabela 6.9 mostra a variação dos resultados obtidos nos ensaios de arrancamento.

Tabela 6.9 - Resultados obtidos nos ensaios de arrancamento da série C80B9

\begin{tabular}{c|c|c|c|c|c|c|c|c}
\hline Modelo & $\begin{array}{c}F_{u} \\
(\mathrm{kN})\end{array}$ & $\begin{array}{c}\mathrm{S}_{u} \\
(\mathrm{~mm})\end{array}$ & $\begin{array}{c}\tau_{0,01} \\
(\mathrm{MPa})\end{array}$ & $\begin{array}{c}\tau_{0,1} \\
(\mathrm{MPa})\end{array}$ & $\begin{array}{c}\tau_{1,0} \\
(\mathrm{MPa})\end{array}$ & $\begin{array}{c}\tau_{u} \\
(\mathrm{MPa})\end{array}$ & $\begin{array}{c}\tau_{m} \\
(\mathrm{MPa})\end{array}$ & Ruptura \\
\hline C80B9-1 & 15,64 & 5,26 & 1,65 & 2,60 & 8,77 & 10,90 & 4,34 & $\mathrm{~A}^{1}$ \\
\hline C80B9-3 & 15,72 & 4,79 & 4,46 & 6,32 & 10,15 & 10,95 & 6,98 & $\mathrm{~A}$ \\
\hline C80B9-4 & 19,08 & 3,01 & 6,27 & 9,78 & 12,54 & 13,29 & 9,53 & $\mathrm{C}^{2}$ \\
\hline C80B9-5 & 15,64 & 0,71 & 5,74 & 8,82 & 8,61 & 10,90 & 7,72 & $\mathrm{C}$ \\
\hline Média & 16,01 & 3,44 & 4,53 & 6,88 & 10,02 & 11,15 & 7,14 & \\
\hline D. P. & 1,704 & 2,063 & 2,066 & 3,203 & 1,820 & 1,187 & 2,154 & \\
\hline C. V. & $10,32 \%$ & $59,90 \%$ & $45,61 \%$ & $46,53 \%$ & $18,16 \%$ & $10,32 \%$ & $30,15 \%$ & \\
\hline - cupturap
\end{tabular}

1 - ruptura por arrancamento da barra

2 - ruptura combinada (ruptura da superfície da barra e posterior fendilhamento do concreto) 
Esta série apresentou grande variabilidade nos resultados, chegando ao valor de aproximadamente $60 \%$ para o deslocamento último. Além disto, o modo de ruptura foi bastante variado, dois modelos romperam por arrancamento e dois por ruptura combinada.

\subsubsection{Série C80B16}

A Figura 6.8 ilustra o comportamento das curvas tensão de aderência $x$ deslocamento para os modelos de arrancamento da série C80B16.

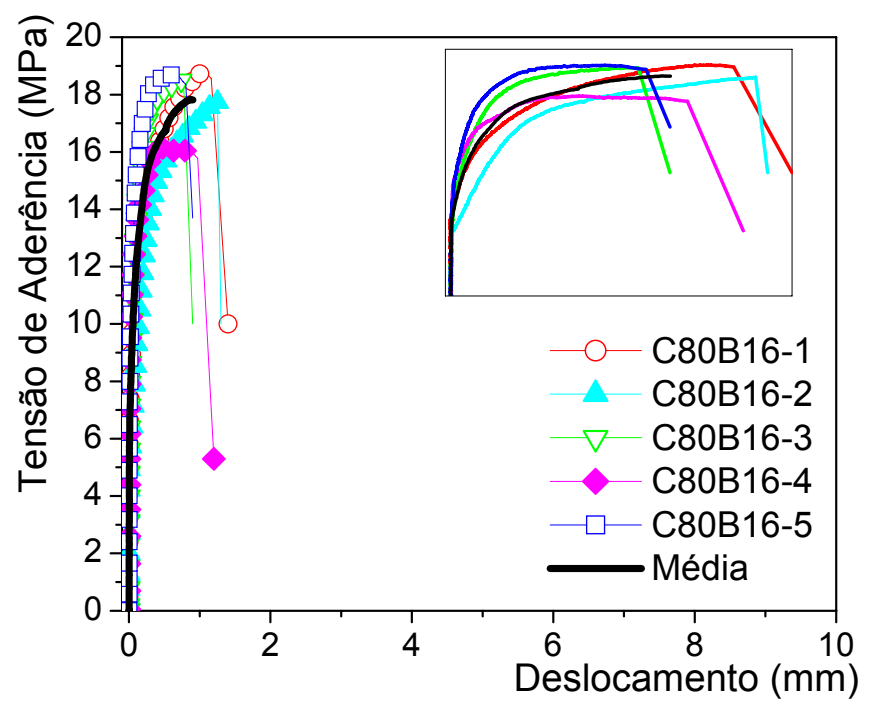

Figura 6.8 - Comportamento dos modelos de arrancamento da série C80B16

A Tabela 6.10 mostra a variação dos resultados obtidos nos ensaios de arrancamento.

Tabela 6.10 - Resultados obtidos nos ensaios de arrancamento da série C80B16

\begin{tabular}{c|c|c|c|c|c|c|c|c}
\hline Modelo & $\begin{array}{c}F_{u} \\
(\mathrm{kN})\end{array}$ & $\begin{array}{c}\mathrm{S}_{u} \\
(\mathrm{~mm})\end{array}$ & $\begin{array}{c}\tau_{0,01} \\
(\mathrm{MPa})\end{array}$ & $\begin{array}{c}\tau_{0,1} \\
(\mathrm{MPa})\end{array}$ & $\begin{array}{c}\tau_{1,0} \\
(\mathrm{MPa})\end{array}$ & $\begin{array}{c}\tau_{u} \\
(\mathrm{MPa})\end{array}$ & $\begin{array}{c}\tau_{m} \\
(\mathrm{MPa})\end{array}$ & Ruptura \\
\hline C80B16-1 & 74,24 & 1,05 & 7,05 & 11,61 & 18,68 & 18,70 & 12,44 & $\mathrm{C}^{*}$ \\
\hline C80B16-2 & 70,28 & 1,25 & 5,23 & 8,67 & 17,12 & 17,70 & 10,34 & $\mathrm{C}$ \\
\hline C80B16-3 & 73,25 & 0,75 & 6,46 & 13,28 & & 18,45 & 9,87 & $\mathrm{C}$ \\
\hline C80B16-4 & 64,17 & 0,54 & 8,17 & 13,30 & & 16,16 & 10,73 & $\mathrm{C}$ \\
\hline C80B16-5 & 74,09 & 0,63 & 7,78 & 14,99 & & 18,66 & 11,38 & $\mathrm{C}$ \\
\hline Média & 71,21 & 0,85 & 6,94 & 12,37 & 17,90 & 17,93 & 10,95 & \\
\hline D. P. & 4,245 & 0,297 & 1,161 & 2,389 & 1,100 & 1,069 & 1,002 & \\
\hline C. V. & $5,96 \%$ & $35,13 \%$ & $16,74 \%$ & $19,32 \%$ & $6,15 \%$ & $5,96 \%$ & $9,15 \%$ & \\
\hline
\end{tabular}

*- ruptura combinada (ruptura da superfície rugosa da barra e posterior fendilhamento do concreto) 
Esta série, como as três séries anteriores, também apresentou grande variação dos resultados para o deslocamento referente à força última (35\%). Os deslocamentos nesta série foram muito pequenos e isto também contribuiu para a grande variabilidade nos resultados.

A conformação superficial das barras de GFRP também contribuiu bastante para a variabilidade dos resultados. Os agregados miúdos impregnados bem como as fibras dispostas helicoidalmente na superfície da barra são responsáveis pela aderência entre a barra de GFRP e o concreto.

A quantidade e disposição dos agregados impregnados nas barras de GFRP pode variar de barra para barra, isto influencia bastante o comportamento da aderência e consequentemente aumenta a variabilidade dos resultados.

Como mostrado no Capítulo 4, foram consideradas cinco repetições para cada modelo ensaiado. Para um melhor controle estatístico dos resultados deveria ter sido moldado um maior número de modelos.

\subsubsection{Comparação entre os modelos de arrancamento}

Neste item é realizado a comparação dos resultados obtidos nos ensaios de arrancamento. Esta comparação tem o objetivo de verificar a influência da resistência do concreto e do diâmetro da barra no comportamento da aderência.

\subsubsection{Influência da resistência do concreto no comportamento da aderência}

As Figuras 6.9 e 6.10 ilustram as curvas referentes ao comportamento médio da tensão de aderência $x$ deslocamento e resistência última de aderência para os modelos de arrancamento com barras de $9 \mathrm{~mm}$ e $16 \mathrm{~mm}$, respectivamente.
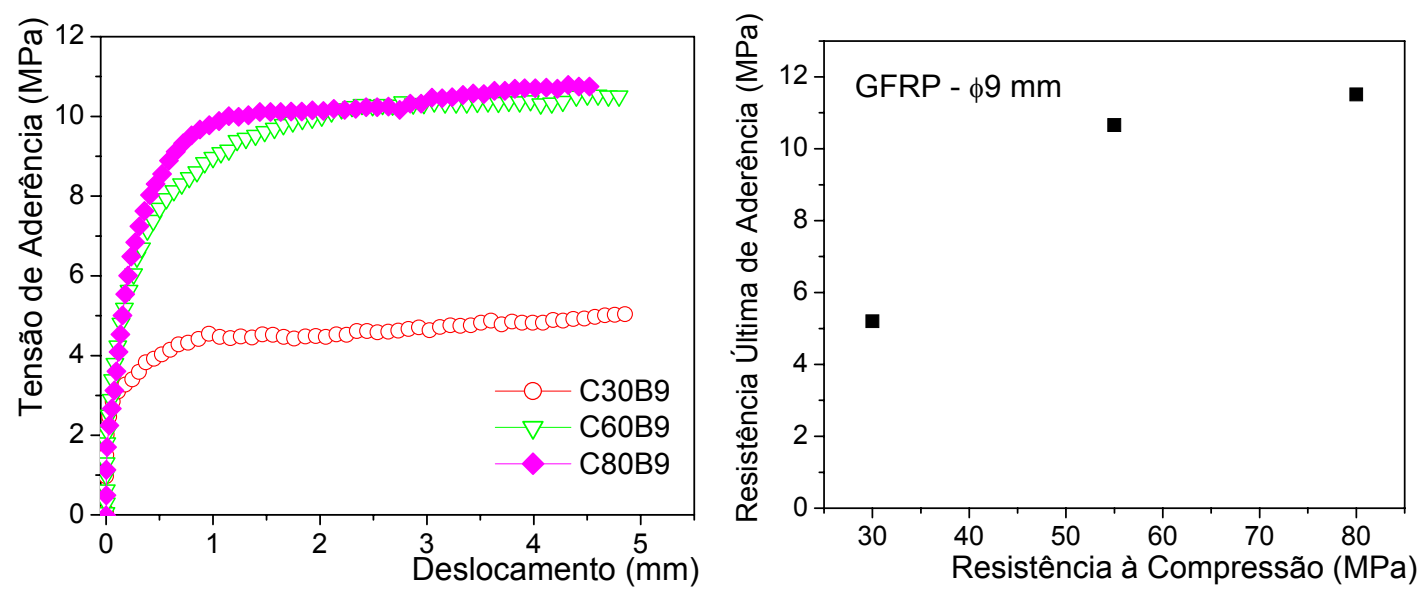

Figura 6.9 - a) Comportamento dos modelos de arrancamento das séries com barras de $9 \mathrm{~mm}$; b) Resistência última de aderência das séries com barras de $9 \mathrm{~mm}$ 

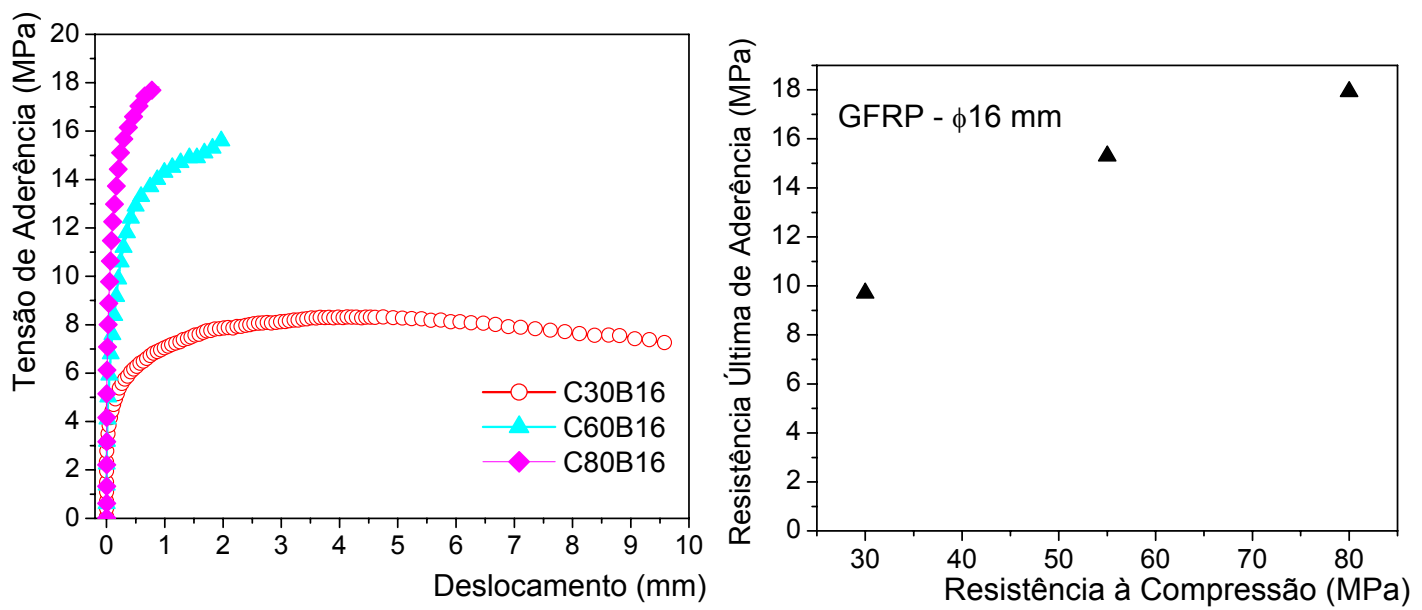

Figura 6.10 - a) Comportamento dos modelos de arrancamento das séries com barras de $16 \mathrm{~mm}$; b) Resistência última de aderência das séries com barras de $16 \mathrm{~m}$

O comportamento da aderência desenvolvido para as séries C60B9 e C80B9 foi similar, mostrando que a resistência do concreto não influenciou o comportamento da aderência neste caso. A série C30B9 apresentou valor de resistência de aderência muito inferior às séries citadas acima (aproximadamente $53 \%$ menor), verificando-se a influência da resistência do concreto quando comparados aos modelos onde se utilizou concreto de resistência à compressão usual (30 MPa) com os modelos onde se utilizou concreto de alta resistência ( $\geq 50 \mathrm{MPa}$ ) (Figura 6.9).

O mesmo foi verificado para o caso dos modelos onde se utilizou barras de 16 mm (Figura 6.10). Ou seja, a resistência do concreto não influenciou significativamente o comportamento da aderência para as séries com concretos de $60 \mathrm{MPa}$ e $80 \mathrm{MPa}$. Além isso, a série C3016 apresentou valor de resistência de aderência inferior as demais (aproximadamente 42\% menor), mostrando neste caso a influência da resistência do concreto na resistência da aderência.

Pode-se concluir então, que a resistência do concreto não interfere significativamente na resistência de aderência quando se utilizam concretos com resistência à compressão superior à $50 \mathrm{MPa}$, pois a ruptura da aderência ocorre na superfície da barra. Consequentemente, a resistência de aderência depende das propriedades da barra e não da resistência do concreto (ACHILLIDES e PILAKOUTAS, 2004).

\subsubsection{Influência do diâmetro da barra no comportamento da aderência}

A Figura 6.11 ilustra as curvas referentes ao comportamento médio da tensão de aderência $x$ deslocamento para os modelos de arrancamento. 


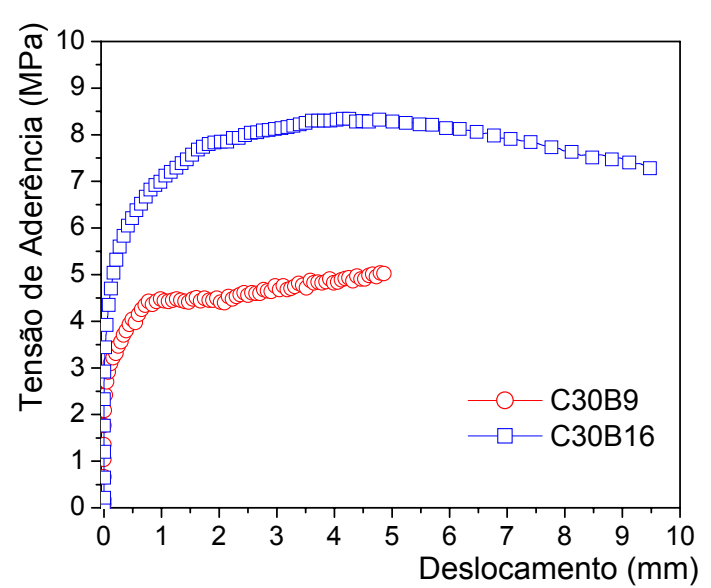

(a)

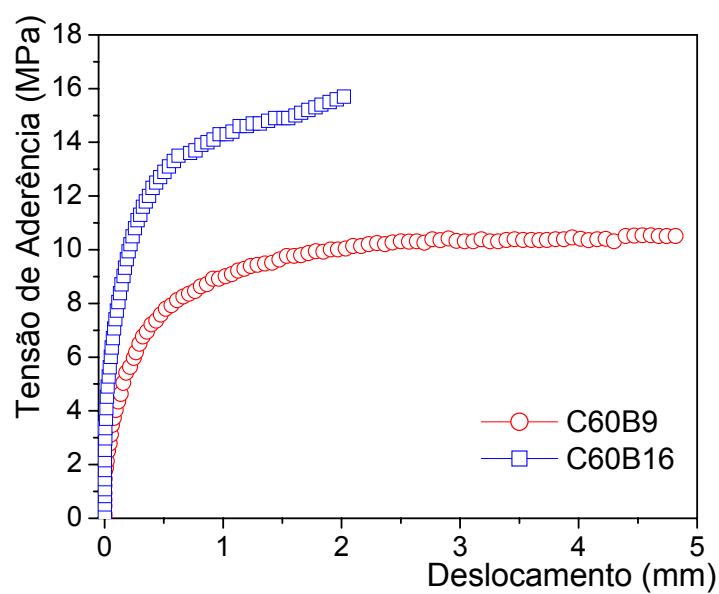

(b)

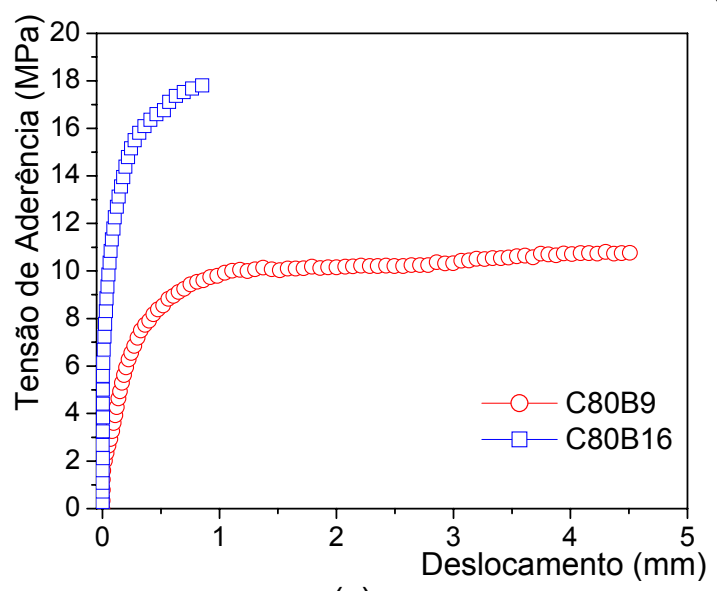

(c)

Figura 6.11 - Comportamento dos modelos de arrancamento das séries com concreto C30, C60 e C80

Em relação à Figura 6.11, pode-se observar que o valor da resistência última de aderência foi superior nos modelos com barras de $16 \mathrm{~mm}$ (variando de $46 \%$ para as séries C30, 30\% para as séries C60,36\% para as séries C 80 ).

A literatura técnica enfatiza o fato da resistência de aderência decrescer com o aumento do diâmetro, porém isto não foi verificado nestes ensaios de arrancamento. As barras analisadas de diâmetro $9 \mathrm{~mm}$ não apresentaram comportamento de aderência satisfatório, a área de contato destas em comparação com as barras de diâmetro 16 mm é menor, o que acarreta a uma menor resistência de aderência.

Vale salientar que a ruptura da aderência para as barras de GFRP ocorre, em grande parte, na superfície externa da barra, portanto se a área de contato for maior a resistência de aderência consequentemente também será maior. 


\subsubsection{Comparação entre modelos analíticos e experimentais em relação ao comportamento da aderência entre barras de GFRP e o concreto}

Apesar da grande quantidade de formulações propostas para previsão do comportamento da aderência entre a barra de aço e o concreto, existem poucos trabalhos publicados neste sentido para as barras de FRP. Além disto, as poucas formulações existentes para barras de FRP ainda precisam ser validadas em relação aos resultados experimentais (COSENZA et al., 1997).

A seguir serão apresentados alguns modelos analíticos para previsão do comportamento da aderência entre a barra de FRP e o concreto, e posteriormente a comparação destes modelos com os resultados experimentais obtidos.

MALVAR (1994) propôs uma formulação para a representação da curva tensão de aderência $x$ deslocamento entre barras de FRP e concretos de diferente resistência à compressão (Eq 6.5). Esta formulação é função de duas constantes empíricas determinadas a partir das curvas experimentais de tensão de aderência $x$ deslocamento.

$$
\tau=\left[\frac{F \cdot\left(s / s_{u}\right)+(G-1) \cdot\left(s / s_{u}\right)^{2}}{1+(F-2) \cdot\left(s / s_{u}\right)+G \cdot\left(s / s_{u}\right)^{2}}\right] \cdot \tau_{u}
$$

Sendo:

$\tau_{\mathrm{u}}$ - resistência última de aderência $(\mathrm{MPa})$;

$\mathrm{s}_{\mathrm{u}}$ - deslocamento da barra referente a resistência última de aderência $(\mathrm{mm})$;

$\mathrm{F}, \mathrm{G}$ - constantes empíricas.

ELIGEHAUSEN et al. (1983) propôs uma formulação para a representação da curva tensão de aderência $x$ deslocamento entre barras de aço e o concreto (Figura $6.12)$, denominado modelo BPE, cujo tramo ascendente da curva é determinado pela Equação 6.6. 


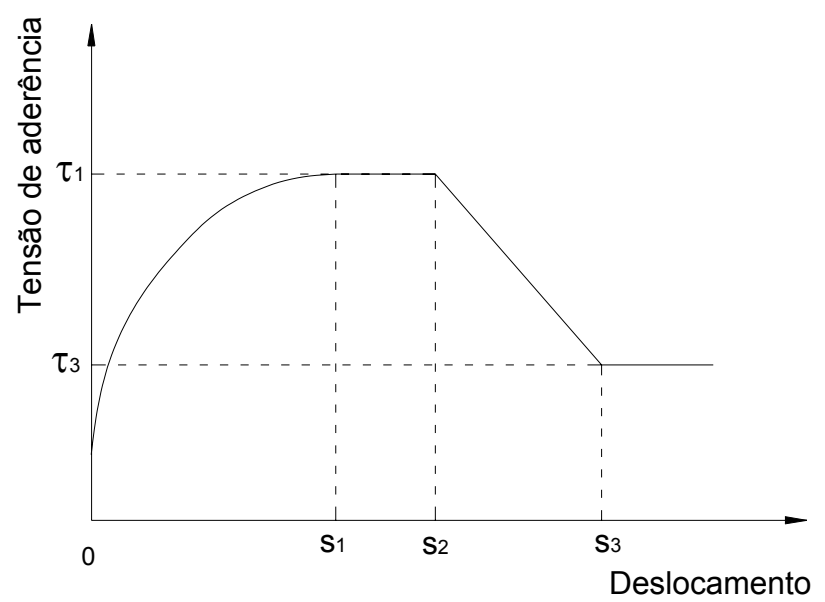

Figura 6.12 - Modelo BPE

$\tau=\left[\left(\frac{s}{s_{u}}\right)^{\alpha}\right] \cdot \tau_{u}$

Sendo:

$\tau_{\mathrm{u}}$ - resistência última de aderência $(\mathrm{MPa})$;

$\mathrm{S}_{\mathrm{u}}$ - deslocamento da barra referente a resistência última de aderência $(\mathrm{mm})$;

$\alpha$ - constante empírica.

O valor de $\alpha$ é adotado de acordo com a curva experimental tensão de aderência $x$ deslocamento e deve ser menor que 1 . No caso de barras de aço $\alpha$ é considerado igual a 0,4 (CEB, 1991).

COSENSA et al. (1997) propôs uma modificação para a formulação do tramo ascendente da curva tensão de aderência $\mathrm{x}$ deslocamento do Modelo BPE, denominado Modelo CRM (Eq.6.7).

$$
\tau=\left[1-e^{-\left(s / s_{r}\right)}\right]^{\beta} \cdot \tau_{u}
$$

Sendo:

$\tau_{\mathrm{u}}$ - resistência última de aderência $(\mathrm{MPa})$;

$\mathrm{s}_{\mathrm{r}}, \beta$ - constantes empíricas adotadas de acordo com resultados experimentais.

A Tabela 6.10 mostra o valor adotado para as constantes, das referidas formulações, com relação aos modelos experimentais. $O$ valor das constantes de cada formulação foi adotado de modo que as formulações representassem de maneira adequada o comportamento do diagrama tensão de aderência x deformação. 
Tabela 6.11 - Valor adotado para as constantes dos modelos analíticos de previsão do comportamento de aderência barra-concreto.

\begin{tabular}{c|c|c|c|c|c}
\hline \multirow{2}{*}{ Modelo } & \multicolumn{2}{|c|}{ MALVAR (1994) } & $\begin{array}{c}\text { BPE } \\
(1983)\end{array}$ & \multicolumn{2}{c}{ CRM (1995) } \\
\cline { 2 - 6 } & $\mathrm{F}$ & $\mathrm{G}$ & $\alpha$ & $1 / \mathrm{s}_{\mathrm{r}}$ & $\beta$ \\
\hline C30B9 & 23 & 1,2 & 0,09 & 2,5 & 0,5 \\
\hline C30B16 & 16 & 1,3 & 0,12 & 1,2 & 0,5 \\
\hline C60B9 & 19 & 1,5 & 0,16 & 1,5 & 0,5 \\
\hline C60B16 & 11,5 & 3 & 0,2 & 2,5 & 0,5 \\
\hline C80B9 & 42 & 2 & 0,05 & 4,0 & 0,5 \\
\hline C80B16 & 23 & 1,2 & 0,17 & 4,8 & 0,5 \\
\hline
\end{tabular}

As Figuras 6.13, 6.14 e 6.15 e a Tabela 6.12 ilustram a comparação dos resultados obtidos experimentalmente com as formulações para previsão do comportamento da aderência barra-concreto.

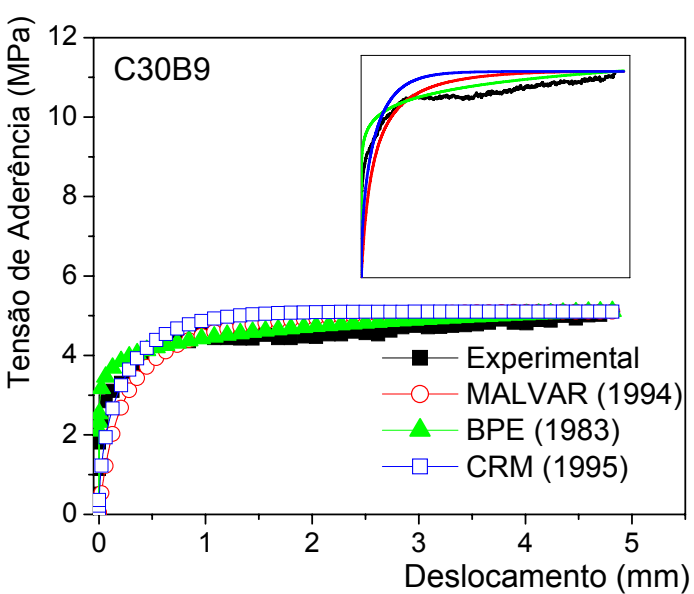

(a)

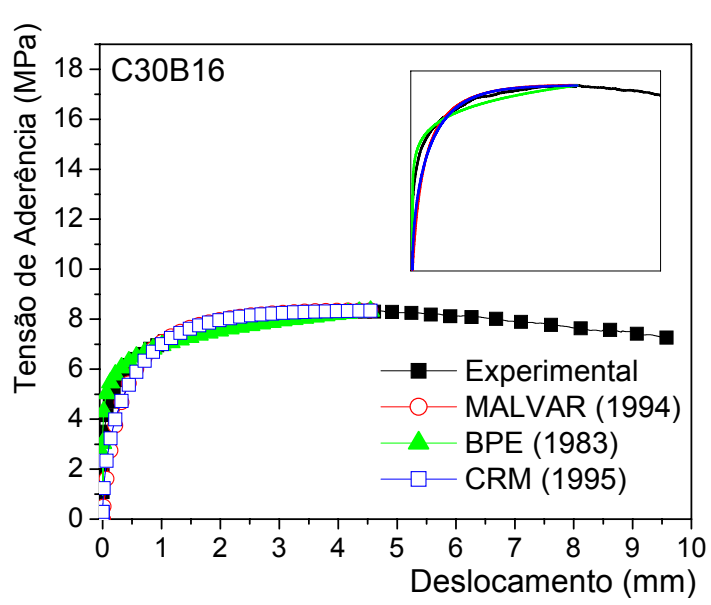

(b)

Figura 6.13 - Comparação entre o comportamento experimental da aderência e modelos analíticos para as séries C30B9 e C30B16 


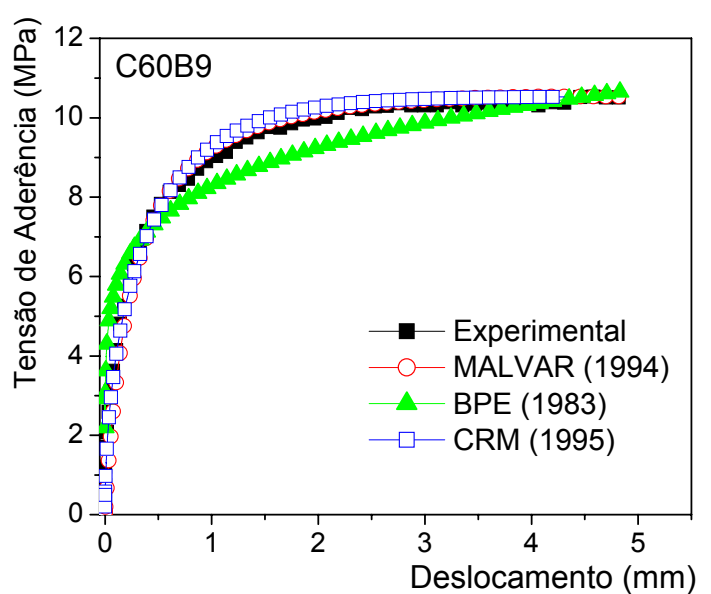

(a)

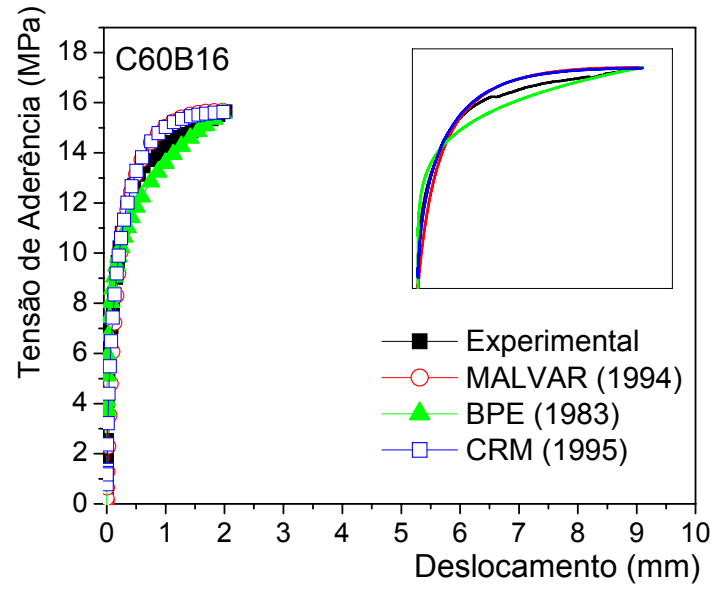

(b)

Figura 6.14 - Comparação entre o comportamento experimental da aderência e modelos analíticos para as séries C60B9 e C60B16

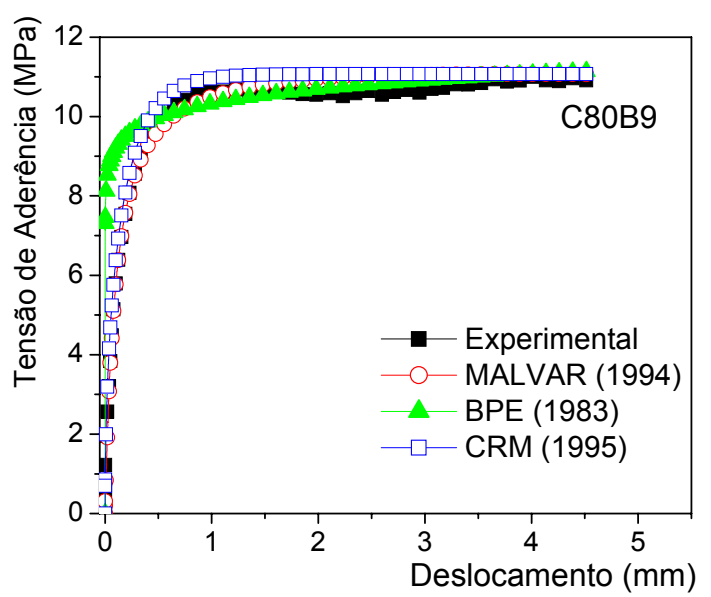

(a)

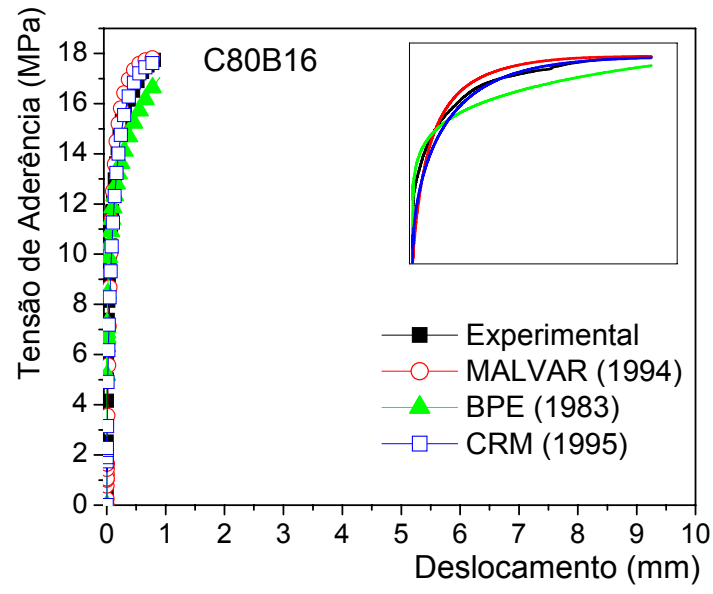

(b)

Figura 6.15 - Comparação entre o comportamento experimental da aderência e modelos analíticos para as séries C80B9 e C80B16

Tabela 6.12 - Comparação entre os valores da resistência última de aderência obtidos experimentalmente e por meio dos modelos analíticos

\begin{tabular}{c|c|c|c|c|c|c|c}
\hline \multirow{2}{*}{ Modelo } & Exp. & \multicolumn{2}{|c|}{$\operatorname{MALVAR}(1994)$} & \multicolumn{2}{c|}{ BPE (1983) } & \multicolumn{2}{c}{ CRM (1995) } \\
\cline { 2 - 8 } & $\begin{array}{c}\tau_{\mathrm{u}} \\
(\mathrm{MPa})\end{array}$ & $\begin{array}{c}\tau_{\mathrm{u}} \\
(\mathrm{MPa})\end{array}$ & $\lambda$ & $\begin{array}{c}\tau_{\mathrm{u}} \\
(\mathrm{MPa})\end{array}$ & $\lambda$ & $\begin{array}{c}\tau_{\mathrm{u}} \\
(\mathrm{MPa})\end{array}$ & $\lambda$ \\
\hline C30B9 & 5,10 & 5,10 & 1,000 & 5,13 & 0,994 & 5,10 & 1,000 \\
\hline C30B16 & 8,35 & 8,35 & 1,000 & 8,35 & 1,000 & 8,33 & 1,002 \\
\hline C60B9 & 10,54 & 10,54 & 1,000 & 10,67 & 0,988 & 10,52 & 1,002 \\
\hline C60B16 & 15,68 & 15,68 & 1,000 & 15,68 & 1,000 & 15,63 & 1,003 \\
\hline C80B9 & 11,07 & 11,07 & 1,000 & 11,14 & 0,994 & 11,07 & 1,000 \\
\hline C80B16 & 17,84 & 17,83 & 1,001 & 17,11 & 1,040 & 17,72 & 1,007 \\
\hline
\end{tabular}


Com base nas Figuras e na Tabela acima percebe-se que as formulações para a previsão do comportamento de aderência barra-concreto representaram de maneira satisfatória o comportamento obtido na investigação experimental para todas as séries de arrancamento.

Comparando o coeficiente $\alpha$ do modelo analítico BPE para as barras de aço e barras de GFRP, observa-se que, o valor de $\alpha$ adotado para os modelos com barras de GFRP foi menor do que o valor recomendado pelo CEB (1991) para as barras de aço $\left(\alpha_{\text {aço }}=0,40\right)$. Isto mostra que, a resistência de aderência referente ao segundo trecho do diagrama tensão de aderência $x$ deslocamento (trecho do gráfico com início da curvatura, ou seja, no inicio da perda da capacidade resistente da ligação) desenvolvida nos modelos com barras de GFRP foi maior que a resistência de aderência desenvolvida entre a barra de aço e o concreto.

Para a série C80B16, o Modelo BPE apresentou comportamento menos rígido quando comparado ao comportamento experimental, com resistência última de aderência aproximadamente $4 \%$ menor.

Com a finalidade de obter equações gerais para a representação do comportamento da aderência barra de GFRP-concreto, foi adotado o valor médio entre os coeficientes de cada formulação. Assim, tem-se o comportamento de aderência para as barras de GFRP utilizadas na investigação experimental (Figuras 6.16, 6.17, 6.18 e Tabela 6.13).

Tabela 6.13 - Equações gerais para a representação do comportamento da aderência barra de GFRP-concreto

\begin{tabular}{c|c|c|c|c}
\hline \multicolumn{2}{c|}{ MALVAR (1994) } & BPE (1983) & \multicolumn{2}{c}{ CRM (1995) } \\
\hline $\mathrm{F}$ & $\mathrm{G}$ & $\alpha$ & $1 / \mathrm{s}_{\mathrm{r}}$ & $\beta$ \\
\hline 22,4 & 1,7 & 0,13 & 2,8 & 0,5 \\
\hline
\end{tabular}

Formulação

$\left.\left.\tau=\left[\frac{22,4 \cdot\left(\mathrm{s} / \mathrm{s}_{u}\right)+(1,7-1) \cdot\left(\mathrm{s} / \mathrm{s}_{u}\right)^{2}}{1+(22,4-2) \cdot\left(\mathrm{s} / \mathrm{s}_{u}\right)+1,7 \cdot\left(\mathrm{s} / \mathrm{s}_{u}\right)^{2}}\right] \cdot \tau_{u}\right] \tau=\left[\left(\frac{\mathrm{s}}{\mathrm{s}_{u}}\right)^{0,13}\right] \cdot \tau_{u}\right] \tau=\left[1-e^{-(2,8 \cdot s)}\right]^{0,5} \cdot \tau_{u}$




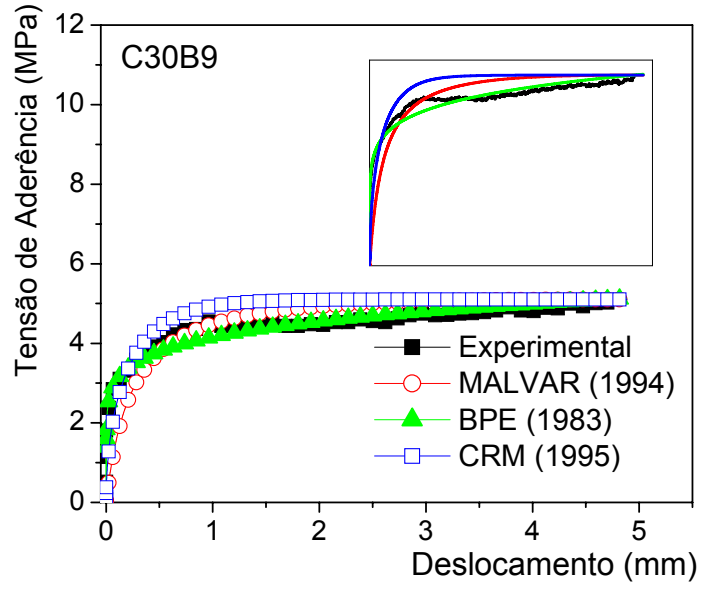

(a)

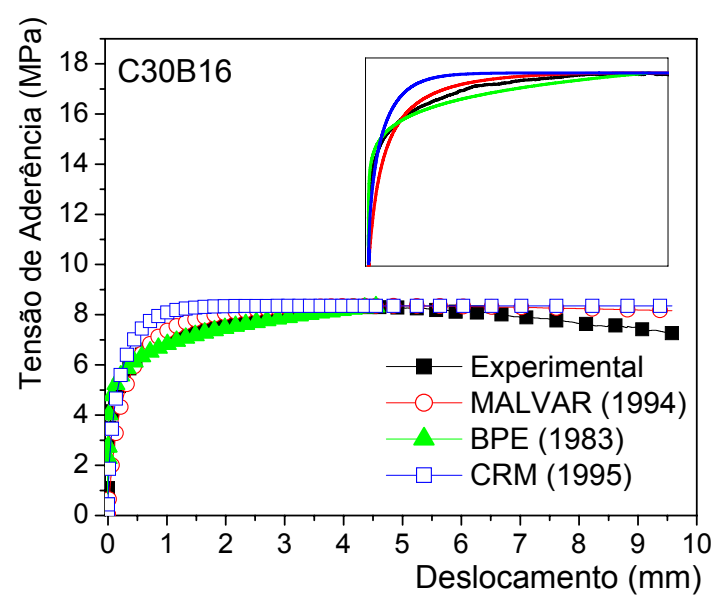

(b)

Figura 6.16 - Comparação entre o comportamento experimental da aderência e modelos analíticos, adotando coeficientes médios, para as séries C30B9 e C30B16

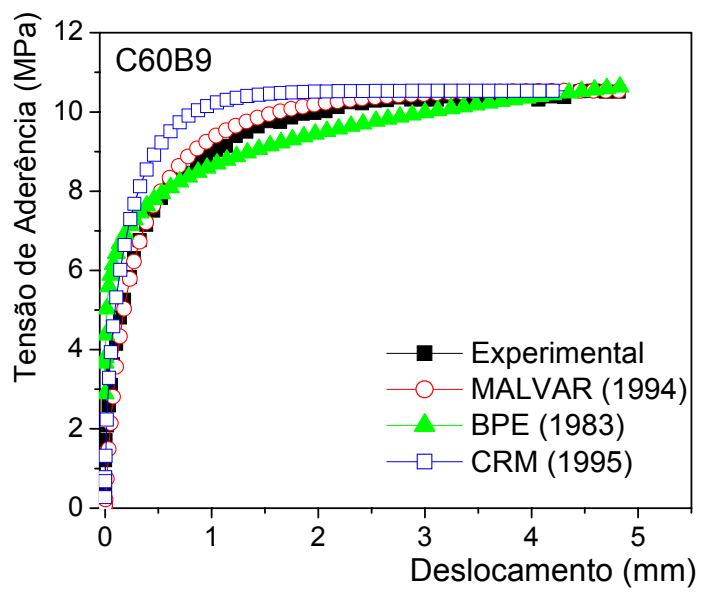

(a)

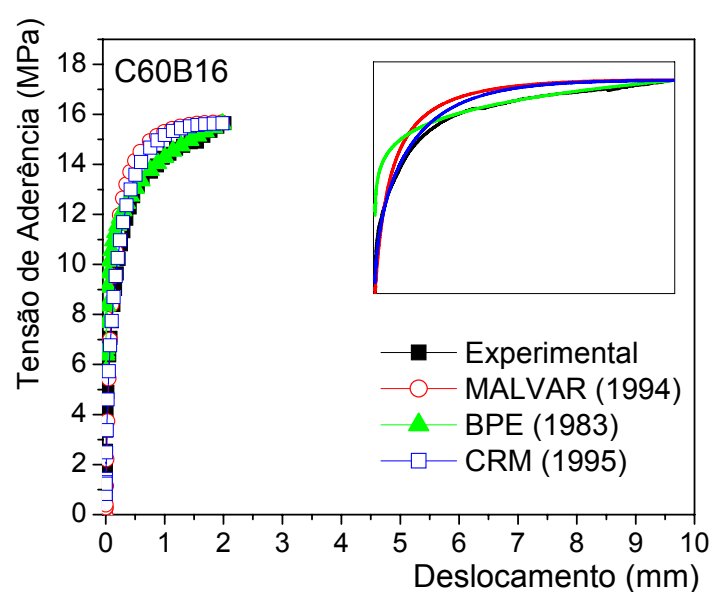

(b)

Figura 6.17 - Comparação entre o comportamento experimental da aderência e modelos analíticos, adotando coeficientes médios, para as séries C60B9 e C60B16

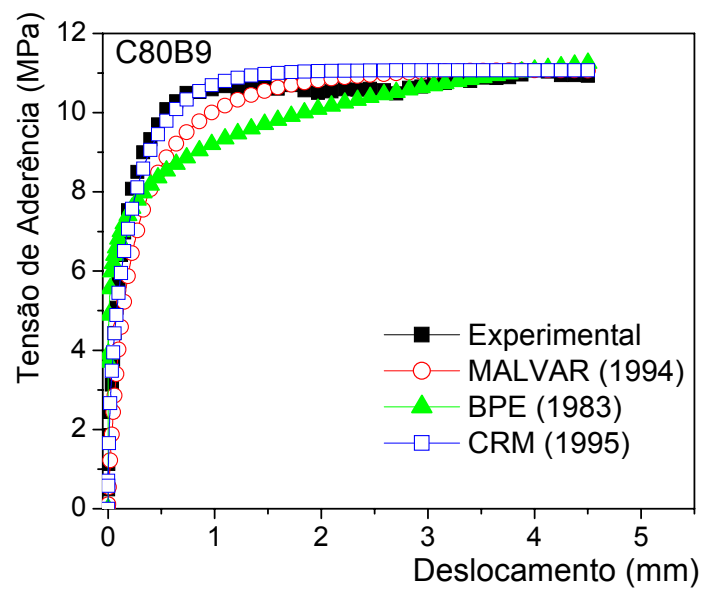

(a)

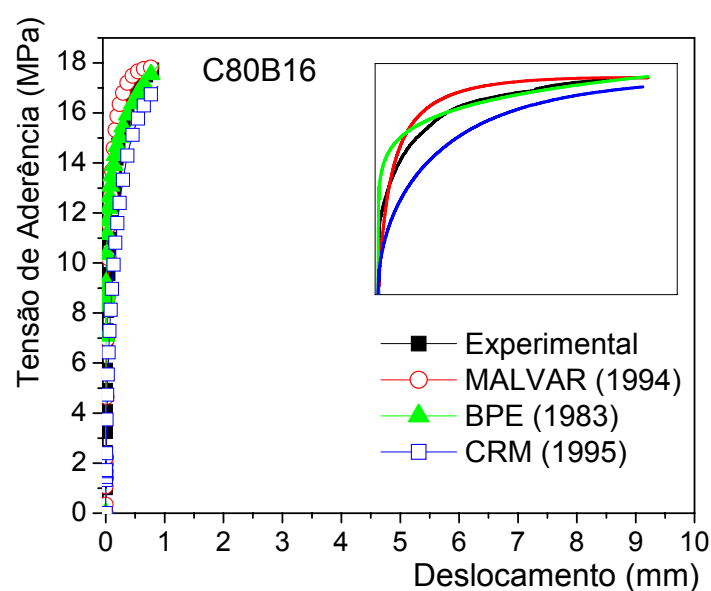

(b)

Figura 6.18 - Comparação entre o comportamento experimental da aderência e modelos analíticos, adotando coeficientes médios, para as séries C80B9 e C80B16 
Tabela 6.14 - Comparação entre os valores da resistência última de aderência obtidos experimentalmente e por meio dos modelos analíticos, adotando coeficientes médios

\begin{tabular}{c|c|c|c|c|c|c|c}
\hline \multirow{2}{*}{ Modelo } & Exp. & \multicolumn{2}{|c|}{ MALVAR (1994) } & \multicolumn{2}{|c|}{ BPE (1983) } & \multicolumn{2}{c}{ CRM (1995) } \\
\cline { 2 - 8 } & $\begin{array}{c}\tau_{\mathrm{u}} \\
(\mathrm{MPa})\end{array}$ & $\begin{array}{c}\tau_{\mathrm{u}} \\
(\mathrm{MPa})\end{array}$ & $\lambda$ & $\begin{array}{c}\tau_{\mathrm{u}} \\
(\mathrm{MPa})\end{array}$ & $\lambda$ & $\begin{array}{c}\tau_{\mathrm{u}} \\
(\mathrm{MPa})\end{array}$ & $\lambda$ \\
\hline C30B9 & 5,10 & 5,10 & 1,000 & 5,15 & 0,991 & 5,10 & 1,000 \\
\hline C30B16 & 8,35 & 8,35 & 1,000 & 8,35 & 1,000 & 8,33 & 1,002 \\
\hline C60B9 & 10,54 & 10,54 & 1,000 & 10,64 & 0,999 & 10,52 & 1,002 \\
\hline C60B16 & 15,68 & 15,68 & 1,000 & 15,68 & 1,000 & 15,65 & 1,002 \\
\hline C80B9 & 11,07 & 11,07 & 1,000 & 11,26 & 0,983 & 11,07 & 1,000 \\
\hline C80B16 & 17,84 & 17,83 & 1,001 & 17,93 & 0,995 & 17,07 & 1,045 \\
\hline
\end{tabular}

Com base nas Figuras 6.16, 6.17 e 6.18 e na Tabela 6.14, pode-se observar que os modelos analíticos conseguiram representar de maneira satisfatória a resistência última de aderência obtida pelos modelos experimentais, sem grande variação nos resultados.

O Modelo BPE não conseguiu representar de maneira adequada o comportamento inicial do diagrama tensão de aderência $\mathrm{x}$ deslocamento após $\mathrm{a}$ consideração dos valores médios do coeficiente $\alpha$, pode-se concluir então, que o Modelo BPE é fortemente influenciado pelo coeficiente $\alpha$.

Considerando as séries C30B9, C30B16, C60B9 e C80B16, o Modelo proposto por MALVAR (1994) foi o modelo que melhor se ajustou ao comportamento inicial do diagrama tensão de aderência $\mathrm{x}$ deslocamento experimental. $\mathrm{E}$, para as séries C60B16 e C80B9 o modelo que melhor se ajustou ao comportamento inicial do diagrama tensão de aderência x deslocamento experimental foi o Modelo CRM (1995).

\subsubsection{Comparação entre a resistência de aderência desenvolvida pelas barras de GFRP e pelas barras de aço}

A resistência de aderência desenvolvida entre as barras de GFRP e o concreto será comparada com valores obtidos por outros autores em ensaios de arrancamento com barras de aço de diâmetros similares.

ALMEIDA FILHO (2006) realizou ensaios de arrancamento de acordo com os procedimentos descritos pela RILEM-CEB-FIP (1973). O estudo considerou modelos de arrancamento com concretos de $30 \mathrm{MPa}$ e $60 \mathrm{MPa}$ e barras de aço com diâmetros de $10 \mathrm{~mm}$ e $16 \mathrm{~mm}$. Os resultados dos ensaios estão representados na Tabela 6.15. 
Tabela 6.15 - Resultados obtidos nos ensaios de arrancamento por ALMEIDA FILHO (2006)

\begin{tabular}{c|c|c|c|c|c|c|c|c}
\hline Modelo & $\begin{array}{c}F_{u} \\
(\mathrm{kN})\end{array}$ & $\begin{array}{c}\mathrm{s}_{u} \\
(\mathrm{~mm})\end{array}$ & $\begin{array}{c}\tau_{0,01} \\
(\mathrm{MPa})\end{array}$ & $\begin{array}{c}\tau_{0,1} \\
(\mathrm{MPa})\end{array}$ & $\begin{array}{c}\tau_{1,0} \\
(\mathrm{MPa})\end{array}$ & $\begin{array}{c}\tau_{u} \\
(\mathrm{MPa})\end{array}$ & $\begin{array}{c}\tau_{m} \\
(\mathrm{MPa})\end{array}$ & Ruptura \\
\hline AF-C30B10 & 18,36 & 1,05 & 3,39 & 4,93 & 11,20 & 11,56 & 6,48 & $\mathrm{~A}^{1}$ \\
\hline AF-C30B16 & 42,36 & 1,64 & 2,80 & 3,82 & 10,11 & 10,75 & 5,48 & $\mathrm{~A}$ \\
\hline AF-C60B10 & 26,78 & 1,64 & 1,70 & 3,60 & 13,11 & 17,05 & 6,14 & $\mathrm{~F}^{2}$ \\
\hline AF-C60B16 & 88,22 & 2,20 & 0,50 & 1,37 & 11,90 & 21,94 & 4,59 & $\mathrm{~F}$ \\
\hline
\end{tabular}

- ruptura por arrancamento da barra

${ }^{2}$ - ruptura por fendilhamento do concreto

Com base nos resultados obtidos experimentalmente, ALMEIDA FILHO (2006) propôs regressões polinomiais para representação do comportamento da aderência dos modelos com concreto de resistência à compressão de $30 \mathrm{MPa}$, e regressões exponenciais para os modelos onde se utilizou concreto de resistência à compressão de $60 \mathrm{MPa}$, como mostra a Tabela 6.16.

Tabela 6.16 - Regressões polinomiais e exponenciais para representação do comportamento da aderência dos modelos de arrancamento, segundo ALMEIDA FILHO (2006)

\begin{tabular}{c|c}
\hline Modelo & Regressões polinomiais \\
\hline AF-C30B10 & $\begin{array}{c}\tau_{(s)}=1,54321+34,13722 \cdot s-48,63661 \cdot s^{2}+37,71357 \cdot s^{3}-17,6379 \cdot s^{4}+ \\
5,01639 \cdot s^{5}-0,84388 \cdot s^{6}+0,07694 \cdot s^{7}-0,00292 \cdot s^{8}\end{array}$ \\
\hline AF-C30B16 & $\begin{array}{c}\tau_{(s)}=1,3067+29,62846 \cdot s-52,85265 \cdot s^{2}+58,18252 \cdot s^{3}-38,30515 \cdot s^{4}+ \\
14,89466 \cdot s^{5}-3,34392 \cdot s^{6}+0,39996 \cdot s^{7}-0,0197 \cdot s^{8}\end{array}$ \\
\hline AF-C60B10 & Regressões exponenciais \\
\hline AF-C60B16 & $\tau_{(s)}=15,13-15,79 \cdot e^{(-s / 0,602)}$ \\
\hline
\end{tabular}

As Figuras 6.19 e 6.20 ilustram as comparações dos resultados obtidos por ALMEIDA FILHO (2006) com os resultados obtidos por meio desta pesquisa com relação às curvas de tensão de aderência $x$ deslocamento, aos valores de deslocamento último, resistência última de aderência e resistência média de aderência. 


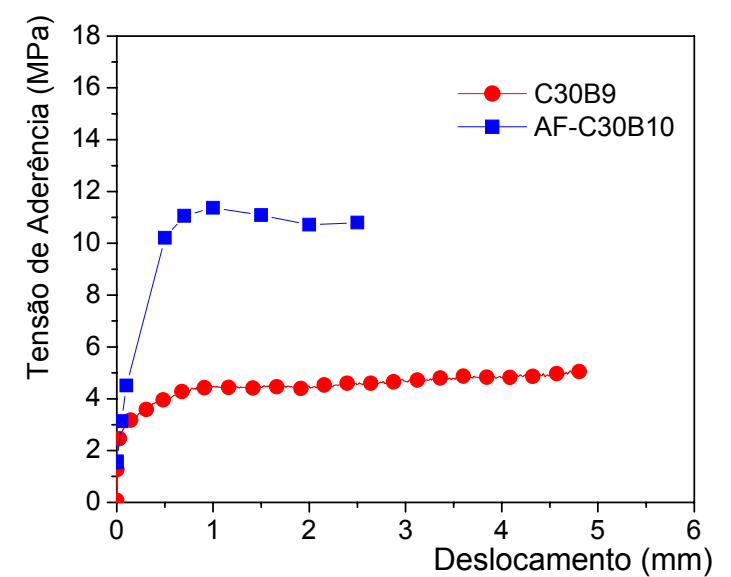

(a)

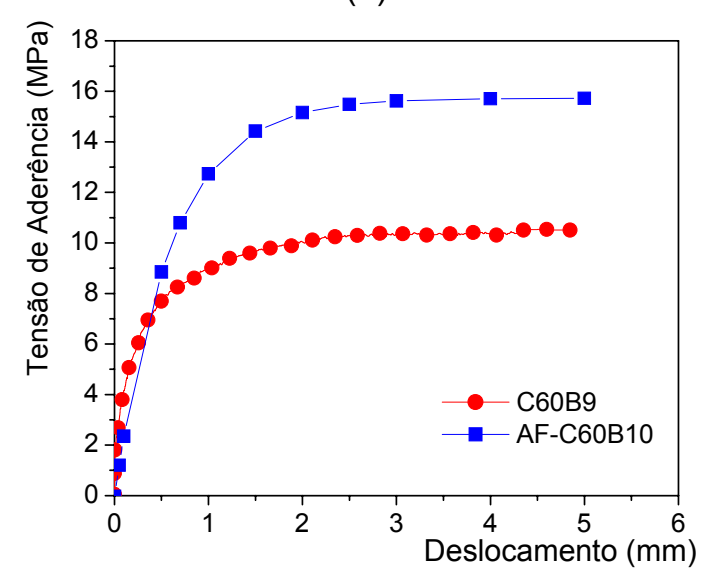

(c)

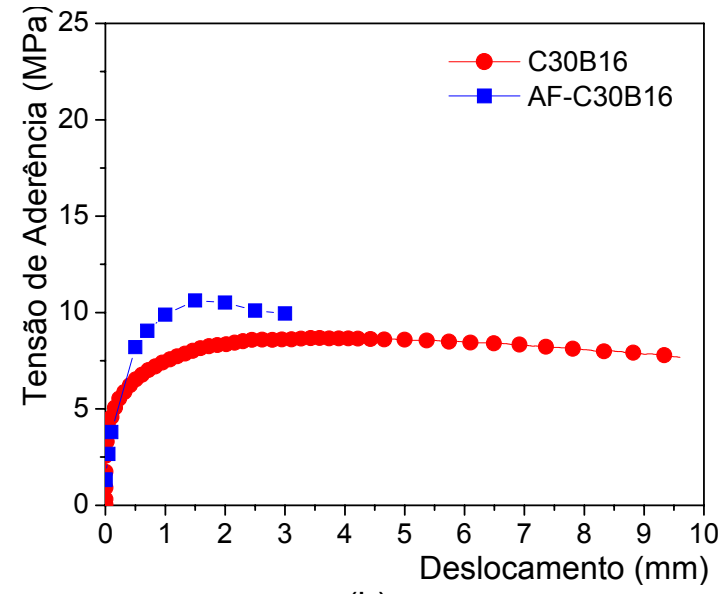

(b)

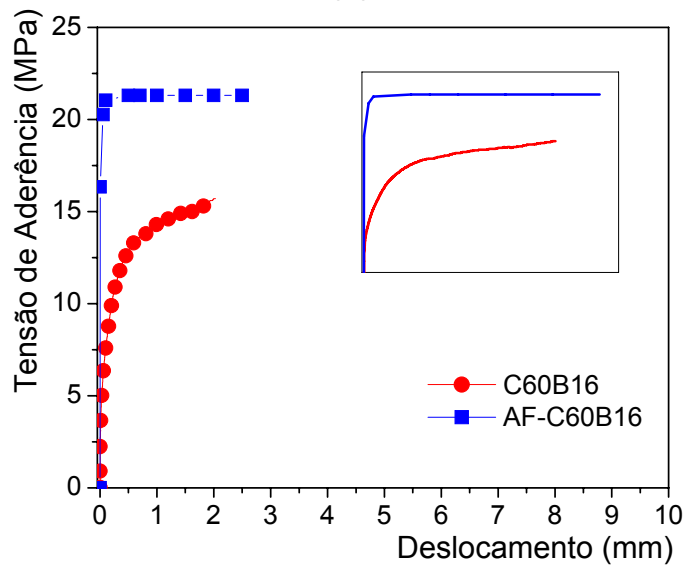

(d)

Figura 6.19 - Comparação das curvas de tensão de aderência x deslocamento obtidas por ALMEIDA FILHO (2006) com as curvas obtidas experimentalmente 


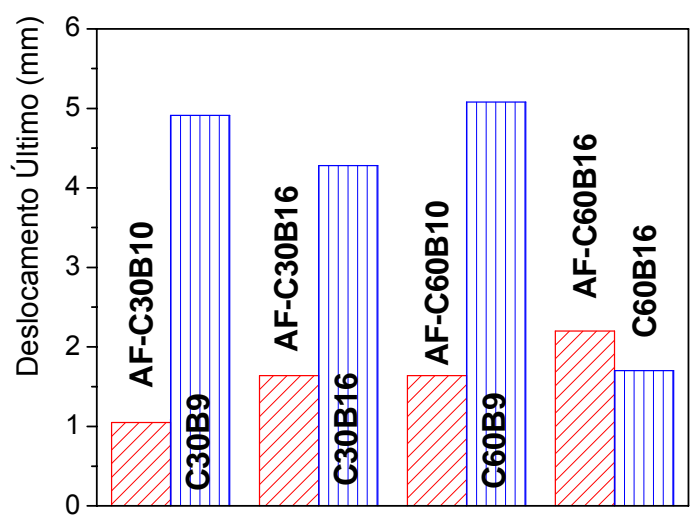

(a)

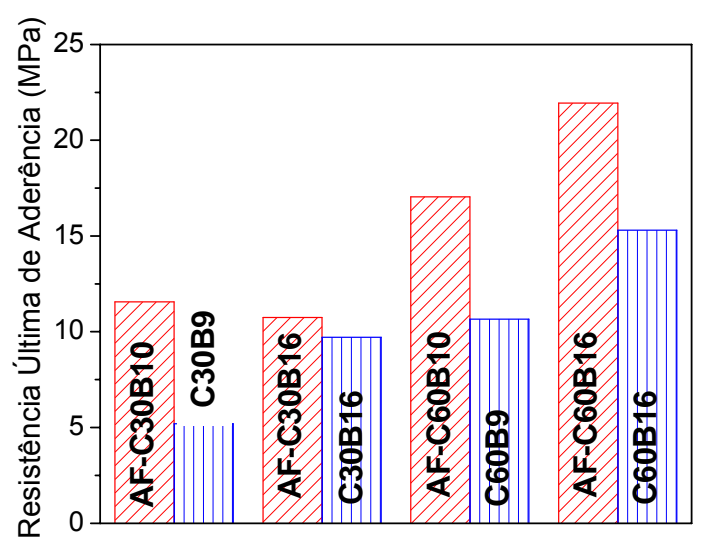

(b)

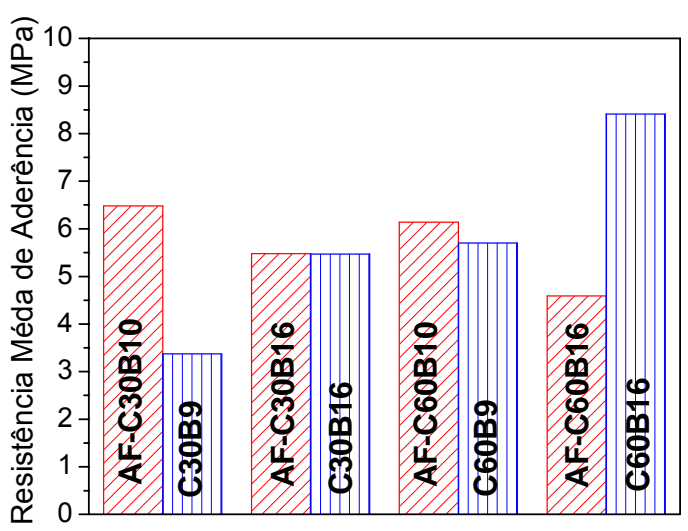

(c)

Figura 6.20 - Comparação dos resultados de deslocamento último, de resistência última de aderência e de resistência média de aderência entre os modelos com barras de GFRP e de aço segundo ALMEIDA FILHO (2006).

De acordo com a Tabela 6.16 e as Figuras 6.19 e 6.20, pode-se concluir parcialmente que:

Os modelos com barras de aço possuem melhor comportamento de aderência quando comparados aos modelos com barras de GFRP, independente da resistência à compressão do concreto e do diâmetro da barra.

A força última de aderência e a resistência última de aderência foram menores para os modelos com barras de GFRP, com os valores variando entre 9\% (C30B16) a $60 \%$ (C30CB9) menores que os modelos similares com barras de aço.

A resistência última de aderência encontrada para os modelos com barras de GFRP foi aproximadamente 33\% menor quando comparados aos modelos com barras de aço.

Os modelos com barras de GFRP apresentaram maiores deslocamentos na ruptura que os modelos com barras de aço, atingindo valores aproximadamente quatro vezes maiores. Com exceção da série AF-C60B16, que apresentou deslocamento $22 \%$ maior que a série C60B16. 
A literatura técnica enfatiza o fato da resistência de aderência entre as barras de FRP e o concreto ser controlada pela parcela da aderência por atrito e não pela aderência mecânica, como acontece com as barras de aço nervuradas. Isto foi comprovado também nos modelos ensaiados neste trabalho, pois a resistência de aderência foi inferior e o deslocamento foi superior nos modelos com barras de GFRP quando comparados aos modelos semelhantes com barras de aço.

A comparação entre a resistência média de aderência dos modelos com barras de GFRP e de aço variou bastante. As séries AF-C30 B16 e C30B16 e AF-C60B10 e C60B9 apresentaram resistência média de aderência semelhante (sem grande variação dos resultados). A série AF-C30B10 obteve um valor aproximadamente $50 \%$ maior do que a série C30B9, enquanto isto, a série AF-C60B16 apresentou um valor $45 \%$ menor do que a série C60B16. Esta dispersão dos resultados pode ser atribuída a grande variação dos valores tensão de aderência referente aos deslocamentos de $0,01 \mathrm{~mm}, 0,1 \mathrm{~mm}$ e $1 \mathrm{~mm}$ encontrados nesta pesquisa e no estudo realizado por ALMEIDA FILHO (2006).

BARBOSA (2001) realizou ensaios de arrancamento de acordo com os procedimentos descritos pela RILEM-CEB-FIP (1973). O estudo considerou modelos de arrancamento com concretos de $20 \mathrm{MPa}, 40 \mathrm{MPa}, 60 \mathrm{mPa}, 80 \mathrm{MPa}$ e $100 \mathrm{MPa}$ e barras de aço com diâmetros de $6,3 \mathrm{~mm}$ a $25 \mathrm{~mm}$. Alguns dos resultados obtidos nesta pesquisa estão representados na Tabela 6.17 .

Tabela 6.17 - Resultados obtidos nos ensaios de arrancamento por BARBOSA (2001)

\begin{tabular}{c|c|c|c|c|c|c|c}
\hline Modelo & $\begin{array}{c}\mathrm{S}_{u} \\
(\mathrm{~mm})\end{array}$ & $\begin{array}{c}\tau_{0,01} \\
(\mathrm{MPa})\end{array}$ & $\begin{array}{c}\tau_{0,1} \\
(\mathrm{MPa})\end{array}$ & $\begin{array}{c}\tau_{1,0} \\
(\mathrm{MPa})\end{array}$ & $\begin{array}{c}\tau_{u} \\
(\mathrm{MPa})\end{array}$ & $\begin{array}{c}\tau_{m} \\
(\mathrm{MPa})\end{array}$ & Ruptura \\
\hline B-C40B10 & 1,20 & 2,88 & 3,99 & 4,70 & 4,75 & 3,86 & $\mathrm{~A}^{1}$ \\
\hline B-40B16 & 1,66 & 4,24 & 5,20 & 16,5 & 19,9 & 8,65 & $\mathrm{~A}$ \\
\hline B-C60B10 & 1,11 & 3,11 & 4,08 & 6,82 & 7,35 & 4,67 & $\mathrm{~A}$ \\
\hline B-C60B16 & 1,63 & 5,17 & 9,70 & 21,30 & 26,6 & 12,0 & $\mathrm{~A}$ \\
\hline B-C80B10 & 1,24 & 3,30 & 4,27 & 8,55 & 8,79 & 5,37 & $\mathrm{~A}$ \\
\hline B-C80B16 & 1,82 & 5,50 & 10,10 & 21,80 & 29,7 & 12,5 & $\mathrm{~F}^{2}$ \\
\hline
\end{tabular}

- ruptura por arrancamento da barra

2 - ruptura por fendilhamento do concreto

A Figura 6.21 ilustra as comparações dos resultados obtidos por BARBOSA (2001) com os resultados dos modelos de arrancamento com barras de GFRP, com relação ao deslocamento último, resistência última de aderência e resistência média de aderência. 


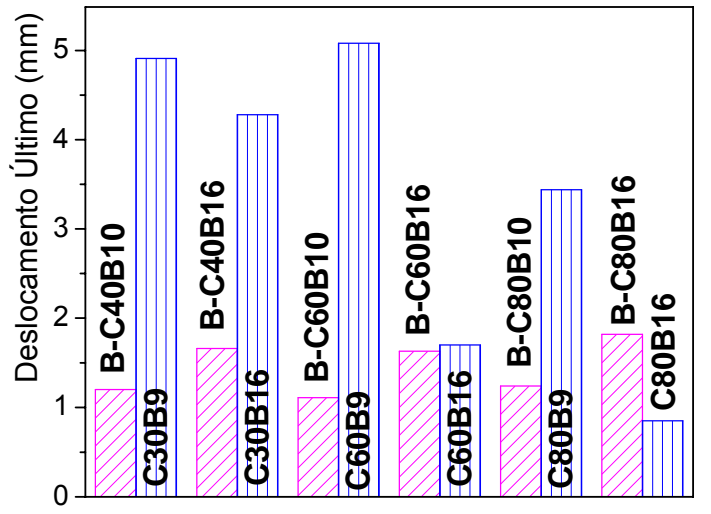

(a)

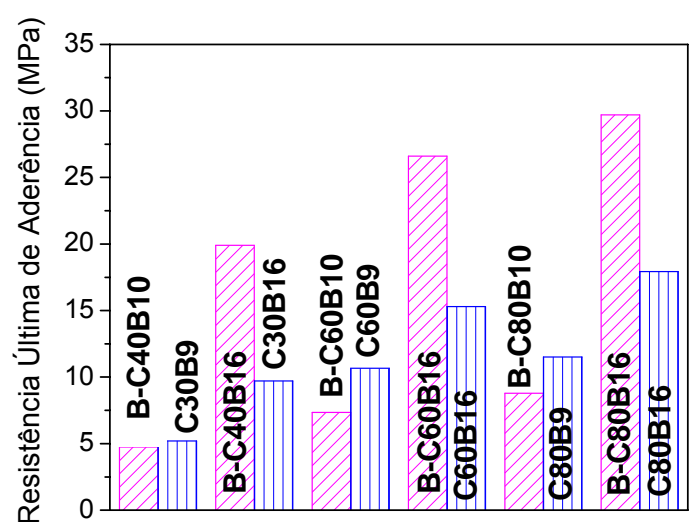

(b)

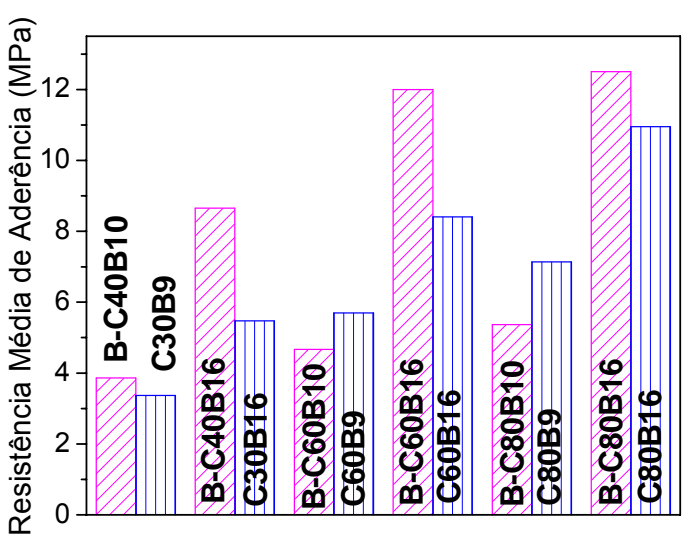

(c)

Figura 6.21- Comparação dos resultados de deslocamento último, de resistência última de aderência e de resistência média de aderência entre os modelos com barras de GFRP e de aço segundo BARBOSA (2001)

Com base na Tabela 6.17 e na Figura 6.21, percebe-se que os deslocamentos últimos desenvolvidos pelas barras de GFRP foram muito maiores que os deslocamentos desenvolvidos pela barras de aço, exceto entre os modelos B-C60B16 e C60B16 e B-C80B16 e C80B16. O mesmo foi observado nas comparações realizadas entre os modelos de GFRP e os modelos de ALMEIDA FILHO (2006).

Os valores de resistência última de aderência e resistência média de aderência foram maiores nos modelos com barras de aço de $16 \mathrm{~mm}$ quando comparados aos modelos com barras de GFRP de $16 \mathrm{~mm}$. Porém, o mesmo não ocorreu nos modelos com barras de $9 \mathrm{~mm}$, os modelos com barras de GFRP apresentaram maiores valores de resistência última de aderência e resistência média de aderência do que os modelos com barras de aço.

Assim como nos modelos de arrancamento com barras de GFRP, os modelos com barras de aço de $10 \mathrm{~mm}$ desenvolvidos por BARBOSA (2001) apresentaram maior resistência de aderência que os modelos de $16 \mathrm{~mm}$.

A partir dos resultados obtidos nos ensaios de arrancamento, BARBOSA (2001) desenvolveu formulações para previsão da resistência de aderência em função 
do deslocamento da barra (Equações 6.8 e 6.9). Estas formulações foram comparadas com os resultados experimentais encontrados neste trabalho, como mostra a Figura 6.22 .

$$
\begin{aligned}
& \tau=19,36 \cdot s^{0,51}(\mathrm{MPa}) \rightarrow f_{c}<50 \mathrm{MPa} \\
& \tau=38,58 \cdot s^{0,48}(\mathrm{MPa}) \rightarrow f_{c} \geq 50 \mathrm{MPa}
\end{aligned}
$$

Sendo:

$\tau$ - resistência de aderência;

s - deslocamento da barra em relação ao concreto.

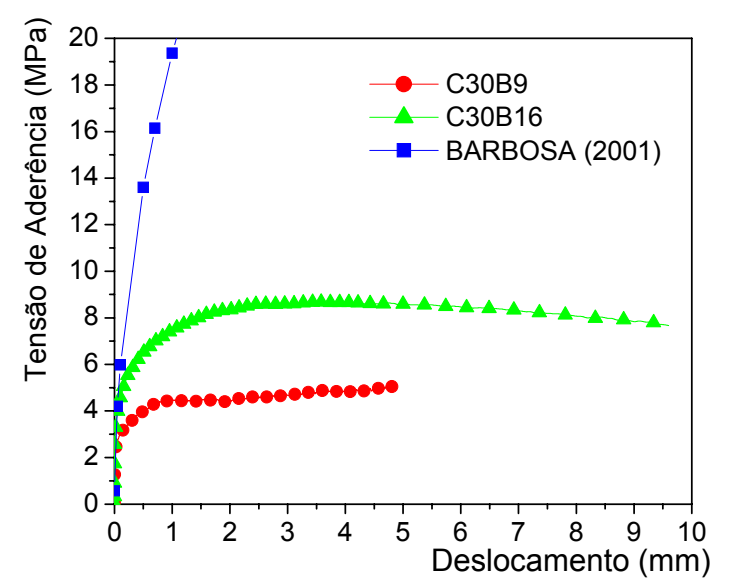

(a)

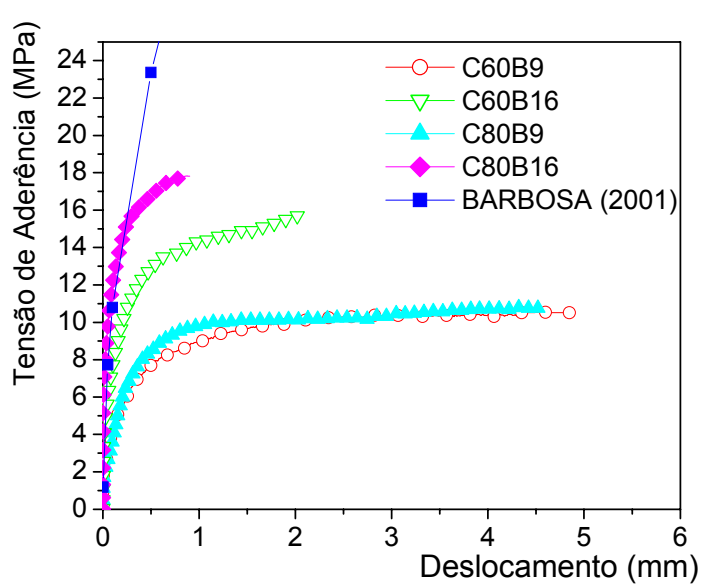

(b)

Figura 6.22 - Comparação dos resultados experimentais com a formulação de BARBOSA (2001) para concreto com resistência à compressão menor que $50 \mathrm{MPa} e$ maior que $50 \mathrm{MPa}$, respectivamente

De acordo com a Figura 6.22, observa-se que as formulações propostas por BARBOSA (2001) para previsão da resistência de aderência se mostraram contra a segurança quando comparadas com os resultados experimentais com barras de GFRP.

Para BARBOSA (2001), a tensão de aderência aumenta muito com o deslocamento, o que não ocorre no caso dos modelos com barras de GFRP. As barras de GFRP apresentaram deslocamento em relação ao concreto muito superior às formulações propostas por BARBOSA (2001) para uma mesma tensão de aderência.

Por fim, os resultados experimentais obtidos neste trabalho foram comparados com formulações de Códigos Normativos (NBR 6118:2003, EUROCODE, 2002 e CEBFIP, 1999) utilizadas para determinar o valor da resistência de aderência de cálculo para as barras de aço. A Tabela 6.18 ilustra as formulações utilizadas nas comparações com os resultados experimentais. 
Tabela 6.18 - Formulações para determinação da resistência de aderência de cálculo segundo os Códigos Normativos

\begin{tabular}{c|c}
\hline Códigos Normativos & Resistência de Aderência de Cálculo \\
\hline NBR 6118:2003 & $f_{b d}=2,25 \cdot \eta_{2} \cdot \eta_{3} \cdot f_{c t d}(M P a)$ \\
\hline EUROCODE (2002) & $f_{b d}=2,25 \cdot \eta_{2} \cdot \eta_{3} \cdot f_{c t d}(M P a)$ \\
\hline CEB-FIP (1999) & $f_{b d}=1,28 \cdot \frac{\ell_{d}}{\phi_{s}} \cdot \ell \mathrm{n}\left(1+\frac{f_{c m}}{10}\right)(M P a)$ \\
\hline
\end{tabular}

A Figura 6.23 mostra as comparações realizadas entre os resultados experimentais e as formulações previstas pelos Códigos Normativos para a determinação da resistência de aderência de cálculo.

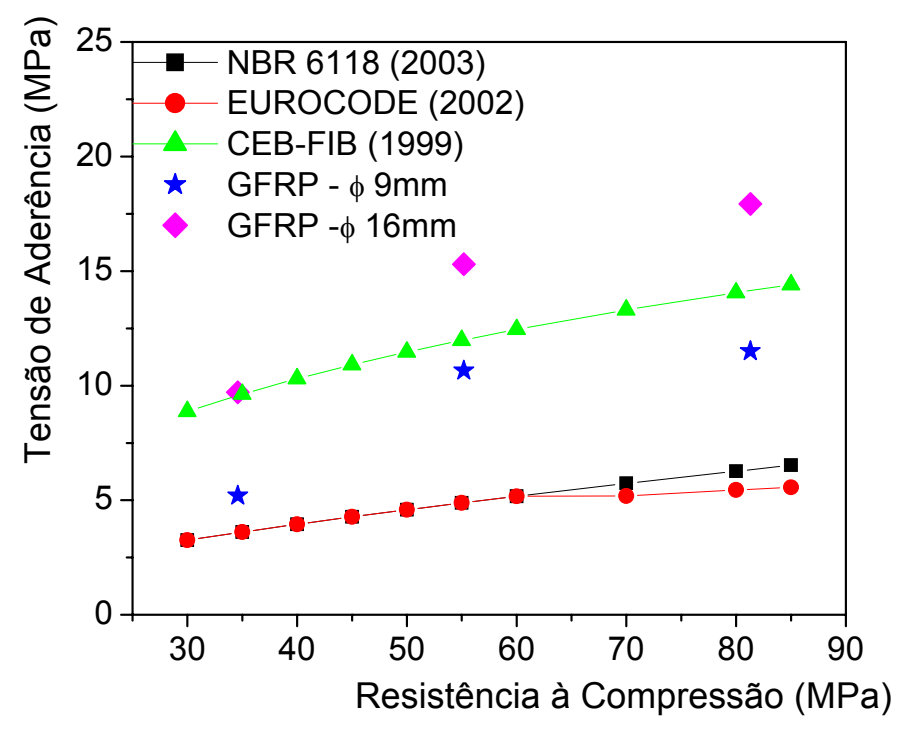

Figura 6.23 - Comparação dos resultados experimentais com a formulações de Códigos Normativos concreto armado com barras de aço

A NBR 6118:2003 e o EUROCODE (2002) se apresentaram bastante conservadores, pois adotam como consideração da perda da aderência a ruptura por adesão. O valor da resistência de aderência foi menor do que o valor encontrado experimentalmente nos modelos com barras de GFRP, para todos os casos. Vale ressaltar que, as comparações realizadas com ALMEIDA FILHO (2006), BARBOSA (2001) e mesmo a literatura técnica mostram que a resistência de aderência entre as barras de FRP e o concreto é menor que a resistência de aderência entre barras de aço e o concreto.

O CEB-FIP (1999) foi o Código Normativo que mostrou melhor aproximação com os resultados experimentais, Porém, os modelos com barras de $9 \mathrm{~mm}$ apresentaram valores de resistência última de aderência inferior à formulação prevista pelo referido código. 


\subsection{Análise do comprimento de ancoragem básico e da resistência de aderência}

Neste item é realizada a análise do comprimento de ancoragem básico $\left(\ell_{b}\right)$ e da resistência de aderência $\left(f_{b d}\right)$ para estruturas em concreto armado com barras de GFRP. Os resultados encontrados nos ensaios de arrancamento foram utilizados para a obtenção de equações que possam representar o comprimento de ancoragem básico e a resistência de aderência para estruturas em concreto armado com barras de GFRP.

É importante ressaltar que as equações desenvolvidas neste item são válidas apenas para as barras utilizadas neste trabalho, pois qualquer alteração no processo de fabricação, tipo e porcentagem de resina e fibra e conformação superficial das barras podem alterar no comportamento de aderência.

A Figura 6.24 ilustra a condição de equilíbrio de uma barra de GFRP, com comprimento igual ao comprimento de ancoragem básico, em uma peça de concreto. Para que a barra não escorregue, é preciso que surja uma resistência de aderência, agindo na superfície da barra, e que se opõe ao movimento de tração da barra.

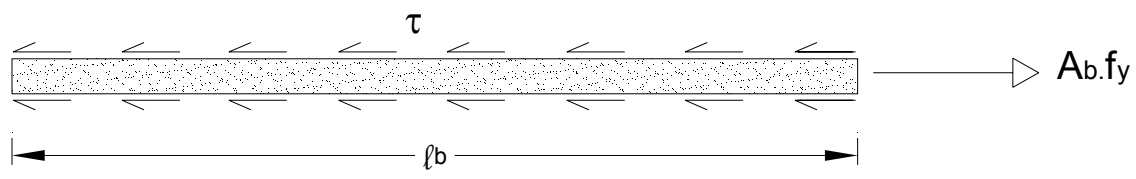

Figura 6.24 - Transferência de força em todo comprimento de ancoragem (ACl 440 1R, 2003)

O equilíbrio de forças pode ser escrito da seguinte maneira:

$\ell_{b} \cdot \pi \cdot \phi \cdot f_{b d}=A_{b} \cdot f_{y}$

Sendo:

$A_{b}$ - área de uma barra;

$\mathrm{f}_{\mathrm{y}}$ - resistência última da barra.

$f_{b d}$ - resistência de aderência,

$\ell_{b}$ - comprimento de ancoragem básico.

Rearranjando a Eq. 6.10, o comprimento de ancoragem básico pode ser expresso de acordo com a Eq. 6.11.

$$
\ell_{b}=\frac{\phi \cdot f_{y}}{4 \cdot f_{b d}}
$$


O ACl 318 (1999) estabelece uma equação (Eq. 6.12) para o cálculo do comprimento de ancoragem básico de barras de aço em estruturas em concreto armado, que é função do diâmetro da barra, resistência última da barra e resistência à compressão do concreto; podendo ser extrapolada para barras de GFRP.

$$
\ell_{b}=K \cdot \frac{A_{b} \cdot f_{y}}{\sqrt{f_{c}}}
$$

Sendo:

$\mathrm{K}$ - constante;

$\mathrm{f}_{\mathrm{c}}$ - resistência à compressão do concreto,

$A_{b}$ - área da seção transversal da barra.

Com base na Eq 6.11 e Eq 6.12 é possível determinar o valor da constante $\mathrm{K}$ (Eq. 6.13):

$$
K=\frac{\sqrt{f_{c}}}{f_{b d} \cdot \pi \cdot \phi}
$$

De acordo com os resultados obtidos na investigação experimental, pode-se determinar o valor de $\mathrm{K}$ e em seguida propor uma equação para o cálculo do comprimento ancoragem básico de barras de GFRP. A Tabela 6.19 mostra o valor de $\mathrm{K}$ encontrado para cada série de ensaios de arrancamento realizada.

Tabela 6.19 - Valor do coeficiente K para as barras de GFRP

\begin{tabular}{c|c|c|c|c}
\hline Séries de arrancamento & $f_{c}(\mathrm{MPa})$ & $\tau_{\max }(\mathrm{MPa})$ & $\phi_{\text {exp }}(\mathrm{cm})$ & $K$ \\
\hline C30B9 & 34,6 & 5,20 & 9,56 & 0,038 \\
\hline C30B16 & 34,6 & 9,71 & 15,88 & 0,012 \\
\hline C60B9 & 55,2 & 10,66 & 9,56 & 0,023 \\
\hline C60B16 & 55,2 & 15,30 & 15,88 & 0,010 \\
\hline C80B9 & 81,3 & 11,51 & 9,56 & 0,026 \\
\hline C80B16 & 81,3 & 17,93 & 15,88 & 0,010 \\
\hline Média & - & - & - & 0,020 \\
\hline
\end{tabular}

$\mathrm{O}$ valor de $\mathrm{K}$ encontrado para as barras de GFRP analisadas foi de 0,020. Porém, deve-se estabelecer um coeficiente de segurança para que não ocorra ruptura da aderência na zona de ancoragem, com base nisto, foi estabelecido o valor de resistência de aderência igual ao valor da tensão de aderência média dos modelos C30B9 $\left(\tau_{\mathrm{m}}=3,40 \mathrm{MPa}\right)$, como está representado na Tabela 6.20. 
Tabela 6.20 - Valor do coeficiente K para as barras de GFRP, considerando menor resistência de aderência

\begin{tabular}{c|c|c|c|c}
\hline Séries de arrancamento & $f_{c}(\mathrm{MPa})$ & $\tau(\mathrm{MPa})$ & $\phi_{\exp }(\mathrm{mm})$ & $K$ \\
\hline C30B9 & 34,6 & 3,40 & 9,56 & 0,058 \\
\hline C30B16 & 34,6 & 3,40 & 15,88 & 0,035 \\
\hline C60B9 & 55,2 & 3,40 & 9,563 & 0,073 \\
\hline C60B16 & 55,2 & 3,40 & 15,88 & 0,044 \\
\hline C80B9 & 81,3 & 3,40 & 9,56 & 0,088 \\
\hline C80B16 & 81,3 & 3,40 & 15,88 & 0,053 \\
\hline Média & - & - & - & 0,058 \\
\hline
\end{tabular}

$\mathrm{O}$ valor de $\mathrm{K}$ encontrado, considerando menor resistência de aderência, foi de 0,058. Com isto, pode-se escrever a equação para o cálculo do comprimento de ancoragem básico para as barras de GFRP analisadas neste trabalho:

$$
\ell_{b}=0,058 \cdot \frac{A_{b} \cdot f_{y}}{\sqrt{f_{c}}}(\mathrm{~mm})
$$

A Eq. 6.15 pode ser rearranjada e expressa em termos da resistência de aderência:

$$
f_{b d}=17,182 \cdot \frac{\sqrt{f_{c}}}{\phi \cdot \pi}(M P a)
$$

Alguns autores propuseram equações para o cálculo do comprimento de ancoragem básico e resistência de aderência de barras de GFRP, com base em resultados de ensaios de arrancamento e viga. A Tabela 6.21 resume os ensaios realizados e os valores de $\mathrm{K}$ propostos pelos autores.

Tabela 6.21 - Valor do coeficiente K para as barras de GFRP, segundo alguns autores

\begin{tabular}{c|c|c|c|c|c}
\hline & Ensaios & $\phi(\mathrm{mm})$ & $f_{c}(\mathrm{MPa})$ & $\left(K_{1}\right)^{1}$ & $\left(K_{2}\right)^{2}$ \\
\hline $\begin{array}{c}\text { PLEIMANN (1987, 1991) } \\
\text { apud ACI 440 1R (2003) }\end{array}$ & Arrancamento & $6 ; 10 ; 13$ & - & 19,40 & 0,052 \\
\hline $\begin{array}{c}\text { FAZA, GANGARAO } \\
(1990)^{4} \text { apud ACI 440 1R } \\
(2003)\end{array}$ & $\begin{array}{c}\text { Viga e } \\
\text { arrancamento }\end{array}$ & - & - & 16,70 & 0,060 \\
\hline $\begin{array}{c}\text { EHSANI, } \\
\text { SAADATMANESH, TAO } \\
(1996)\end{array}$ & $\begin{array}{c}\text { Viga e } \\
\text { arrancamento }\end{array}$ & $10 ; 13 ; 29$ & $28 ; 56$ & 21,30 & 0,047 \\
\hline $\begin{array}{c}\text { TIGHIOUART, } \\
\text { BENMOKRANE, GAO } \\
(1998)\end{array}$ & Viga & $13 ; 16 ; 19$ & 31 & 15,61 & 0,064 \\
\hline $\begin{array}{c}\text { Tonstante utilizada no cálculo de } \mathrm{f}_{\mathrm{bd}} \\
2 \text { constante utilizada no cálculo de } \ell_{b}\end{array}$ \\
\hline
\end{tabular}


Os valores de $\mathrm{K}_{1}$ e $\mathrm{K}_{2}$ sugeridos neste trabalho são diferentes dos encontrados na literatura técnica (Tabela 6.16), isto ocorre porque tanto os ensaios realizados como as barras utilizadas por cada autor são diferentes.

TIGHIOUART, BENMOKRANE, GAO (1998), admitiram o valor do coeficiente $\mathrm{K}$ para barras de aço nervuradas, de acordo com ensaios de aderência em vigas, igual a 0,04 . Com base neste valor de $K$, pode-se dizer que o comprimento de ancoragem básico para as barras de GFRP estudadas é cerca de $45 \%$ maior quando comparado ao comprimento de ancoragem básico para as barras de aço nervuradas de diâmetro similar.

\subsection{Simulação numérica}

Neste item será apresentado a análise dos resultados para os modelos numéricos de arrancamento realizados no Capítulo 5. Procurou-se analisar o comportamento das tensões na superfície de contato (utilizando elementos de concreto) e as tensões principais na direção $Z$ no instante de carregamento definido.

ALMEIDA FILHO (2006) verificou o comportamento das tensões ao longo do comprimento aderente, utilizando elementos de contato e elementos de concreto situados na superfície mais próxima à superfície de contato. Foi observado que as tensões no concreto conduziram a resultados mais próximos da realidade quando comparado aos elementos de contato.

Assim, neste trabalho utilizaram-se os elementos de concreto (situados na superfície mais próxima à superfície de contato) para a verificação das tensões na superfície de contato.

Vale salientar a falta de resultados experimentais para avaliação do comportamento das tensões de aderência ao longo do comprimento aderente. Então, os resultados obtidos na simulação numérica são considerados como uma estimativa de como seria o comportamento dessas tensões.

Os pontos de medição adotados no contato estão representados na Figura 6.25 .

${ }^{3}$ PLEIMANN, L. G.(1987), "Tension and Bond Pullout Tests of Deformed Fiberglass Rods," Final Report for Marshall-Vega Corporation, Marshall, Arkansas, Civil Engineering Department, University of Arkansas, Fayetteville, Ark., pp. 5-11.

${ }^{3}$ PLEIMANN, L. G. (1991), "Strength, Modulus of Elasticity, and Bond of Deformed FRP Rods," Proceedings of the Specialty Conference on Advanced Composite Materials in Civil Engineering Structures, Material Engineering Division, American Society of Civil Engineers, pp. 99-110.

${ }^{4}$ FAZA, S. S., and GANGARAO, H. V. S. (1990), "Bending and Bond Behavior of Concrete Beams Reinforced with Plastic Rebars," Transportation Research Record 1290, pp. 185-193. 


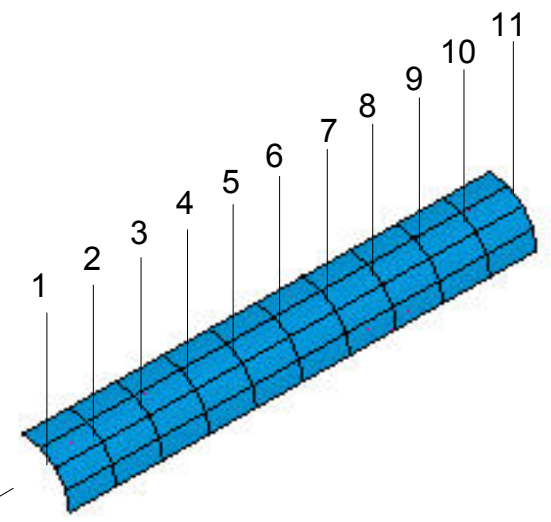

Sentido do carregamento

Figura 6.25 - Pontos de medição de força e deslocamento no elemento de contato

\subsubsection{Série C30B9}

A Figura 6.16 ilustra a variação da resistência na superfície de contato durante o passo de carga correspondente ao ponto 1 do diagrama força $\mathrm{x}$ deslocamento, determinado no Capítulo 5.

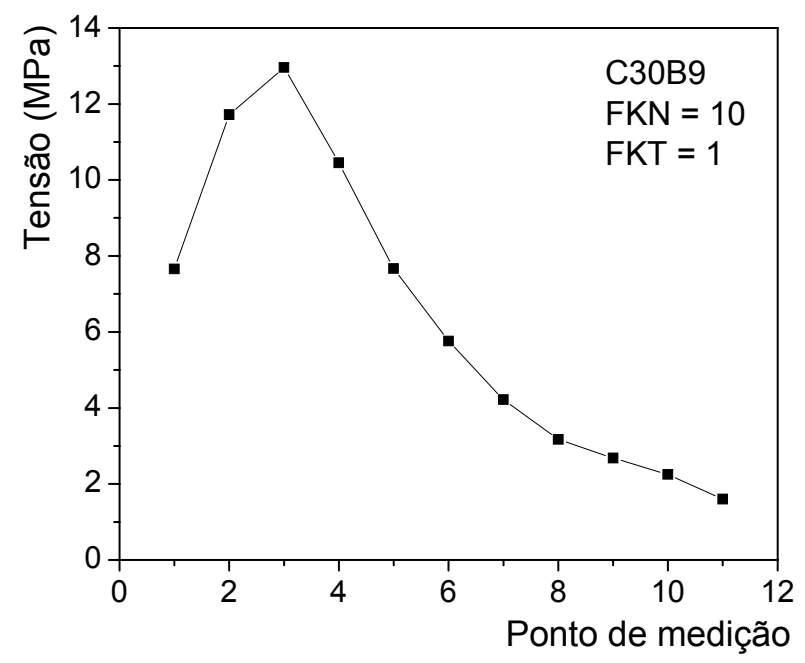

Figura 6.26 - Tensão na superfície de contato para o modelo C30B9

De acordo com a Figura 6.26, observa-se que a tensão de aderência no contato diminuiu a mediada que os pontos de medição se aproximaram da extremidade não carregada da barra, ou seja, os pontos iniciais se mostraram mais solicitados quando comparados aos pontos finais.

A Figura 6.27 ilustra as tensões principais na direção $Z$ (sentido do deslocamento da barra em relação ao concreto) no passo de carga correspondente ao ponto 1. 

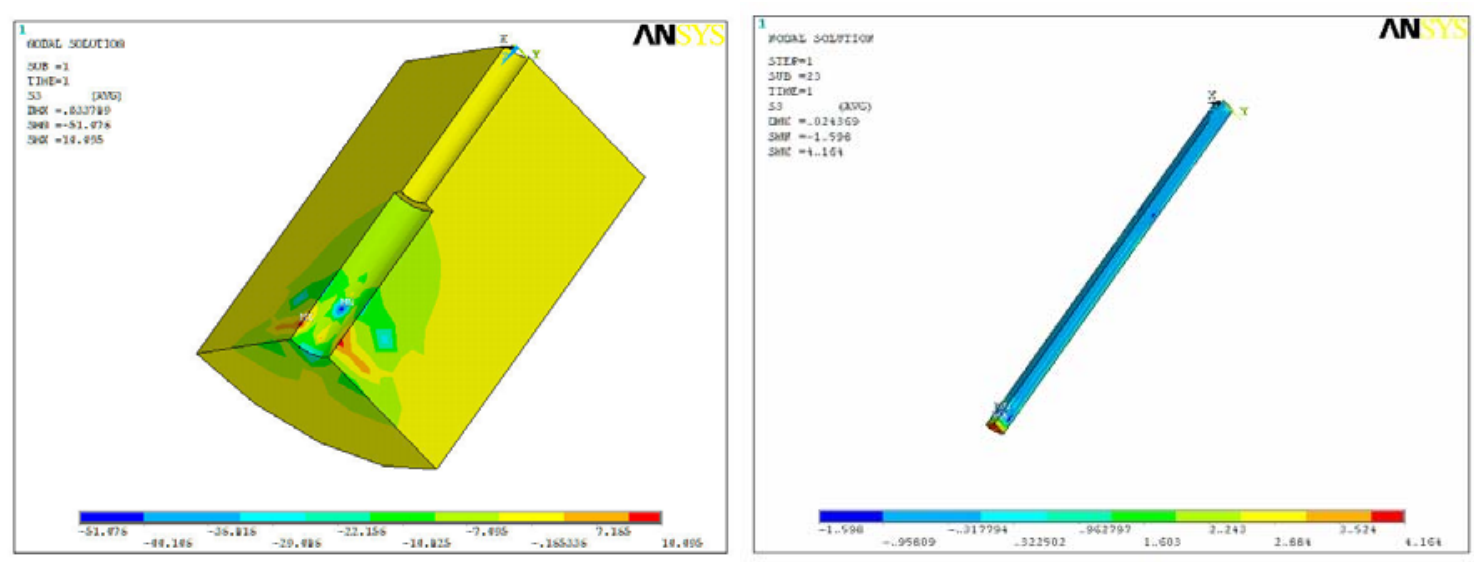

Figura 6.27 - Tensões principais na direção Z para o modelo C30B9

De acordo com a Figura 6.27, pode-se perceber que o prisma de concreto se mostrou pouco solicitado à tração, ou seja, a provável ruptura da aderência neste caso seria por arrancamento da barra.

A barra de GFRP apresentou pouca tensão de tração ao longo do seu comprimento, não alcançando sua carga de ruptura.

\subsubsection{Série C30B16}

A Figura 6.28 ilustra a variação da resistência na superfície de contato durante o passo de carga correspondente ao ponto 1 do diagrama experimental força $\mathrm{x}$ deslocamento.

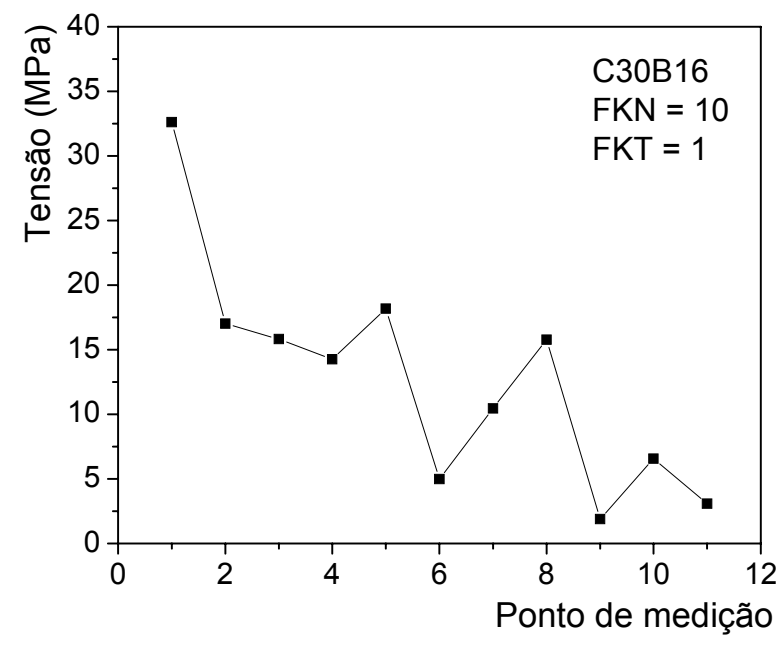

Figura 6.28 - Tensão na superfície de contato para o modelo C30B9

De acordo com a Figura 6.28, observa-se grande variação das tensões de aderência no contato, por exemplo, o ponto de medição 8 apresentou maior tensão quando comparado ao ponto 3 ou 4 . 
A Figura 6.29 ilustra as tensões principais na direção $Z$ (sentido do deslocamento da barra em relação ao concreto) no passo de carga correspondente ao ponto 1 .
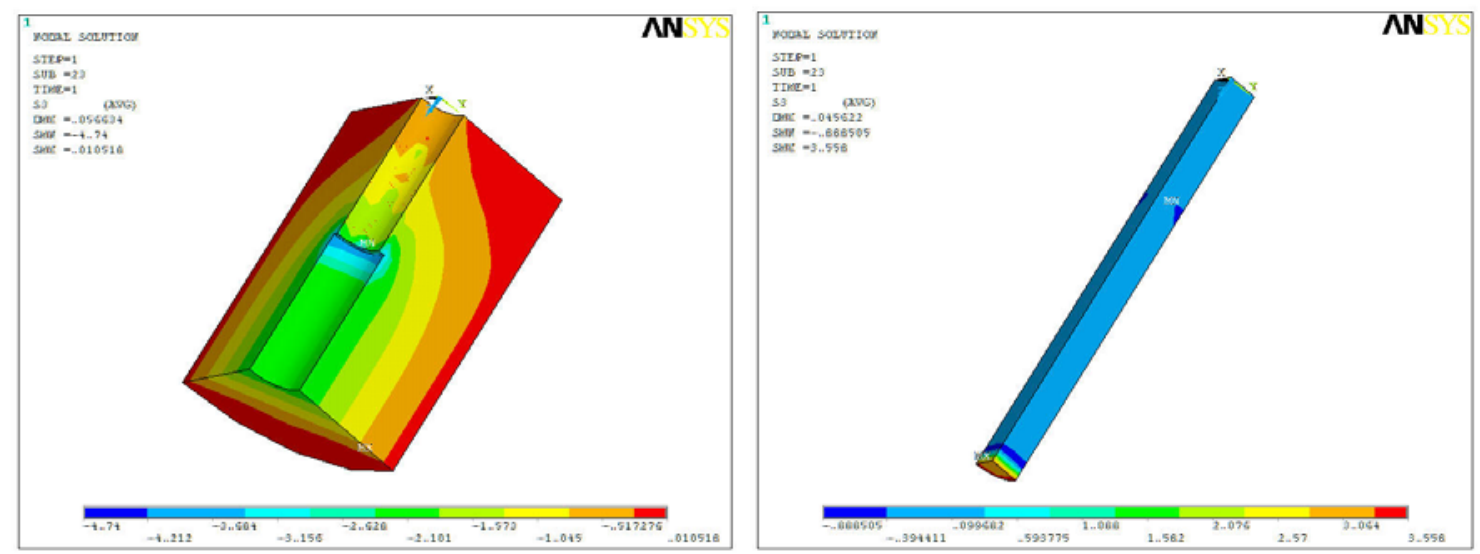

Figura 6.29 - Tensões principais na direção Z para o modelo C30B9

De acordo com a Figura 6.29, observa-se que o prisma de concreto apresentou tensões de tração na superfície mais externa, porém os valores são considerados baixos, dentro do limite de resistência à tração do concreto.

A barra de GFRP apresentou pouca tensão de tração ao longo do seu comprimento, não alcançando sua carga de ruptura.

\subsubsection{Série C60B9}

A Figura 6.30 ilustra a variação da resistência na superfície de contato durante o passo de carga correspondente ao ponto 1 do diagrama experimental força $\mathrm{x}$ deslocamento.

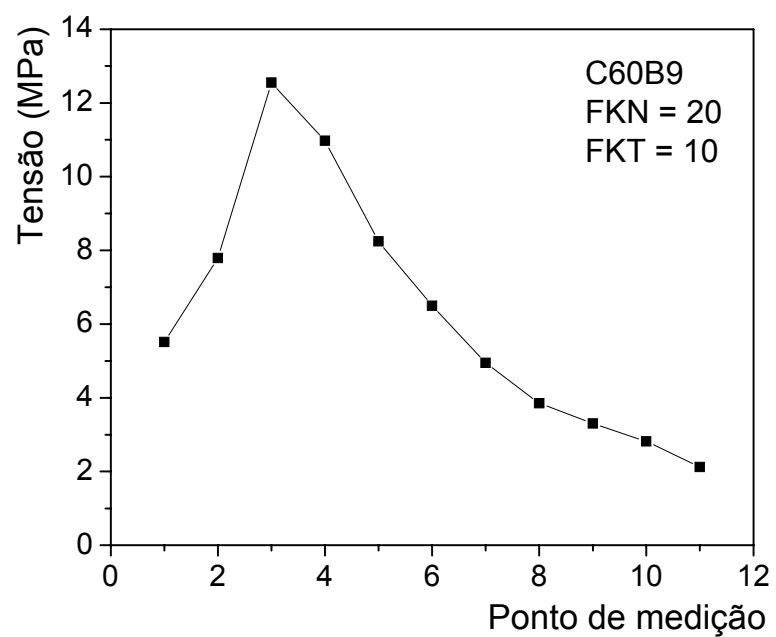

Figura 6.30 - Tensão na superfície de contato para o modelo C30B9 
De acordo com a Figura 6.30, observa-se que a tensão de aderência no contato diminuiu a mediada que os pontos de medição se aproximaram da extremidade da barra oposta aquela em que se aplicou a força, ou seja, os pontos iniciais se mostraram mais solicitados quando comparados aos pontos finais.

A Figura 6.27 ilustra as tensões principais na direção $Z$ (sentido do deslocamento da barra em relação ao concreto) no passo de carga correspondente ao ponto 1.

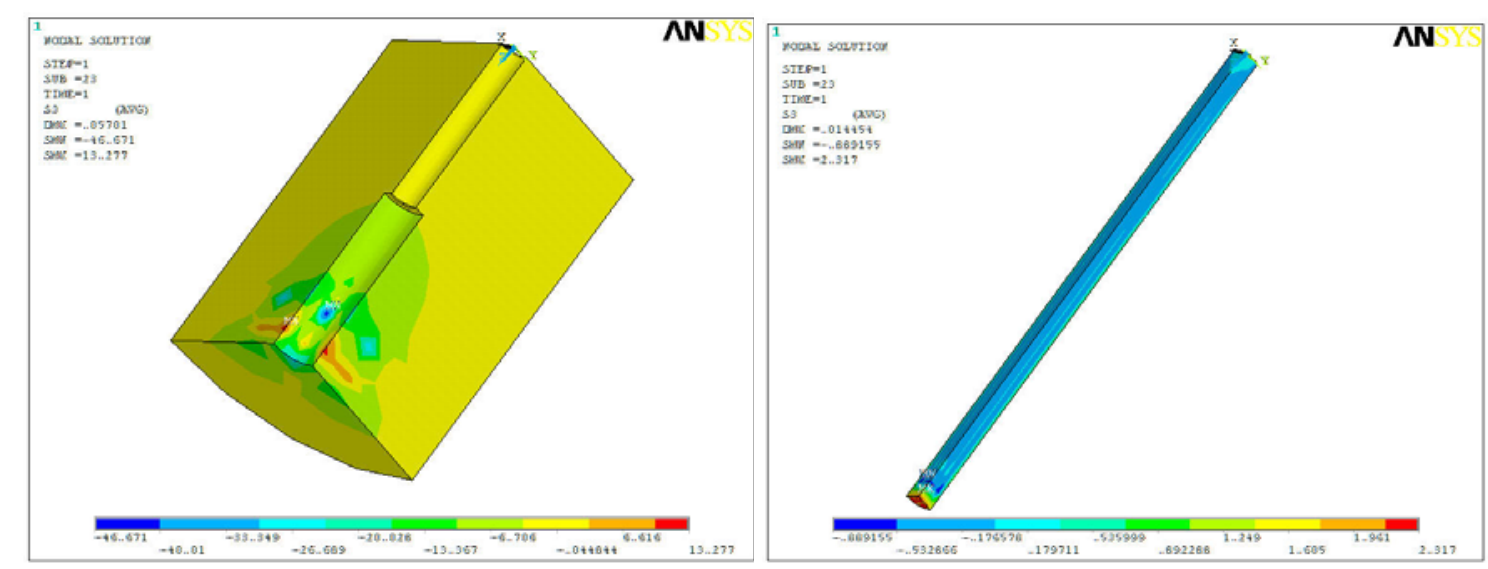

Figura 6.31 - Tensões principais na direção Z para o modelo C30B9

De acordo com a Figura 6.31, pode-se perceber que o prisma de concreto se mostrou pouco solicitado à tração, ou seja, a provável ruptura da aderência neste caso seria por arrancamento da barra.

A barra de GFRP apresentou pouca tensão de tração ao longo do seu comprimento, não alcançando sua força de ruptura.

\subsubsection{Série C60B16}

A Figura 6.32 ilustra a variação da resistência na superfície de contato durante o passo de carga correspondente ao ponto 1 do diagrama força $\mathrm{x}$ deslocamento, determinado no Capítulo 5. 


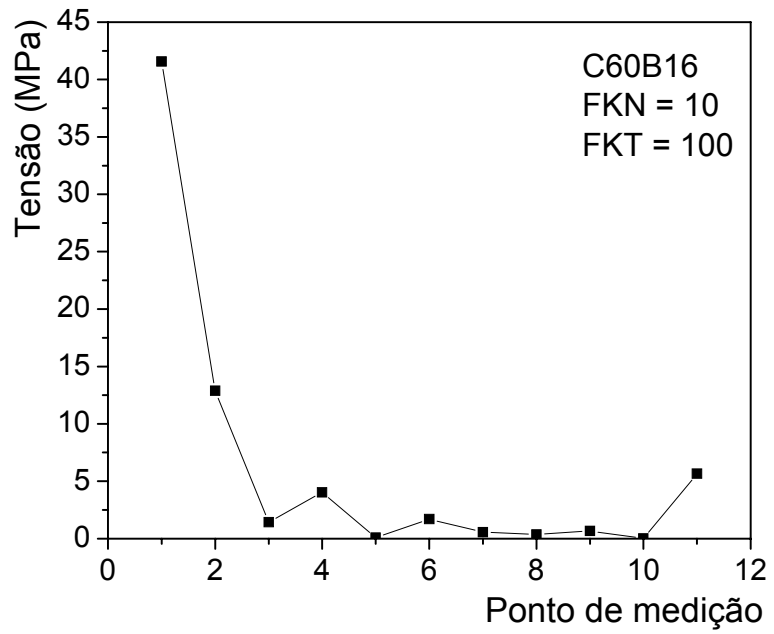

Figura 6.32 - Tensão na superfície de contato para o modelo C30B9

De acordo com a Figura 6.32, observa-se que a tensão de aderência no contato diminuiu à medida que os pontos de medição se aproximaram da extremidade não carregada da barra. Os pontos 3 a 12 apresentaram certa variação de resultados, mas pode-se considerar que o contato foi pouco solicitado em relação a estes pontos.

A Figura 6.33 ilustra as tensões principais na direção $Z$ (sentido do deslocamento da barra em relação ao concreto) no passo de carga correspondente ao ponto 1.
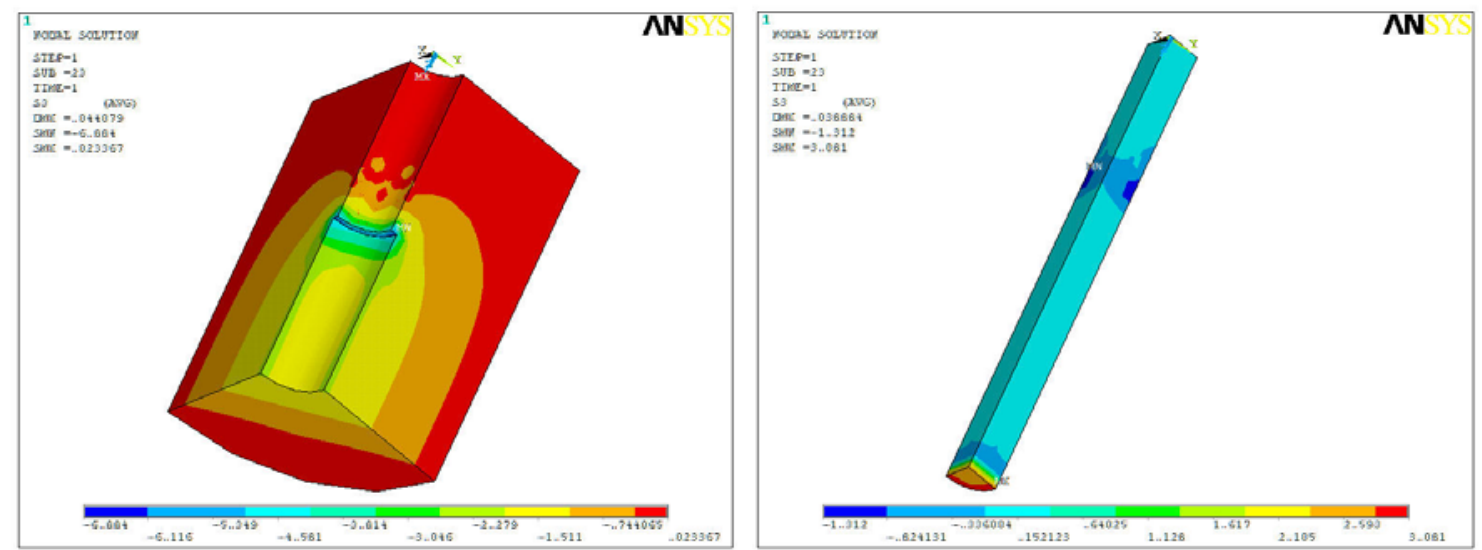

Figura 6.33 - Tensões principais na direção Z para o modelo C30B9

De acordo com a Figura 6.33, pode-se perceber que o prisma de concreto se mostrou solicitado à tração, ou seja, a ocorrência de ruptura por fendilhamento do concreto pode ocorrer em um passo de carga posterior.

A barra de GFRP apresentou pouca tensão de tração ao longo do seu comprimento, não alcançando sua carga de ruptura. 


\subsubsection{Série C80B9}

A Figura 6.34 ilustra a variação da resistência na superfície de contato durante o passo de carga correspondente ao ponto 1 do diagrama força $\mathrm{x}$ deslocamento, determinado no Capítulo 5.

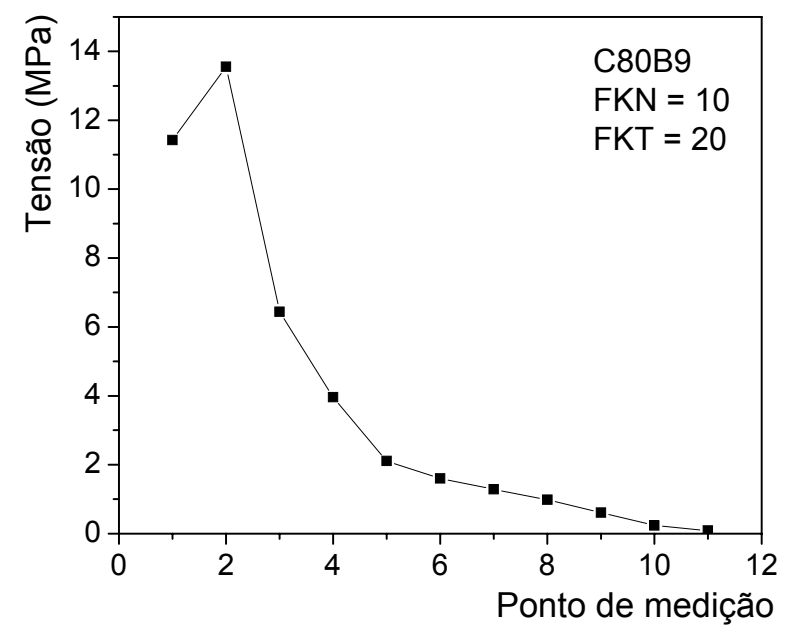

Figura 6.34 - Tensão na superfície de contato para o modelo C30B9

De acordo com a Figura 6.34, observa-se que a tensão de aderência no contato diminuiu à medida que os pontos de medição se aproximaram da extremidade não carregada da barra, ou seja, os pontos iniciais se mostraram mais solicitados quando comparados aos pontos finais.

A Figura 6.35 ilustra as tensões principais na direção $Z$ (sentido do deslocamento da barra em relação ao concreto) no passo de carga correspondente ao ponto 1.
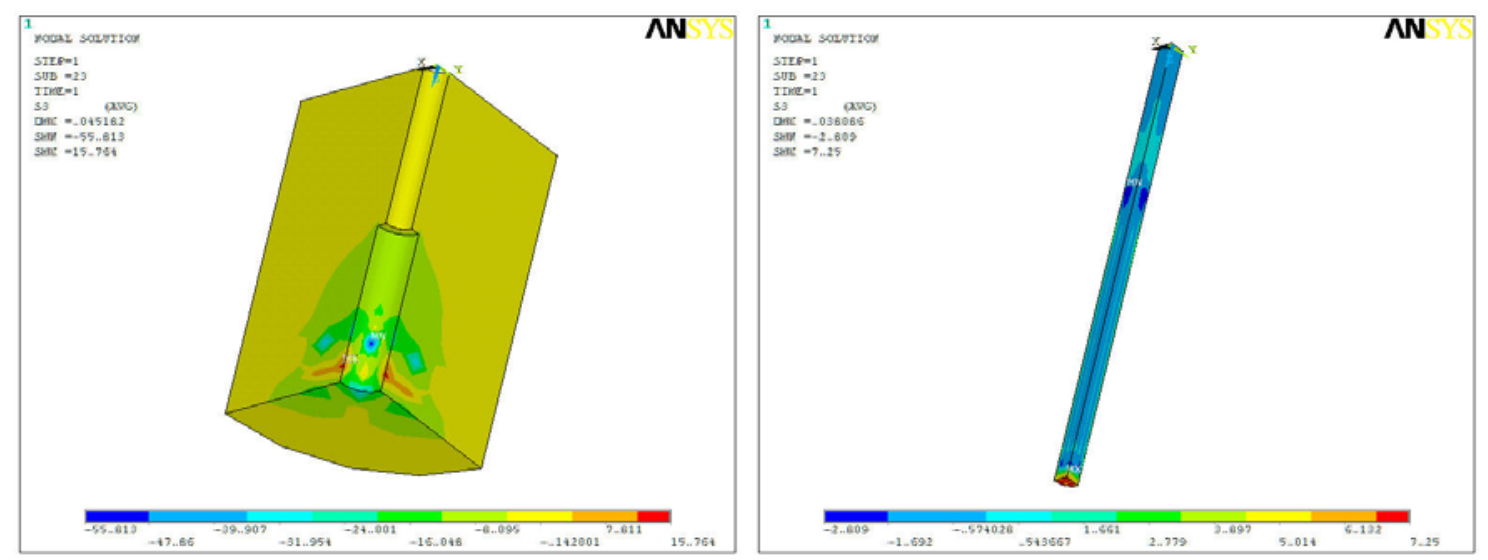

Figura 6.35 - Tensões principais na direção Z para o modelo C30B9 
De acordo com a Figura 6.31, pode-se perceber que o prisma de concreto se mostrou pouco solicitado à tração, ou seja, a provável ruptura da aderência neste caso seria por arrancamento da barra.

A barra de GFRP apresentou pouca tensão de tração ao longo do seu comprimento, não alcançando sua carga de ruptura.

\subsubsection{Série C80B16}

A Figura 6.36 ilustra a variação da resistência na superfície de contato durante o passo de carga correspondente ao ponto 1 do diagrama força $\mathrm{x}$ deslocamento, determinado no Capítulo 5.

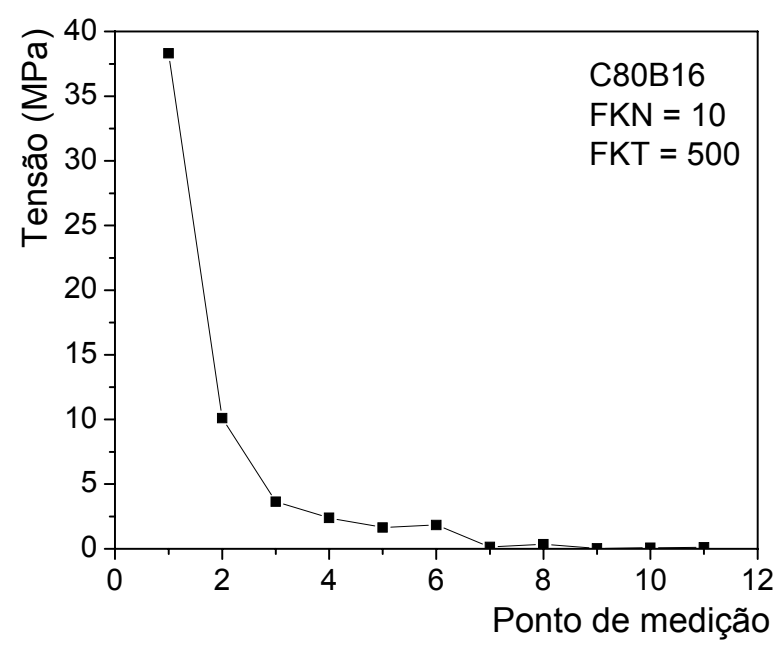

Figura 6.36 - Tensão na superfície de contato para o modelo C30B9

De acordo com a Figura 6.36, observa-se que a tensão de aderência no contato diminuiu a mediada que os pontos de medição se aproximaram da extremidade não carregada da barra. Os pontos 7 a 12 apresentaram valores de tensão próximos de zero, mostrando que para estes pontos o contato não foi solicitado.

A Figura 6.27 ilustra as tensões principais na direção $Z$ (sentido do deslocamento da barra em relação ao concreto) no passo de carga correspondente ao ponto 1. 

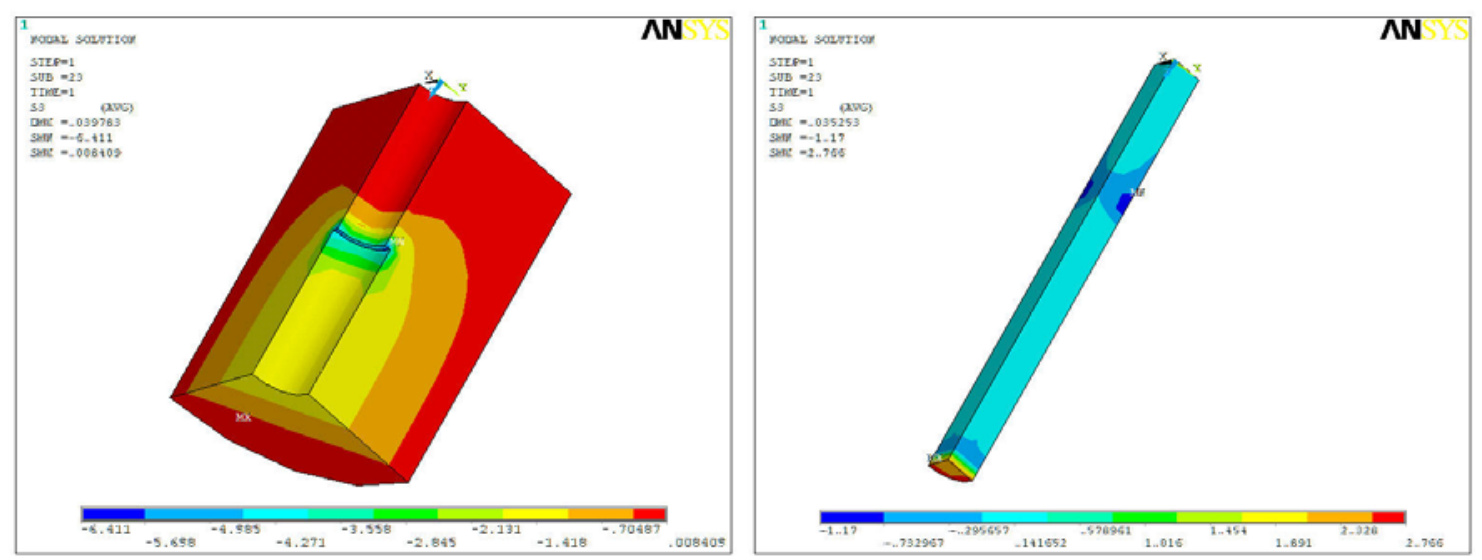

Figura 6.37 - Tensões principais na direção Z para o modelo C30B9

De acordo com a Figura 6.37, pode-se perceber que o prisma de concreto se mostrou solicitado à tração, ou seja, a ocorrência de ruptura por fendilhamento do concreto pode ocorrer em um passo de carga posterior.

A barra de GFRP apresentou pouca tensão de tração ao longo do seu comprimento, não alcançando sua carga de ruptura.

Com relação aos valores de tensão no concreto obtidos nos modelos numéricos apresentados acima, alguns ultrapassaram o seu valor de resistência à compressão e à tração. Isto pode ser explicado pelo fato da simulação numérica linear não considerar a resistência última de cada material constituinte, para uma melhor representação do comportamento experimental é justificado o uso de um modelo numérico não linear com critério de ruptura.

As tensões na superfície de contato obtidas por meio da simulação numérica apresentam maiores valores quando comparados aos valores experimentais de resistência última de aderência, para todos os modelos analisados, isto também foi verificado por ALMEIDA FILHO (2006), ALMEIDA FILHO et al. (2006).

Os modelos com barras de diâmetro de $9 \mathrm{~mm}$ apresentaram comportamento similar, independente da resistência do concreto, isto tanto para as tensões principais na direção $Z$ como para as tensões desenvolvidas ao longo da superfície de contato. $O$ mesmo foi observado quando se consideram os modelos com barra de diâmetro de 16 $\mathrm{mm}$.

A Figura 6.37 ilustra a comparação dos resultados da tensão ao longo da superfície de contato para os modelos numéricos com barra de $9 \mathrm{~mm}$ (Figura 6.37-a) e com barra de $16 \mathrm{~mm}$ (Figura 6.37-b). 


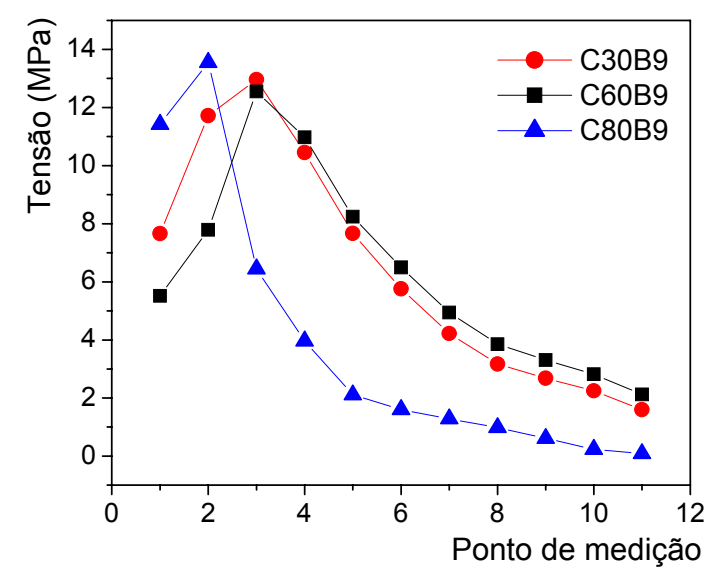

(a)

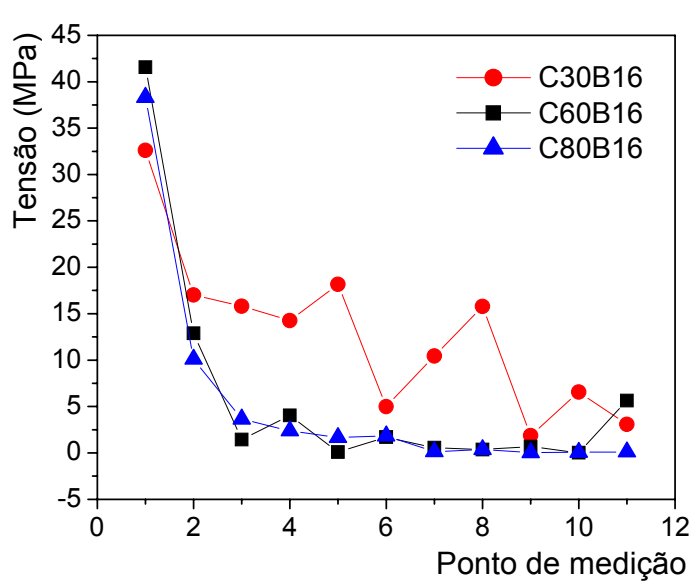

(b)

Figura 6.38 - Comparação entre as tensões desenvolvidas na superfície de contato para os modelos com barras de $9 \mathrm{~mm}$ e com barras de $16 \mathrm{~mm}$

De acordo com a Figura 6.37, ocorreu pouca variação nos valores referentes à tensão máxima na superfície de contato para os modelos com barra de $9 \mathrm{~mm}$ e 16 $\mathrm{mm}$. Porém, nos modelos com barra de $9 \mathrm{~mm}$ a tensão máxima foi muito inferior à tensão máxima desenvolvida nos modelos com barra de $16 \mathrm{~mm}$ (aproximadamente $65 \%$ menor), o que foi verificado também na investigação experimental.

Com base no que foi apresentado pode-se concluir que o diâmetro das barras de GFRP apresentou grande influencia no comportamento da aderência. E, a resistência do concreto pareceu não influenciar de maneira significativa no comportamento da aderência. 


\section{CONCLUSÃO}

Este capítulo apresenta as conclusões do trabalho, bem como as sugestões para pesquisas futuras, tendo como objetivo o maior entendimento das propriedades mecânicas das barras de GFRP e do comportamento da aderência entre estas barras e o concreto de diferentes classes de resistência à compressão.

\subsection{Propriedades mecânicas das barras de GFRP}

Com relação à análise das propriedades das barras de GFRP, pode-se constatar que:

O ensaio de tração das barras de GFRP foi de difícil realização, pois as barras possuíam pouca resistência ao cisalhamento, o que favoreceu a ruptura prematura em seções transversais junto ou próximas ao dispositivo de ancoragem;

- As barras de GFRP apresentaram comportamento tensão x deformação elástico-linear até a ruptura, com ruptura brusca, sem aviso prévio;

- A resistência última alcançada pela barras foi inferior à resistência última indicada pelo fabricante;

- O dispositivo de alumínio fabricado de acordo com as especificações ASTM D 3916-02 não se mostrou eficiente durante o ensaio, pois não evitou que as barras rompessem por cisalhamento junto a ele.

\subsection{Ensaios de arrancamento}

De acordo com os resultados obtidos nos ensaios de arrancamento, pode-se constatar que:

- Os modelos de arrancamento foram de fácil construção e considerados adequados para a medida do deslocamento da barra de GFRP em relação ao cilindro de concreto; 
- Em alguns casos, observou-se grande variação dos resultados quando se consideram principalmente o deslocamento último e as tensões de aderência $\tau_{0,01}, \tau_{0,1}$;

- Os modelos com barras de $9 \mathrm{~mm}$ apresentaram ruptura por arrancamento da barra. Em alguns casos, quando se utilizou concreto de resistência à compressão de 80 MPa ocorreu ruptura combinada;

- Os modelos com barras de $16 \mathrm{~mm}$ foram caracterizados pela ruptura combinada (ruptura da superfície externa da barra e posterior ruptura por fendilhamento do concreto), exceto os modelos com concreto de resistência à compressão de $30 \mathrm{MPa}$, que apresentaram ruptura por arrancamento da barra;

\subsection{Influência da resistência do concreto no comportamento da aderência}

Com base nos resultados obtidos pode-se constatar que:

- Os modelos que utilizaram os concretos de alta resistência à compressão (60 MPa e $80 \mathrm{MPa}$ ) apresentaram resistência de aderência sensivelmente superior quando comparados aos modelos com 0 concreto de resistência à compressão de $30 \mathrm{MPa}$;

- A resistência de aderência não apresentou variação significativa entre os modelos das séries com concreto de resistência à compressão de 60 MPa e de 80MPa.

Assim, de acordo com os resultados pode-se dizer que, a resistência à compressão do concreto não influenciou de maneira significativa na resistência de aderência entre a barra de GFRP e o concreto quando se consideram concretos de resistência à compressão maior ou igual a $50 \mathrm{MPa}$, pois neste caso a resistência de aderência é influenciada basicamente pelas propriedades da barra.

\subsection{Influência do diâmetro da barra no comportamento da aderência}

De acordo com os resultados experimentais, pode-se concluir que: 
- A resistência de aderência foi sensivelmente maior nos modelos com barra de $16 \mathrm{~mm}$ quando comparados aos modelos com barra de $9 \mathrm{~mm}$, independente da resistência à compressão do concreto.

Observou-se que as barras de diâmetro $9 \mathrm{~mm}$ não apresentaram comportamento de aderência satisfatório, pois a área de contato é menor em comparação com as barras de diâmetro $16 \mathrm{~mm}$, que acarreta uma menor resistência de aderência.

\subsection{Comparação entre modelos analíticos e experimentais em relação ao comportamento da aderência entre barras de GFRP e o concreto}

De acordo com os resultados obtidos, pode-se concluir que:

- Os modelos propostos por Malvar (1994), ELIGEHAUSEN et al. (1983) e COSENSA et al. (1997) representaram de maneira adequada o comportamento experimental da aderência entre a barra de GFRP e o concreto;

- Foi possível a obtenção de equações gerais, de acordo com a formulação proposta por cada autor, para previsão do comportamento da aderência para a barra de GFRP analisada;

- A partir da consideração das equações gerais para a previsão do comportamento da aderência, os modelos propostos por MALVAR (1994) e COSENSA et al. (1997) apresentaram valores muito próximos aos resultados experimentais.

\subsection{Comparação entre a resistência de aderência desenvolvida pelas barras de GFRP e pelas barras de aço}

De acordo com os resultados obtidos, pode-se concluir que:

- Os modelos com barras de aço possuem melhor comportamento de aderência quando comparados aos modelos com barras de GFRP, 
independente da resistência à compressão do concreto e do diâmetro da barra.

- Os modelos com barras de GFRP apresentaram maiores deslocamentos na ruptura que os modelos com barras de aço, atingindo valores até quatro vezes maiores;

- No caso da comparação dos resultados experimentais de resistência última de aderência com os Códigos Normativos, a NBR 6118:2003 e o EUROCODE (2002) se mostraram bastante conservadores (o valor da resistência de aderência proposto foi menor do que o valor encontrado experimentalmente nos modelos com barras de GFRP), porém CEBFIP (1999) mostrou melhor aproximação com os resultados experimentais.

Com base na análise dos resultados dos modelos de arrancamento com barras de GFRP e dos modelos de arrancamento com barras de aço, comprovou-se o fato da resistência de aderência entre as barras de GFRP e o concreto ser controlada pela parcela da aderência por atrito, visto que a resistência de aderência foi inferior e o deslocamento foi superior nos modelos com barras de GFRP quando comparados aos modelos semelhantes com barras de aço.

\subsection{Simulação numérica}

De acordo com os resultados obtidos nas simulações numéricas realizadas, pode-se concluir que:

- Com a simulação numérica linear não foi possível representar, de maneira adequada, 0 comportamento dos diagramas força $x$ deslocamento obtidos na análise experimental;

- A representação dos modelos numéricos teve como parâmetro para calibração dos resultados os valores das constantes FKN e FKT, que são responsáveis pela influência da superfície normal e tangencial do contato, respectivamente.

- Para os modelos com concretos de resistência à compressão de 30 $\mathrm{MPa}$, encontrou-se boa aproximação entre os resultados obtidos para força e deslocamento por meio da simulação numérica e os ensaios de arrancamento ; 
- Para os modelos com concreto de resistência à compressão de $60 \mathrm{MPa}$ e $80 \mathrm{MPa}$, não verificou-se boa aproximação entre os resultados obtidos numericamente e experimentalmente para o valor da força de aderência;

- Com relação às tensões desenvolvidas na superfície de contato, observou-se a grande influência do diâmetro da barra nas tensões de aderência (modelos com barra de $9 \mathrm{~mm}$ apresentaram tensões máximas sensivelmente menores que os modelos com barra de 16 mm), o mesmo não ocorreu com o aumento da resistência à compressão do concreto.

Desta forma, para melhor representação do comportamento da aderência entre as barras de GFRP e o concreto é justificado o desenvolvimento de modelos numéricos não-lineares com critério de ruptura.

\subsection{Comentários finais}

As barras de GFRP possuem propriedades mecânicas diferentes da barras de aço nervuradas, além disto, a impregnação de areia e filamentos de fibras dispostos helicoidalmente na superfície externa da barra garantem sua rugosidade, permitindo a aderência com o concreto.

Com base nos ensaios para determinar as propriedades das barras de GFRP, verificou-se o comportamento elástico linear até a ruptura, que ocorreu de modo prematuro por cisalhamento junto ao dispositivo de ancoragem, o que justifica a adoção de outro mecanismo de ancoragem para o ensaio.

De acordo com o conjunto de resultados obtidos, observou-se que os ensaios de arrancamento realizados se mostraram adequados para a avaliação do comportamento de aderência entre as barras de GFRP e o concreto, porém, alguns valores de deslocamento último e das tensões de aderência $\tau_{0,01}$ e $\tau_{0,1}$ apresentaram grande variabilidade nos resultados.

Os modelos de arrancamento com concreto de alta resistência à compressão (60 MPa e $80 \mathrm{MPa}$ ) apresentaram ruptura combinada, com ruptura da superfície externa da barra e posterior ruptura por fendilhamento do prisma de concreto. Já os modelos com concreto de resistência à compressão de $30 \mathrm{MPa}$ apresentaram ruptura por arrancamento da barra. 
A resistência à compressão do concreto não influenciou de maneira significativa na resistência de aderência quando se consideram concretos com resistência à compressão maior que $50 \mathrm{MPa}$, pois neste caso a resistência de aderência é influenciada basicamente pelas propriedades da barra.

Com relação aos diâmetros das barras, os modelos com barra de $9 \mathrm{~mm}$ não apresentaram comportamento de aderência satisfatório, o que pode ser justificado pela menor área de contato destas barras em comparação às barras de diâmetro de 16 $\mathrm{mm}$.

Comparando o comportamento da aderência nos modelos de arrancamento com barras de GFRP e com barras de aço, verificou-se que os modelos com barras e GFRP apresentaram menor resistência de aderência e maior deslocamento último que os modelos com barras de aço. Comprovando o fato da resistência de aderência entre as barras de GFRP e o concreto ser controlada pela parcela da aderência por atrito, diferente dos modelos com barra de aço, cuja parcela que exerce maior influencia é a aderência mecânica.

Com relação a analise numérica realizada, pode-se dizer que o modelo numérico linear não representou de maneira adequada o comportamento experimental dos modelos de aderência, tornando-se necessário o desenvolvimento de um modelo numérico não-linear com critério de ruptura.

Assim, como conclusão final desta pesquisa teórico-experimental, o comportamento da aderência entre as barras de GFRP e o concreto é inferior ao comportamento de modelos similares com barras de aço nervuradas. Ainda, os deslocamentos desenvolvidos entre as barras de GFRP e o concreto foram superiores aos deslocamentos encontrados em modelos similares com barras de aço nervuradas. Com relação ao modo de ruptura, os modelos com barra de GFRP apresentaram uma ruptura peculiar, definida por um aumento significativo do deslocamento sem incremento na tensão de aderência.

A adoção de barras de GFRP, de acordo com o estudado é viável, porém, a sua utilização, em virtude da menor resistência de aderência quando comparada às barras de aço, requer maior comprimento de ancoragem (em relação às barras de aço) para o adequado comportamento da estrutura.

\subsection{Pesquisas futuras}

Como propostas para pesquisas futuras, se propõem: 
- Realização de ensaios de aderência com barras de GFRP de diferentes conformações superficiais, com o objetivo de avaliar a influência da conformação superficial da barra na resistência de aderência;

- Realização de ensaios de aderência em vigas, para melhor representação do comportamento real de estruturas submetidas à ação de momento fletor, e posterior comparação dos resultados com os modelos de arrancamento;

- Desenvolver um modelo numérico não linear com critério de ruptura, com a finalidade de se obter melhor aproximação em relação aos resultados experimentais;

- Desenvolvimento de modelos experimentais específicos para a análise das tensões de aderência desenvolvidas na interface barra de GFRPconcreto. Assim, os resultados experimentais podem ser comparados com a simulação numérica. 


\section{REFERÊNCIAS BIBLIOGRÁFICAS}

ACHILLIDES, Z.; PILAKOUTAS, K. (2004) "Bond behavior of fiber reinforced polymer bars under direct pullout conditions", Journal of Composites for Construction, v. 8, n. 2.

ALCANTARA, M. A. M.; LORRAIN, M. S.; BARBOSA, M. P (2004) "Avaliação da influência da posição da armadura no desenvolvimento das tensões de aderência na interface entre o concreto auto-adensável e a armadura" 46 IBRACON, v.5, pp76-90.

ALMEIDA FILHO, F. M (2006), "Contribuição ao estudo da aderência entre barras de aço e concretos auto-adensáveis", Tese de Doutorado, EESC, São Carlos, SP, Brasil.

ALMEIDA FILHO, F. M.; EL DEBS, A. L. H. C.; EL DEBS, M. K. (2006), "Theoretical and numerical approach of the bond behavior in pull-out tests using self-compacting concrete and steel bars", XXVII CILAMCE - Iberian Latin-American Congress on Computational Methods in Engineering, Proceedings..., Belém-PA, Brasil.

AMERICAN CONCRETE INSTITUTE (1996) "ACI 440 R - State-of-the-art report on fiber reinforced plastic (FRP) reinforcement for concrete structures", United States.

AMERICAN CONCRETE INSTITUTE (2003) "ACI 440 1R - Guide for design and concrete reinforced with FRP bars", United States.

AMERICAN CONCRETE INSTITUTE (2004) "ACI 440 3R - Guide test methods for fiberreinforced polymers (FRPs) for reinforcing or strengthening concrete structures", United States.

AMERICAN CONCRETE INSTITUTE (1999), "ACI 318 - Building code requirements for structural concrete", Detroit, United States. 
AMERICAN SOCIETY FOR TESTING AND MATERIALS (1991), "ASTM C 234 - Standard test method for comparing concretes on the basis of the bond developed with reinforced steel", Philadelphia.

AMERICAN SOCIETY FOR TESTING AND MATERIALS (2002), "ASTM D 3916 Standard test method for tensile properties of pultruded glass-fiber-reinforced plastic rod", United States.

ASSOCIAÇÃO BRASILEIRA DE NORMAS TÉCNICAS (1980), "NBR 5739:1980 - Ensaio de compressão de corpos-de-prova cilíndricos de concreto", Rio de Janeiro, RJ, Brasil.

ASSOCIAÇÃO BRASILEIRA DE NORMAS TÉCNICAS (1982), "NBR 7217:1982 Agregados: Determinação da composição granulométrica", Rio de Janeiro, RJ, Brasil.

ASSOCIAÇÃO BRASILEIRA DE NORMAS TÉCNICAS (1982), "NBR 7223:1982 Determinação da consistência do concreto pelo abatimento do tronco de cone - ensaio de abatimento", Rio de Janeiro, RJ, Brasil.

ASSOCIAÇÃO BRASILEIRA DE NORMAS TÉCNICAS (1982), "NBR 7251:1982 Agregado no estado solto: determinação da massa unitária", Rio de Janeiro, RJ, Brasil.

ASSOCIAÇÃO BRASILEIRA DE NORMAS TÉCNICAS (1982), "NBR 7477:1982 Determinação do coeficiente de conformação superficial de barras e fios de aço destinados a armaduras de concreto armado, método de ensaio", Rio de Janeiro, RJ, Brasil.

ASSOCIAÇÃO BRASILEIRA DE NORMAS TÉCNICAS (1983), "NBR 7211:1983 Agregados para concreto", Rio de Janeiro, RJ, Brasil.

ASSOCIAÇÃO BRASILEIRA DE NORMAS TÉCNICAS (1983), "NBR 7222:1983 Argamassas e concretos - determinação da resistência à tração por compressão diametral de corpos-de-prova cilíndricos", Rio de Janeiro, RJ, Brasil.

ASSOCIAÇÃO BRASILEIRA DE NORMAS TÉCNICAS (1984), "NBR 8522:1984 Concreto - determinação do módulo de deformação estática e diagrama tensão $x$ deformação", Rio de Janeiro, RJ, Brasil. 
ASSOCIAÇÃO BRASILEIRA DE NORMAS TÉCNICAS (1987), "NBR 9776:1987 Agregados - determinação da massa específica de agregados miúdos por meio do Frasco de Chapmam", Rio de Janeiro, RJ, Brasil.

ASSOCIAÇÃO BRASILEIRA DE NORMAS TÉCNICAS (1987), "NBR 9937:1987 Agregados - determinação da absorção e da massa específica de agregados graúdos", Rio de Janeiro, RJ, Brasil.

ASSOCIAÇÃO BRASILEIRA DE NORMAS TÉCNICAS (2003), "NBR 6118:2003 - Projeto de estruturas de concreto", Rio de Janeiro, RJ, Brasil.

BAKIS, C. E.; UPPULURI, V. S.; NANNI, A.; BOOTHBY, T. E. (1998), "Analysis of bonding mechanisms of smooth and lugged FRP rods embedded in concrete", Composites Science and Technology, v. 58, p.1307-1319.

BAKIS, C.E. et al. (2002) "Fiber reinforced polymer composites for construction - State-ofthe-art review", Journal of composites for Construction, v. 6, n. 2, p. 73-87.

BARBOSA, M. T. G. et al. (2000), "Estudo da influência do diâmetro da barra e da resistência à compressão do concreto no ensaio de pull out para determinação da tensão última de aderência". In: IV Congresso de Engenharia Civil, v. 1, p. 435-464, Juiz de Fora, MG, Brasil.

BARBOSA, M. T. G. (2001), "Avaliação do comportamento da aderência em concretos de diferentes classes de resistência", Tese de Doutorado, UFRJ - COPE, Rio de Janeiro, RJ, Brasil.

BENMOKRANE, B. et al. (2002) "Durability of glass fiber-reinforced polymer reinforcing bars in concrete environment", Journal of Composites for Construction, v. 6, n. 3, p. 143153.

BELARBI, A.; WANG, H. (2004), "Bond-slip response of FRP reinforcing bars in fiber reinforced concrete under direct pullout", University of Missouri-Rolla, USA.

CAMARGO CORREA CIMENTOS S/A (2006). Disponível em: <http://www.caue.com.br>. Acesso em 31 de outubro. 
CASTRO, C. M. (2002), "Concreto de Alto Desempenho: Estudo da Aderência com a Armadura sob Ações Repetidas", Dissertação de Mestrado., EESC, São Carlos, SP, Brasil.

CHAMIS, C. C. (1984), "Simplified composite micromechanical equations for strength, fracture toughness and environmental effects", SAMPE Quarterly, v.15, p-44-55.

CLARK, C. R.; JOHNSTON, D. W. (1983), "Early loading effects and bond strength", Journal of the $\mathrm{ACl}$, p. 532-539.

COMITE EURO-INTERNATIONAL DU BETON (1982) "Bond action and bond behavior of reinforcement: state-of-the-art report", Bulletin d'Information, n. 151.

COMITE EURO-INTERNATIONAL DU BETON (1991) "CEB-FIP model code 1990", Bulletin d'Information 203-205.

COMITÉ EURO-INTERNATIONAL DU BÉTON (1999), “CEB - FIP Model Code 1990", Bulletin d'information, n. 195-197.

COSENZA, E.; MANFREDI, G.; REALFONZO, R. (1997), "Behavior and modeling of bond of FRP rebars to concrete", Journal of Composites for Construction, v.1, n. 2.

DEGUSSA BRASIL. Disponível em: <http://www. degussa-cc.com.br>. Acesso em 31 de outubro.

ELIGEHAUSEN, R.; POPOV, E. P.; BERTERO, V. V. (1983). Local bond stress-slip relationships of deformed bars under generalized excitations. Report no UCB/EERC83/23, University of California, Berkeley.

EUROPEAN STANDARD (2002), "Eurocode 2: Design of concrete structures", Brussels, Belgium.

FEDERATION INTERNATIONALE DU BETON (2003) "FIB 9.3 TG - FRP as reinforcement in concrete", (Proposta de norma), Sheffield, Inglaterra.

FERNANDES, R. M. (2000), "Influência das Ações Repetidas na Aderência AçoConcreto", Dissertação de Mestrado, EESC, São Carlos, SP, Brasil. 
FRANÇA, H.V. (2004), "Aderência aço-concreto - Uma análise do comportamento do concreto fabricado com resíduos de borracha", Dissertação de Mestrado, UNESP, Ilha Solteira, SP.

FUSCO, P. B. (1995), “Técnica de Armar as Estruturas de Concreto", PINI, São Paulo, SP, Brasil.

GOTO, Y. (1971) "Cracks formed in concrete around deformed tension bars", ACI Journal, v. 68, n. 4 , p. $244-251$.

HELENE, P.; TERZIAN, P. (1992), "Manual de dosagem e controle do concreto", Editora PINI, $1^{\text {a }}$ edição, São Paulo, SP, Brasil.

HOLCIM BRASIL S/A (2006). Disponível em: <http://www.holcim.com.br>. Acesso em 31 de outubro.

HOLLAWAY, L.C. (2003) "The evolution of and the way forward for advanced polymer composites in the civil infrastructure", Construction and Building Materials, v.17, p. 365378.

HUGHES BROTHERS (2006). Disponível em: <http://www. hughesbros.com>. Acesso em 24 de março.

HULATT, J.; HOLLAWAY, L.; THORNE, A. (2002) "Preliminary investigations on the environmental effects on new heavyweight fabrics for use in civil engineering", Composites Part B: Engineering, v. 33, n. 6, p. 407-414.

ISA, M. M.; CEA, A. A.; RENÓFIO, A. (2004) "Aderência entre concreto auto-adensável de alta resistência e Armadura", Acta Scientiarum. Technology, Maringá, v. 26, n. 2, p. 135-139.

JORQUERA, P.; MAYORGA, C. V. (1998) "Barras de plástico reforçado com fibra de vidro", Universidade do Chile, Janeiro.

KAJORNCHEAPPUNNGAM, S. et al. (2002) "Effect of Aging Environment on Degradation of Glass-Reinforced Epoxy", Journal of Composites for Construction, v. 6, n. 1, p. 61-69. 
LEONHARDT, F.; MÖNNIG, E. (1977), "Construções de Concreto: Princípios Básicos do Dimensionamento de Estruturas de Concreto Armado" Interciência, v. 1, Rio de Janeiro, RJ, Brasil.

MALVAR, L. J. (1994), "Bond stress-slip characteristics of FRP rebars", TR-2013-SHR, Naval Facillities Engineering Service Center, Port Hueneme.

MICELLI, F.; NANNI, A. (2004) "Durability of FRP rods for concrete Structures", Construction and Building Materials, v.18, n. 7, p. 491-503.

PILAKOUTAS, K.; GUADAGNINI, R. M. [s.d.] "Design guidelines for FRP reinforced concrete", University of Sheffield, UK, /Apresentação em PowerPoint/.

RE-BAR CHILE [s.d] "Barras anticorrosivas de material compuesto com fibra de vidro para refuerzo de hormigones sometidos a medio ambientes agresivos", Chile.

REHM, G.; ELIGEHAUSEN, R. (1979), "Bond of ribbed bars under high cycle repeated loads", ACI Journal, Symposium Paper, n. 76-15, p. 297-309.

RILEM/FIP/CEB (1973) "Bond Test for Reinforcing Steel, 1. Beam Test (7 - II - 28 D), 2. Pull-Out Test (7 - II - 128), Tentative Recommendations", RILEM Journal Materials and Structurals, v.6, n. 32, p. 96-105.

SCOTT, B. D.; PARK, R.; PRIESTLEY, M. J. N. (1982), "Stress-strain behavior of concrete confined by overlapping hoops at low and high strain rates", Journal of ACl, v.79, p-13-27.

TANNOUS, F. E.; SAADATMANESH, H. (1999) "Durability of AR glass fiber reinforced plastic bars", Journal of Composites for Construction, v. 3, n. 1, p. 12-19.

TAVARES, D. H. (2006) "Análise teórica e experimental do comportamento de vigas de concreto armadas com barras de GFRP", Dissertação de Mestrado, EESC, São Carlos, SP, Brasil.

TEPFERS, R. (1979), "Cracking of Concrete cover along Anchored Deformed Reinforced Bars", Magazine of Concrete Research, v. 31, n. 106, p. 3-12. 
TIGHIOUART, B.; BENMOKRANE, B.; GRAO, D. (1998), "Investigation of bond in concrete with fiber reinforced polymer (FRP) bar", Construction Building and Materials,v. 12 , n. 8, p. 453-462.

UOMOTO, T. et al. (2002) "Use of fiber reinforced polymer composites as reinforcing material for concrete", Journal of Materials in Civil Engineering, v.14, n. 3, p. 191-209. 